NIST Technical Note 2032

\title{
Building for Environmental and Economic Sustainability (BEES) Online 2.0 Technical Manual
}

\author{
Joshua Kneifel \\ Anne Landfield Greig \\ Priya Lavappa \\ Brian Polidoro
}

This publication is available free of charge from: https://doi.org/10.6028/NIST.TN.2032
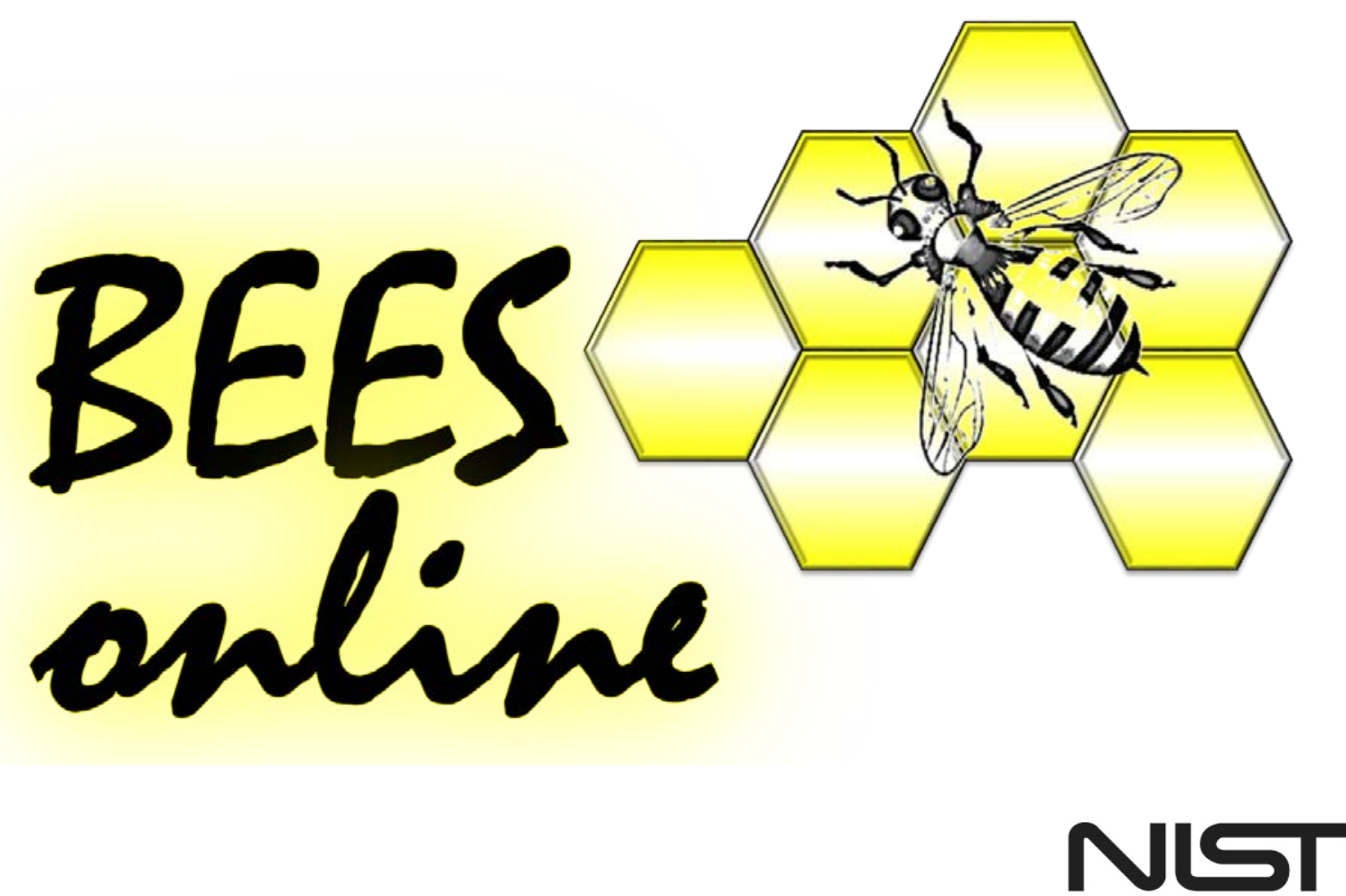

National Institute of Standards and Technology U.S. Department of Commerce 



\title{
Building for Environmental and Economic Sustainability (BEES) Online 2.0 Technical Manual
}

\author{
Joshua Kneifel \\ Priya Lavappa \\ Brian Polidoro \\ Applied Economics Office \\ Engineering Laboratory \\ Anne Landfield Greig \\ Four Elements Consulting, $L L C$
}

This publication is available free of charge from:

https://doi.org/10.6028/NIST.TN.2032

December 2018

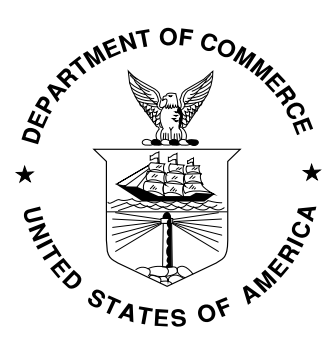

U.S. Department of Commerce Wilbur L. Ross, Jr., Secretary

National Institute of Standards and Technology Walter Copan, NIST Director and Under Secretary of Commerce for Standards and Technology 
Certain commercial entities, equipment, or materials may be identified in this document in order to describe an experimental procedure or concept adequately. Such identification is not intended to imply recommendation or endorsement by the National Institute of Standards and Technology, nor is it intended to imply that the entities, materials, or equipment are necessarily the best available for the purpose.

National Institute of Standards and Technology Technical Note 2032 Natl. Inst. Stand. Technol. Tech. Note 2032, 224 pages (December 2018) CODEN: NTNOEF

This publication is available free of charge from:

https://doi.org/10.6028/NIST.TN.2032 


\begin{abstract}
Building stakeholders need practical metrics, data, and tools to support decisions related to sustainable building product selection. The Engineering Laboratory of the National Institute of Standards and Technology (NIST) has addressed this national need by developing a new version of its metrics and tools for sustainable building products, known as Building for Environmental and Economic Sustainability (BEES) Online. BEES Online 2.0 implements the same BEES framework using metrics based on process-based life-cycle assessment (LCA) and life-cycle costing (LCC) approaches to assess the environmental and economic performance of building products. BEES Online 2.0 includes a more user-friendly interface with more expansive user customization, options, and guidance. The existing products in BEES Online 1.0 (and new products) are in the process of being transitioned to BEES Online 2.0, including updating the LCA and LCC results using up-to-date methodologies and data sources, with focus on the largest and most widely viewed product categories.
\end{abstract}

\title{
Keywords
}

Building economics; life cycle costing; life cycle assessment; life cycle impact assessment; residential buildings; commercial buildings; sustainability; green buildings 


\section{Preface}

This documentation was developed by the Applied Economics Office (AEO) in the Engineering Laboratory (EL) at the National Institute of Standards and Technology (NIST). The document explains how the BEES database was developed, including the assumptions and data sources. The intended audience is BEES users, researchers and decision makers in the building sector, and others interested in building sustainability.

\section{Disclaimers}

The policy of the National Institute of Standards and Technology is to use metric units in all its published materials. Because this report is intended for the U.S. construction industry that uses U.S. customary units, it is more practical and less confusing to include U.S. customary units as well as metric units. Measurement values in this report are therefore stated in metric units first, followed by the corresponding values in U.S. customary units within parentheses. 


\section{Acknowledgements}

The BEES tool could not have been completed without the help of others. Thanks are due the NIST Engineering Laboratory (EL) for its support of this work.

The EPA Office of Research and Development, Sustainable Technology Division TRACI team were instrumental in developing the life cycle impact assessment methods incorporated into BEES. The author is particularly grateful for the key cooperation and support offered by a wide variety of industry associations and manufacturers with products represented in BEES. Their cooperation exceeded all expectations and led to a significant expansion and refinement of the underlying BEES performance data.

The authors wish to thank all those who contributed ideas and suggestions for this report. They include David Webb and Dr. David Butry of EL's Applied Economics Office, Dr. William Healy of EL’s Energy and Environment Division, and Dr. Nicos S. Martys of EL’s Materials and Structural Systems Division. 


\section{Author Information}

Joshua Kneifel

Economist

National Institute of Standards and Technology

Engineering Laboratory

100 Bureau Drive, Mailstop 8603

Gaithersburg, MD 208998603

Tel.: 301-975-6857

Email: joshua.kneifel@nist.gov

Priya Lavappa

Computer Specialist

National Institute of Standards and Technology

Engineering Laboratory

100 Bureau Drive, Mailstop 8603

Gaithersburg, MD 208998603

Tel.: 301-975-4522

Email: priya.lavappa@nist.gov

Brian Polidoro

Computer Specialist

National Institute of Standards and Technology

Engineering Laboratory

100 Bureau Drive, Mailstop 8633

Gaithersburg, MD 208998633

Tel.: 301-975-6445

Email: brian.polidoro@nist.gov

Anne Landfield Greig

Principal

Four Elements Consulting, LLC

Seattle, WA

Tel: 206-935-4600

Email: anne@fourelementsllc.com 


\section{Contents}

Abstract...1.

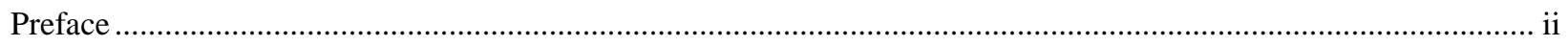

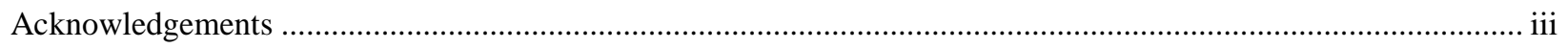

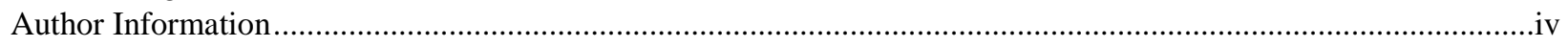

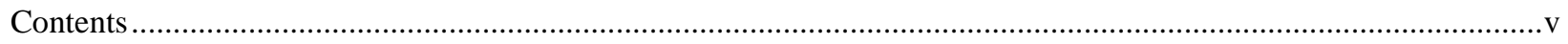

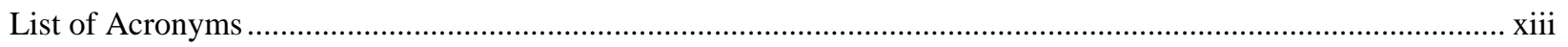

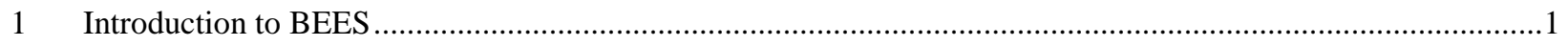

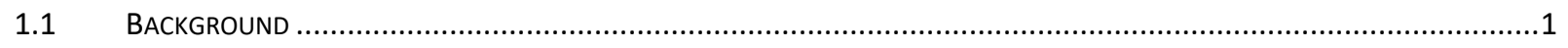

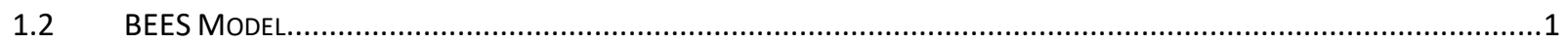

$1.3 \quad$ NOTABLE CHANGES IN BEES ONLINE 2.0

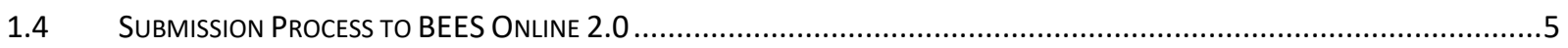

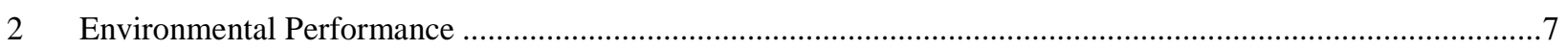

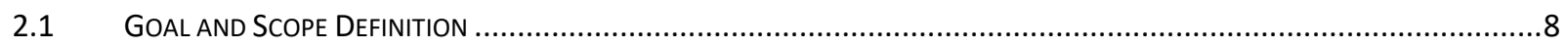

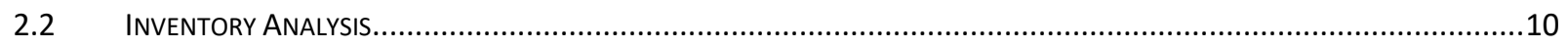

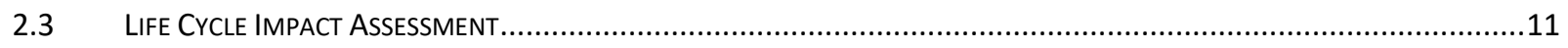

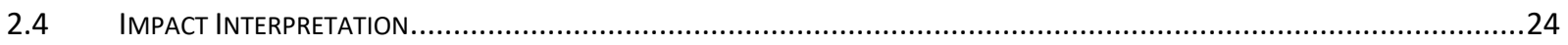

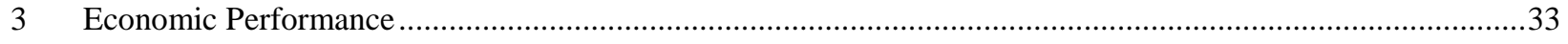

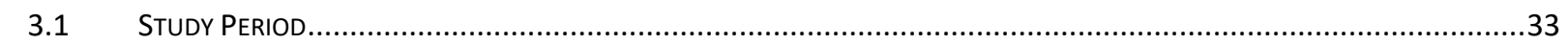

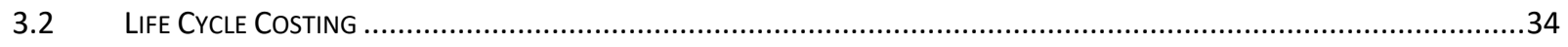

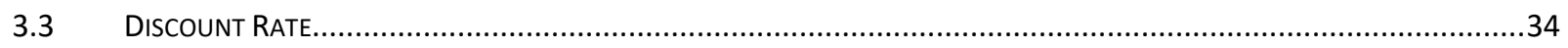

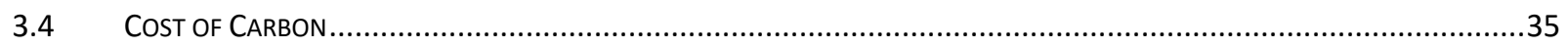

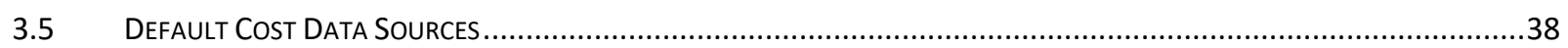

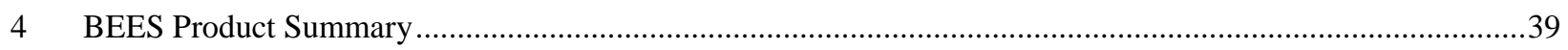

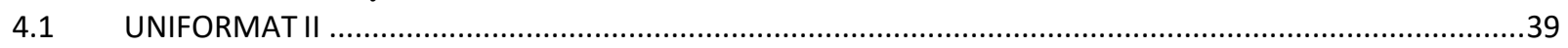

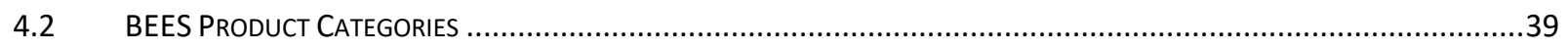

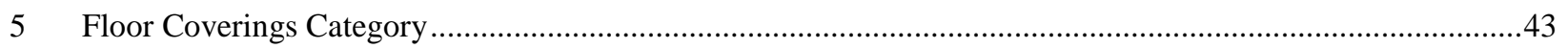

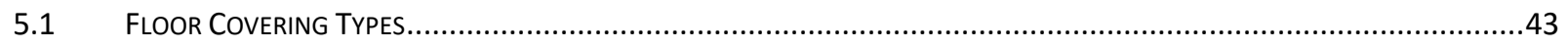

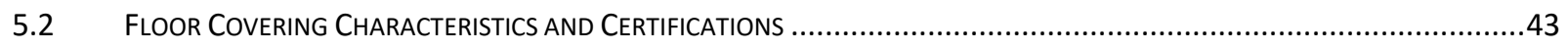

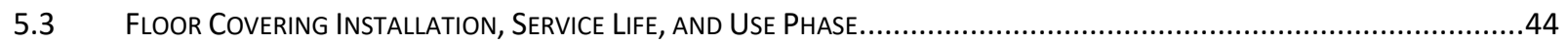

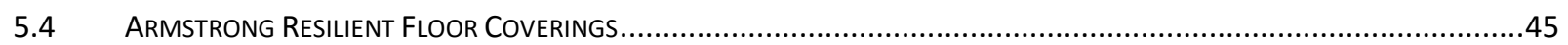

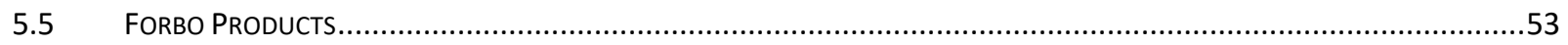

5.6 TANDUS CENTIVA COMMERCIAL CARPET

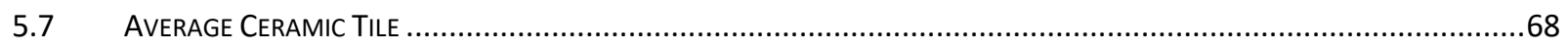

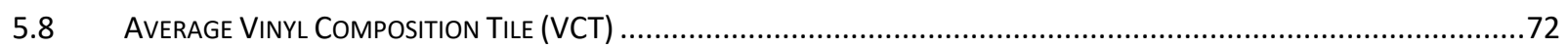

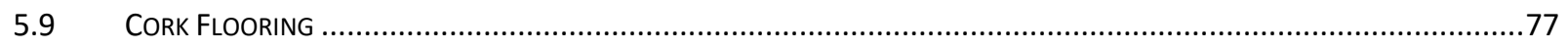

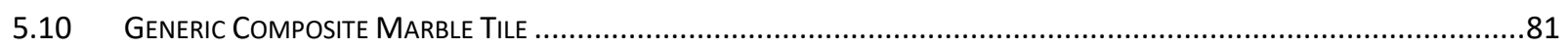

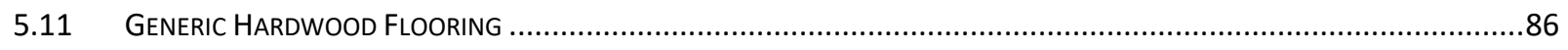

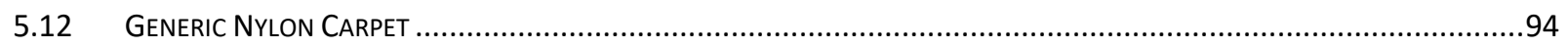

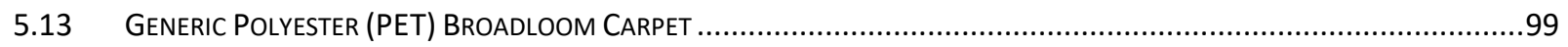

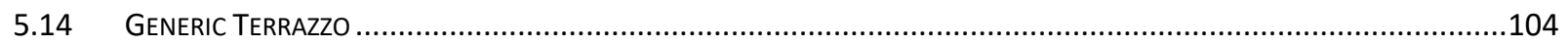

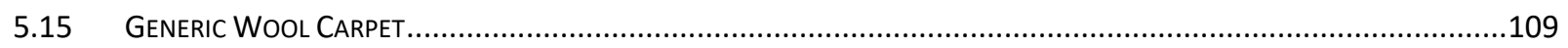

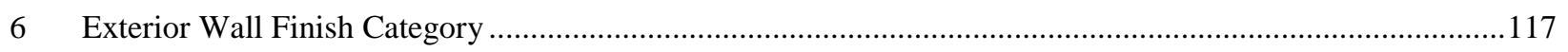

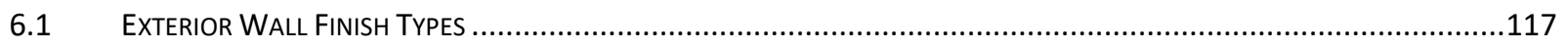

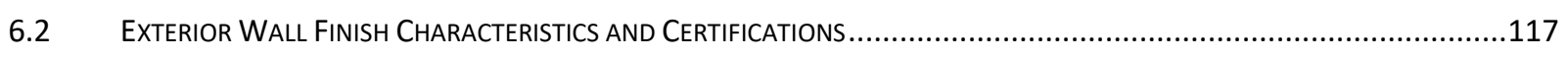

6.3 EXTERIOR WALL FINISH INSTALLATION, SERVICE LIFE, AND USE PHASE ...........................................................117

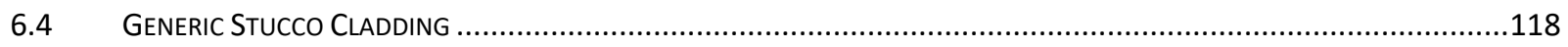

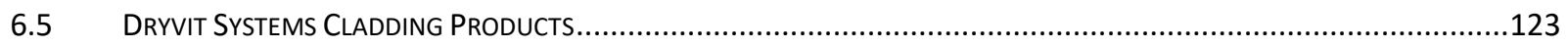




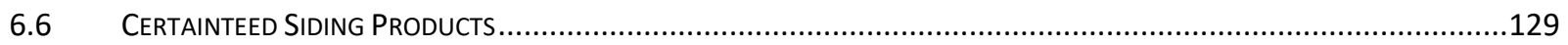

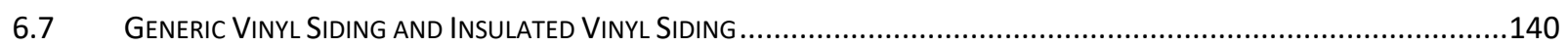

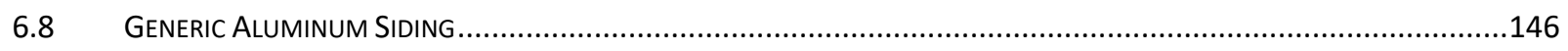

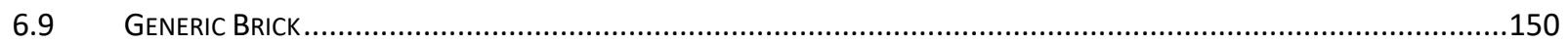

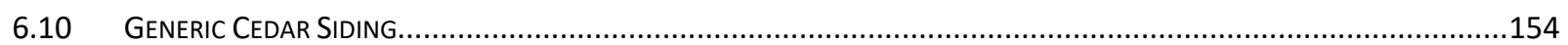

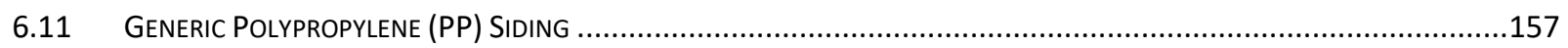

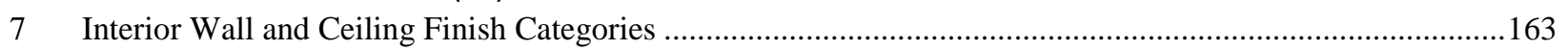

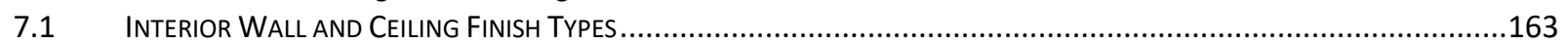

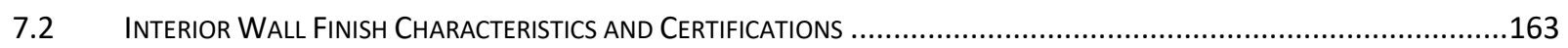

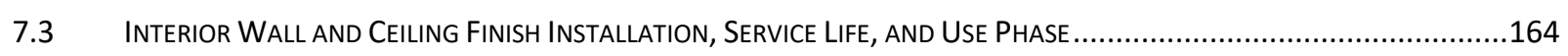

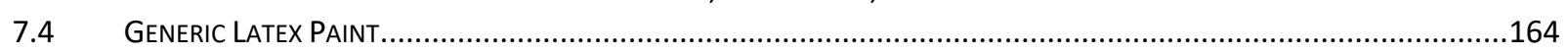

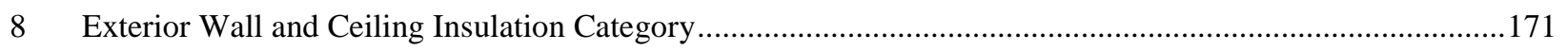

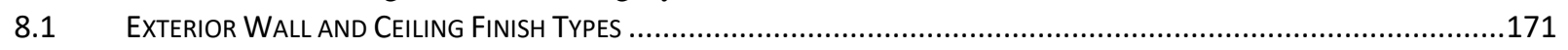

8.2 EXTERIOR WALl AND CEILING InSULATION CHARACTERISTICS AND CERTIFICATIONS...............................................172

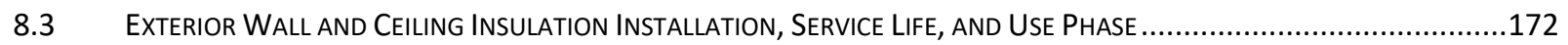

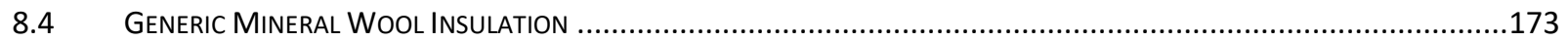

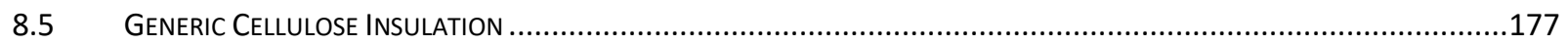

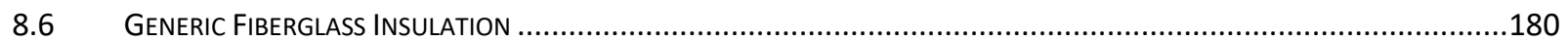

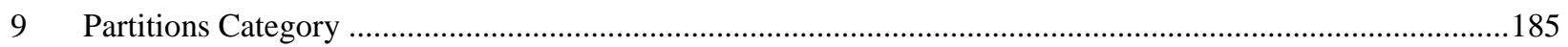

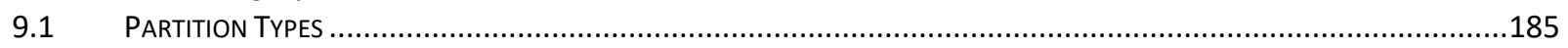

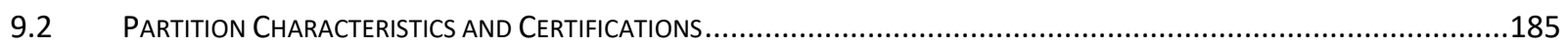

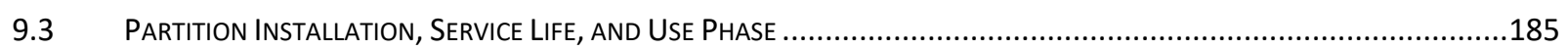

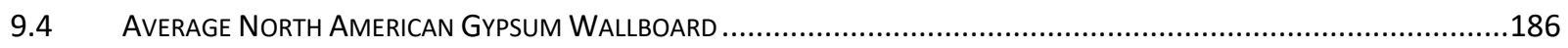

10 Wall Sheathing Category (Under Development) ..................................................................................191

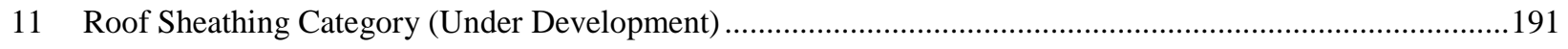

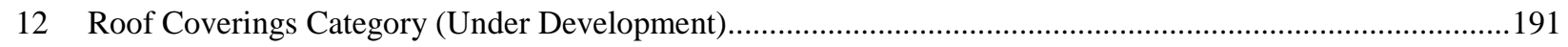

13 Parking Lot Paving Category (Under Development) ......................................................................191

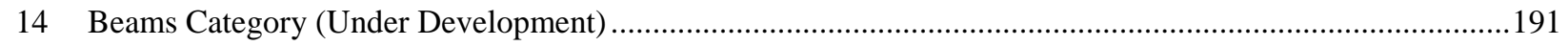

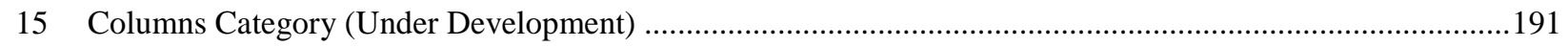

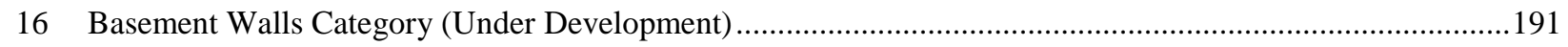

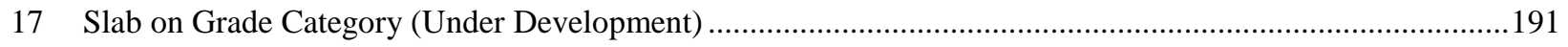

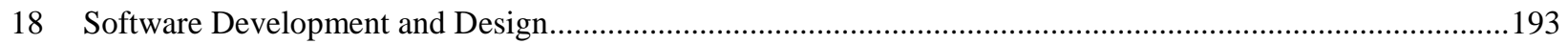

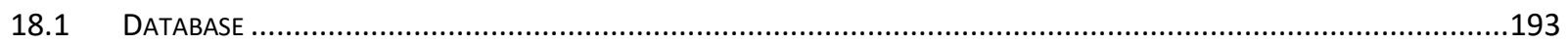

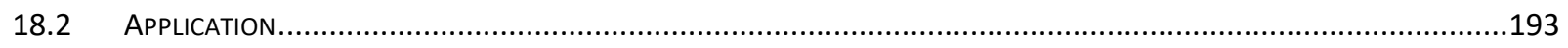

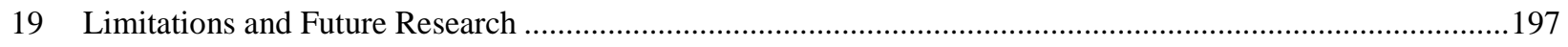

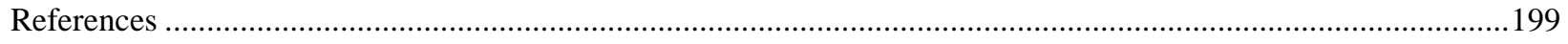




\section{List of Figures}

FIGURE 2-1 DECISION CRITERIA FOR SETTING PRODUCT SYSTEM BOUNDARIES ……............................................

FIGURE 2-2 BEES INVENTORY DATA CATEGORIES ................................................................................

FiguRE 2-3 BEES STAKeHOLDER PANEl IMPORTANCE WEIGHTS SyNTHESIZED ACROSS Voting INTEREST AND Time

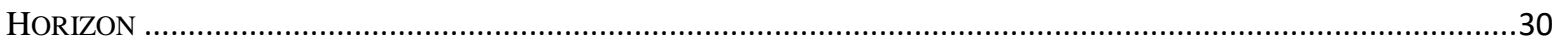

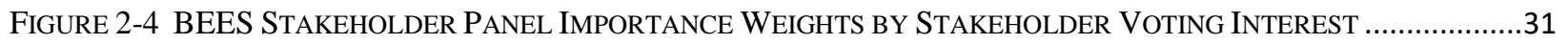

FiguRE 2-5 BEES STAKEHOLDER PANEL IMPORTANCE WEIGHTS BY TIME HORIZON ...............................................31

FiguRE 3-1 EU ETS GHG AllowANCE PRICE (APRIL 2008 THROUGH SEPTEMBER 2018).....................................37

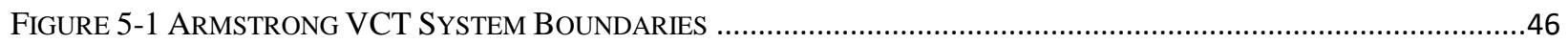

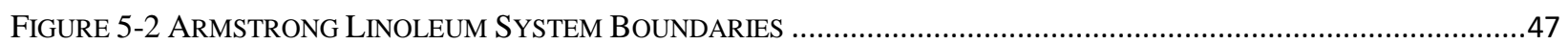

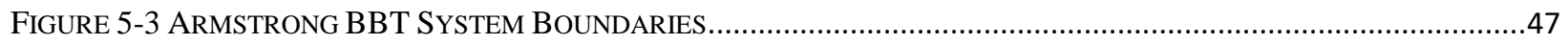

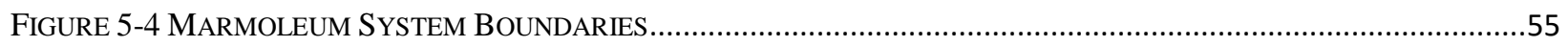

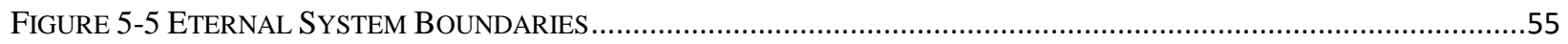

FiguRE 5-6 TANDUS CENTIVA ER3 MOdULAR RS FLOORING SySTEM BOUNDARIES............................................63

FIGURE 5-7 TANDUS CENTIVA ETHOS FLOORING SYSTEM BOUNDARIES .............................................................63

Figure 5-8 Tandus Centiva Powerbond Cushion RS, Powerbond Medfloor RS and FleX-Aire Cushion

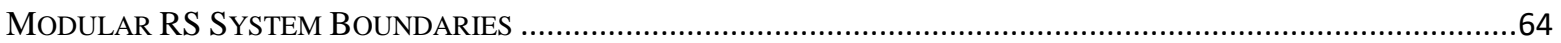

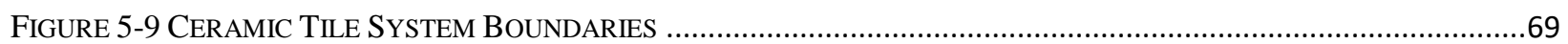

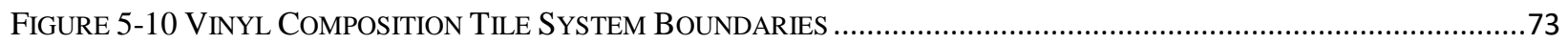

FIGURE 5-11 CORK FLOATING PLANK FLOOR SYSTEM BOUNDARIES ...................................................................

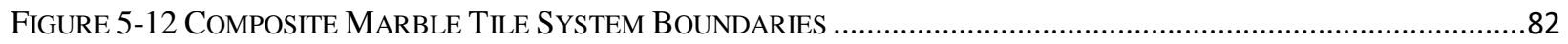

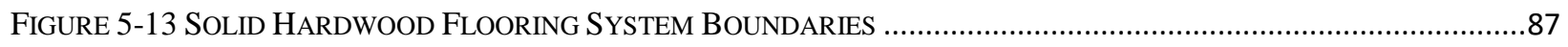

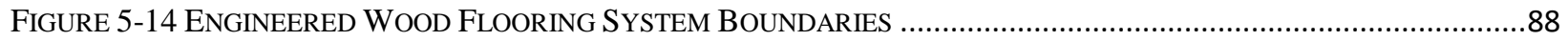

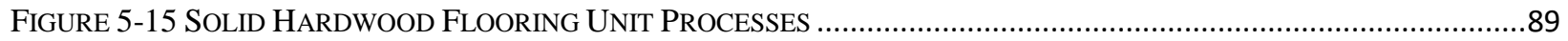

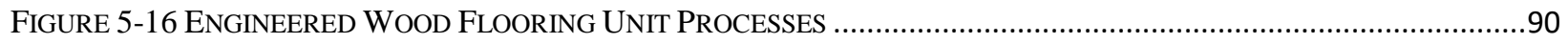

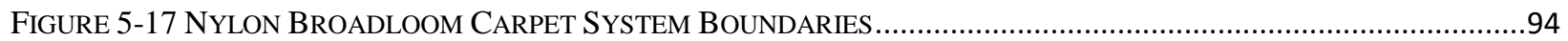

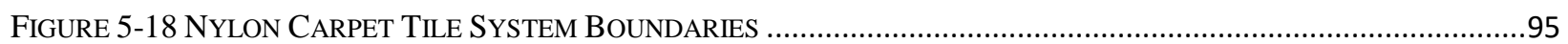

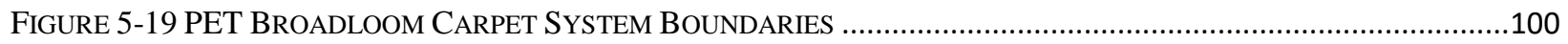

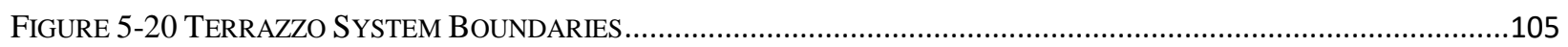

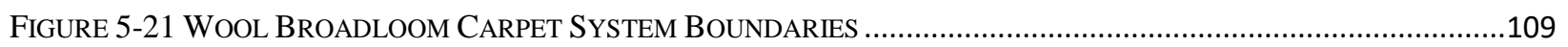

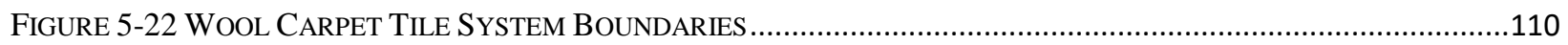

FiguRE 6-1 PoRTLAND CEMENT THREE-COAT STUCCO SYSTEM BOUNDARIES …….............................................119

FiguRE 6-2 MASONRY CEMENT THREE-COAT STUCCO SYSTEM BOUNDARIES ……............................................120

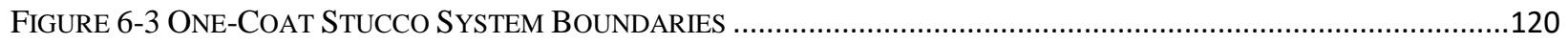

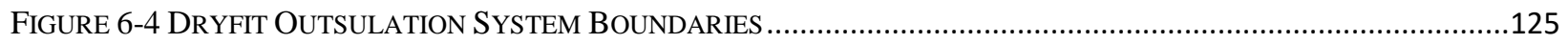

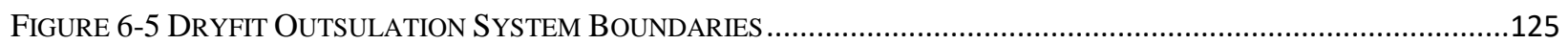

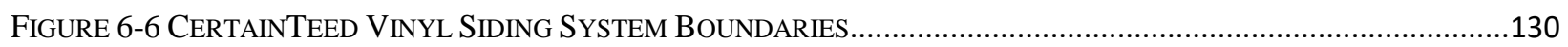

FIGURE 6-7 CERTAINTEED RECYCLED CONTENT CEDARBOARDS SYSTEM BOUNDARIES .........................................131

FIGURE 6-8 CERTAINTEED CEDAR IMPRESSIONS SYSTEM BOUNDARIES .............................................................131

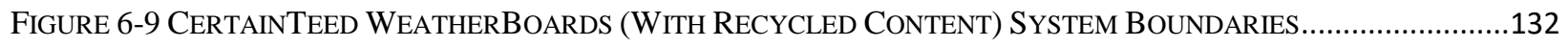

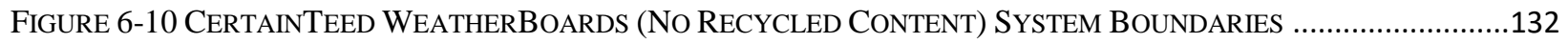

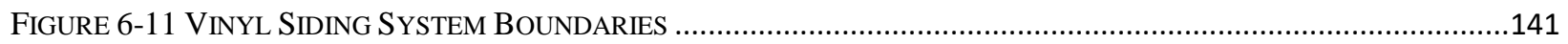

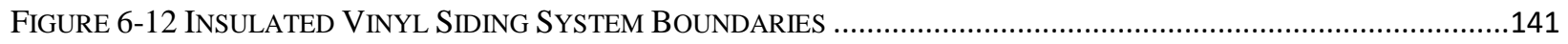

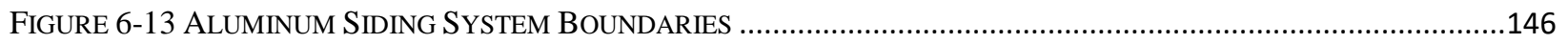

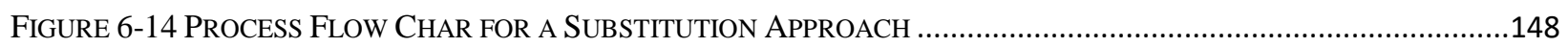

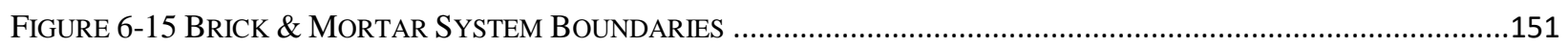

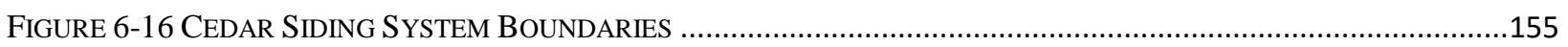

FIGURE 6-17 POLYPROPYLENE SIDING SYSTEM BOUNDARIES.........................................................................158 


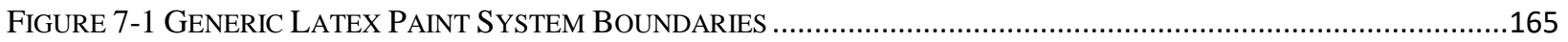

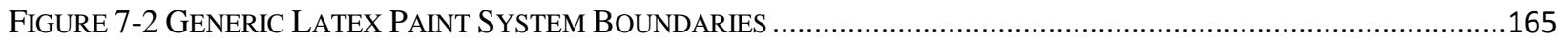

FIGURE 8-1 MINERAL WOOL BOARD INSULATION SYSTEM BOUNDARIES ......................................................174

FIGURE 8-2 LOOSE FILL MINERAL WOOL INSULATION SYSTEM BOUNDARIES................................................174

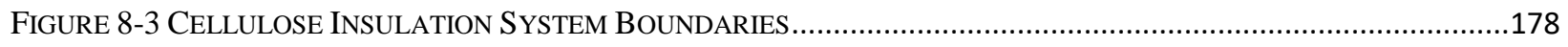

FIGURE 8-4 FIBERGLASS BATT INSULATION SYSTEM BOUNDARIES ..............................................................181

FIGURE 8-5 LOOSE FILL FIBERGLASS INSULATION SYSTEM BOUNDARIES .........................................................181

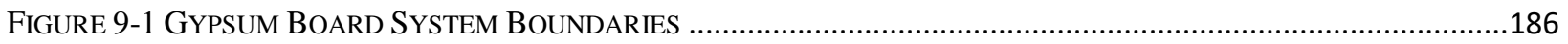

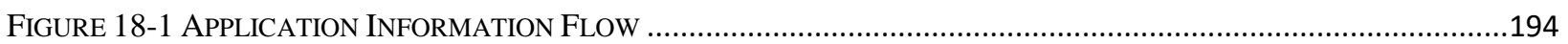




\section{List of Tables}

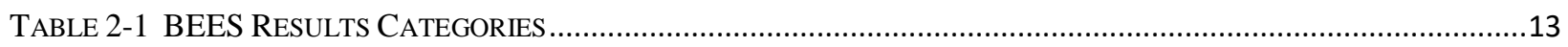

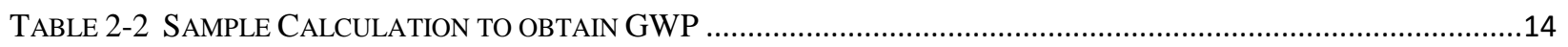

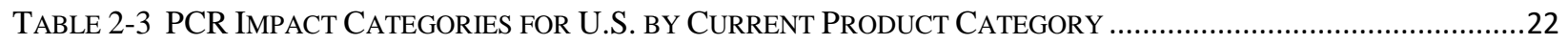

TABLE 2-4 PCR IMPACT CATEGORIES BY FUTURE PRODUCT CATEGORY ……............................................................23

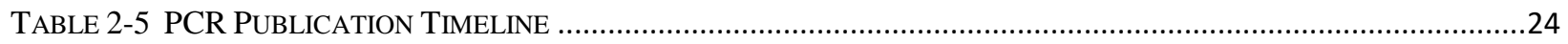

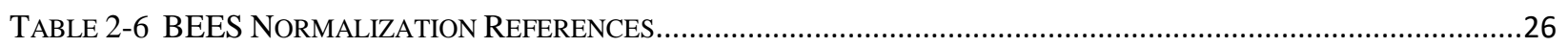

TABLE 2-7 PAIRWISE COMPARISON VALUES FOR DERIVING IMPACT CATEGORY IMPORTANCE WEIGHTS ...................28

TABLE 2-8 RELATIVE IMPORTANCE WEIGHTS BASED ON SCIENCE ADVISORY BOARD STUDY .....................................28

TABLE 2-9 RELATIVE IMPORTANCE WEIGHTS BASED ON BEES STAKEHOLDER PANEL JUDGMENTS ............................30

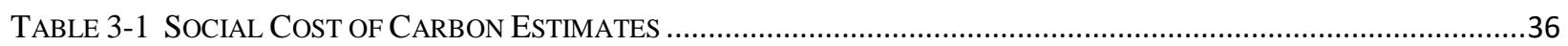

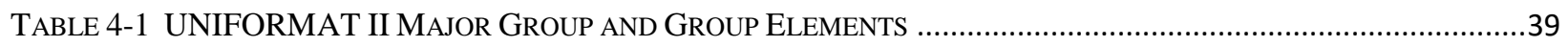

TABLE 4-2 BEES PRODUCT CATEGORIES BY UNIFORMAT ELEMENT ………....................................................

TABle 4-3 BeES Product CATEgory Functional Unit AND Use Phase Options ...........................................42

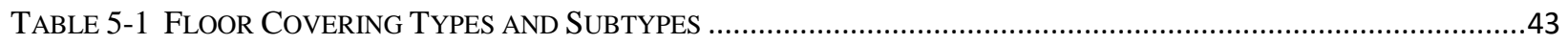

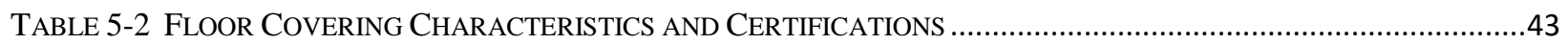

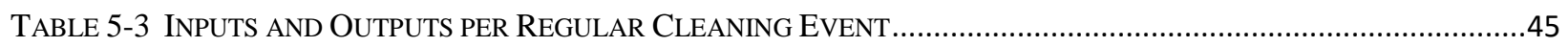

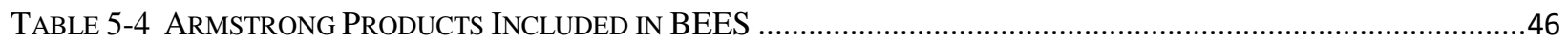

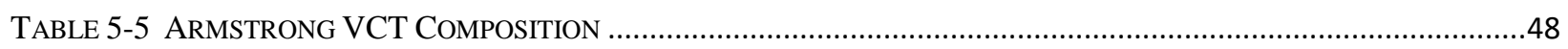

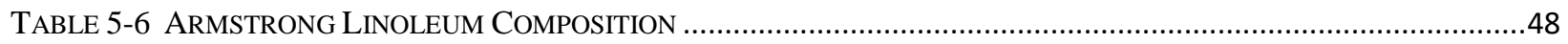

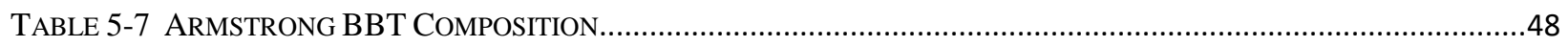

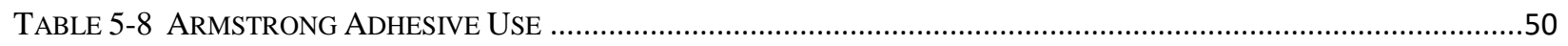

TABLE 5-9 INPUTS AND OUTPUTS PER REGULAR CLEANING EVENT ....................................................................52

TABLE 5-10 VCT AND BBT CLEANING PROCESSES AND FREQUENCY'...............................................................52

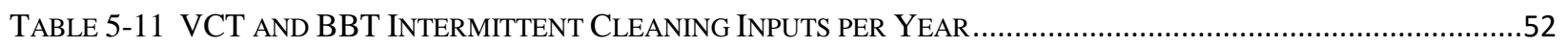

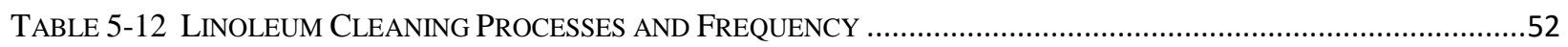

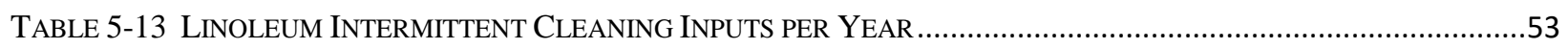

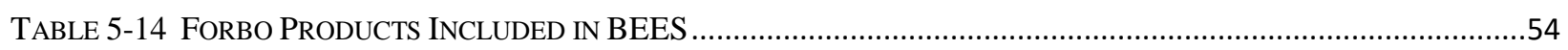

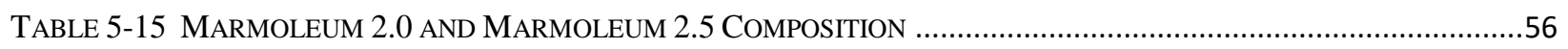

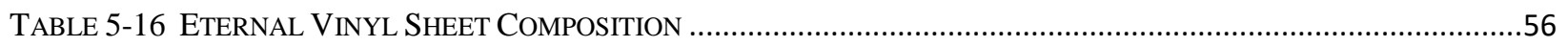

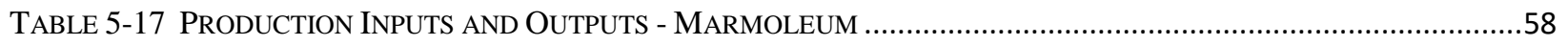

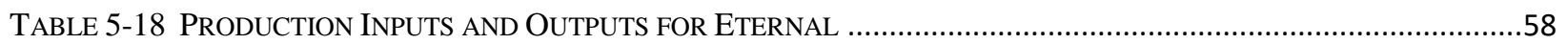

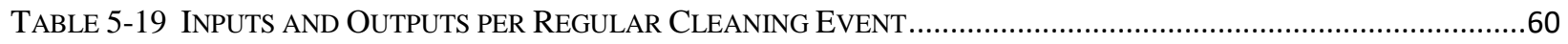

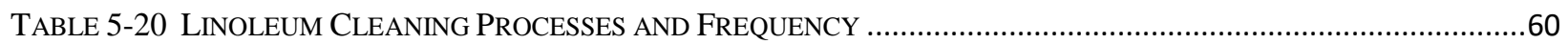

TABLE 5-21 LINOLEUM INTERMITTENT CLEANING INPUTS PER YEAR ........................................................................60

TABLE 5-22 VinYl FLOOR Covering CLEANING PROCESSES AND FREQUENCY..................................................61

TABLE 5-23 VINYL INTERMITTENT CLEANING INPUTS PER YEAR ........................................................................61

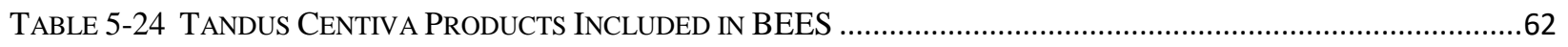

TABLE 5-25 TANDUS CENTIVA FLOORING COMPOSITIONS ...............................................................................64

Table 5-26 Tandus Centiva Powerbond Cushion RS, FleX-Aire Cushion Modular RS, AND Powerbond

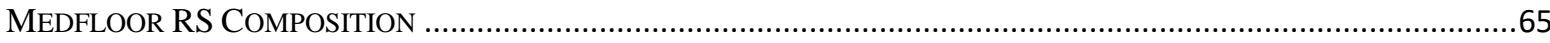

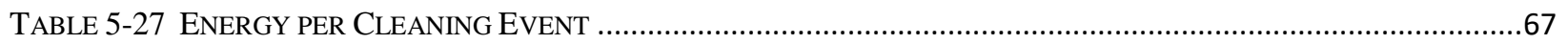

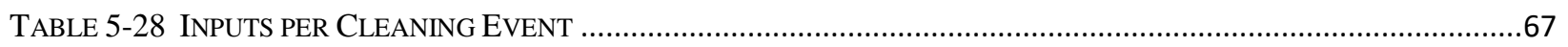

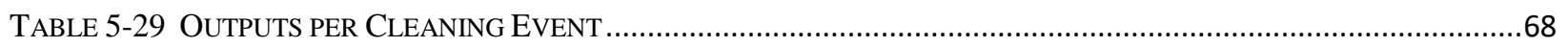

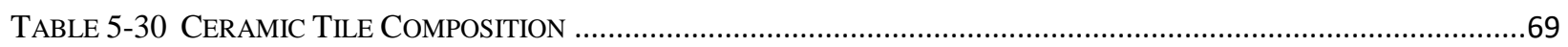

TABLE 5-31 LATEX/MORTAR BLEND COMPOSITION ……..............................................................................

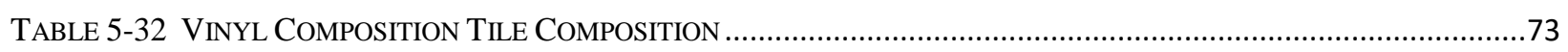

TABLE 5-33 INPUTS AND OUTPUTS PER REGULAR CLEANING EVENT....................................................................76 


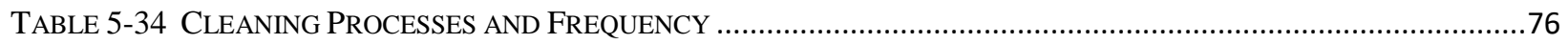

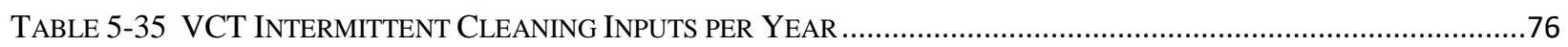

TABLE 5-36 CORK FLOATING PLANK FLOOR COMPOSITION.............................................................................78

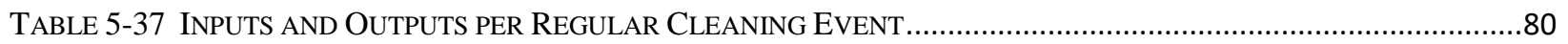

TABLE 5-38 CoRK FloORING Covering CLEANING PROCESSES AND FREQUENCY …….........................................8

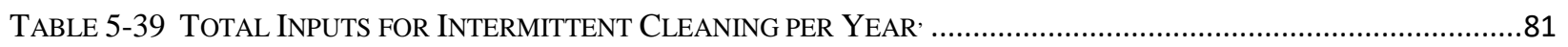

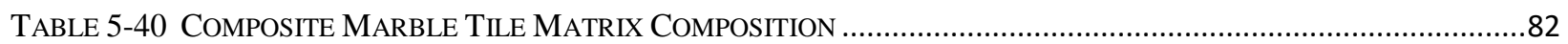

TABLE 5-41 ENERGY REQUIREMENTS FOR COMPOSITE MARBLE TILE MANUfACTURING ……...................................83

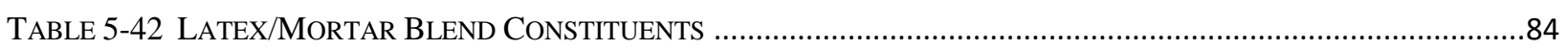

TABLE 5-43 INPUTS AND OUTPUTS PER REGULAR CLEANING EVENT .................................................................8

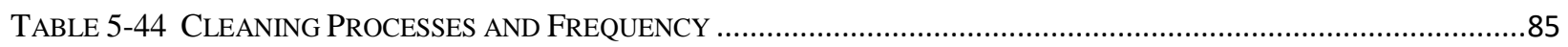

TABLE 5-45 CoMPOSITE MARBLE TILE INTERMITTENT CLEANING INPUTS PER YEAR................................................8

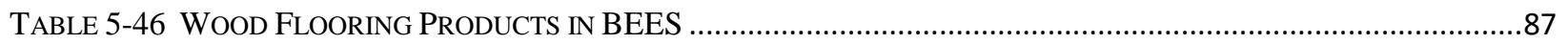

TABLE 5-47 INSTALLATION MATERIALS - WOOD FLOORING ……......................................................................91

TABLE 5-48 INPUTS AND OUTPUTS PER REGULAR CLEANING EVENT .................................................................92

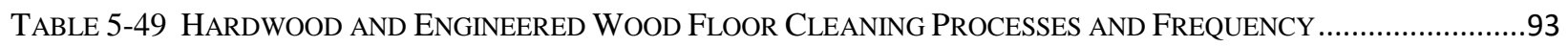

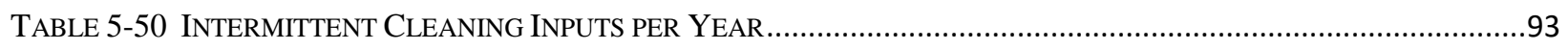

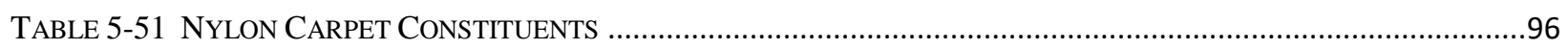

TABLE 5-52 ENERGY REQUIREMENTS FOR NYLON CARPET MANUFACTURING …….................................................97

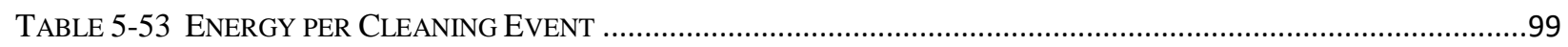

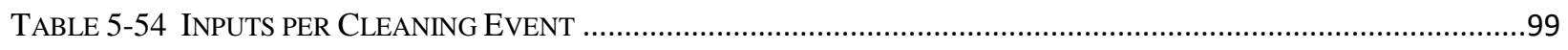

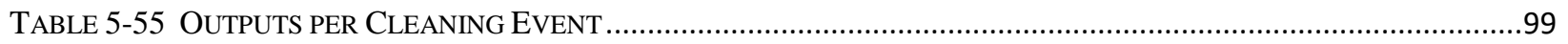

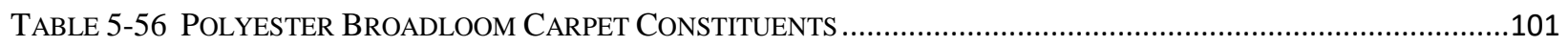

TABLE 5-57 ENERGY REQUIREMENTS FOR PET CARPET MANUFACTURING ......................................................101

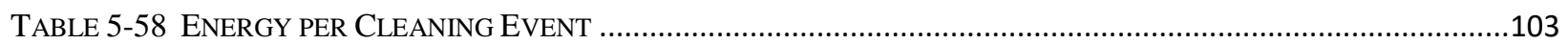

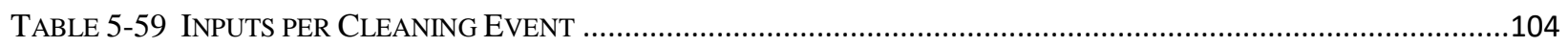

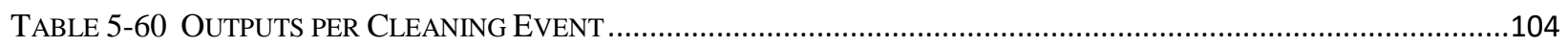

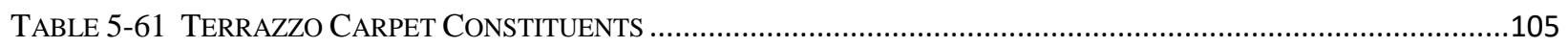

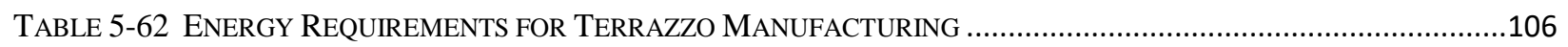

TABLE 5-63 INPUTS AND OUTPUTS PER REGULAR CLEANING EVENT ...................................................................108

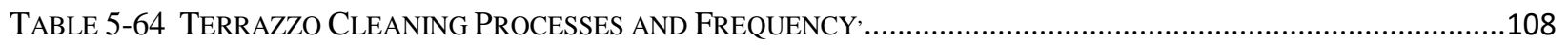

TABLE 5-65 TERRAZZO INTERMITTENT CLEANING INPUTS PER YEAR ...............................................................108

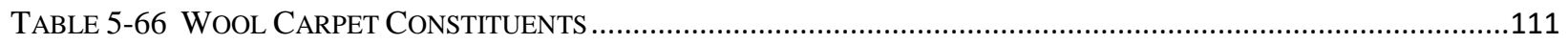

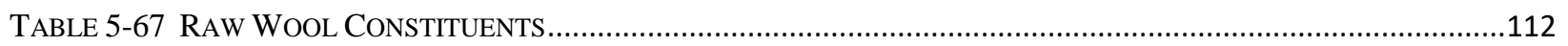

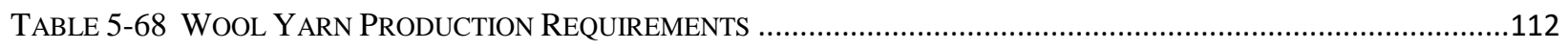

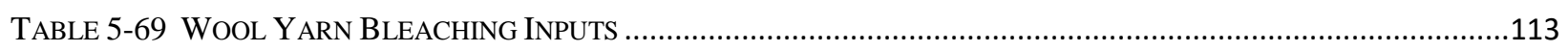

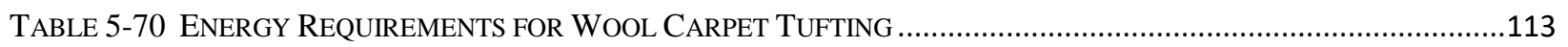

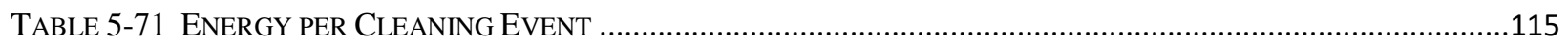

TABLE 5-72 INPUTS PER CLEANING EVENT ………..................................................................................115

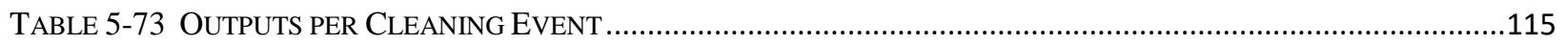

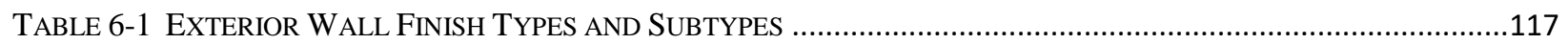

TABLE 6-2 EXTERIOR WALL FINISH CHARACTERISTICS AND CERTIFICATIONS …….............................................117

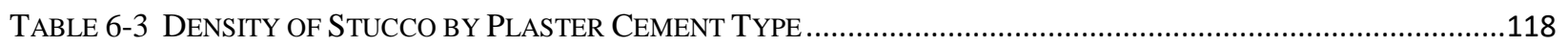

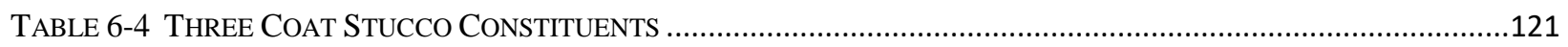

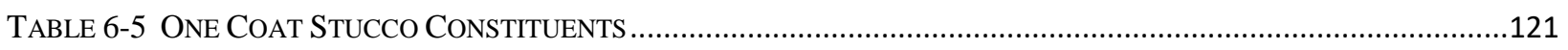

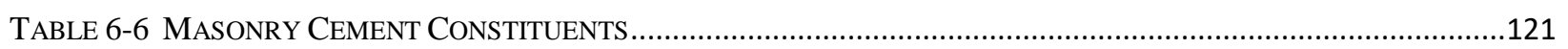

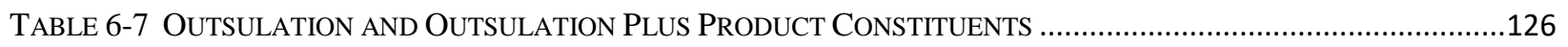

TABLE 6-8 OUTSULATION MD PRODUCT CONSTITUENTS ..................................................................................126

TABLE 6-9 ENERGy REQUIREMENTS FOR MiXING DRYVIT OUTSULATION AND OUTSUlation Plus MATERIALS ....127 


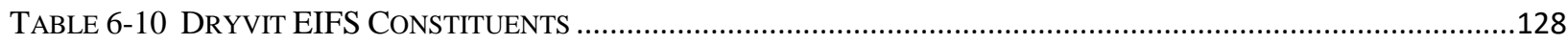

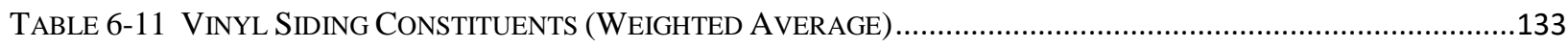

TABLE 6-12 RECYCLED CONTENT CEDARBOARDS SidiNG CONSTITUENTS .........................................................133

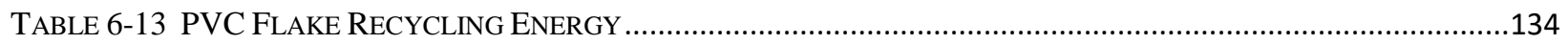

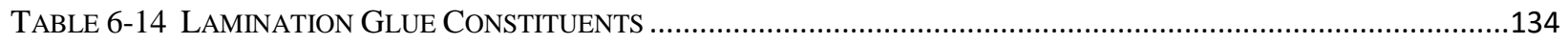

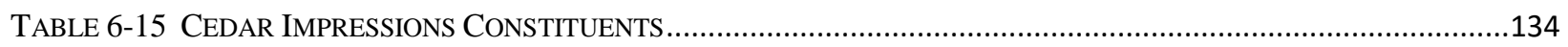

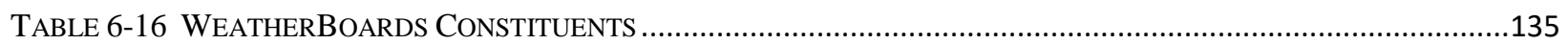

TABLE 6-17 ENERGY REQUIREMENTS FOR CERTAINTEED VINYL- AND PP-BASED PRODUCTS...................................136

TABLE 6-18 Other Process Data For CERTAINTEEd VinYL- AND PP-BASEd ProductS......................................136

TABLE 6-19 ENERGY REQUIREMENTS FOR WEATHERBOARDS ........................................................................137

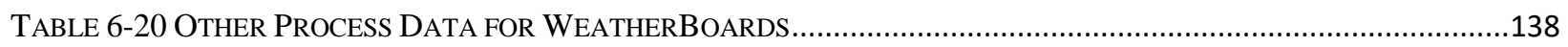

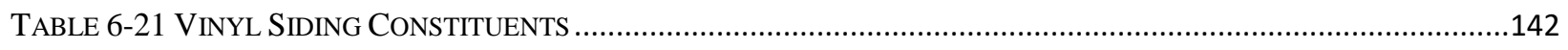

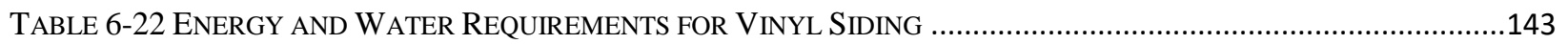

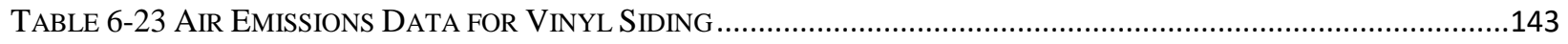

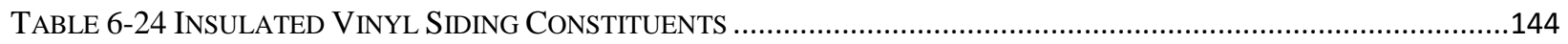

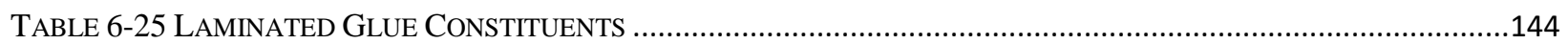

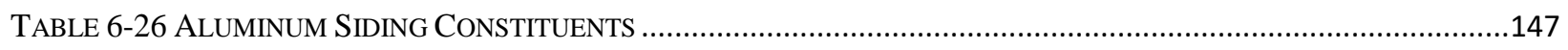

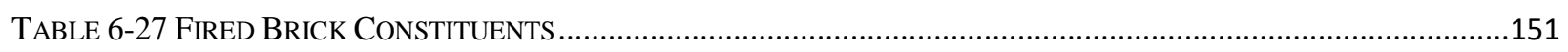

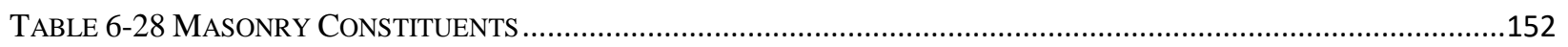

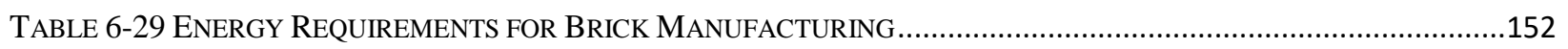

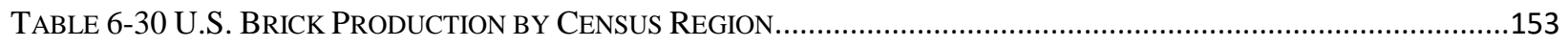

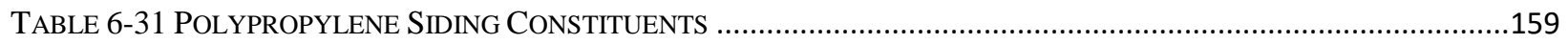

TABLE 6-32 ENERGY AND WATER REQUIREMENTS FOR POLYPROPYLENE SIDING ……….....................................159

TABLE 7-1 INTERIOR WALL AND CEILING FINISH TYPES AND SUBTYPES ..........................................................163

TABLE 7-2 EXTERIOR WALL AND CEILING FINISH CHARACTERISTICS AND CERTIFICATIONS ....................................164

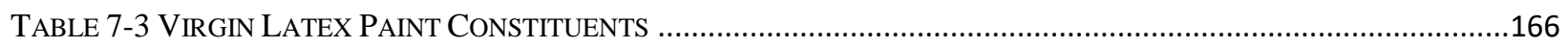

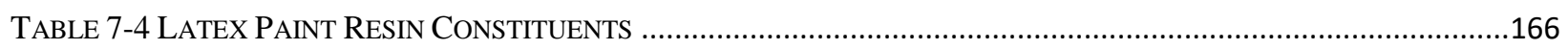

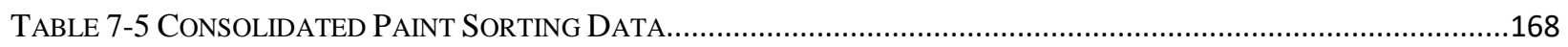

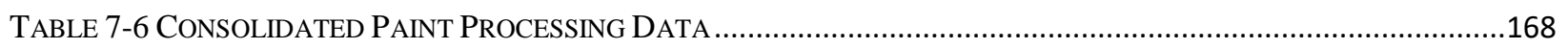

TABLE 7-7 REPROCESSED PAINT SORTING AND PROCESSING DATA........................................................................169

TABLE 8-1 INTERIOR WALl AND CEILING INSULATION TyPES, SUBTyPES, AND FUNCTION UNIT CONVERSION ........172

TABLE 8-2 EXTERIOR WALL AND CEILING INSULATION CHARACTERISTICS AND CERTIFICATIONS...........................172

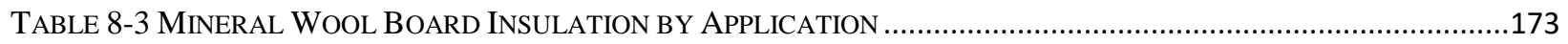

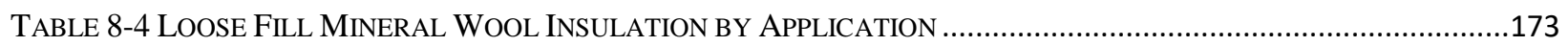

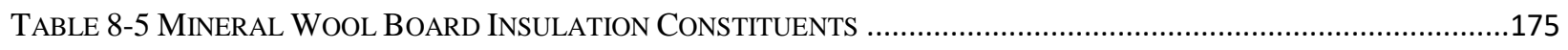

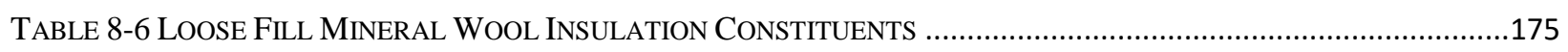

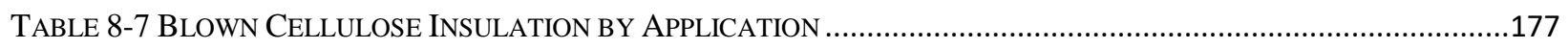

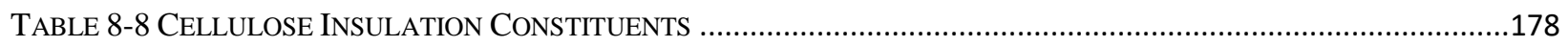

TABLE 8-9 FIBERGLASS BATT INSULATION BY APPLICATION ............................................................................180

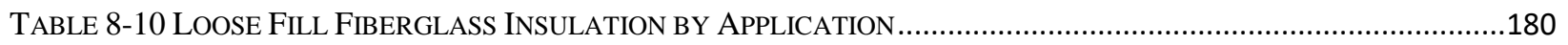

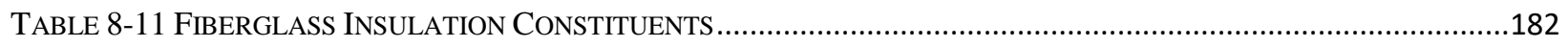

TABLE 9-1 INTERIOR WALL AND CEILING FINISH TYPES AND SUBTYPES...........................................................185

TABLE 9-2 EXTERIOR WALL AND CEILING FINISH CHARACTERISTICS AND CERTIFICATIONS ..................................185

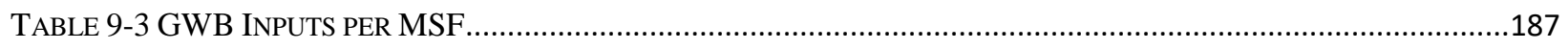

TABLE 9-4 INDUSTRY-AVERAGE DISTANCES TO BUILDING SITE....................................................................188 


\section{List of Acronyms}

\begin{tabular}{|c|c|}
\hline Acronym & Definition \\
\hline AA & Aluminum Association \\
\hline ACC & American Chemistry Council \\
\hline $\mathrm{ADP}$ & abiotic depletion potential \\
\hline AEO & Applied Economics Office \\
\hline AHP & Analytical Hierarchy Process \\
\hline ASA & acrylonitrile styrene acrylate \\
\hline ASHRAE & American Society of Heating, Refrigerating and Air-Conditioning Engineers \\
\hline ASTM & American Society for Testing and Materials \\
\hline AWARE & Available Water Remaining \\
\hline BBT & BioBased Tile \\
\hline BEES & Building for Environmental and Economic Sustainability \\
\hline BETR & Berkeley-Trent \\
\hline BIRDS & Building Industry Reporting and Design for Sustainability \\
\hline BIRDS NEST & BIRDS Neutral Environment Software Tool \\
\hline $\mathrm{CaCO}_{3}$ & calcium carbonate \\
\hline CCACTI & Consortium on Competitiveness for the Apparel, Carpet, and Textile Industries \\
\hline CED & Cumulative Energy Demand \\
\hline CFC & chlorofluorocarbons \\
\hline CFC-11 & trichlorofluoromethane \\
\hline CML & Center of Environmental Science of Leiden University \\
\hline CML-IA & CML Impact Assessment Characterisation Factors \\
\hline $\mathrm{CO}_{2} \mathrm{e}$ & carbon dioxide equivalent \\
\hline CORRIM & Consortium for Research on Renewable Industrial Materials \\
\hline CPG & Comprehensive Procurement Guideline \\
\hline CPI & Consumer Price Index \\
\hline CRI & Carpet and Rug Institute \\
\hline CTUh & comparative toxic units for human toxicity \\
\hline CTUe & comparative toxic units for ecotoxocity \\
\hline DEHP/DINP/DIDP & phthalate esters \\
\hline DOE & Department of Energy \\
\hline DOTP & Dioctyl Terephthalate \\
\hline EDIP & Environmental Development of Industrial Products \\
\hline EIFS & Exterior Insulation and Finish Systems \\
\hline EL & Engineering Laboratory \\
\hline EPA & Environmental Protection Agency \\
\hline EPD & environmental product declaration \\
\hline EPS & expanded polystyrene \\
\hline ETS & Emissions Trading Systems \\
\hline EU & European Union \\
\hline FEMP & Federal Energy Management Program \\
\hline
\end{tabular}




\begin{tabular}{|c|c|}
\hline Acronym & Definition \\
\hline FGD & flue gas desulfurization \\
\hline GA & Gypsum Association \\
\hline GHG & greenhouse gas \\
\hline GSA & General Services Administration \\
\hline GWB & gypsum wallboard \\
\hline GWP & Global Warming Potential \\
\hline HDF & High Density Fiberboard \\
\hline HDPE & high density polyethylene \\
\hline HHW & Household Hazardous Waste \\
\hline IAQ & indoor air quality \\
\hline ICC & International Code Council \\
\hline IE4B & Impact Estimator for Buildings \\
\hline IPCC & Intergovernmental Panel on Climate Change \\
\hline ISO & International Organization for Standardization \\
\hline LCA & life-cycle assessment \\
\hline LCC & life-cycle cost \\
\hline LCCA & life-cycle cost analysis \\
\hline LCI & life-cycle inventory \\
\hline LCIA & life-cycle impact assessment \\
\hline LDPE & low-density polyethylene \\
\hline LEED & Leadership in Energy and Environmental Design \\
\hline MEK & methyl ethyl ketone \\
\hline MEKP & methyl ethyl ketone peroxide \\
\hline MSDS & material safety data sheet \\
\hline NAIMA & North American Insulation Manufacturers Association \\
\hline NIST & National Institute of Standards and Technology \\
\hline NREL & National Renewable Energy Laboratory \\
\hline NTMA & National Terrazzo and Mosaic Association \\
\hline $\mathrm{O}_{3}$ & ozone \\
\hline PAF & potentially affected fraction \\
\hline PC & post-consumer \\
\hline PCA & Portland Cement Association \\
\hline PCR & product category rules \\
\hline PET & polyethylene terephthalate \\
\hline PM2.5 & particulate matter less than 2.5 micrometers in diameter \\
\hline $\mathrm{PP}$ & propylene \\
\hline PUR & polyurethane \\
\hline PVA & polyvinyl acetate \\
\hline PVB & polyvinyl butyral \\
\hline PVC & polyvinyl chloride \\
\hline RECs & Renewable Energy Credits \\
\hline RS & Revolutionary System \\
\hline
\end{tabular}




\begin{tabular}{|c|c|}
\hline Acronym & Definition \\
\hline RGGI & Regional Greenhouse Gas Initiative \\
\hline SAB & Science Advisory Board \\
\hline SB & Styrene butadiene \\
\hline SCAQMD & South Coast Air Quality Management District \\
\hline SCC & social cost of carbon \\
\hline SETAC & Society of Environmental Toxicology and Chemistry \\
\hline SMA & Stucco Manufacturers Association \\
\hline $\mathrm{SO}_{2}$ & sulfur dioxide \\
\hline SOM & soil organic matter \\
\hline TCNA & Tile Council of North America, Inc. \\
\hline TRACI & Tool for the Reduction and Assessment of Chemical and other environmental Impacts \\
\hline UF & urea-formaldehyde \\
\hline UNEP & United Nations Environment Programme \\
\hline USDA & U.S. Department of Agriculture \\
\hline USES-LCA & Uniform System for the Evaluation of Substances adapted for LCA \\
\hline USEtox & UNEP-SETAC toxicity \\
\hline $\begin{array}{l}\text { USGBC } \\
\text { UV }\end{array}$ & $\begin{array}{l}\text { U.S. Green Building Council } \\
\text { ultraviolet }\end{array}$ \\
\hline VCT & vinyl composition tile \\
\hline VOC & volatile organic compound \\
\hline VSI & Vinyl Siding Institute \\
\hline WARM & Waste Reduction Model \\
\hline WATSON & $\begin{array}{l}\text { water and soil environmental fate and exposure model of noxious substances at the European } \\
\text { scale }\end{array}$ \\
\hline WRONZ & Wool Research Organization of New Zealand \\
\hline
\end{tabular}




\section{Introduction to BEES}

\subsection{Background}

Building stakeholders need practical metrics, data, and tools to support decisions related to sustainable building products. To assist in meeting this national need, the Applied Economics Office (AEO) in the Engineering Laboratory (EL) of the National Institute of Standards and Technology (NIST) developed software, known as Building for Environmental and Economic Sustainability (BEES), to analyze the sustainability of building products. The initial version of BEES was released as a desktop application in 1997 followed by several updated versions throughout the 2000s. In 2010, BEES was transitioned into a web-based application called BEES Online (National Institute of Standards and Technology (NIST), 2010). Through a combination of NIST-funded and privately-funded data development, over 230 products across over 30 product categories are currently available in BEES Online.

AEO has developed a new version of BEES Online, named BEES Online 2.0, that uses the BEES framework in combination with new and updated data sources, methodologies, and processes to update the sustainability results for the building products available in BEES Online. In so doing, AEO is keeping BEES scientifically sound while maintaining consistency with current sustainability evaluation practices desired by industry stakeholders. This technical manual documents the development, including the assumptions and data sources used, of the BEES Online 2.0 product database and web application.

\subsection{BEES Model}

The BEES methodology takes a multidimensional, life cycle approach by considering multiple sustainability criteria: environmental, economic, and social impacts, over the entire life of a building product. Considering multiple impacts and life cycle stages is necessary because product selection decisions based on one criteria or life cycle stage could obscure others that might cause equal or greater damage. Consider the recent trend of climate change-focused, "carbon neutral" product labeling, which only considers the amount of carbon emitted due to its production but may ignore any carbon associated with other life cycle stages, such as the product's use, maintenance, replacement, and/or disposal. A single-impact focus excludes other environmental impacts, such as smog formation, the effects of acid gases, or water consumption, that a product may potentially cause over its useful life. Without consideration of these other environmental impacts as well as the cost-competitiveness and/or social implications of a product over its useful life, the true sustainability of a product is not adequately evaluated. In other words, a multidimensional, life cycle approach is necessary for a comprehensive, balanced analysis on building product sustainability.

It is relatively straightforward to select products based on initial costs because building products are bought and sold in the marketplace. However, the costs realized after a product is installed are often ignored in purchasing decisions. Some products last longer 
than others, requiring consideration of when products must be replaced, and their associated future costs. Even more difficult is to include life cycle environmental impacts in our purchasing decisions. Environmental impacts such as global warming potential (GWP), water pollution, and resource depletion are generally economic externalities with their costs not reflected in the market prices of the products that generated the externalities. Moreover, even if there were a mandate today to include environmental "costs" in market prices, it would be nearly impossible to do so due to difficulties in assessing these impacts in economic terms. Economists have debated how to value clean air, clean water, and human health for decades, and consensus does not appear likely in the short-term future.

While environmental performance typically cannot be measured on a monetary scale, it can be quantified using the multi-disciplinary approach known as environmental Life Cycle Assessment (LCA) that addresses multiple impact categories over multiple life cycle stages. The BEES methodology measures environmental performance using LCA, following guidance in the International Organization for Standardization (ISO) 14040 and 14044 standards for LCA (International Organization for Standardization (ISO), 2006a, 2006b). These environmental performance measures can then be synthesized into an overall performance measure using the American Society for Testing and Materials (ASTM) standard for Multiattribute Decision Analysis (ASTM, 2016).

Economic performance is measured using the ASTM International standard life cycle cost (LCC) approach (ASTM, 2015). For the entire BEES analysis, building products are defined and classified based on UNIFORMAT II, the ASTM standard classification for building elements (ASTM, 2015e). LCA and LCC approaches implemented in BEES will be described in detail in Chapter 2 and Chapter 3, respectively. BEES product categories are summarized in Chapter 4 and BEES products' modeling and assumptions are described in Chapter 5 through Chapter 17. Chapter 18 summarizes the BEES Online 2.0 software development and design. Chapter 19 discusses current limitations and development plans for BEES Online.

\subsection{Notable Changes in BEES Online 2.0}

\subsubsection{Reasons for Updating BEES Online}

NIST recognized that BEES Online needed updating, both in terms of the software interface and the underlying impact methods and product data. Given requirements for LCA in green certification programs, such as MRc2 - Building Product Disclosure and Optimization: Environmental Product Declaration in USGBC’s LEED v4 (U.S. Green Building Council, 2018), it is apparent that the use of standardized LCAs, such as Environmental Product Declarations (EPDs) based on industry-defined Product Category Rules (PCRs), is a strong trend in the industry that will continue to grow in the future. NIST has therefore developed BEES Online 2.0 to engage in this trend and address the needs of a broad range of stakeholders (architects, designers, government agencies, 
certified LCA practitioners, green certification organizations, and consumers) who need affordable, standardized product LCAs.

New and proposed changes to redevelop BEES' methodology, data, and interface came about through discussions with stakeholders including the U.S. Green Building Council (USGBC), American Chemistry Council (ACC), Department of Energy (DOE) Federal Energy Management Program (FEMP), General Services Administration (GSA), Environmental Protection Agency (EPA), Federal government interagency environmental and sustainability groups/committees, standards and codes organizations, such as the American Society of Heating, Refrigerating and Air-Conditioning Engineers (ASHRAE) and International Code Council (ICC), as well as industry organizations and manufacturers.

\subsubsection{Methodology and Data}

Since the release of BEES Online in 2011, the science of LCA has improved both in terms of the methodology for LCA and life cycle impact assessment (LCIA) development as well as the quality of the available Life Cycle Inventory (LCI) data sources used to develop product LCAs/LCIAs. One of the key changes is the inclusion of the use phase for those products for which maintenance can vary significantly depending on application and occupant behavior.

All products from BEES Online are being transitioned to BEES Online 2.0, including updating the product data and results, removing any products no longer on the market or that are irrelevant, and identifying and adding new products. Product categories with one or two products, or products not explicitly installed in buildings (e.g., furniture cleaners) have lowest priority in the transition. BEES currently includes updated data for the following BEES’ product categories: flooring, partitions (e.g., gypsum board), exterior wall finishes (e.g., cladding or siding), interior wall and ceiling finishes (e.g., paint), and wall and ceiling insulation.

The LCI results output is no longer available to users. Based on feedback from BEES users, they are more interested in aggregated results for decision making instead of detailed LCI flow analysis. Providing aggregated results allows for more focused attention (i.e., funding and labor) on providing a faster, more powerful user interface. Providing only aggregated results is also more practical; the impact results using the EPA's Tool for Reduction and Assessment of Chemicals and Other Environmental Impacts (TRACI) 2 methodology draw from thousands of LCI flows. This approach contrasts with the more rudimentary previous "BEES impact methodology", where the LCI flow list was much shorter and thus easier to manage.

The initial release of BEES Online used TRACI 1.0 methodology and impact categories to develop the product LCIAs. BEES Online 2.0 provides the same BEES categories but updates the methodology to the state-of-the-art impact methodologies including TRACI 2.1, Center of Environmental Science of Leiden University (CML) Impact Assessment Characterisation Factors (CML-IA), and Cumulative Energy Demand (CED) while 
expanding impact categories to include water, land, and indoor air quality (IAQ). All products can be evaluated using one of three impact methodologies: TRACI 2.1, BEES, and PCR Impact Categories. TRACI 2 includes all TRACI 2.1 impact categories while BEES includes all TRACI 2.1 impact categories plus water use, land use, and IAQ. Selecting PCR Impact Categories will provide the user with only those impact categories specified in the product category's PCR, which could include TRACI and/or CML impact categories.

\subsubsection{Interface}

The BEES Online interface was redeveloped from scratch for BEES Online 2.0, allowing for a complete reevaluation of the needs and wants of BEES users. The resulting tool has improved the user experience and user options and has been designed for seamless expansion with future integration of current and new product categories.

BEES Online 2.0 increases the BEES user experience by making the interface more user friendly. Products are filterable based on product type and/or characteristics like recycled content, bio-based content, or product certification. The ability to filter simplifies the user experience and is important for selections that are made based on acquisition requirements not necessarily based on the LCA. Users can now easily navigate back to previous screens to make changes to their selections by using the Back and Next buttons available on each page. The results are customized to the user's selections and the user can download the results, allowing users to analyze the results in ways not currently provided within BEES.

Users are also provided with more options to customize their BEES analysis. A user can select from the traditional TRACI 2 impact categories, the more expansive BEES categories, or focus on the impact categories specified in the product category's PCR. BEES still includes life cycle cost analysis (LCCA) with custom real discount rate selection, but it now expands the capabilities by allowing users to customize the installed cost of each selected product as well as provides the ability to include a user-defined social cost of carbon. BEES Online 2.0 allows users to customize some use phase assumptions for the products where cleaning or maintaining the functionality of the product is an essential part of the life of the product (such as flooring). Users can customize the expected product service life and quantity of product installed. It is reasonable to assume that a product may not have the same expected service life in different applications (e.g., traffic patterns for flooring). Regardless of the selected product life, the results are provided on a per functional unit basis (e.g., impact per $\mathrm{ft}^{2}$ of installed flooring) as well as total value of the quantity of product installed (e.g., impact of $1000 \mathrm{ft}^{2}$ of installed flooring) over 60 years. This timeframe is an increase from the assumed 50 years in BEES Online 1.0 to become consistent with the minimum building service life of 60 years for green building certification programs to fully account for maintenance and replacement. 


\subsection{Submission Process to BEES Online 2.0}

\subsubsection{Cost}

NIST provides these standardized results at low or no cost to industry. When the timing allows, i.e., during a product development or update period, NIST covers the cost of developing and incorporating submitted products into BEES. NIST puts forth effort to inform manufacturers and industry organizations that NIST is open to new product submissions.

By leveraging internal project funds and economies of scale, NIST drastically decreases the cost of LCA development. This approach provides small manufacturers, which often consider the cost of completing an EPD prohibitive, an opportunity to participate and help grow competition in green product markets. If a manufacturer wants to submit a product to BEES in-between a product development/update period, the manufacturer pays a minimal fee for the LCA, after which their product may be added to an existing BEES category immediately.

NIST is dedicated to maintaining, further developing, and supporting BEES with internal funds to provide a reliable, user-friendly, free tool to help users make sustainable product selection decisions. Data collection for BEES Online 2.0 was done under contract with Four Elements Consulting, LLC using the SimaPro version 8 LCA software (PRe Sustainability, 2018). For more information about submitting a product to BEES, please contact Joshua Kneifel at joshua.kneifel@nist.gov.

\subsubsection{BEES Product LCA Development Process}

BEES environmental LCAs are developed with the SimaPro software (PRe Sustainability, 2018) using a standardized LCA model and well-respected and globally-accepted LCA databases including ecoinvent (Ecoinvent, 2017) and the U.S. LCI database (National Renewable Energy Laboratory (NREL), 2012). NIST works with industry associations and manufacturers to strive for product data that is temporally, geographically, and technologically representative. The BEES product database is maintained by updating both product-specific data and background data every several years, dependent on changes to PCRs, impact methods, source data, and available funding and resources. The same boundary conditions, assumptions, and study period (60 years) are applied to all products in a category. Since the same software, datasets, and system boundaries are used for all products in a category, the variability issues often seen in LCAs across an industry are greatly minimized. Although not currently included in BEES Online 2.0, NIST is evaluating the ability to incorporate uncertainty into the product LCIAs in future releases of BEES to better assist in product comparison.

\subsubsection{Products with Existing EPDs}

PCRs provide some parameters around standardizing the development of consistent LCAs and resulting EPDs. However, the use of different background databases, data set 
availabilities for materials, and allocation or other methodological rules, create variability amongst different LCA models, even for the same product. Despite this problem, the limitations around differences in LCAs based on these factors are generally understood within the LCA community, and public EPDs caution users to avoid making comparisons with other EPDs, such as:

EPDs are not comparative assertions and are either not comparable or have limited comparability when they cover different life cycle stages, are based on different product category rules or are missing relevant environmental impacts.

While the intended purpose of an EPD is anything but using it to compare with other products, comparisons are still made. Since there is so much variability amongst the LCAs behind the EPDs, making comparisons could lead to erroneous conclusions, especially for users who do not understand these limitations.

The goal for BEES has always been to minimize this variability issue and allow for fair comparability by ensuring that all its LCA models are built using the same background data sets and methodological considerations.

When a product has already undergone the EPD process and the EPD owner wants that product in BEES, NIST obtains the underlying information (e.g., the primary data) and then rebuilds the LCA model within SimaPro using the same background data as other products in that category. This process inevitably may lead to different results for some impact categories than those published in the EPD. EPD owners review the results and assumptions, and in our experience, they have been accepting of the differences as being the nature of the current state of LCA, not just an issue with BEES. NIST recognizes that, in general, data set variability would be minimized with a publicly available, standardized, comprehensive database to be used with all LCA software platforms or tools (like BEES or even EPDs), but such a database does not currently exist.

Based on the language in Leadership in Energy and Environmental Design (LEED) v4, we are aware that LCAs are required to be "critically reviewed" to be used toward LEED credit. While NIST develops well-documented, cradle-to-grave product LCAs based on the standards and requirements conforming to ISO 14044 and the most recent PCRs and has implemented an internal validation process, the LCAs do not go through an official $3^{\text {rd }}$ party verification process as would be completed during a formal EPD process. 


\section{Environmental Performance}

Environmental LCA is a "cradle-to-grave," systems approach for measuring environmental performance. The approach is based on the logic that all stages in the life of a product generate environmental impacts and must therefore be analyzed, including raw materials acquisition, product manufacture, transportation, installation, operation and maintenance, and ultimately recycling and waste management. An analysis that excludes any of these stages - without explicit rationale for doing so - is limited because it ignores the full range of upstream and downstream impacts of stage-specific processes.

The strength of LCA is its comprehensive, multi-dimensional scope. Some green product claims and strategies are based on a single life cycle stage or a single environmental impact. A product may be claimed to be green simply because it has recycled content or accused of not being green because it emits volatile organic compounds (VOCs) during its installation and use. These single-attribute claims may be misleading because they ignore the possibility that other life cycle stages, or other environmental impacts, may yield offsetting effects. For example, a product with recycled content may have a high embodied fuel content, leading to fossil fuel depletion, GWP, and acid rain impacts during the raw materials acquisition, manufacturing, and transportation life cycle stages. LCA thus broadens the environmental discussion by accounting for potential shifts of environmental problems from one life cycle stage to another, or one environmental medium (land, air, water) to another. The benefit of the LCA approach is in implementing a trade-off analysis to assess where in the life cycle overall impacts may be reduced, rather than limiting the scope to a shift of impact.

The general LCA methodology involves four steps (International Organization for Standardization (ISO), 2006a, 2006b).

1. Goal and scope definition

2. Inventory analysis

3. Impact assessment

4. Interpretation

The goal and scope definition step outlines the purpose of the study and its breadth and depth. The inventory analysis step identifies and quantifies the environmental inputs and outputs associated with a building product over its entire life cycle. The quantification and aggregation of results is called the LCI, which includes elementary flow inputs (i.e., resources from the earth, such as water, fossil fuels, minerals). Elementary flow outputs include releases to air, land, and water. The LCI output is large, and it is difficult to assign meaning to its individual elements. Nonetheless, we are interested in the LCI flows' consequences, or how they may potentially impact the environment and human health, and this determination is done in the impact assessment step. The impact assessment step characterizes the flows in the LCI results in relation to a set of environmental impacts. For example, the impact assessment relates carbon dioxide $\left(\mathrm{CO}_{2}\right)$ and other greenhouse gas (GHG) emissions (e.g., methane), to GWP (an impact). Finally, 
the interpretation step examines the results in accordance with the goals of the LCA study.

\subsection{Goal and Scope Definition}

The goal of BEES LCAs is to generate environmental impacts for building product alternatives sold in North America. These impacts are combined with economic performance to help the building community select cost-effective, environmentallypreferred building products. The goal and scope definitions include defining the system boundaries, cut-off criteria, the functional unit, and the data collection strategy.

Defining the system boundaries involves identifying the unit processes to be included. A unit process is the "smallest element considered in the LCI analysis for which input and output data are quantified." 1 The manufacture of a product usually involves many unit processes (e.g., ethylene production for input to the manufacture of the styrene-butadiene bonding agent used in stucco cement in cladding). Each unit process involves many inventory flows, some of which themselves involve other, subsidiary unit processes. Boundary-setting rules determine which unit processes are included in the LCA, especially those that need collection of primary data. In the BEES system, the boundarysetting rule consists of a set of three decision criteria. For each candidate unit process, mass and energy contributions to the product system are the primary decision criteria. In some cases, cost contribution is used as a third criterion. ${ }^{2}$ Together, these criteria provide a robust screening process, as illustrated in Figure 2-1. A material must have a large contribution to at least one decision criterion to be selected. The weight criterion selects materials A, B, and C; the energy criterion selects material E; and cost selects material I. As a result, the unit processes for producing ancillary materials A, B, C, E, and I are included in the system boundaries.

\footnotetext{
${ }^{1}$ Sec. 3.34 of International Organization for Standardization (ISO) (2006b).

${ }^{2}$ While a large cost contribution does not directly indicate a significant environmental impact, it may indicate scarce natural resources or numerous subsidiary unit processes potentially involving high energy consumption.
} 


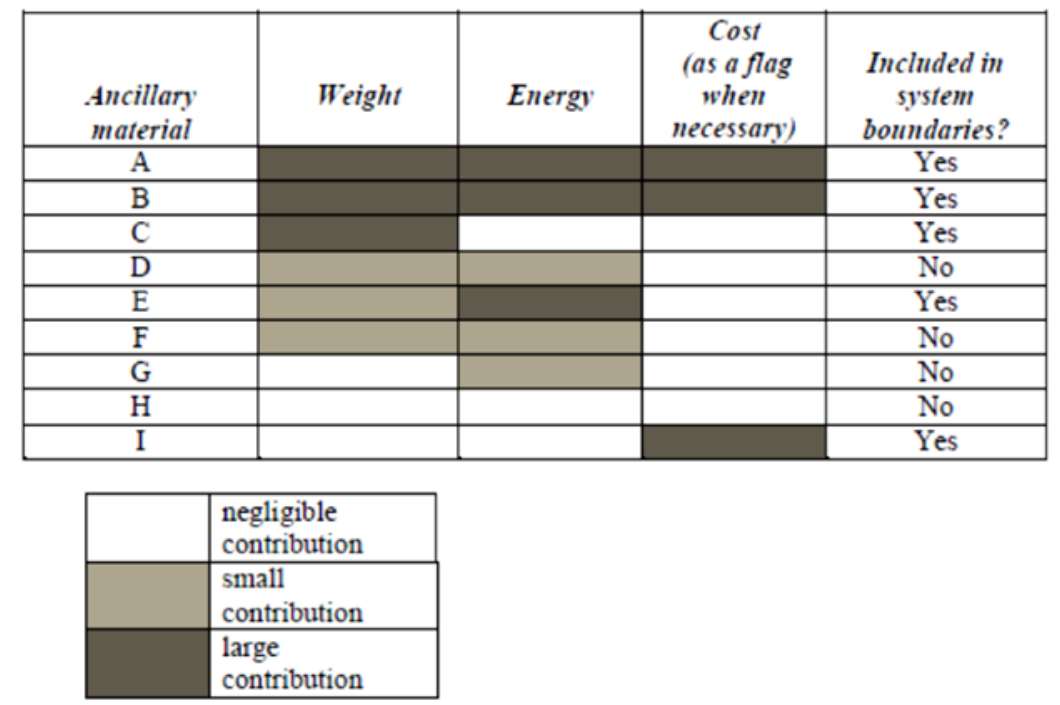

Figure 2-1 Decision Criteria for Setting Product System Boundaries

For each unit process that is identified in the system boundary, and where background data from LCA databases are not available, data need to be collected. Manufacturers responsible for manufacturing operations of and the bill of materials for a product can use a questionnaire to collect data. Outflows collected are often those that are relevant to the specific industry (e.g., particulates from mining). Databases take care of background data sets, which are the supporting data for the products' defined unit processes. Background data can include materials, energy and fuel inputs, and transportation. Where manufacturers do not have control over data on their products, such as whether their product is recycled or landfilled at end of life, the LCA practitioner makes assumptions or uses industry-backed data on the typical practice.

Defining the unit of comparison is another important task in the goal and scoping phase of LCA. The basis for all units of comparison is the functional unit, defined so that the products compared may be true substitutes for one another. The functional unit provides the critical reference point to which all inventory flows are scaled. For example, the functional unit for the floor covering alternatives is $0.093 \mathrm{~m}^{2}\left(1 \mathrm{ft}^{2}\right)$ of flooring; its production, installation, maintenance, end of life management, and replacements over the 60 -year study period are all quantified and normalized to this defined area.

Data requirements are defined in the scoping phase as well. BEES includes the following:

- Geographic coverage - The data are based on North American conditions and technology wherever possible.

- Time period coverage - When updating products, the goal is to collect the most recent, best available data from manufacturers or industry associations. Primary data from manufacturers and industry associations is targeted to be less than five years old. Background data are targeted to be less than 10 years old. These data goals are typically met by updating product categories every three to five years and ensuring that the latest databases used in LCA modeling tools are current. Databases, 
especially ones like ecoinvent (Ecoinvent, 2017), are constantly being updated with newer foreground and/or background data.

- Technology coverage - For generic products, the most representative technology is evaluated. When data for the most representative technology are not available, an aggregated result is developed based on the U.S. average technology for that industry.

- Databases - The data for fuels, energy, transportation means, and materials (where available) come from the U.S. LCI database, developed using a common, ISO 14040consistent research protocol (National Renewable Energy Laboratory (NREL), 2012). Data for all other materials come from ecoinvent (Ecoinvent, 2017).

\subsection{Inventory Analysis}

Inventory analysis entails quantifying the inputs and outputs for the unit processes within a product system. One of the primary tasks is data collection that ensures the product system evaluated is representative and appropriately addresses the cut-off criteria, data and data quality requirements, and other scoping factors. Data are collected for each defined unit process. As shown in Figure 2-2, to produce a given product or intermediate product, inputs collected include energy, fuels, net water use, ancillary materials, and product components/materials. Outputs may include direct emissions to air and water, and waste categories.

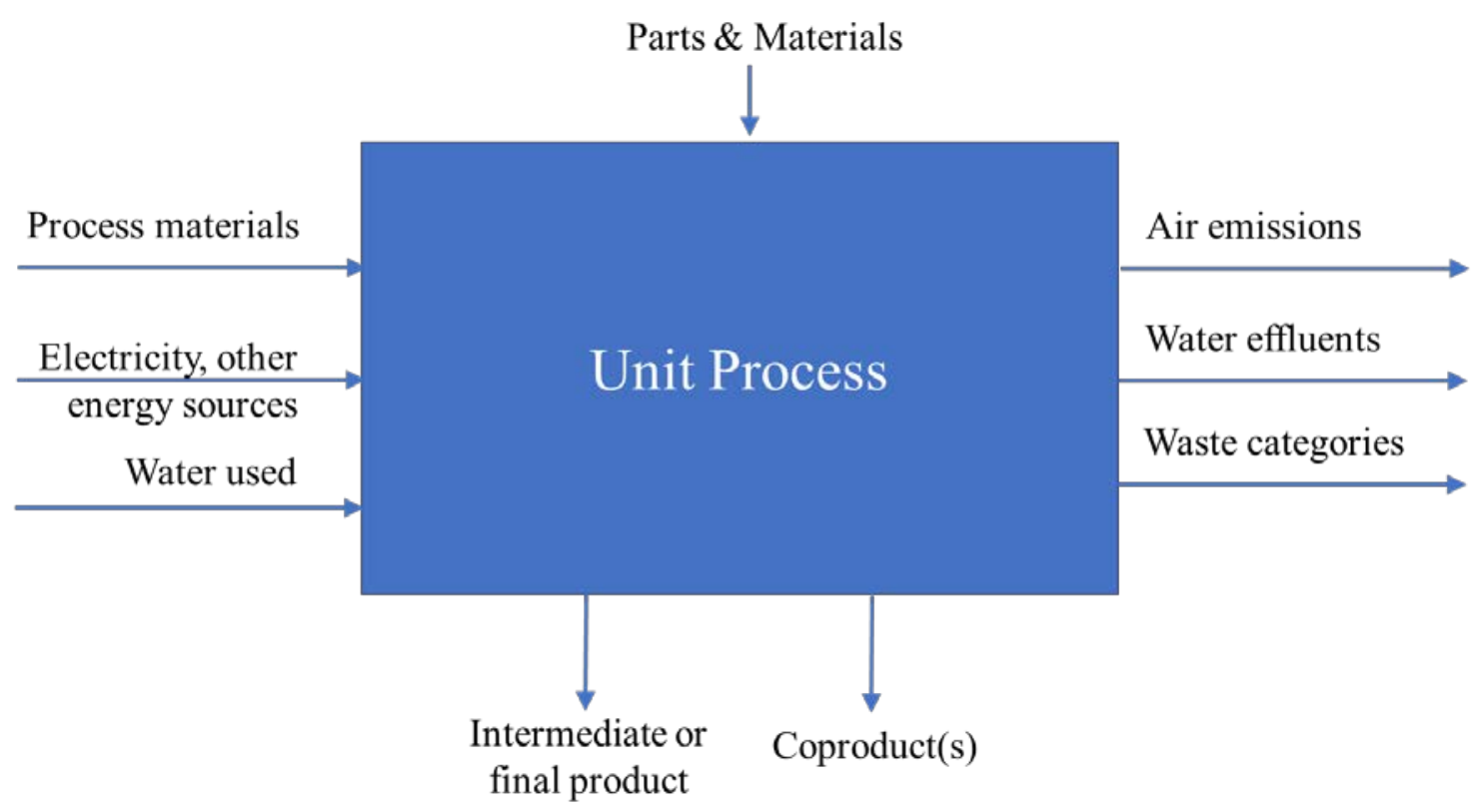

Figure 2-2 BEES Inventory Data Categories

Numerous approaches may be used to collect inventory data for LCAs. These range from (EPA, 1993):

- Unit process- and facility-specific: collect data from a process within a given facility that are not combined in any way 
- Composite: collect data from the same process combined across locations

- Aggregated: collect data combining more than one process

- Industry-average: collect data derived from a representative sample of locations believed to statistically describe the typical process across technologies

- Descriptive: collect data whose representation may be unknown but which are qualitatively descriptive of a process

For the generic BEES products necessitating U.S.- or North American-average data and results, generic product data are primarily collected using the industry-average approach. Manufacturer-specific product data are primarily collected using the unit process- and facility-specific approach (and documentation of specific data are often aggregated to preserve manufacturer confidentiality). It is NIST's goal to strive for product data that represents the closest approximations available of the impacts and attributes associated with each product. Some of the products in BEES are built using detailed LCA questionnaires and/or shorter surveys sent to industry experts, while others are built using published LCA reports. In most cases, any assumptions regarding the associated unit processes are verified through experts in the respective industries to assure the data have been appropriately represented in BEES. Today, many industry average and company specific products have already-published EPDs, which are based on externally-verified LCAs. For products in BEES that have undergone the EPD process, much, if not all, of the product data come from the EPDs' supporting LCAs, with the approval of the EPD owner.

\subsection{Life Cycle Impact Assessment}

The impact assessment step of LCA quantifies the potential contribution of LCI results flows to a range of environmental impacts. The approach preferred by most LCA practitioners and scientists today involves a two-step process:

- Classification of inventory flows that contribute to specific environmental impacts. For example, GHGs such as $\mathrm{CO}_{2}$, methane, and nitrous oxide are classified as contributing to GWP.

- Characterization of the potential contribution of each classified inventory flow to the corresponding environmental impact. This characterization results in a set of indices, one for each impact, which is obtained by weighting each classified inventory flow by its relative contribution to the impact. For instance, the GWP index is derived by expressing each GHG in terms of its equivalent amount of $\mathrm{CO}_{2}$ heat trapping potential.

There are two general applications of this LCIA approach: midpoint-level and endpointlevel analyses. An endpoint-level analysis attempts to measure the ultimate damage that each environmental input and output in the inventory will have along the cause-effect chain. Methods of this type usually include just a few impact categories, such as damage to human health, ecosystems, and resource availability. The fewer categories make it 
easier to interpret results. But this approach is criticized for the numerous assumptions, value judgments, and gaps in coverage of the underlying damage models. A midpointlevel analysis, on the other hand, selects points along the cause-effect chain at which more certain and comprehensive assessments may be carried out. While this approach generates many impact categories and makes results interpretation more difficult, it is more scientifically defensible. Even so, not all environmental impacts covered by the midpoint-level analysis offer the same degree of relevance. For global and regional effects (e.g., GWP and acidification) the method provides a more accurate description of the potential impact given the body of scientific evidence. For impacts dependent upon local conditions (e.g., smog), it may result in an oversimplification of the actual impacts because the indices are not tailored to localities. For other impacts dependent upon local conditions and toxicity effects, there exist even greater uncertainties. This consequence is discussed in the human toxicity and ecotoxicity section below. Note that some impact assessments apply a mix of midpoint and endpoint approaches. For BEES, the mid-point level analysis is used. It should be emphasized that LCIA results are relative expressions and do not predict impacts on category endpoints, the exceeding of thresholds, safety margins or risks.

There are many LCIA methodologies available for LCA practitioners to assess the life cycle environmental profiles of products. While ISO 14044 does not specify which methodology needs to be used, the rationale for choosing one over another should be provided. The original BEES Online implemented U.S. EPA's TRACI version 1, which was based on North American conditions (Bare, Young, QAM, Hopton, \& Chief, 2012). EPA's TRACI 2 is used in BEES Online 2.0. It is still considered to be the most well accepted methodology for North American LCA studies. It is also the methodology prescribed for many North American EPDs, either alone or in conjunction with more global methodologies, such as CML-IA. Finally, TRACI's comprehensive offering of impact categories meets the needs for a broad set of impact categories needed for BEES. It follows ISO's recommendation that the LCIA methodology "employ a sufficiently comprehensive set of category indicators," when comparisons are being made. ${ }^{3}$

In addition to TRACI 2, BEES 2.0 carries over from previous BEES versions additional environmental measures addressing water use, land use, energy, and indoor air quality (IAQ). A new feature in BEES 2.0 enables the user to choose the impact categories that are specified in the current PCR document for any given product category. For EPDs with North American PCRs (or North American versions of PCRs), TRACI 2 is generally required while CML categories tend to be optional for an EPD for global applicability. Table 2-1 summarizes the impact categories currently presented in BEES 2.0. The remainder of this section describes these methodologies and impact categories, including the impact categories required by PCRs for each product category.

\footnotetext{
${ }^{3}$ Section 4.4.5. International Organization for Standardization (ISO) (2006b)
} 
Users should note that BEES does not address all information that may be required by a PCR, for example, the reporting of regulated hazardous substances contained in the product and dangerous substances released from the manufacturing of the product (UL Environment, 2018a). Such information is outside the scope of BEES, which provides LCIA impact category results specified in the PCR but is not a pure substitute for an EPD.

At this time BEES does not include formal uncertainty analysis. Uncertainty exists throughout all levels of LCA, from the background data to impact characterization to normalization factors. NIST is evaluating the inclusion of uncertainty analysis into future releases of BEES.

\section{Table 2-1 BEES Results Categories}

\begin{tabular}{|c|c|c|c|}
\hline BEES Results Sets & Included Impact Categories & Unit & $\begin{array}{l}\text { Originating } \\
\text { Methodology }\end{array}$ \\
\hline \multirow[t]{10}{*}{ TRACI 2} & Ozone Depletion Potential & kg CFC-11 eq. & TRACI 2 \\
\hline & Global Warming Potential & $\mathrm{kg} \mathrm{CO} 2$ eq. & TRACI 2 \\
\hline & Smog Formation Potential & $\mathrm{kg} \mathrm{O}_{3}$ eq. & TRACI 2 \\
\hline & Acidification Potential & $\mathrm{kg} \mathrm{SO}_{2}$ eq. & TRACI 2 \\
\hline & Eutrophication Potential & kg N eq. & TRACI 2 \\
\hline & Carcinogenics Potential & CTUh & TRACI 2 \\
\hline & Non-carcinogenics Potential & CTUh & TRACI 2 \\
\hline & Respiratory Effects Potential & kg PM2.5 eq. & TRACI 2 \\
\hline & Ecotoxicity Potential & CTUe & TRACI 2 \\
\hline & Primary Energy Consumption* & MJ & CED \\
\hline \multirow[t]{4}{*}{ BEES } & Above set of TRACI 2 impacts, plus & & \\
\hline & Water Use & $\mathrm{L}$ & ReCiPe \\
\hline & Land Use & $\mathrm{m}^{2}$ & ReCiPe \\
\hline & Indoor Air Quality (IAQ) & $\mathrm{kg}$ VOC & NIST \\
\hline Other Categories & Abiotic Depletion Potential & kg Sb eq. & CML \\
\hline \multirow{7}{*}{ Specified in PCRs } & Global Warming Potential & $\mathrm{kg} \mathrm{CO}_{2}$ eq. & CML \\
\hline & Ozone Depletion Potential & kg CFC-11 eq. & CML \\
\hline & Photochemical Oxidization Potential & $\mathrm{kg} \mathrm{C}_{2} \mathrm{H}_{4}$ eq. & CML \\
\hline & Acidification Potential & $\mathrm{kg} \mathrm{SO}_{2}$ eq. & CML \\
\hline & Eutrophication Potential & $\mathrm{kg} \mathrm{PO}_{4}$ eq. & CML \\
\hline & Primary Energy (non-renewable) & MJ & CED \\
\hline & Primary Energy (renewable) & MJ & CED \\
\hline
\end{tabular}

\subsubsection{TRACI 2.1}

The EPA's TRACI impact methodology is a set of state-of-the-art, peer-reviewed life cycle impact assessment methods (Environmental Protection Agency, 2018), and provides characterization factors for LCIA, industrial ecology, and sustainability metrics. Characterization factors quantify the potential impacts that inputs and releases have on specific impact categories in common equivalence units (Ryberg, 2014). BEES Online 2.0 implements TRACI version 2, which has been updated to include additional substances and updated methodologies (Environmental Protection Agency, 2018) relative to TRACI version 1 that was implemented in the original BEES Online. TRACI 2.1 
impact categories will be summarized in this section. The EPA has plans for updating TRACI (Version 3), which would include additional impact categories for land and water use. For more information, the user may consult the TRACI version 2.1 User's Manual (Bare, 2012), which references Bare, Gloria, and Norris (2006) and Frischknecht (2007).

\subsubsection{Global Warming Potential (GWP)}

The Earth absorbs radiation from the Sun, mainly at the surface. This energy is then redistributed by the atmosphere and ocean and re-radiated to space at longer wavelengths. GHGs in the atmosphere, principally water vapor, but also $\mathrm{CO}_{2}$, methane, chlorofluorocarbons, and ozone, absorb some of the thermal radiation. The absorbed energy is re-radiated in all directions, downwards as well as upwards, such that the radiation that is eventually lost to space is from higher, colder levels in the atmosphere. The result is that the surface loses less heat to space than it would in the absence of the GHGs and consequently stays warmer than it would be otherwise. This phenomenon, which acts like a 'blanket' around the Earth, is known as the greenhouse effect.

The greenhouse effect is a natural phenomenon. The GWP measure was developed to characterize the change in the greenhouse effect due to emissions (an increase in the effect) and absorptions (a decrease in the effect) attributable to humans. GWP is reported in kilograms $(\mathrm{kg})$ of $\mathrm{CO}_{2}$-equivalents $\left(\mathrm{CO}_{2} \mathrm{e}\right.$ or $\mathrm{CO}_{2}$-eq) for both TRACI 2 and $\mathrm{CML}$, and the relative impact weights, or characterization factors, represent a 100-year time horizon. The characterization factors are based on data from the Intergovernmental Panel on Climate Change (IPCC). ${ }^{4}$

To arrive at the GWP, the characterization factors for the different GHGs are multiplied by the mass outputs of their respective GHGs in the LCI results. Table 2-2 presents the conversion of sample inventory results of $\mathrm{CO}_{2}$, methane $\left(\mathrm{CH}_{4}\right)$, and nitrous oxide $\left(\mathrm{N}_{2} \mathrm{O}\right)$ to GWP. Other impact categories are calculated in this way, using the characterization factors and classified flows for each respective category.

Table 2-2 shows a sample calculation of total GWP using the 3 most common GHG flows and their associated weighting factors. The same approach is used in calculating the total flows for each impact category below.

\section{Table 2-2 Sample Calculation to obtain GWP}

\begin{tabular}{lccr}
\hline Flow (i) & $\begin{array}{c}\text { Weighting Factor } \\
\text { (100 Years) }\end{array}$ & LCI Result & Calculated GHG Result \\
\hline Carbon Dioxide $\left(\mathrm{CO}_{2}\right.$, net) & 1 & $2000.0 \mathrm{~kg}$ & $2000.0 \mathrm{~kg} \mathrm{CO}$-eq. \\
Methane $\left(\mathrm{CH}_{4}\right)$ & 30.5 & $15.0 \mathrm{~kg}$ & $457.5 \mathrm{~kg} \mathrm{CO}$-eq. \\
Nitrous Oxide $\left(\mathrm{N}_{2} \mathrm{O}\right)$ & 265 & $0.05 \mathrm{~kg}$ & $15.9 \mathrm{~kg} \mathrm{CO}$-eq. \\
\hline & & Total GWP & $\mathbf{2 4 7 3 . 4} \mathbf{~ k g ~ C O}$-eq. \\
\hline
\end{tabular}

\footnotetext{
${ }^{4}$ For more information, see IPCC at https://www.ipcc.ch/. Background data based on IPCC (2013).
} 


\subsubsection{Ozone Depletion Potential}

Ozone depletion potential characterizes ozone depleting gases in product systems, which may include chlorofluorocarbons (CFCs) (e.g., Freon), halons, carbon tetrachloride, and trichloroethane. A decline in the ozone layer allows more harmful short-wave radiation to reach the Earth's surface, potentially causing damage to human health, plants, and changes to ecosystems. Ozone depletion is reported in kg of trichlorofluoromethaneequivalents (CFC-11-eq) for both TRACI 2 and CML.

\subsubsection{Smog Formation Potential}

Smog forms under certain climatic conditions when air emissions (e.g., nitrous oxides $\left.\left(\mathrm{NO}_{\mathrm{X}}\right), \mathrm{VOCs}\right)$ from industry and transportation are trapped at ground level where they react in the presence of ultraviolet (UV) radiation and produce photochemical oxidants, including ozone $\left(\mathrm{O}_{3}\right)$. Smog formation potential, called photochemical oxidation potential by the CML methodology, measures the potential for smog to negatively affect human health and vegetation. Smog formation potential is reported in $\mathrm{kg}$ of $\mathrm{O}_{3}$ equivalents. For $\mathrm{CML}$, it is reported in $\mathrm{kg}$ ethylene equivalents $\left(\mathrm{C}_{2} \mathrm{H}_{4}\right.$-eq).

\subsubsection{Respiratory Effects Potential}

Particulate matter and precursors to secondary particulates, including sulfur dioxide $\left(\mathrm{SO}_{2}\right)$ and $\mathrm{NOx}$, are generated by combustion of fossil fuels and wood. Dust from roadways and materials handling also contribute to particulate matter formation. Inhaling particulates and dust in the air may result in health issues such as asthma and other respiratory illnesses. This impact category is reported in kg PM2.5 (particulate matter of size less than or equal to 2.5 micrometers) equivalents.

\subsubsection{Human and Ecological Toxicity}

Human toxicity provides an indication of the risk to human health (carcinogenics, non-carcinogenics, and respiratory effects), while ecotoxicity results provide an indication of the risks of damage to land and water ecosystems. For toxicity, TRACI 2 has adopted the United Nations Environment Programme-Society of Environmental Toxicology and Chemistry (UNEP-SETAC) toxicity (USETox) methodology, a scientific consensus model whose development included contributions from CalTOX, IMPACT 2002, Uniform System for the Evaluation of Substances adapted for LCA (USES-LCA), Berkeley-Trent (BETR), Environmental Development of Industrial Products (EDIP), water and soil environmental fate and exposure model of noxious substances at the European scale (WATSON), and EcoSense (Rosenbaum, 2008). The characterization factors for human toxicity and ecotoxicity impacts are expressed in comparative toxic units for human toxicity and ecotoxicity (CTUh and CTUe, respectively), and for TRACI 2, factors have been customized to North American conditions. According to Fantke (2017), the CTUh provides the estimated increase in morbidity - number of cancer or non-cancer cases - in the total human population per unit mass of a contaminant emitted, 
while CTUe provides an estimate of the potentially affected fraction (PAF) of species integrated over time and volume per unit mass of a chemical emitted.

BEES users should be aware that toxicity related methodologies used within the LCA framework do not provide the same level of reliability in the results as other methods. In general, limitations of more localized, toxicity-related LCIA results can be described as follows:

Spatial and temporal resolutions are not reflected in aggregated LCA results. When emissions are normalized to a functional unit of a product system, all impact results are relative and potential. The temporal and geographical characteristics which are needed to assess local environmental impacts, which may cause toxic effects, are not available in LCA impact results.

Threshold effects are lost in an LCA. LCA is based on a linear extrapolation of mass loadings with the assumption that this loading contributes to an environmental effect. This assumption is contrary to threshold-driven environmental and toxicological mechanisms. Thus, while the linear extrapolation of mass loadings is a reasonable approach for more global and regional impact categories such as GWP and acidification potential, it is not as appropriate a measure for human health- and ecotoxicity-related impacts because of the lack of concentration and exposure data. More conventional risk assessment methodologies for human health and ecotoxicity must then be applied.

Thanks to important contributions from numerous research organizations, the level of precision in USETox has decreased the uncertainty of toxicity impacts: for human health, the precision of the current USEtox characterization factors falls within 100 and 1000 orders of magnitude, and for freshwater ecotoxicity it is within 10 to 100 orders of magnitude (Rosenbaum, 2008). Users of BEES should understand these limitations, and as a result may not want to place as much emphasis on the toxicity results than some of the other categories in BEES such as GWP.

\subsubsection{Eutrophication Potential}

Eutrophication is the addition of mineral nutrients to the soil or water. In both media, the addition of large quantities of mineral nutrients, such as nitrogen and phosphorous, results in generally undesirable shifts in the number of species in ecosystems and a reduction in ecological diversity. In water, it tends to increase algae growth, which can lead to a lack of oxygen and subsequent death of species like fish. Eutrophication Potential is measured in kg of nitrogen $(\mathrm{N})$ equivalents for TRACI 2 and phosphate $\left(\mathrm{PO}_{4}\right)$ equivalents for CML.

\subsubsection{Acidification Potential}

Acidifying compounds may, in a gaseous state, either dissolve in water or fix on solid particles. These compounds reach ecosystems through dissolution in rain or wet deposition and can affect trees, soil, buildings, animals, and humans. The two compounds 
principally involved in acidification are sulfur and nitrogen compounds, with their principal human source being fossil fuel and biomass combustion. Other compounds released by human sources, such as hydrogen chloride and ammonia, also contribute to acidification. Acidification is measured in terms of $\mathrm{kg}$ of $\mathrm{SO}_{2}$ equivalents for both TRACI 2 and CML.

\subsubsection{Primary Energy Consumption}

Total energy encompasses the energy used for fuel throughout the product system and the embodied energy in products, such as the hydrocarbons in plastics and chemicals. Total energy is further broken down into non-renewable and renewable energy. Non-renewable energy sources include fossil fuels and nuclear power. Examples of renewable energy include hydropower, wind power, and biomass. The energy category comes from the Cumulative Energy Demand (CED) methodology and results are reported in megajoules (MJ) (Frischknecht, 2007). ${ }^{5}$

\subsubsection{Resource Depletion Category in TRACI 2}

The TRACI 2 methodology includes a category called Fossil Fuel Depletion, reported in surplus megajoules (MJ surplus), which addresses the more general issue of resource depletion. This impact category is not included in BEES. Fossil fuel depletion characterizes the effect of the extraction and use of coal, natural gas, and oil as they relate to their respective remaining reserves in the earth. The Fossil Fuel Depletion methodology in TRACI 2 is carried over from the original version of TRACI, and (Bare, 2012) acknowledges that "quantification of this [sort of impact category is] the most controversial" relative to other impact categories whose science is less controversial, being based on legislation or international agreements.

\subsubsection{BEES}

The "BEES method" implements the same nine impact categories as defined in TRACI 2.1 plus three additional impact categories: land use, water use, and IAQ. Since TRACI 2.1 does not include land and water use, these two important resource depletion impacts are assessed using other characterization methods. IAQ impact category is included because it is of unique importance to occupants that a building maintains healthy indoor conditions. Following are brief descriptions of the three BEES-specific impact categories.

\subsubsection{Water Use}

For BEES, water use is measured by the amount of freshwater consumption in the product system and is calculated using the water use category in ReCiPe - representing the initials of the major collaborator institutions of RIVM and Radboud University, CML, and PRé (Huijbregts et al., 2017). ReCiPe's water use category is simply the inventory of net water used throughout the product system from lakes, rivers, wells, and unspecified

\footnotetext{
${ }^{5}$ See www.pre.nl and www.ecoinvent.org for more information.
} 
natural origins. No weighting, characterization, or regionalization is accounted for in this category, and as a result, model uncertainty is minimized. While there are water footprinting and other water use methodologies that apply characterization factors and weighting to geographical regions based on water scarcity levels and other parameters, these approaches were not used but could be considered for future versions of BEES, such as the Available Water Remaining (AWARE) model (Boulay, 2018). The unit in BEES is liters (L) of water used.

\subsubsection{Land Use}

For BEES, the land use category from ReCiPe is used, accounting for surface area of land occupied and/or transformed within the system boundaries of the product system (Huijbregts et al., 2017). These flows are taken directly from the inventory results without further characterization of what happens to the quality of the land itself (such as depletion of soil organic matter (SOM)) or decrease of biodiversity. This approach to using only the area of land used or transformed minimizes uncertainty in the category results, since broad variability, and constantly changing factors pertaining to soil, land, species richness, etc. are removed from the equation. Land use is measured in square meters $\left(\mathrm{m}^{2}\right)$.

\subsubsection{Indoor Air Quality}

Indoor air quality impacts are not included in traditional life cycle impact assessments. However, the indoor air performance of building products is of concern to the building community and should be explicitly considered in any building product LCA. Ideally, characterization factors would be available for indoor air pollutants as they are for other flows such as global warming gases. However, there is little scientific consensus about the relative contributions of pollutants to indoor air performance. In the absence of reliable characterization factors, the product's total VOC emissions at installation and during use phase are used as a proxy for indoor air performance. Note that a "total” VOC clusters and equally weights the contributions of the individual volatile compounds in the product system. Also, reliance on VOC emissions alone may be misleading if other indoor air contaminants, such as particulates, specific aerosols, and mold, are also present. Finally, total VOC published for different BEES products are highly dependent on the analytical method used, and there is no single analytical method that can measure the entire range of VOCs, rendering the term "total” somewhat misleading. The BEES user should understand these limitations.

Indoor air quality is assessed for building elements that are determined to potentially have a non-negligible release of VOCs, such as floor coverings, interior wall finishes, and furniture. 


\subsubsection{CML-IA}

CML-IA was developed by the Institute of Environmental Sciences, Leiden University, The Netherlands. Like TRACI, CML is an impact assessment method that groups LCA results in midpoint categories. It has European Union (EU), general European, and global-based normalization factors but does not offer the further step of weighting. CML impact category results are available for product categories for which the current PCR document specifies CML. PCRs will be discussed in further detail later in this section. The CML impact categories that are the same as or parallel to the TRACI 2 categories (e.g., GWP, acidification potential, etc.) are discussed in the TRACI 2 sections, above. CML's abiotic depletion potential (ADP), which is required by some PCRs, is briefly described as follows.

ADP, developed by CML, is separated into two categories: minerals (measured in terms of kg antimony (Sb) equivalents per kg of mineral extraction) and fossil fuels (measured in terms of megajoule (MJ) equivalents per MJ of fuel extracted). ADP is calculated based on the mineral or fuel's content in the earth's crust and the rate of depletion, as they relate to their inputs in the product system. The factors for ADP are global in scope. ADP is included in BEES since it is listed as a required impact category in many PCRs. Nonetheless, for similar reasons as stated in the description for TRACI 2's fossil fuel depletion, ADP has many limitations, and this restriction should be understood by the BEES user. Access to the method, and to the characterization factors themselves, is provided at http://www.cml.leiden.edu/software/data-cmlia.html.

\subsubsection{PCR Impact Categories by Product Category}

Consumer demand for proof of claims that products are environmentally friendly has led to the development of what is called an EPD. An EPD is a comprehensive report that documents a product's life cycle environment impact using LCA. Although EPDs do not rank products nor indicate meeting any environmental performance criteria, EPDs are a disclosure of an LCA evaluation of the product that can better inform consumers on a product's environmental performance (UL, 2018).

Products that serve the same function are required to follow the same rules and requirements for the development of the LCA reported in an EPD, which are defined in what is called a PCR. The PCR specifies rules for all aspects of the LCA, including the required LCA method and impact categories, which vary across product categories. The goal is to standardize the process to improve the transparency and consistency of the LCA results in EPDs for a given product group or category (Subramanian, Ingwersen, Hensler, \& Collie, 2012). To stay consistent with industry trends, BEES Online 2.0 includes the option of analyzing only the LCA method(s) and impact categories specified in the current PCR for a given product category. The remainder of this section will identify the LCA method impact categories required for each of the building product categories in BEES Online 2.0. 


\subsubsection{Comparability of LCAs and EPDs}

Although progress in standardization has improved through PCRs, the requirements within PCRs to date still do not make it feasible to directly compare results in EPDs due to the use of different background databases, data set availabilities for materials, and allocation or other methodological rules. It is uncertain whether LCAs are comparable unless it is known that the LCA results were generated using the same data sources, boundary conditions, and other assumptions in the same software package by the same LCA practitioner.

BEES Online 2.0 is in the unique situation of meeting all these necessary conditions, allowing for a reliable direct comparison of product environmental performance across the same impact categories as defined in a product category's PCR.

\subsubsection{Current BEES Product Categories}

LCIA results have been developed for a range of products across several product categories. Table 2-3 shows the impact categories for the product categories currently in BEES 2.0 - floor coverings, interior wall and ceiling finishes (architectural coatings), partitions (gypsum board), wall and ceiling insulation, and exterior wall finishes (cladding/siding). For all product categories, five of the most common LCA-related impact categories accepted for public disclosure (i.e., in EPDs) are included:

- Global Warming Potential

- Acidification Potential

- Smog Formation/Photochemical Oxidization Potential

- Eutrophication Potential

- Ozone Depletion Potential

Additionally, primary energy consumption is required by all PCRs. Other impact categories may be required or are optional depending on the PCR. In summary, the impact methodologies used in BEES are a combination of TRACI 2.1, CML, IPCC (for GWP), and energy demand (based on CED).

Floor covering products are covered under the current PCR for EPDs - Flooring: Carpet, Resilient, Laminate, Ceramic, Wood Version 2 (NSF International, 2014), which is valid through June 23, 2019 and specifies the reporting of seven CML impact categories and two primary energy demand categories: GWP, Acidification Potential, Photochemical Oxidization, Eutrophication Potential, Ozone Depletion Potential, Abiotic Depletion Potential, Primary Energy Consumption - Non-Renewable, and Primary Energy Consumption - Renewable. TRACI impact categories can be declared but are not required.

Interior wall and ceiling finishes included in BEES are covered by the PCR for Architectural Coatings (NSF International, 2017), which is valid through June 23, 2022 
and specifies the reporting of five CML impact categories: GWP, Acidification Potential, Photochemical Oxidization, Eutrophication Potential, and Ozone Depletion Potential. Additionally, Primary Energy Consumption - Non-Renewable and Primary Energy Consumption - Renewable are required.

Partitions included in BEES are covered by Product Category Rules for North American Gypsum Boards (FPInnovations, 2013), which is valid through September 30, 2018 (no update currently available) and specifies the reporting of six TRACI 2.1 impact categories: GWP, Acidification Potential, Smog Formation Potential, Eutrophication Potential, Ozone Depletion Potential, and Abiotic Depletion Potential. Additionally, Primary Energy Consumption - Non-Renewable and Primary Energy Consumption Renewable are required.

Interior wall and ceiling insulation included in BEES are covered by "Product Category Rule (PCR) Guidance for Building-Related Products and Services - Part B: Building Envelope Thermal Insulation EPD Requirements" (UL Environment, 2018b) and "Part A: Life Cycle Assessment Calculation Rules and Report Requirements” (UL Environment, 2018a), which is valid through April 10, 2023 and specifies the reporting of seven impact categories: GWP, Acidification Potential, Smog Formation Potential, Eutrophication Potential, Ozone Depletion Potential, and Abiotic Depletion Potential.

Exterior wall finishes included in BEES are covered by "Product Category Rule (PCR) for Preparing an Environmental Product Declaration (EPD) for Product Group - Cladding System Products” (UL Environment, 2015), which is valid through June 18, 2019 and specifies the reporting of six impact categories: GWP, Acidification Potential, Smog Formation Potential, Eutrophication Potential, Ozone Depletion Potential, and Primary Energy - Fossil Fuels. 
Table 2-3 PCR Impact Categories for U.S. by Current Product Category

\begin{tabular}{|c|c|c|c|c|c|}
\hline \multirow[b]{2}{*}{ Impact Category } & \multicolumn{5}{|c|}{ Product Categories } \\
\hline & $\begin{array}{l}\text { Floor } \\
\text { Coverings }\end{array}$ & $\begin{array}{c}\text { Wall / } \\
\text { Ceiling } \\
\text { Finishes }\end{array}$ & Partitions & $\begin{array}{c}\text { Wall / } \\
\text { Ceiling } \\
\text { Insulation }\end{array}$ & $\begin{array}{c}\text { Exterior } \\
\text { Wall } \\
\text { Finishes }\end{array}$ \\
\hline Global Warming Potential & $\begin{array}{c}\text { CML } \\
\text { (TRACI*) }\end{array}$ & TRACI** & TRACI** & TRACI & TRACI** \\
\hline Ozone Depletion Potential & $\begin{array}{c}\text { CML } \\
\left(\mathrm{TRACI}^{*}\right)\end{array}$ & $\begin{array}{l}\text { TRACI or } \\
\text { CML }\end{array}$ & TRACI & TRACI & $\begin{array}{l}\text { TRACI } \\
\left(\mathrm{CML}^{*}\right)\end{array}$ \\
\hline Eutrophication Potential & $\begin{array}{c}\text { CML } \\
\text { (TRACI*) }\end{array}$ & $\begin{array}{l}\text { TRACI or } \\
\text { CML }\end{array}$ & TRACI & TRACI & $\begin{array}{l}\text { TRACI } \\
\left(\mathrm{CML}^{*}\right)\end{array}$ \\
\hline Acidification Potential & $\begin{array}{c}\text { CML } \\
\text { (TRACI*) }\end{array}$ & $\begin{array}{l}\text { TRACI or } \\
\text { CML }\end{array}$ & TRACI & TRACI & $\begin{array}{l}\text { TRACI } \\
\left(\mathrm{CML}^{*}\right)\end{array}$ \\
\hline $\begin{array}{l}\text { Smog Formation / Photochemical } \\
\text { Oxidization Potential }\end{array}$ & $\begin{array}{c}\text { CML } \\
\text { (TRACI*) }\end{array}$ & $\begin{array}{l}\text { TRACI or } \\
\text { CML }\end{array}$ & TRACI & TRACI & $\begin{array}{l}\text { TRACI } \\
\left(\mathrm{CML}^{*}\right)\end{array}$ \\
\hline Abiotic Depletion Potential & CML & & CML† & CML† & $\begin{array}{l}\text { TRACI } \\
\left(\mathrm{CML}^{*}\right)\end{array}$ \\
\hline Primary Energy Consumption & & & & CED & CED \\
\hline $\begin{array}{l}\text { Primary Energy Consumption } \\
\text { (non-renewable) }\end{array}$ & CED & CED & CED & CED & CED \\
\hline $\begin{array}{l}\text { Primary Energy Consumption } \\
\text { (renewable) }\end{array}$ & CED & CED & CED & CED & CED \\
\hline \multicolumn{6}{|c|}{$\begin{array}{l}\text { * Optional Reporting Impact Category } \\
\text { ** TRACI GWP uses the most recent IPCC (AR5) and is consistent with PCRs with IPCC as optional or } \\
\text { required. } \\
\text { † PCR states the use of TRACI } 2.1 \text { but requires ADP, which is not included in the TRACI method. } \\
\text { Note 1: Water, Land, Human Health, and Ecological Toxicity Categories are currently not required for any } \\
\text { BEES product category PCRs. } \\
\text { Note 2: TRACI Fossil Fuel Depletion impact category is replaced with Primary Energy Consumption }\end{array}$} \\
\hline
\end{tabular}

\subsubsection{Future Product Categories}

Over the next year, LCIA results will be developed for a range of products across several product categories. Table 2-4 shows the impact categories for the product categories that are expected - wall and roof sheathing, roof coverings, paving, beams, columns, and basement walls - to be included in BEES Online 2.1, and the impact category requirements specified in the applicable PCR.

Wall and roof sheathing included in BEES are covered by "PCR for preparing an EPD North American Structural and Architectural Wood Products” (FPInnovations, 2015), which is an interim release valid through December 31, 2018 and specifies the reporting of 5 impact categories (impact method unspecified): GWP, Acidification Potential, Smog Formation Potential, Eutrophication Potential, and Ozone Depletion Potential. Additionally, Primary Energy Consumption - Total, Primary Energy Consumption Non-Renewable, and Primary Energy Consumption - Renewable are also required.

Paving included in BEES are covered by two PCRs, one for asphalt and another for concrete. "PCR for Asphalt Mixtures" (NAPA, 2017) is valid through January 2022 
while "PCR for ISO 14025 Type III EPDs - Concrete" (PE International, 2013) is valid through September 2018. Both PCRs specify the reporting of five TRACI impact categories: GWP, Acidification Potential, Smog Formation Potential, Eutrophication Potential, and Ozone Depletion Potential. Primary Energy Consumption - Total, Primary Energy Consumption - Non-Renewable, and Primary Energy Consumption - Renewable are also required.

Beams, columns, and basement walls included in BEES are covered by "PCRs for ISO 14025 Type III EPDs - Concrete” (PE International, 2013), which is valid through September 2018 and specifies the reporting of five TRACI impact categories: GWP, Acidification Potential, Smog Formation Potential, Eutrophication Potential, and Ozone Depletion Potential. Primary Energy Consumption - Total, Primary Energy Consumption - Non-Renewable, and Primary Energy Consumption - Renewable are also required.

Roof coverings included in BEES are covered by "PCRs for preparing an EPD for Product Group - Asphalt Shingles, Built-up Asphalt Membrane Roofing and Modified Bituminous Membrane Roofing” (ASTM, 2014), which is valid through June 2019 and specifies the reporting of five TRACI impact categories: GWP, Acidification Potential, Smog Formation Potential, Eutrophication Potential, and Ozone Depletion Potential. Primary Energy Consumption - Total, Primary Energy Consumption - Non-Renewable, and Primary Energy Consumption - Renewable are also required.

Table 2-4 PCR Impact Categories by Future Product Category

\begin{tabular}{|c|c|c|c|c|}
\hline \multirow[b]{2}{*}{ Impact Category } & \multicolumn{4}{|c|}{ Product Categories } \\
\hline & $\begin{array}{l}\text { Wall / Roof } \\
\text { Sheathing }\end{array}$ & $\begin{array}{c}\text { Roof } \\
\text { Coverings }\end{array}$ & Paving $\dagger$ & $\begin{array}{l}\text { Beams, Columns, } \\
\text { Basement Walls, } \\
\text { \& Slab on Grade }\end{array}$ \\
\hline Global Warming Potential & TRACI or CML & TRACI & TRACI & TRACI (CML*) \\
\hline Ozone Depletion Potential & TRACI or CML & TRACI & TRACI & TRACI (CML*) \\
\hline Eutrophication Potential & TRACI or CML & TRACI & TRACI & TRACI (CML*) \\
\hline Acidification Potential & TRACI or CML & TRACI & TRACI & TRACI \\
\hline $\begin{array}{l}\text { Smog Formation / Photochemical } \\
\text { Oxidization Potential }\end{array}$ & TRACI or CML & TRACI & TRACI & TRACI \\
\hline \multicolumn{5}{|l|}{ Abiotic Depletion Potential } \\
\hline Primary Energy Consumption & CED & & CED & CED \\
\hline $\begin{array}{l}\text { Primary Energy Consumption } \\
\text { (non-renewable) }\end{array}$ & CED & CED & CED & CED \\
\hline $\begin{array}{l}\text { Primary Energy Consumption } \\
\text { (renewable) }\end{array}$ & CED & CED & CED & CED \\
\hline \multicolumn{5}{|c|}{$\begin{array}{l}\text { * Optional Reporting Impact Category } \\
\text { † Asphalt PCR does not include an option to include CML impact categories. Therefore all paving } \\
\text { (asphalt and concrete) products do not include the CML reporting option found in other categories with } \\
\text { concrete-based products. } \\
\text { Note: Water, Land, Human Health, and Ecological Toxicity Categories are currently not required for any }\end{array}$} \\
\hline
\end{tabular}




\subsubsection{Dynamics of Product Manufacturing and PCRs}

The dynamic nature of PCRs, and LCIA more generally, is an important factor to consider when using and interpreting BEES results. New LCA methodologies, data, processes, and impact categories are developed on an almost continuous basis. Additionally, PCRs are regularly updated at a minimum of every 5 years. Depending on the PCR update cycle and the changes implemented in those updates, the impact categories and/or the process in developing the impact category results may differ from those used in BEES LCIA development. NIST will do its best to update product categories soon after the publication of a new PCR given its labor and funding constraints. Table 2-5 shows the timeline of PCR expiration and associated BEES product category update plans. Note that NIST is currently evaluating funding availability and allocation across its different activities in measuring sustainability in buildings (i.e., BEES, BIRDS - Building Industry Reporting and Design for Sustainability, and BIRDS NEST - Neutral Environment Software Tool). NIST will work with industry organizations to be aware of developments in PCR updates to ensure timely corresponding updates to BEES.

\section{Table 2-5 PCR Publication Timeline ${ }^{6}$}

\begin{tabular}{|c|c|c|c|c|}
\hline \multirow[b]{2}{*}{ Product Category } & \multirow[b]{2}{*}{$\begin{array}{c}\text { PCR } \\
\text { Publication } \\
\text { Year }\end{array}$} & \multicolumn{3}{|c|}{ Timeline } \\
\hline & & $\begin{array}{l}\text { PCR Expiration } \\
\text { Date }\end{array}$ & $\begin{array}{l}\text { Last BEES } \\
\text { Update }\end{array}$ & $\begin{array}{c}\text { Planned } \\
\text { BEES Update }\end{array}$ \\
\hline Floor Coverings & 2014 & Jun 23, 2019 & 2016 & 2021 \\
\hline Wall / Ceiling Finishes & 2017 & Jun 23, 2022 & 2018 & TBD \\
\hline Partitions & 2013 & Sep 30, 2018 & 2018 & TBD \\
\hline Wall / Ceiling Insulation & 2018 & Feb 2023 & 2018 & TBD \\
\hline Exterior Wall Finishes & 2014 & Jun 18, 2019 & 2018 & TBD \\
\hline Wall / Roof Sheathing & 2013 & Dec 31, 2018 & $2019 *$ & TBD \\
\hline Roof Coverings & 2014 & Jun 2019 & $2019 *$ & TBD \\
\hline Paving (Asphalt/Concrete) & 2017 / 2013 & Jan 2022 / Dec 2018 & $2019 *$ & TBD \\
\hline Beams & 2013 & Dec 2018 & 2019* & TBD \\
\hline Columns & 2013 & Dec 2018 & $2019 *$ & TBD \\
\hline Basement Walls & 2013 & Dec 2018 & $2019 *$ & TBD \\
\hline Slab on Grade & 2013 & Dec 2018 & 2019* & TBD \\
\hline
\end{tabular}

\subsection{Impact Interpretation}

Once impacts have been classified and characterized, the resulting LCIA metrics are expressed in incommensurate units, for example: GWP in $\mathrm{CO}_{2}$-eq, acidification in $\mathrm{SO}_{2}$ -

\footnotetext{
${ }^{6}$ Up to date at the time of publication of this user guide.
} 
equivalents, etc. To assist in the next LCA step, interpretation, these metrics need to be placed on the same scale and are rectified through normalization.

\subsubsection{Category Normalization and Aggregation Methodology}

The EPA has developed "normalization references" corresponding to its TRACI 2 set of impact assessment methods (Bare et al., 2006). These U.S. data are updated and expanded for use in BEES. Shown in Table 2-6, these values quantify the U.S. economy's annual contributions to each impact category. As such, they represent a "U.S. impact yardstick" against which to evaluate the significance of product-level impacts. Details on the majority of the normalization factors can be found in Ryberg (2014), which are the most recent updated factors for TRACI. The land, primary energy, and water use normalization factors are based on total U.S. land area (CIA, 2018), total U.S. primary energy consumption in 2017 (EIA, 2018), and total U.S. fresh water consumption in 2015 (USGS, 2018), respectively.

Normalization is accomplished by dividing BEES product-level impact assessment results by the fixed U.S.-scale normalization references, expressed in the same units, yielding an impact category score for a building that has been placed in the context of annual U.S. contributions to that impact. By placing each product-level impact result in the context of its associated U.S. impact result, the measures are all reduced to the same scale, allowing comparison across impacts.

The environmental impact of a single product is small relative to the total U.S. impact in a category, leading to normalized values that are small fractions of a percent. To improve the user experience, BEES Online 2.0 adjusts these normalized values by multiplying by the U.S. population ( 308.7 million) (US Census, 2018), creating a normalized value that represents the fraction of U.S. emissions per capita for each impact category. 
Table 2-6 BEES Normalization References

\begin{tabular}{|c|c|c|c|}
\hline Impact Category & U.S. Total per Year & Units & Source \\
\hline Global Warming & $7.4 \mathrm{E}+12$ & $\mathrm{~kg} \mathrm{CO} 2 \mathrm{eq}$ & Ryberg (2014) \\
\hline Primary Energy Consumption - Non-Renewable & $2.963 \mathrm{E}+13(9.16 \mathrm{E}+13)$ & kWh (MJ) & EIA (2018) \\
\hline Primary Energy Consumption - Renewable & $3.764 \mathrm{E}+12(1.16 \mathrm{E}+13)$ & kWh (MJ) & EIA (2018) \\
\hline HH Criteria Air & $7.4 \mathrm{E}+10^{9}$ & $\mathrm{~kg} \mathrm{PM}_{2.5}$ eq & Ryberg (2014) \\
\hline HH Cancer* & $1.57 \mathrm{E}+04$ & CTUcanc. & Ryberg (2014) \\
\hline Water Consumption & $3.883 \mathrm{E}+14(1.026 \mathrm{E}+14)$ & L (gal) & USGS (2018) \\
\hline Ecological Toxicity* & $3.32 \mathrm{E}+12$ & CTUe & Ryberg (2014) \\
\hline Eutrophication & $6.6 \mathrm{E}+09$ & kg N eq & Ryberg (2014) \\
\hline Land Use & $9.15 \mathrm{E}+12(2.26 \mathrm{E}+09)$ & $\mathrm{m}^{2}$ (acre) & CIA (2018) \\
\hline HH Non-cancer* & $3.21 \mathrm{E}+05$ & CTUnon-canc. & Ryberg (2014) \\
\hline Smog Formation & $4.2 \mathrm{E}+11$ & $\mathrm{~kg} \mathrm{O}_{3}$ eq & Ryberg (2014) \\
\hline Acidification & $2.8 \mathrm{E}+10$ & $\mathrm{~kg} \mathrm{SO}_{2}$ eq & Ryberg (2014) \\
\hline Ozone Depletion & $4.9 \mathrm{E}+07$ & kg CFC-11 eq & Ryberg (2014) \\
\hline Indoor Air Quality & $1.08 \mathrm{E}+10$ & kg VOC & NIST (2010) \\
\hline U.S. Population (2010) & $3.087 \mathrm{E}+8$ & people & US Census (2018) \\
\hline
\end{tabular}

At the BEES LCA interpretation step, a building's normalized impact scores are evaluated. The midpoint-level impact assessment yields values for twelve impact categories, making interpretation at this level difficult. To enable comparisons across buildings, the scores across impact categories may be synthesized. Note that in BEES, the synthesis of impact scores is optional.

Impact scores may be synthesized by weighting each impact category by its relative importance to overall environmental performance, then computing the weighted average impact score. In BEES, the set of importance weights is selected by the user. Several alternative weight sets are provided as guidance and may be either used directly or as a starting point for developing user-defined weights. The alternative weight sets are based on an EPA Science Advisory Board study, a BEES Stakeholder Panel's structured judgments, a set of equal weights, and a set exclusively focusing on the climate change impact, representing a spectrum of ways in which people value diverse aspects of the environment.

At this time BEES does not report any uncertainty analysis. Uncertainty exists in all levels of LCA, from the data source to the elementary flows to the characterization into impact categories to impact category normalization factors. NIST is evaluating the inclusion of uncertainty analysis into future releases of BEES. 


\subsubsection{EPA Science Advisory Board Study}

In 1990 and again in 2000, EPA's Science Advisory Board (SAB) developed lists of the relative importance of various environmental impacts to help EPA best allocate its resources (U.S. EPA Science Advisory Board, 1990, 2000). The following criteria were used to develop the lists:

- The spatial scale of the impact

- The severity of the hazard

- The degree of exposure

- The penalty for being wrong

Ten of the twelve BEES impact categories were covered by the SAB lists of relative importance:

- Highest-Risk Problems: climate change, land use

- High-Risk Problems: ecological toxicity, human health (cancer and non-cancer effects)

- Medium-Risk Problems: ozone depletion, smog, acidification, eutrophication, and human health - criteria air pollutants

The SAB did not explicitly consider primary energy consumption or water consumption. For BEES, these impacts are assumed to be relatively medium-risk and low-risk problems, respectively, based on other relative importance lists (Levin, 1996).

Verbal importance rankings, such as "highest risk," may be translated into numerical importance weights by following ASTM International standard guidance for applying a Multi-attribute Decision Analysis method known as the Analytic Hierarchy Process (AHP) (ASTM, 2011). The AHP methodology suggests the following numerical comparison scale:

1 Two impacts contribute equally to the objective (in this case environmental performance)

3 Experience and judgment slightly favor one impact over another

5 Experience and judgment strongly favor one impact over another

7 One impact is favored very strongly over another, its dominance demonstrated in practice

9 The evidence favoring one impact over another is of the highest possible order of affirmation

$* 2,4,6$, and 8 can be selected when compromise between values of $1,3,5,7$, and 9 , is needed.

Through an AHP known as pairwise comparison, numerical comparison values are assigned to each possible pair of environmental impacts. Relative importance weights can then be derived by computing the normalized eigenvector of the largest eigenvalue of the 
matrix of pairwise comparison values. Table 2-7 and Table 2-8 list the pairwise comparison values assigned to the verbal importance rankings, and the resulting SAB importance weights computed for the BEES impacts, respectively. Note that the pairwise comparison values were assigned through an iterative process based on NIST's background and experience in applying the AHP technique. Furthermore, while the SAB evaluated cancer and non-cancer effects as a group, the resulting $13 \%$ weight was apportioned between the two based on the relative judgments of the BEES Stakeholder Panel discussed in the next section.

\section{Table 2-7 Pairwise Comparison Values for Deriving Impact Category Importance} Weights

\begin{tabular}{lc}
\hline $\begin{array}{c}\text { Verbal Importance } \\
\text { Comparison }\end{array}$ & $\begin{array}{c}\text { Pairwise } \\
\text { Comparison Value }\end{array}$ \\
\hline Highest vs. Low & 6 \\
Highest vs. Medium & 3 \\
Highest vs. High & 1.5 \\
High vs. Low & 4 \\
High vs. Medium & 2 \\
Medium vs. Low & 2 \\
\hline
\end{tabular}

Table 2-8 Relative Importance Weights based on Science Advisory Board Study

\begin{tabular}{lc}
\hline Impact Category & Relative Importance Weight (\%) \\
\hline Climate Change & 18 \\
Primary Energy Consumption & 7 \\
HH Criteria Air & 7 \\
HH Cancer & 8 \\
Water Consumption & 3 \\
Ecological Toxicity & 12 \\
Eutrophication & 5 \\
Land Use & 18 \\
HH Non-cancer & 5 \\
Smog Formation & 7 \\
Acidification & 5 \\
Ozone Depletion & 5 \\
\hline
\end{tabular}

\subsubsection{BEES Stakeholder Panel Judgments}

While the derived EPA SAB-based weight set is helpful and offers expert guidance, several interpretations and assumptions were required to translate SAB findings into numerical weights for interpreting LCA-based analyses. A more direct approach to weight development would consider a closer match to the context of the application; that is, environmentally preferable purchasing in the United States based on life cycle impact assessment results, as reported by BEES.

To develop such a weight set, NIST assembled a volunteer stakeholder panel that met at its facilities in Gaithersburg, Maryland, for a full day in May 2006. To convene the panel, 
invitations were sent to individuals representing one of three "voting interests:" producers (e.g., building product manufacturers), users (e.g., green building designers), and LCA experts. Nineteen individuals participated in the panel: seven producers, seven users, and five LCA experts. These "voting interests" were adapted from the groupings ASTM International employs for developing voluntary standards, to promote balance and support a consensus process.

The BEES Stakeholder Panel was led by Dr. Ernest Forman, founder of the AHP firm Expert Choice Inc. Dr. Forman facilitated panelists in weighting the BEES impact categories using the AHP pairwise comparison process. The panel weighted all impacts in the Short Term (0 years to 10 years), Medium Term (10 years to 100 years), and Long Term (>100 years). One year's worth of U.S. flows for each pair of impacts was compared, with respect to their contributions to environmental performance. For example, for an impact comparison over the Long Term, the panel evaluated the effect that the current year's U.S. emissions would have more than 100 years hence.

Once the panel pairwise-compared impacts for the three time horizons, its judgments were synthesized across the selected time horizons. Note that when synthesizing judgments across voting interests and time horizons, all panelists were assigned equal importance, while the short, medium, and long-term time horizons were assigned by the panel to carry $24 \%, 31 \%$, and $45 \%$ of the weight, respectively.

The environmental impact importance weights developed through application of the AHP technique at the facilitated BEES Stakeholder Panel event are shown in Table 2-9. These weights reflect a synthesis of panelists' perspectives across all combinations of stakeholder voting interest and time horizon. The weight set draws on each panelist's personal and professional understanding of, and value attributed to, each impact category. While the synthesized weight set may not equally satisfy each panelist's view of impact importance, it does reflect contemporary values in applying LCA to real world decisions. This synthesized BEES Stakeholder Panel weight set is offered as an option in BIRDS online.

The panel's application of the AHP process to derive environmental impact importance weights is documented in an appendix to Gloria, Lippiatt, and Cooper (2007), ASTM (2011), and ASTM (2016). 
Table 2-9 Relative Importance Weights based on BEES Stakeholder Panel Judgments

\begin{tabular}{lc}
\hline Impact Category & Relative Importance Weight (\%) \\
\hline Climate Change & 29 \\
Primary Energy Consumption & 10 \\
HH Criteria Air & 9 \\
HH Cancer & 8 \\
Water Consumption & 8 \\
Ecological Toxicity & 7 \\
Eutrophication & 6 \\
Land Use & 6 \\
HH Non-cancer & 5 \\
Smog Formation & 4 \\
Acidification & 3 \\
IAQ & 3 \\
Ozone Depletion & 2 \\
\hline
\end{tabular}

The three figures below display in graphical form the BEES Stakeholder Panel weights used in BEES. Figure 2-3 displays the synthesized weight set. Figure 2-4 displays the weights specific to panelist voting interest, and Figure 2-5 displays the weights specific to time horizon. The BEES user is free to interpret results using either of the weight sets displayed in Figure 2-4 and Figure 2-5 or by entering them as a user-defined weight set.

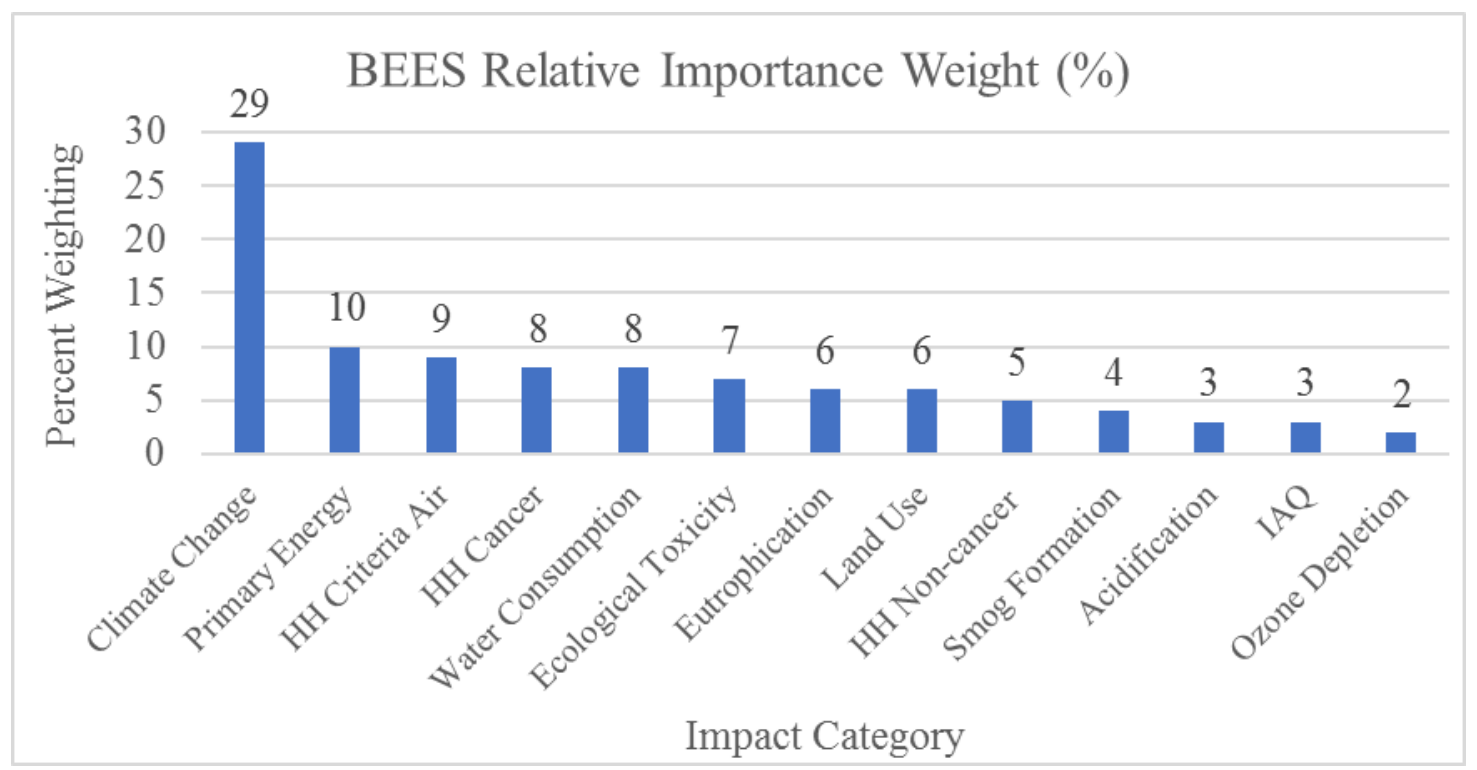

Figure 2-3 BEES Stakeholder Panel Importance Weights Synthesized across Voting Interest and Time Horizon 


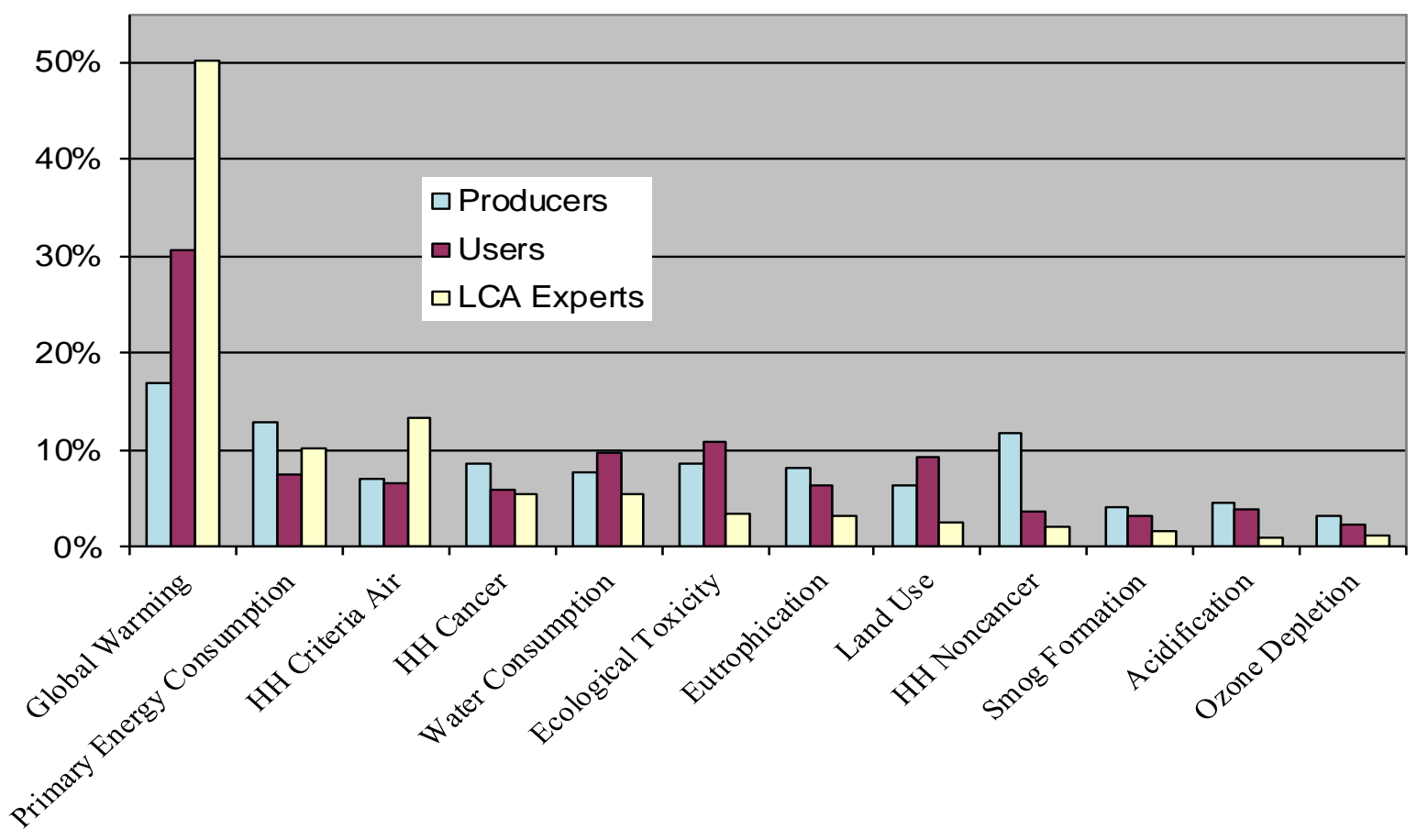

Figure 2-4 BEES Stakeholder Panel Importance Weights by Stakeholder Voting Interest

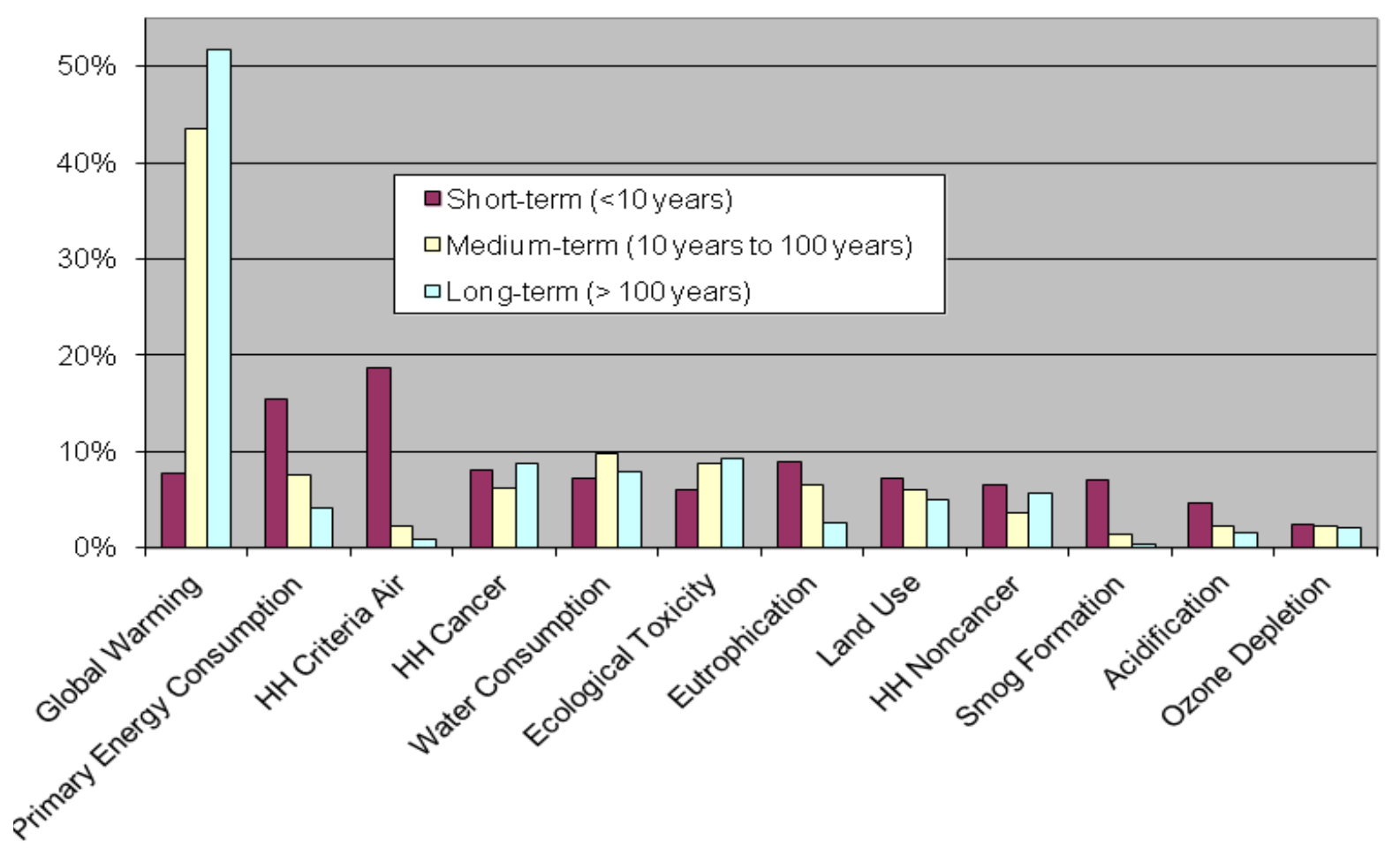

Figure 2-5 BEES Stakeholder Panel Importance Weights by Time Horizon 


\section{Economic Performance}

Measuring the economic performance of building products is more straightforward than measuring environmental performance. Published economic data are readily available, and there are well-established ASTM standard methods for conducting economic performance evaluations. The most appropriate method for measuring the economic performance of building products is the LCC method (Fuller \& Petersen, 1996). BEES follows the ASTM standard method for life cycle costing of building-related investments (ASTM, 2017).

\subsection{Study Period}

It is important to distinguish between the time periods used to measure environmental performance and economic performance. These time periods are different. Recall that in environmental LCA, the time period begins with raw material acquisition and ends with product end-of-life. Economic performance, on the other hand, is evaluated over a fixed period (known as the study period) that begins with the purchase and installation of the product and ends at some point in the future that does not necessarily correspond with product end-of-life.

Economic performance is evaluated beginning at product purchase and installation because this is when out-of-pocket costs begin to be incurred, and investment decisions are made based upon out-of-pocket costs. The study period ends at a fixed date in the future. For a private investor, its length is set at the period of product or facility ownership. From a societal perspective, the study period length is often set at the useful life of the longest-lived product alternative. However, when alternatives have very long lives, (e.g., more than 60 years), a shorter study period may be selected for three reasons:

- Technological obsolescence occurs before the end of the product life

- Data for future costs become too uncertain

- Costs in the distant future are of lower importance than costs now or in the near future

In the BEES model, economic performance is measured over a 60 -year study period. This study period is selected to reflect a reasonable time over which to evaluate economic performance for society. The same 60-year period is used to evaluate all products, even if they have different useful lives. The LCC method allows for considering the useful life of each product to be the same. It accounts for the fact that different products have different useful lives by evaluating them over the same study period.

For consistency, the BEES model evaluates the use stage of environmental performance over the same 60-year study period. Product replacements over this 60-year period are accounted for in the life cycle inventory analysis, and end-of-life inventory flows are prorated to year 60 for products with lives longer than the 60-year study period. 


\subsection{Life Cycle Costing}

The LCC method sums over the study period all relevant costs associated with a product. Alternative products for the same function, say floor covering, can then be compared based on their LCCs to determine which is the least cost means of fulfilling that function over the study period. Categories of cost typically include costs for purchase, installation, operation, maintenance, repair, and replacement. The residual value is the product value remaining at the end of the study period and is, therefore, a negative cost value. In the BEES model, the residual value is computed by prorating the purchase and installation cost over the product life remaining beyond the 60 -year period.

The total LCC of a product $\left(C_{L C C}\right)$ is the sum of the present values of first cost $\left(C_{F i r s t}\right)$ and future costs $\left(C_{\text {Future }}\right)$ minus the residual value $(R V)$ as shown in the following equation:

$$
C_{L C C}=C_{\text {First }}+C_{\text {Future }}-R V
$$

\subsection{Discount Rate}

The LCC method accounts for the time value of money by using a discount rate to convert all future costs to their equivalent present value. Future costs must be expressed in terms consistent with the discount rate. There are two approaches. First, a real discount rate may be used with constant-dollar costs. Real discount rates reflect the portion of the time value of money attributable to the real earning power of money over time and not to general price inflation. Even if all future costs are expressed in constant dollars, they must be discounted to reflect this portion of the time-value of money. Second, a market (nominal) discount rate may be used with current-dollar amounts (e.g., actual future prices). Market discount rates reflect the time value of money stemming from both inflation and the real earning power of money over time. When applied properly, both approaches yield the same LCC results. The BEES model computes LCCs using constant dollars and a real discount rate.

As a default, BEES offers a real rate of $3.0 \%$, the 2018 real discount rate for DOE energy efficiency, water conservation, and renewable energy project evaluation (Lavappa \& Kneifel, 2018) and the "social rate of time preference" (OIRA, 2011; OMB, 2003).

Lavappa and Kneifel (2018) sets the real discount rate at $3 \%$ based on the process defined in 10 CFR 436, which is the higher of two values: (1) The real discount rate calculated using long-term Treasury Bond rates averaged over 12 months and the general inflation rate published in the Report of the President's Economic Advisors, Analytical Perspectives (OMB, 2017) or (2) a prescribed floor of $3 \%$. The calculated real discount rate has been lower than the prescribed floor of $3 \%$ for the past $10+$ years.

Circular A-4 assumes that "the rate that the average saver uses to discount future consumption is a measure of the social rate of time preference, the real rate of return on long-term government debt may provide a fair approximation” and determines the $3 \%$ 
real discount rate based on the average real annual terms on a pre-tax basis for 1973 to 2003 (OMB, 2003).

Given that the $3 \%$ discount rates using either Circular A-4 or 10 CFR 436 are based on either dated data (15+ years old) or a prescribed floor that does not capture the current economic conditions, it may be appropriate to select an alternative discount rate. For example, Appendix C of Circular A-94 (OMB, 1992) is updated annually to specify the real discount rates applicable to general capital investments based on Treasury Notes and Bonds with maturities from 3 years to 30 years. For 2018, those rates vary from $0.5 \%$ for 3 years to $0.7 \%$ for 30 years (Lavappa \& Kneifel, 2018). After accounting for inflation, real discount rates may be near or below $0.0 \%$ depending on the study period.

Another alternative is the "historical average before-tax rate of return to private capital in the U.S. economy," which Circular A-4 estimates to be 7.0\% (OMB, 2003). This value is consistent with what has been termed at "Siegel's Constant" of real returns from the stock market of $6.5 \%$ (Wright et al., 2011).

Circular A-4 also recommends a lower discount rate in the case of longer-term decisionmaking that includes intergenerational impacts, in which case "the agency might consider a sensitivity analysis using a lower but positive discount rate, ranging from 1 percent to 3 percent, in addition to calculating net benefits using discount rates of 3 percent and 7 percent” (OIRA, 2011).

The approaches thus far have been focused on financial markets (i.e., stocks and bonds). Another approach to estimate a discount rate is to develop an implied social discount rate using time preference, risk/inequality aversion, and expected growth rate using the Ramsey Rule (NAS, 2017). The literature using this approach have estimates of the implied long-term social discount rate ranging from $1.4 \%$ to $6.0 \%$ depending on the study (NAS, 2017).

Aggregated average discount rates discussed above range from $-0.5 \%$ to $7.0 \%$. However, a BEES user may have a different personal real discount rate than the estimated or prescribed social or economy-wide discount rates because personal preferences can vary significantly from person to person. Studies have found some real personal discount rates can vary from $0 \%$ to $30 \%$ with many finding average personal discount rates higher than $7.0 \%$ depending on the specific demographics, magnitude of the trade-off values, and topic and approach in the study (Alberini \& Chiabai, 2007; Cameron \& Gerdes, 2002; Moore \& Viscusi, 1990; Scharff \& Viscusi, 2011; Warner \& Pleeter, 2001). Therefore, it is important for the BEES user to consider the purpose of the analysis and select an appropriate discount rate.

\subsection{Cost of Carbon}

An optional addition to the economic analysis is the inclusion of a cost of GHG emissions in $\mathrm{CO}_{2} \mathrm{e}$ (referred to as "carbon" moving forward) into the BEES LCCA. If a user decides to include a cost of carbon into their LCCA, BEES provides the ability for 
the user to customize their estimates' marginal value of damages to society, or the "social cost of carbon” (SCC). BEES currently uses a fixed price for all GHG emissions measured by the GWP impact category $\left(\mathrm{CO}_{2} \mathrm{e}\right.$ emissions) regardless of whether the emissions are embodied in the product itself or the use phase. However, the SCC has been projected to rise over time. Future versions of BEES could introduce time varying prices if deemed beneficial to users.

BEES does not give any recommendations on the appropriate cost of carbon for any given user to apply to their analysis. However, BEES does provide a default value of \$12/ton, which is based on the most conservative average SCC estimate for 2010 published in the United States Government Interagency Working Group on Social Cost of Greenhouse Gasses (Working Group on Social Cost of Carbon, 2016). A user can choose to use the default value or input their own desired value. In case of the latter, numerous resources are discussed in the remainder of this section.

Working Group on Social Cost of Carbon (2016) provides distributions of SCC estimates (2007 US dollars) assuming different discount rates: $5 \%$, $3 \%$, and $2.5 \%$. Table 3-1 shows the average SCC values for each discount rate in 5-year increments adjusted to 2018 dollars by multiplying by the Consumer Price Index (CPI) factor $=$ 1.2161 (Alioth, 2018). A $4^{\text {th }}$ value, the $95^{\text {th }}$ percentile value for the $3 \%$ discount rate case is an example of a high SCC scenario. The estimate distributions have a left-skewed distribution with long right tails. Please see Working Group on Social Cost of Carbon (2016) for more detailed information on these distributions.

Table 3-1 Social Cost of Carbon Estimates

\begin{tabular}{|c|c|c|c|c|}
\hline \multicolumn{5}{|c|}{ SCC Per Metric Ton (2018 US dollars) } \\
\hline \multirow[t]{2}{*}{ Year } & \multicolumn{3}{|c|}{ Average Price } & \multirow{2}{*}{$\begin{array}{r}\text { 95th Pct } \\
3 \%\end{array}$} \\
\hline & $5 \%$ & $3 \%$ & $2.5 \%$ & \\
\hline 2010 & $\$ 12$ & $\$ 38$ & $\$ 61$ & $\$ 105$ \\
\hline 2015 & $\$ 13$ & $\$ 44$ & $\$ 68$ & $\$ 128$ \\
\hline 2020 & $\$ 15$ & $\$ 51$ & $\$ 75$ & $\$ 150$ \\
\hline 2025 & $\$ 17$ & $\$ 56$ & $\$ 83$ & $\$ 168$ \\
\hline 2030 & $\$ 19$ & $\$ 61$ & $\$ 89$ & $\$ 185$ \\
\hline 2035 & $\$ 22$ & $\$ 67$ & $\$ 95$ & $\$ 204$ \\
\hline 2040 & $\$ 26$ & $\$ 73$ & $\$ 102$ & $\$ 223$ \\
\hline 2045 & $\$ 28$ & $\$ 78$ & $\$ 108$ & $\$ 240$ \\
\hline 2050 & $\$ 32$ & $\$ 84$ & $\$ 116$ & $\$ 258$ \\
\hline CPI I & on $\mathrm{Fc}$ & $r(20$ & to 2018 & $=1.2161$ \\
\hline
\end{tabular}

GHGs are global pollutants, and therefore the marginal reduction in damages from GHG reductions may be comparable around the world. The current $\mathrm{CO}_{2}$ market prices in Emissions Trading Systems (ETSs) in the U.S. and around the world may be useful proxies for estimating the SCC for a BEES user. Within the U.S., the first carbon market created was the Regional Greenhouse Gas Initiative (RGGI) in the Northeast with auction prices ranging from $\sim \$ 2.50 /$ ton to $\sim \$ 5.00 /$ ton in 2017 and 2018 (RGGI, 2018). 
The other carbon market is the California Cap-and-Trade Program, which had clearing auction prices in 2018 range from $\$ 14.61 /$ ton to $\$ 15.05 /$ ton (CARB, 2018).

The most well-known carbon market in the world is the EU ETS. Figure 3-1 shows that the EU allowance (EUA) prices have historically been below $\$ 10 /$ ton until a recent rise over 2018 to $~ \$ 20 /$ ton in September (Sandbag, 2018).

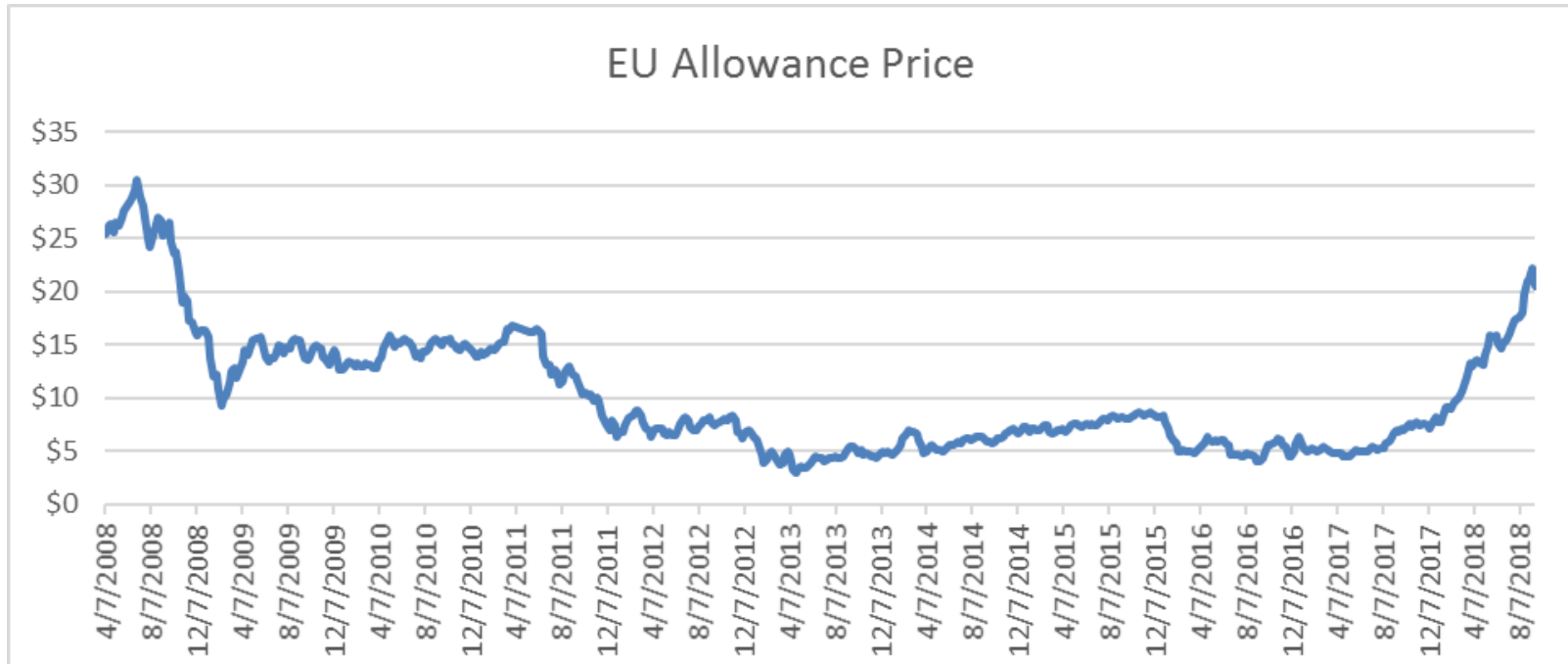

Figure 3-1 EU ETS GHG Allowance Price (April 2008 through September 2018)

Worldwide, there are 42 national jurisdictions (i.e., countries) and 25 subnational jurisdictions (i.e., states, provinces, or cities) with a carbon tax or carbon ETS (World Bank, 2018). As of 2016, the prices in these ETSs around the world ranged from $\$ 13 /$ ton to $\$ 31 /$ ton in 2016 US dollars (CDP, 2016). More recent data are published in World Bank Group (2018) in 2018 US dollars. In Canada, carbon ETS prices range from $\$ 15 /$ ton to $\$ 23 /$ ton depending on the province. Many European countries, along with their participation in the EU ETS, also have carbon taxes that range from $\$ 8 /$ ton (Portugal) to \$139/ton (Sweden). Japan has a \$3/ton carbon tax while Tokyo's ETS carbon price is $\$ 6 /$ ton. Korea's ETS carbon price is $\$ 21 /$ ton. China has implemented pilot ETS at the city level, with current carbon prices of $\$ 2 /$ ton to $\$ 9 /$ ton. To research current carbon pricing schemes around the world, please see World Bank (2018).

Many private companies have begun to include carbon pricing into their business strategies, either through their own SCC estimates or based on the market prices in the carbon market that applies to their location (CDP, 2016). The estimates used by corporations vary significantly across and within countries. For example, U.S. companies have disclosed using carbon prices ranging from $\$ 1 /$ ton to $\$ 150 /$ ton (CDP, 2016). These price differences are driven by, among other things, the likelihood of regulation facing a firm's market sector as well as differences in their short-term versus long-term perspectives. 
In summary, the selection of an appropriate SCC for a BEES user is dependent on their preferences, which could lead to prices anywhere from $\$ 0 /$ ton to $\$ 150+/$ ton.

\subsection{Default Cost Data Sources}

Cost data are collected from several data sources. For specific product lines, the publicly available suggested retail price is assumed for the cost of the product. For generic or industry average product cost data, RS Means and Whitestone cost databases or industry group suggested prices were used. The same databases were used to estimate the cost of installing each product. Replacement costs are assumed to be identical to the installed cost (product plus installation cost) of the product. Industry interviews are used to supplement these data sources to ensure realistic cost estimates. No costs are incorporated for maintenance during the use phase or the cost of removing the product at the end of its service life.

BEES users are recommended to adjust the installed cost values based on their specific cost information. 


\section{BEES Product Summary}

This chapter gives an overview of the product category formatting implemented in BEES (UNIFORMAT II) and the current and future product categories available in the current version of BEES.

\subsection{UNIFORMAT II}

All BEES product categories are defined using UNIFORMAT II, which is a standard classification for building-related elements defined in ASTM Standard E1557 (ASTM, 2015e). Individual building elements are aggregated into "groups" and "major groups" as shown in Table 4-1.

\section{Table 4-1 UNIFORMAT II Major Group and Group Elements}

\begin{tabular}{ll} 
Major Group Element & Group Element \\
\hline Substructure & Foundations \\
& Basement Construction \\
\hline Shell & Superstructure \\
& Exterior Enclosure \\
& Roofing \\
\hline Interiors & Interior Construction \\
& Stairs \\
& Interior Finishes \\
\hline Services & Conveying \\
& Plumbing \\
& HVAC \\
& Fire Protection \\
& Electrical \\
\hline Equipment \& Furnishings & Equipment \\
& Furnishings \\
\hline Special Construction \& Demolition & Special Construction \\
& Selective Building Demolition \\
\hline Building Sitework & Site Preparation \\
& Site Improvements \\
& Site Mechanical Utilities \\
& Site Electrical Utilities \\
& Other Site Construction \\
\hline &
\end{tabular}

\subsection{BEES Product Categories}

Table 4-2 shows the BEES product categories by individual element, group element, and major element sorted by the elements included in BEES Online 2.0, the planned elements to be added in BEES Online 2.1, and the elements not yet updated that are in the original 
version of BEES Online. Note that some discretion has been used in identifying the appropriate individual element for a given product (e.g., all pipes and fittings have been grouped together in a single element for this document). 
Table 4-2 BEES Product Categories by UNIFORMAT Element

\begin{tabular}{|c|c|c|c|c|}
\hline & \multicolumn{3}{|c|}{ UNIFORMAT Elements* } & \multirow[b]{2}{*}{$\begin{array}{l}\text { Data } \\
\text { Year }\end{array}$} \\
\hline & Major Group Element & Group Element & Individual Element & \\
\hline \multirow{7}{*}{$\begin{array}{l}\text { BEES Online } \\
2.0 \\
\text { (75 Products) }\end{array}$} & Interiors & Interior Finishes & Floor Coverings & 2016 \\
\hline & Interiors & Interior Finishes & $\begin{array}{l}\text { Wall Finishes to Interior } \\
\text { Walls }\end{array}$ & 2018 \\
\hline & Interiors & Interior Finishes & Ceiling Finishes & 2018 \\
\hline & Interiors & Interior Construction & Partitions/Gypsum Board & 2018 \\
\hline & Shell & Exterior Enclosure & Wall Insulation & 2018 \\
\hline & Shell & Roofing & Ceiling Insulation & 2018 \\
\hline & Shell & Roofing & Roof Coatings & 2018 \\
\hline \multirow{8}{*}{$\begin{array}{l}\text { BEES Online } \\
2.1 \\
(300+ \\
\text { Products } \\
\text { Under } \\
\text { Development) }\end{array}$} & Shell & Roofing & Roof coverings & 2019 \\
\hline & Shell & Exterior Enclosure & Wall Sheathing & 2019 \\
\hline & Shell & Superstructure & Beams & 2019 \\
\hline & Shell & Superstructure & Columns & 2019 \\
\hline & Shell & Superstructure & Roof Sheathing & 2019 \\
\hline & Building Sitework & Site Improvements & Parking Lot Paving & 2019 \\
\hline & Substructure & Foundations & Slab on Grade & 2019 \\
\hline & Substructure & Basement Construction & Basement Walls & 2019 \\
\hline \multirow{23}{*}{$\begin{array}{l}\text { Remaining in } \\
\text { BEES Online } \\
\text { (Categories } \\
\text { not installed } \\
\text { in a building } \\
\text { and/or have } \\
\text { few products) }\end{array}$} & Equipment \& Furnishings & Furnishings & Chairs & N/A \\
\hline & Equipment \& Furnishings & Furnishings & Fixed Casework & N/A \\
\hline & Equipment \& Furnishings & Furnishings & $\begin{array}{l}\text { Table Tops, Counter Tops, } \\
\text { Shelving }\end{array}$ & N/A \\
\hline & Domestic Water Distribution & $\begin{array}{l}\text { Hot \& Cold Water } \\
\text { Distribution }\end{array}$ & Pipes \& Fittings & N/A \\
\hline & Building Repair \& Remodeling & Remodeling Products & $\begin{array}{l}\text { Adhesive or Mastic } \\
\text { Remover }\end{array}$ & N/A \\
\hline & Building Sitework & Site Electrical Utilities & Transformer oil & N/A \\
\hline & Building Sitework & Site Improvements & Fertilizer & N/A \\
\hline & Building Sitework & Site Improvements & $\begin{array}{l}\text { Site Development (Fences } \\
\text { \& Gates) }\end{array}$ & N/A \\
\hline & Building Sitework & Site Improvements & $\begin{array}{l}\text { Site Development } \\
\text { (Railings) }\end{array}$ & N/A \\
\hline & Building Sitework & Site Improvements & Roadway Dust Control & N/A \\
\hline & Building Maintenance & Cleaning Products & Carpet Cleaners & N/A \\
\hline & Building Maintenance & Cleaning Products & Floor strippers & N/A \\
\hline & Building Maintenance & Cleaning Products & Bath and tile cleaner & N/A \\
\hline & Building Maintenance & Cleaning Products & Glass cleaners & N/A \\
\hline & Building Maintenance & Cleaning Products & $\begin{array}{l}\text { Grease and graffiti } \\
\text { remover }\end{array}$ & N/A \\
\hline & Services & Plumbing & Plumbing Fixtures & N/A \\
\hline & Interiors & Interior Construction & Lockers & N/A \\
\hline & Interiors & Fittings & Fabricated Toilet Partitions & N/A \\
\hline & Sanitary Waste & Drain/Waste/Vent & Piping & N/A \\
\hline & Shell & Roofing & Roof Coatings & N/A \\
\hline & Shell & Exterior Enclosure & $\begin{array}{l}\text { Exterior Sealers \& } \\
\text { Coatings }\end{array}$ & N/A \\
\hline & Shell & Exterior Enclosure & Framing & N/A \\
\hline & Shell & Exterior Enclosure & Trim & N/A \\
\hline
\end{tabular}


The functional unit and use phase options (if appropriate) for each product category are shown in Table 4-3. Note that the functional unit of the old product categories may be changed in BEES Online 2.0 relative to the original BEES Online categories if deemed appropriate.

\section{Table 4-3 BEES Product Category Functional Unit and Use Phase Options}

\begin{tabular}{|c|c|c|c|}
\hline Version & Product Category & Functional Unit & $\begin{array}{l}\text { Use Phase } \\
\text { Options }\end{array}$ \\
\hline \multirow[t]{4}{*}{$\begin{array}{l}\text { BEES } \\
\text { Online } 2.0\end{array}$} & Floor Coverings & $0.093 \mathrm{~m}^{2}\left(1 \mathrm{ft}^{2}\right)$ & $\begin{array}{l}\text { Vacuum, } \\
\text { Sweep / } \\
\text { Dry Mop }\end{array}$ \\
\hline & \multirow{3}{*}{$\begin{array}{l}\text { Gypsum Board } \\
\text { Wall \& Ceiling Insulation } \\
\text { Interior Wall \& Ceiling } \\
\text { Finishes }\end{array}$} & $0.093 \mathrm{~m}^{2}\left(1 \mathrm{ft}^{2}\right)$ & None \\
\hline & & $\mathrm{R}-1$ per $0.093 \mathrm{~m}^{2}\left(1 \mathrm{ft}^{2}\right)$ & None \\
\hline & & Sealing/coating $0.093 \mathrm{~m}^{2}\left(1 \mathrm{ft}^{2}\right)$ & None \\
\hline \multirow{5}{*}{$\begin{array}{l}\text { BEES } \\
\text { Online } 2.1\end{array}$} & Roof coverings & $9.29 \mathrm{~m}^{2}\left(100 \mathrm{ft}^{2}\right)$ & None \\
\hline & Beams \& Columns & $0.76 \mathrm{~m}^{3}\left(1 \mathrm{yd}^{3}\right)$ & None \\
\hline & Basement Walls \& Slabs & $0.76 \mathrm{~m}^{3}\left(1 \mathrm{yd}^{3}\right)$ & None \\
\hline & Parking Lot Paving & $0.76 \mathrm{~m}^{3}\left(1 \mathrm{yd}^{3}\right)$ & None \\
\hline & Roof \& Wall Sheathing & $0.093 \mathrm{~m}^{2}\left(1 \mathrm{ft}^{2}\right)$ & None \\
\hline \multirow{23}{*}{$\begin{array}{l}\text { Remaining } \\
\text { in } \\
\text { BEES } \\
\text { Online }\end{array}$} & Chairs & 1 chair & None \\
\hline & Fixed Casework & $0.093 \mathrm{~m}^{2}\left(1 \mathrm{ft}^{2}\right)$ & None \\
\hline & $\begin{array}{l}\text { Table Tops, Counter Tops, } \\
\text { Shelving }\end{array}$ & $0.093 \mathrm{~m}^{2}\left(1 \mathrm{ft}^{2}\right)$ & None \\
\hline & Pipes \& Fittings & $305 \mathrm{~m}(1000 \mathrm{ft})$ & None \\
\hline & Adhesive or Mastic Remover & Removing $9.29 \mathrm{~m}^{2}\left(100 \mathrm{ft}^{2}\right)$ of mastic/adhesive & None \\
\hline & Transformer oil & Cooling for one $1000 \mathrm{kV} \cdot \mathrm{A}$ transformer & None \\
\hline & Fertilizer & 0.40 ha (1 acre) & None \\
\hline & $\begin{array}{l}\text { Site Development (Fences \& } \\
\text { Gates) }\end{array}$ & $0.3 \mathrm{~m}(1 \mathrm{ft})$ & None \\
\hline & Site Development (Railings) & $0.3 \mathrm{~m}(1 \mathrm{ft})$ & None \\
\hline & Roadway Dust Control & $92.9 \mathrm{~m}^{2}\left(1000 \mathrm{ft}^{2}\right)$ of surface area & None \\
\hline & Carpet Cleaners & Cleaning $92.9 \mathrm{~m}^{2}\left(1000 \mathrm{ft}^{2}\right)$ & None \\
\hline & Floor strippers & $\begin{array}{l}\text { Remove } 3 \text { layers wax \& } 1 \text { layer sealant from } \\
9.29 \mathrm{~m}^{2}\left(100 \mathrm{ft}^{2}\right)\end{array}$ & None \\
\hline & Bath and tile cleaner & 3.8 l (1 gal) of cleaner & None \\
\hline & Glass cleaners & $3.785 \mathrm{~m} 3$ (1,000 gal) of glass cleaner & None \\
\hline & Grease and graffiti remover & $3.8 \mathrm{l}$ (1 gal) of grease and graffiti remover & None \\
\hline & Plumbing Fixtures & 1 toilet & None \\
\hline & Lockers & $0.093 \mathrm{~m}^{2}\left(1 \mathrm{ft}^{2}\right)$ & None \\
\hline & Fabricated Toilet Partitions & $0.093 \mathrm{~m}^{2}\left(1 \mathrm{ft}^{2}\right)$ & None \\
\hline & Piping & 305 m (1000 ft) & None \\
\hline & Roof Coatings & $0.093 \mathrm{~m}^{2}\left(1 \mathrm{ft}^{2}\right)$ & None \\
\hline & Exterior Sealers \& Coatings & Sealing/coating $9.29 \mathrm{~m}^{2}\left(100 \mathrm{ft}^{2}\right)$ & None \\
\hline & Framing & $0.093 \mathrm{~m}^{2}\left(1 \mathrm{ft}^{2}\right)$ & None \\
\hline & Trim & 1 linear foot & None \\
\hline
\end{tabular}




\section{Floor Coverings Category}

The floor coverings category covers both residential and commercial flooring products.

\subsection{Floor Covering Types}

There are a range of flooring types included in the floor coverings category as shown in Table 5-1.

\section{Table 5-1 Floor Covering Types and Subtypes}

\begin{tabular}{ll} 
Types & Floor Covering \\
Subtypes \\
\hline Carpet & Broadloom \\
& Tile \\
\hline Resilient Flooring & Biobased tile (BBT) \\
& Cork Floating Floor \\
& Linoleum Sheet \\
& Linoleum Tile \\
& Vinyl Composition Tile \\
& Vinyl Sheet \\
\hline Hardwood & Engineered \\
& Solid Strip \\
\hline Hybrid Resilient Flooring & Sheet \\
\hline Stone, Aggregate, or Composite & Ceramic Tile \\
& Composite Marble Tile \\
& Terrazzo \\
\hline
\end{tabular}

\subsection{Floor Covering Characteristics and Certifications}

BEES Online 2.0 has added a feature to filter/restrict products selected based on product characteristics, such as fraction recycled materials, and product certifications, such as U.S. Department of Agriculture (USDA) Certified Biobased. The current list of characteristics and certifications are listed in Table 5-2.

\section{Table 5-2 Floor Covering Characteristics and Certifications}

\begin{tabular}{ll}
\hline \multicolumn{2}{c}{ Characteristics and Certifications } \\
\hline Federal Agency Certifications & USDA Certified Biobased \\
& EPA Comprehensive Procurement Guideline (CPG) \\
\hline Standard Certification & NSF/ANSI 140 Certified \\
& NSF/ANSI 332 Certified \\
\hline NGO Certification & UL 2818 GREENGUARD \\
& FloorScore Certified \\
\hline Characteristics & $25 \%$ Recycled Content \\
& $35 \%$ Recycled Content \\
& $50 \%$ Recycled Content \\
& $75 \%$ Recycled Content \\
\hline
\end{tabular}




\subsection{Floor Covering Installation, Service Life, and Use Phase}

To evaluate the life cycle impacts of floor coverings, it is necessary to include the installation and use phase impacts, both of which could vary depending on decisions outside the product manufacturer's control. Materials used in the installation phase may not be the manufacturer-recommended products. For example, adhesives are often required to install some flooring types, which may release different levels of VOCs. For this reason, a product that used adhesive in installation is offered with two installation options, a typical or manufacturer recommended VOC adhesive and a no-VOC adhesive (identified with $\mathrm{a} *$ at the end of the product name). Details on adhesive selection is defined for each BEES product in its associated documentation.

The service lives of floor products vary depending on the amount of floor traffic, type and frequency of maintenance, and flooring construction. The assumed service life is defined for each BEES product in its associated documentation.

BEES includes cleaning and maintenance of products during their useful lifetime. Because of differing manufacturers' maintenance recommendations, there is no single maintenance regimen that is followed. Cleaning equipment used to maintain floors will depend on the maintenance system selected by the building owner, often based on the desired overall appearance. Frequency of deep cleaning and refinishing or polishing, and types and quantities of these compounds will also depend on the maintenance programs developed by individual building owners. For BEES, cleaning and maintenance is modeled based on industry-wide specifications or recommendations obtained from published EPDs; industry- or manufacturer-specific maintenance guides published online; or in some instances, general internet research on best maintenance practices.

Cleaning and maintenance in BEES is divided into two parts. The first, regular cleaning of dirt and dust (i.e., by way of vacuuming (electrical requirements) or sweeping / dust mopping (non-electrical)) is a variable in BEES. The BEES user chooses the method of regular cleaning along with the frequency per week. The default number for commercial applications is set at four, averaging out the cleaning needs of different volumes of traffic. Inputs and outputs per cleaning event of regular maintenance are shown in Table 5-3. 
Table 5-3 Inputs and Outputs per Regular Cleaning Event ${ }^{7}$

\begin{tabular}{lcc}
\hline Vacuum choice & Per $^{2}$ & Per ft $^{2}$ \\
Electricity & $0.014 \mathrm{MJ}$ & $3.70 \mathrm{E}-04 \mathrm{kWh}$ \\
Solid waste & $0.0077 \mathrm{~kg}$ & $0.0016 \mathrm{lb}$ \\
& & \\
& & \\
Sweep / dry mop choice & $\boldsymbol{~}^{2}$ & Per ft \\
Solid waste & $0.0077 \mathrm{~kg}$ & $0.0016 \mathrm{lb}$ \\
\hline
\end{tabular}

The second part of cleaning is characterized as intermittent deeper cleaning and other maintenance, and this operation is a non-variable in BEES, although as acknowledged above, this may vary from building to building. Intermittent cleaning and maintenance schedules and resource requirements for the different floor products are defined for each BEES product in its associated documentation.

\subsection{Armstrong Resilient Floor Coverings}

The development of all Armstrong resilient floor coverings included in BEES Online 2.0 use the same underlying data and methodology as described in this section.

\subsubsection{Product Description}

Headquartered in Lancaster, PA, Armstrong Flooring Inc. has an extensive portfolio of resilient and wood flooring products. Armstrong's mission is to "create innovative flooring solutions that inspire spaces where people live, work, learn, heal and play."” Armstrong Commercial Flooring submitted three floor covering products into BEES: Armstrong vinyl composition tile (VCT), Armstrong $2.5 \mathrm{~mm}$ linoleum sheet, and Armstrong BioBased Tile (BBT).

Armstrong VCT is a resilient floor covering comprised mostly of limestone in a vinyl binder matrix and is manufactured in Jackson, MS, Kankakee, IL, and South Gate, CA. Linoleum is a resilient floor covering made from natural raw materials including linseed oil, gum rosin from pine trees, recycled wood waste, jute fiber, and limestone. Armstrong linoleum is manufactured in Delmenhorst, Germany, and it is shipped worldwide, including to the U.S. Armstrong BBT is a non-polyvinyl chloride (PVC) tile with 85\% limestone and BioStride, a biobased polyester binder. BBT is manufactured in Jackson, MS. The thickness and mass per area of the Armstrong products in BEES are provided in Table 5-4.

\footnotetext{
${ }^{7}$ Energy input and solid waste quantity based on Tables 8 and 10 of Lu, Overcash, and Realff (2008). This is modeled on an assumption that carpet and other floors have attracted similar quantities of dirt and dust.

${ }^{8}$ Retrieved from https://www.armstrongflooring.com/corporate/products.asp.
} 
Table 5-4 Armstrong Products Included in BEES

\begin{tabular}{|c|c|c|}
\hline Products & $\begin{array}{c}\text { Nominal } \\
\text { Thickness mm (in) }\end{array}$ & $\begin{array}{l}\text { Mass per Applied } \\
\text { Area } \mathrm{kg} / \mathrm{m}^{2}\left(\mathbf{l b} / \mathbf{f t}^{2}\right)\end{array}$ \\
\hline Armstrong VCT & $3.175(0.125)$ & $6.84(1.4)$ \\
\hline Armstrong Linoleum Sheet & $2.5(0.098)$ & $2.88(0.59)$ \\
\hline Armstrong BBT & $3.175(0.125)$ & $7.03(1.44)$ \\
\hline
\end{tabular}

The functional unit used for this BEES category is a flooring covering of $0.093 \mathrm{~m}^{2}\left(1 \mathrm{ft}^{2}\right)$ used over the building's operating lifetime of 60 years. Data for BEES is based on the EPDs published in 2014 on these products, with permission from Armstrong. While specific product detail in the EPDs is minimal, Armstrong provided Four Elements with the raw data files to comprehensively model the products for BEES. These products are applicable to the commercial market.

\subsubsection{Flow Diagram}

The flow diagrams in Figure 5-1, Figure 5-2, and Figure 5-3 show the major elements of the production of Armstrong products as they are modeled for BEES.

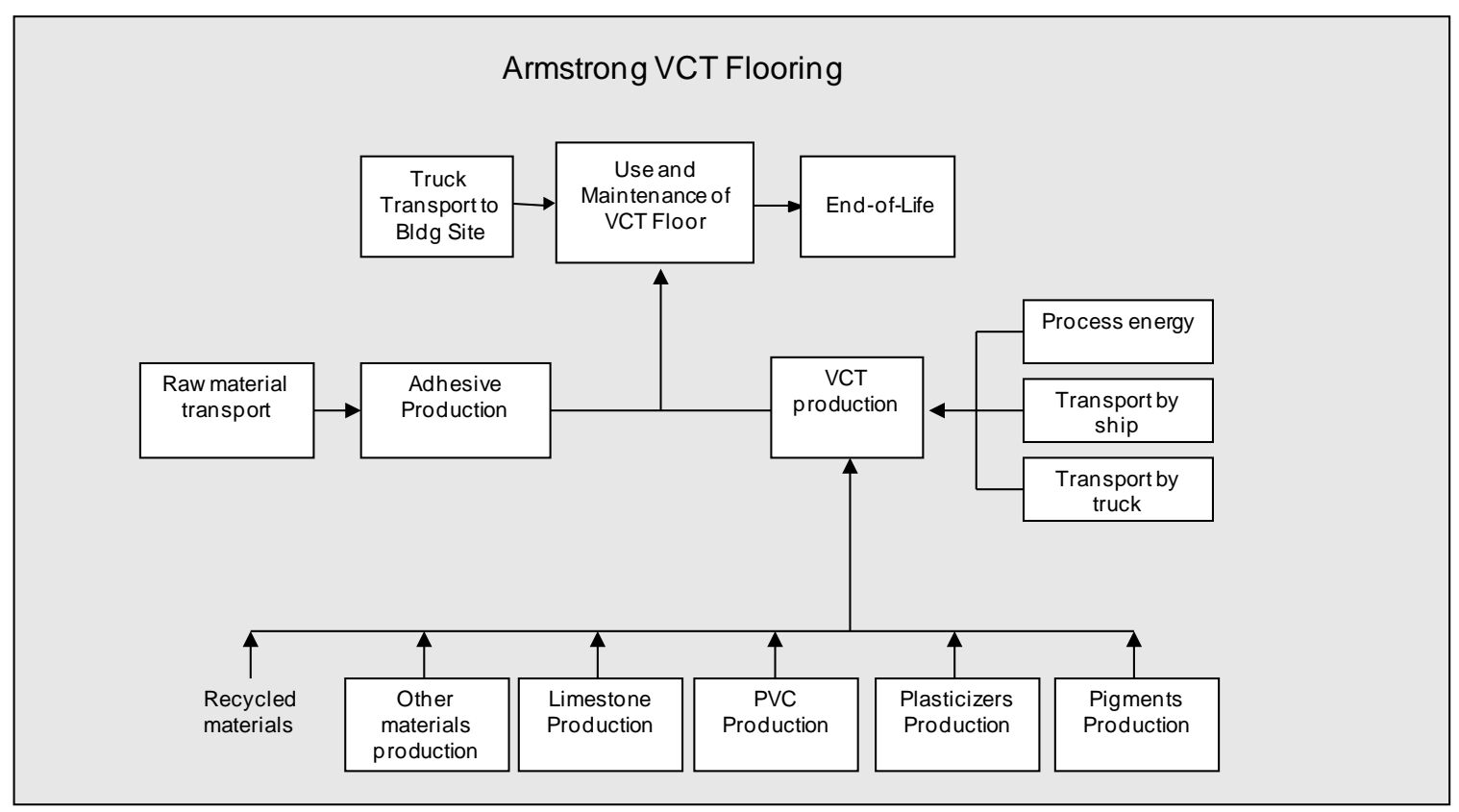

Figure 5-1 Armstrong VCT System Boundaries 


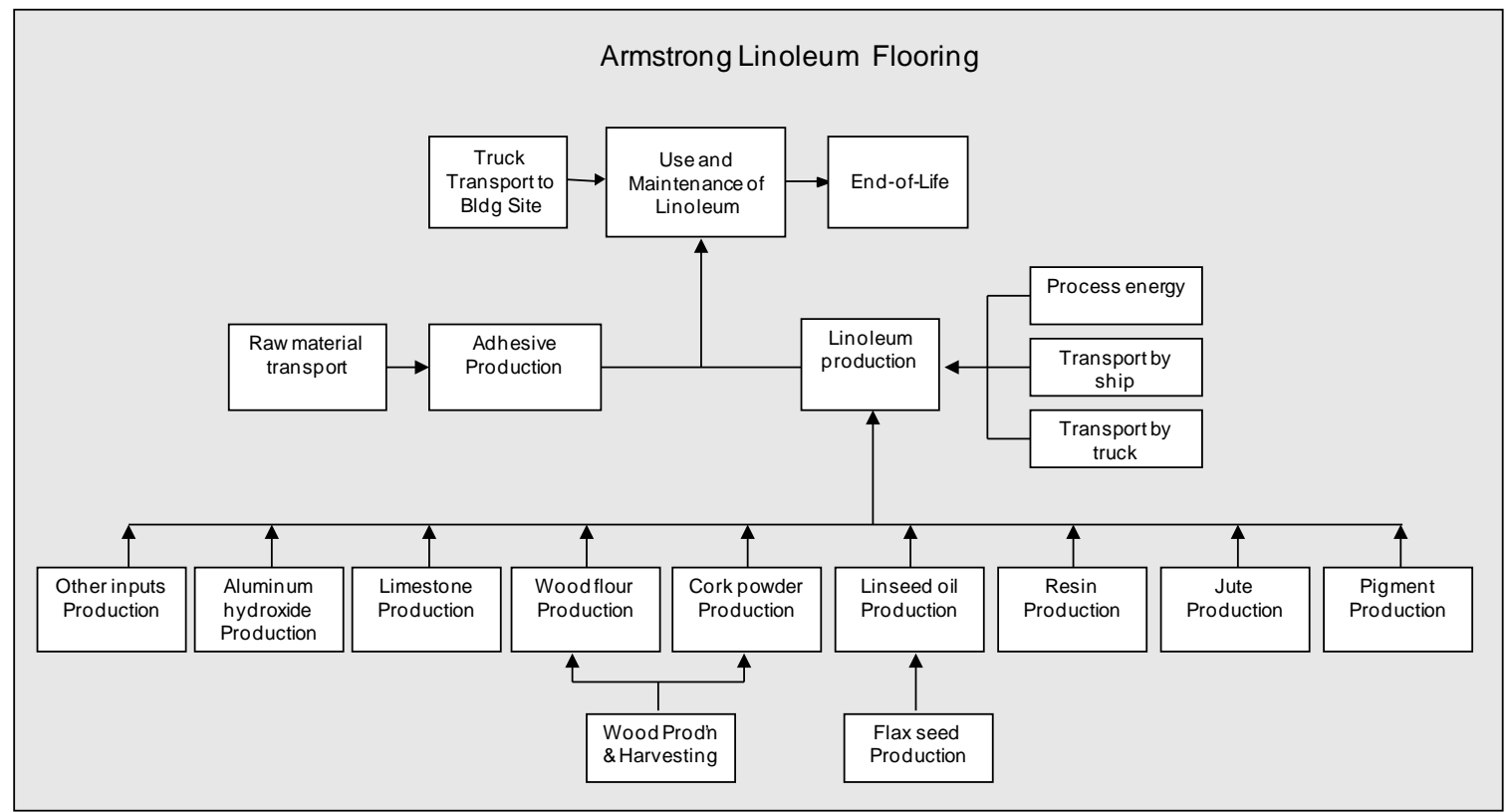

Figure 5-2 Armstrong Linoleum System Boundaries

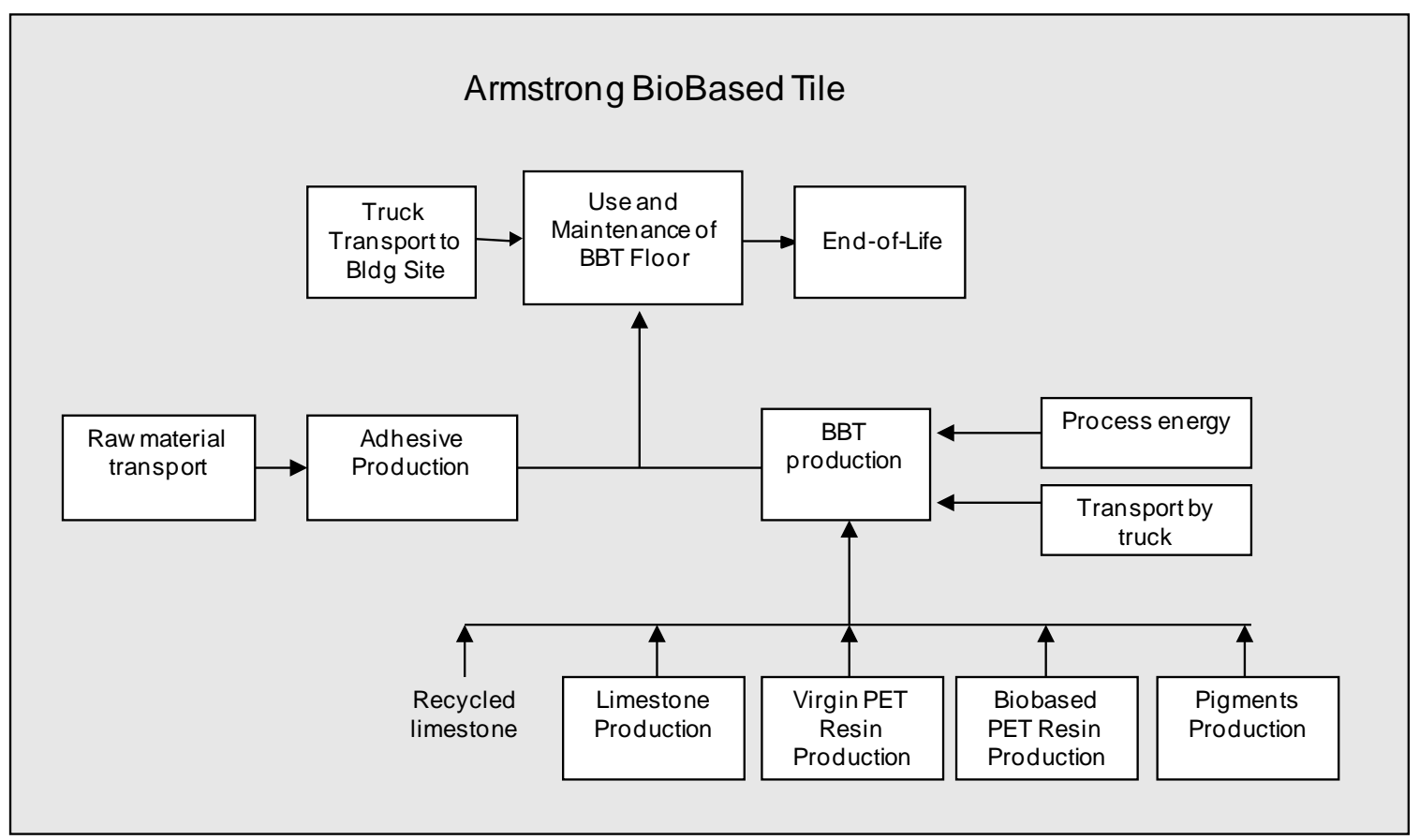

Figure 5-3 Armstrong BBT System Boundaries

\subsubsection{Raw Materials}

The material contents of the Armstrong floor products are provided in Table 5-5, Table 5-6, and Table 5-7. 
Table 5-5 Armstrong VCT Composition ${ }^{9}$

\begin{tabular}{|c|c|c|c|}
\hline Component & Material & $\%$ in VCT & Sourcing location \\
\hline Filler & Limestone & 84.0 & USA/Canada/Europe \\
\hline Binder & PVC & 10.0 & Indonesia/China \\
\hline Plasticizers & $\begin{array}{l}\text { Dioctyl Terephthalate (DOTP), blended } \\
\text { dibenzoates, \& dibutyl terephthalate }\end{array}$ & 4.5 & USA, Germany \\
\hline Pigment & $\begin{array}{l}\text { Titanium dioxide } \\
\text { Colored mineral pigments }\end{array}$ & $\begin{array}{c}0.5 \\
<0.1\end{array}$ & $\begin{array}{l}\text { Internal } \\
\text { Global }\end{array}$ \\
\hline Stabilizer & Calcium zinc compound & $<0.1$ & Global \\
\hline Other & Recycled materials* & 1.0 & \\
\hline & Total & $100 \%$ & \\
\hline
\end{tabular}

Table 5-6 Armstrong Linoleum Composition ${ }^{10}$

\begin{tabular}{llcl}
\hline Component & Material & \% in Linoleum & Sourcing location \\
\hline Filler & Limestone & 15.0 & Germany \\
& Wood / Cork powder & 28.0 & Germany \\
Backing & Jute & 8.0 & India \\
Binder & Linseed oil & 31.0 & Germany \\
& Tree resins & 5.0 & Indonesia \\
Fire retardant & Aluminum hydroxide & 7.0 & Hungary \\
Pigment & Titanium dioxide & 5.0 & Belgium \\
& Colored mineral pigments & 0.5 & Various \\
Stabilizer & Proprietary ingredient & 0.5 & Proprietary \\
\hline & Total & $\mathbf{1 0 0 \%}$ & \\
\hline
\end{tabular}

Table 5-7 Armstrong BBT Composition ${ }^{11}$

\begin{tabular}{|c|c|c|c|}
\hline Component & Material & $\%$ in $B B T$ & Sourcing location \\
\hline Filler & Limestone (10\% recycled) & 85 to 88 & U.S. \\
\hline Binder & Biobased polyester resin & 11 to 14 & U.S. \\
\hline \multirow[t]{3}{*}{ Pigment } & Titanium dioxide & 0.5 & U.S. \\
\hline & Colored mineral pigments & $<0.1$ & U.S. \\
\hline & Total & $100 \%$ & \\
\hline
\end{tabular}

The U.S. LCI database provided data for the vinyl as polyvinyl chloride resin, and wood powder, as sawdust. The limestone, titanium dioxide, jute, and aluminum hydroxide data were provided by ecoinvent.

The Dioctyl Terephthalate (DOTP) data are a confidential data set based on one U.S. manufacturer's late 2010's primary data. It is considered representative technology. The other plasticizers are based on a dataset averaging three common phthalate esters

\footnotetext{
9 Table 4 of Armstrong (2014a)

${ }^{10}$ Armstrong Linoleum EPD, Table 4 of Armstrong (2014b)

11 Table 4 of Armstrong (2014c)
} 
(DEHP/DINP/DIDP) (PricewaterhouseCoopers/Ecobilan, 2001). This data set was used as a proxy to represent common plasticizers but is not reflective of product content. The colored mineral pigments are assumed to be iron oxide based, and an internally-produced dataset on red iron oxide was used. No data were available for the calcium zinc compound.

Cork powder is a recycled material; while it has no upstream impacts, its transport to the flooring facility and processing is accounted for. The data for linseed oil, from flax seed, is based in internally-produced data sets. The tree resin, assumed to be pine rosin from tapped pine trees, is based on internally-produced data. The carbon in these biomass materials is modeled as sequestered except for the portion that is assumed to decompose in a landfill (see End of Life section).

The biobased polyester resin is a proprietary dataset that includes biobased polyethylene terephthalate (PET) resin and virgin PET. The virgin PET comes from the U.S. LCI database and the biobased PET is an internally-produced dataset with specific data provided by Armstrong.

The non-specified additives, proprietary ingredients, or other materials in Table 5-5, Table 5-6, and Table 5-7 are included in the inventory modeling but are not provided in this documentation, consistent with the level of detail released in the EPD. Production of this information is based mainly on the ecoinvent database and some U.S. LCI data.

Table 5-5, Table 5-6, and Table 5-7 provide the sourcing locations for materials used. Armstrong provided Four Elements with specific transportation distances and modes for each material to the Armstrong facilities. Transportation taking place outside North America was modeled using ecoinvent, while in the U.S., the U.S. LCI database was used.

Packaging materials and their transportation to Armstrong facilities have been included in the BEES model. Armstrong VCT and BBT are packaged in a recyclable corrugated box and Armstrong Linoleum is rolled and wrapped in Kraft paper. In all cases, wooden pallets are used to protect unit loads during shipping.

\subsubsection{Manufacturing}

Sec 5.2 of the VCT and BBT EPDs describe the manufacturing process as hot mixing of the raw materials milled and calendared into a hot sheet. Once cooled, the sheet is punched into floor tiles. VCT and BBT have a factory applied finish to protect the tile face during packaging and installation.

According to Fig. 2 of the Linoleum EPD, linoleum is made by first combining linseed oil and tree rosins to create linoleum cement. The cement is added to the fillers limestone and the wood/cork powder and pigments. The mixture is calendared and put onto a jute backing. The flooring is cured in an oven for 14 to 21 days, and then factory finishes are applied. The product is trimmed and packaged. 
Detailed data on the energy requirements (including electricity and natural gas thermal energy), water use, air emissions, and waste from production of these products were provided to Four Elements, and these data were included in the models. These data are not provided in this documentation, consistent with the level of detail released in the EPD.

Data for electricity and natural gas come from the U.S. LCI database. Armstrong linoleum product-related waste is negligible, as rejected material and process trim scrap can be reused in the manufacturing process. Other manufacturing waste data for linoleum, plus waste for the other products, was provided to Four Elements and modeled as transported to and disposed of in a landfill or incinerated.

\subsubsection{Transportation}

Transportation of Armstrong VCT and BBT is done by heavy-duty truck to the building site, and $805 \mathrm{~km}$ (500 mi) was modeled. Linoleum is transported $5800 \mathrm{~km}$ (3 $605 \mathrm{mi}$ ) by ocean freighter and $805 \mathrm{~km}$ (500 mi) by heavy duty truck. Transportation models come from U.S. LCI database.

\subsubsection{Installation}

At installation, a layer of a water-based adhesive is applied to the products. Table 5-8 presents the adhesive products recommended by Armstrong, their quantity used, VOC contents, and recommended adhesive alternatives.

Table 5-8 Armstrong Adhesive Use

\begin{tabular}{lccc}
\hline & Armstrong VCT & Armstrong Linoleum & Armstrong BBT \\
\hline $\begin{array}{l}\text { Adhesive Product } \\
\text { (baseline) }\end{array}$ & $\begin{array}{c}\text { Armstrong S-750 } \\
\text { Premium Floor Tile } \\
\text { Adhesive }\end{array}$ & $\begin{array}{c}\text { Armstrong S-780 } \\
\text { Synthetic Polymer Based } \\
\text { Linoleum Adhesive }\end{array}$ & $\begin{array}{c}\text { Armstrong S-525 } \\
\text { BioBased Tile Adhesive }\end{array}$ \\
\hline $\begin{array}{l}\text { Quantity per kg/m }{ }^{2} \\
\left(\mathbf{l b} / \mathrm{ft}^{2} \text { ) }\right.\end{array}$ & $0.130(0.027)$ & $0.435(0.089)$ & $0.139(0.029)$ \\
\hline VOC content g/l & 5.9 & 5.1 & 16.2 \\
\hline $\begin{array}{l}\text { VOC emission } \\
\text { kg/m }{ }^{2} \text { (lb/ft }{ }^{2} \text { ) }\end{array}$ & $0.00068(0.00014)$ & $0.0015(0.0003)$ & $0.002(0.0004)$ \\
\hline $\begin{array}{l}\text { Zero-VOC Adhesive } \\
\text { Alternative }\end{array}$ & $\begin{array}{c}\text { Armstrong S-515 } \\
\text { Floor Tile Adhesive }\end{array}$ & -- & Flip Spray Adhesive \\
\hline
\end{tabular}

BEES allows the user to choose between the VOC- and no-VOC adhesives, although it is acknowledged that the VOC levels in the baseline adhesives are far below the VOC emissions limits set out in Rule \#1168 of California's South Coast Air Quality Management District (SCAQMD), which is the VOC emissions limit standard used in BEES for the baseline adhesives in the floor covering category. ${ }^{12}$ Installation is primarily

\footnotetext{
${ }^{12}$ For example, the limit for VCT adhesive is $50 \mathrm{~g} / \mathrm{l}$ (0.4 lb/gal). For more information, see Table 1 of SCAQMD (2011)
} 
a manual process, so no energy use is modeled for the installation phase. Ecoinvent datasets were used to build the adhesive.

Scrap generated during installation is modeled as 3\% according to the Armstrong EPDs. Installation waste is modeled as transported $48 \mathrm{~km}$ (30 mi) by diesel truck and disposed of in a landfill. While some of the packaging waste at installation can be recycled, it is modeled as disposed of in a landfill.

\subsubsection{Use and Maintenance}

The service lives of floor products vary depending on the amount of floor traffic, type and frequency of maintenance, and flooring construction. The level of maintenance is also dependent on the actual use and desired appearance of the floor. For BEES, VCT has a lifetime of 25 years, consistent with the industry-average VCT EPD (RFCI, 2013a). BBT and linoleum are modeled as having lifetimes of 25 years and 30 years, respectively, consistent with Armstrong's EPDs. Replacement, including production of raw materials, manufacturing, transport to installation, etc., is included to account for the BEES flooring category's operating lifetime of 60 years.

BEES includes cleaning and maintenance of products during their useful lifetime. Because of differing manufacturers' maintenance recommendations, there is no single maintenance regimen that is followed. Cleaning equipment used to maintain floors will depend on the maintenance system selected by the building owner, often based on the desired overall appearance. Frequency of deep cleaning and refinishing or polishing, and types and quantities of these compounds will also depend on the maintenance programs developed by individual building owners. For BEES, cleaning and maintenance is modeled based on industry-wide specifications or recommendations obtained from published EPDs; industry- or manufacturer-specific maintenance guides published online; or in some instances, general internet research on best maintenance practices.

Cleaning and maintenance in BEES is divided into two parts. The first, regular cleaning of dirt and dust (i.e., by way of vacuuming (electrical requirements) or sweeping / dust mopping (non-electrical)) is a variable in BEES. The BEES user chooses the method of regular cleaning along with the frequency per week. The default number for commercial applications is set at four, averaging out the cleaning needs of different volumes of traffic. Inputs and outputs per cleaning event of regular maintenance are shown in Table 5-9. 
Table 5-9 Inputs and Outputs per Regular Cleaning Event ${ }^{13}$

\begin{tabular}{lcc}
\hline Vacuum choice & Per m $^{2}$ & Per ft $^{2}$ \\
Electricity & $0.014 \mathrm{MJ}$ & $3.70 \mathrm{E}-04 \mathrm{kWh}$ \\
Solid waste & $0.0077 \mathrm{~kg}$ & $0.0016 \mathrm{lb}$ \\
& & \\
& & \\
Sweep / dry mop choice & $\boldsymbol{P e r} \mathrm{m}^{2}$ & Per ft \\
Solid waste & $0.0077 \mathrm{~kg}$ & $0.0016 \mathrm{lb}$ \\
\hline
\end{tabular}

The solid waste is modeled as being transported by diesel truck and disposed of in a landfill.

The second part of cleaning is characterized as intermittent deeper cleaning and other maintenance, and this is a non-variable in BEES, although as acknowledged above, this may vary from building to building. Table 5-10 through Table 5-13 present the intermittent cleaning and maintenance schedules and resource requirements for the different floor products.

Table 5-10 VCT and BBT Cleaning Processes and Frequency ${ }^{14,15}$

\begin{tabular}{lcc}
\hline Cleaning Process & Frequency & Resources Used \\
Damp mop / neutral cleaner & 1x per week & Hot water, neutral detergent \\
Spray buff / finish restorer & 1x per month & Floor finish, Electricity \\
Strip and 2 coats finish & 1x per year & Finish remover, floor finish, Electricity \\
\hline
\end{tabular}

\section{Table 5-11 VCT and BBT Intermittent Cleaning Inputs per Year ${ }^{16}$}

\begin{tabular}{lcc}
\hline Cleaning Input & ${\text { Per } \mathrm{m}^{2}}$ & ${\text { Per } \mathrm{ft}^{2}}$ \\
Detergent (ml) & 124 & 11.5 \\
Electricity (kWh) & 0.025 & 0.002 \\
Finish (liter) & 0.22 & 0.02 \\
Finish remover (liter) & 0.041 & 0.004 \\
Water (liter) & 6.2 & 0.58 \\
\hline
\end{tabular}

\section{Table 5-12 Linoleum Cleaning Processes and Frequency ${ }^{17}$}

\begin{tabular}{lll}
\hline Cleaning Process & \multicolumn{1}{c}{ Frequency } & \multicolumn{1}{c}{ Resources Used } \\
Damp mop / neutral cleaner & 1x per week & Hot water, neutral detergent \\
Deep cleaning (scrub) & 1x per month & Electricity, neutral detergent, water \\
Polish & 6x per year & Floor finish, electricity \\
Damp mop / neutral cleaner & 1x per week & Hot water, neutral detergent \\
\hline
\end{tabular}

\footnotetext{
${ }^{13}$ Energy input and solid waste quantity based on Tables 8 and 10 of Lu et al. (2008). This is modeled on an assumption that carpet and other floors have attracted similar quantities of dirt and dust.

${ }^{14}$ According to the manufacturer, BBT has similar maintenance requirements as VCT.

${ }^{15}$ Based on Table 1 in RFCI (2013a)

16 Table 2 in RFCI (2013a)

${ }^{17}$ Based on Table 5 in Armstrong (2014b)
} 
Table 5-13 Linoleum Intermittent Cleaning Inputs per Year ${ }^{18}$

\begin{tabular}{lcc}
\hline Cleaning Input & Per $\mathrm{m}^{2}$ & ${\text { Per } \mathrm{ft}^{2}}^{2}$ \\
Detergent (ml) & 124 & 11.5 \\
Electricity (kWh) & 0.033 & 0.003 \\
Polish/finish (liter) & 0.10 & 0.009 \\
Water (liter) & 6.2 & 0.58 \\
\hline
\end{tabular}

\subsubsection{End of Life}

All products are modeled as landfilled at end of life. End of life modeling includes transportation of the products and adhesive by heavy-duty diesel-fuel powered truck approximately $48 \mathrm{~km}$ (30 mi) to a landfill, plus impacts of the materials in a landfill. Truck transportation is based on the U.S. LCI database and disposal in a landfill is modeled based on ecoinvent end of life waste management process data. VCT and BBT are modeled in an inert material landfill; BBT's biobased resin is assumed to not decompose as it is bound within the plastic resin. As such, its carbon content remains sequestered in the product.

Much of the linoleum product is sourced from biobased materials, so disposal includes data for both inert material in a landfill and disposal of biogenic material in a landfill. Mahalle (2011) and the EPA Waste Reduction Model (WARM) describe the impacts from biogenic material in a landfill as being made up of $\mathrm{CH}_{4}$ from decomposition of biomass and $\mathrm{CO}_{2}$ emissions associated with flaring these emissions where landfill gas is not recovered for energy; and $\mathrm{CO}_{2}$ emissions avoided through landfill gas-to-energy projects. An assumed 23\% of the wood decomposes, so storage of the remaining biogenic carbon is also accounted for (Section 5.1 in Mahalle (2011)). The data for net GHG emissions from landfill gas management practices comes from Table 31 in Mahalle (2011). For linoleum, these emissions are $0.379 \mathrm{~kg} \mathrm{CO} 2$ per $\mathrm{kg}$ linoleum and $0.017 \mathrm{~kg}$ methane per kg linoleum.

\subsection{Forbo Products}

The development of all Forbo flooring systems included in BEES Online 2.0 use the same underlying data and methodology as described in this section.

\subsubsection{Product Description}

Based in the Netherlands, the Flooring Systems division of Forbo is a global provider of commercial and residential floor coverings. Forbo Flooring Systems offers a range of linoleum, vinyl flooring, entrance flooring systems for cleaning and drying shoes, carpet tiles, needlefelt floor coverings and Flotex - the washable textile flooring - and building

\footnotetext{
${ }^{18}$ No material or energy usage quantities were provided in the Armstrong EPD, so inputs were modeled using adjusted data from Table 2 in RFCI (2013a)
} 
and construction adhesives. Forbo submitted three floor covering products into BEES: two thicknesses of Marmoleum tile (their linoleum brand) and one vinyl sheet floor covering. Marmoleum is a resilient floor covering made from natural raw materials including linseed oil, which comes from the flax plant seeds, gum rosin from pine trees, recycled wood waste of wood from controlled forests, and limestone. Marmoleum is manufactured in Kirkcaldy, United Kingdom. Eternal vinyl sheet floor covering is a resilient floor covering made up of PVC, plasticizer, mineral filler, stabilizers, and glass fiber. Eternal is manufactured in Coevorden, the Netherlands. The products are shipped worldwide, including to the U.S. Their thickness and mass per area are listed in Table 5-14.

\section{Table 5-14 Forbo Products Included in BEES}

\begin{tabular}{|c|c|c|}
\hline Products & $\begin{array}{c}\text { Nominal } \\
\text { Thickness mm (in) }\end{array}$ & $\begin{array}{l}\text { Mass per Applied } \\
\text { Area } \mathrm{kg} / \mathrm{m}^{2}\left(\mathbf{l b} / \mathrm{ft}^{2}\right)\end{array}$ \\
\hline Marmoleum $2.0 \mathrm{~mm}$ tile & $2.0(0.079)$ & $2.3(0.471)$ \\
\hline Marmoleum $2.5 \mathrm{~mm}$ tile & $2.5(0.098)$ & $3.0(0.614)$ \\
\hline Eternal Vinyl Sheet & $2.0(0.079)$ & $2.8(0.573)$ \\
\hline
\end{tabular}

The functional unit used for this BEES category is a flooring covering of $0.093 \mathrm{~m}^{2}\left(1 \mathrm{ft}^{2}\right)$ used over the building's operating lifetime of 60 years. Data for BEES comes from the EPDs published on these products, with permission from Forbo. The detailed LCA data used to build the models are published in the back of each EPD. These products are applicable to both the commercial and residential markets.

\subsubsection{Flow Diagram}

The flow diagrams in Figure 5-4 and Figure 5-5 show the major elements of the production of these products as they are modeled for BEES. 


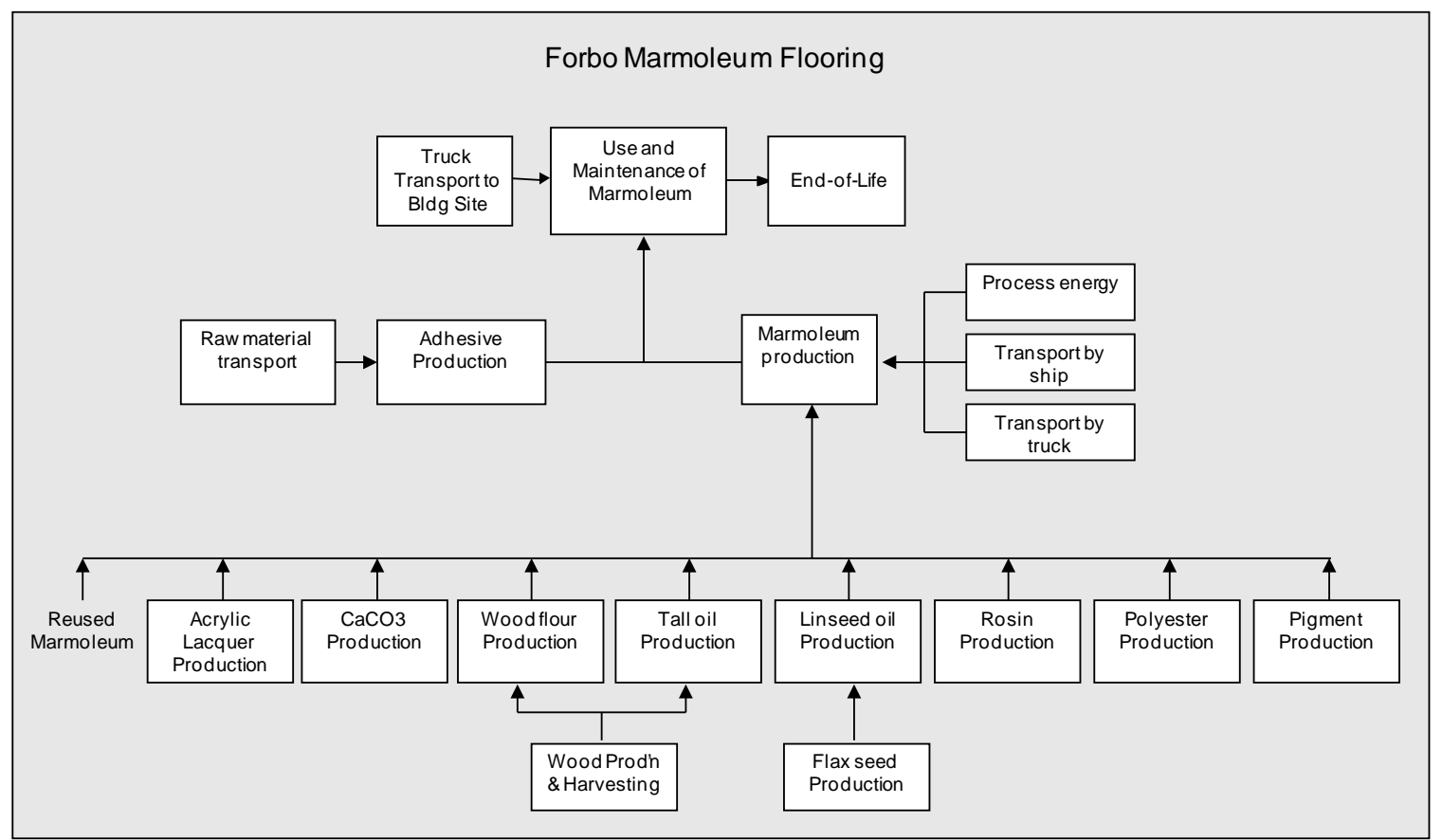

Figure 5-4 Marmoleum System Boundaries

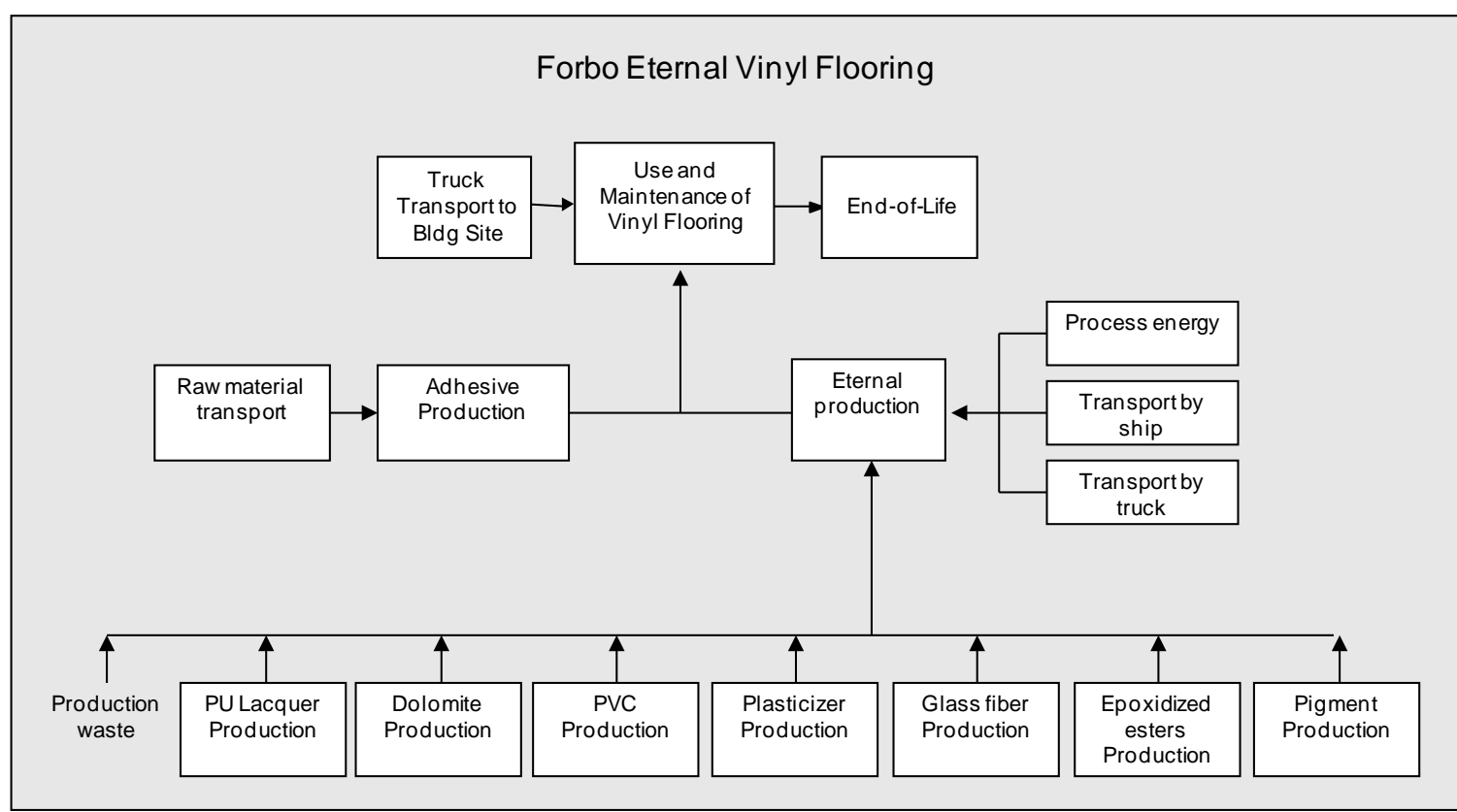

Figure 5-5 Eternal System Boundaries

\subsubsection{Raw Materials}

The compositions of the products are provided in Table 5-15 and Table 5-16. 
Table 5-15 Marmoleum 2.0 and Marmoleum 2.5 Composition ${ }^{19}$

\begin{tabular}{llcl}
\hline Component & Material & $\begin{array}{c}\text { \% in 2.0mm } \\
\text { \& 2.5mm }\end{array}$ & Sourcing location \\
\hline Binder & Linseed oil & 20.0 & USA/Canada/Europe \\
& Gum rosin & 2.0 & Indonesia/China \\
& Tall oil & 6.0 & USA \\
\multirow{2}{*}{ Filler } & Wood flour & 31.0 & Germany \\
& Calcium carbonate & 8.0 & Germany \\
\multirow{2}{*}{ Pigment } & Reused Marmoleum & 23.0 & Internal \\
Backing & Titanium dioxide & 3.0 & Global \\
Finish & Polyester & 5.0 & Europe \\
& Lacquer & 1.0 & Netherlands \\
\hline \multicolumn{4}{c}{$\mathbf{1 0 0 \%}$} \\
\hline * According to the EPD, recycled materials may make up one or more of the \\
materials in VCT.
\end{tabular}

Table 5-16 Eternal Vinyl Sheet Composition ${ }^{20}$

\begin{tabular}{llcl}
\hline Component & Material & \% in Linoleum & Sourcing location \\
\hline Binder & PVC & 39 & Europe \\
& DINP \& Dibenzoates & 17 & Europe \\
Filler & Dolomite & 22 & Europe \\
$\begin{array}{l}\text { Stabilizers \& } \\
\text { additives } \\
\text { Carrier }\end{array}$ & $\begin{array}{l}\text { Epoxidized esters \& proprietary } \\
\text { mixtures \& lubricants }\end{array}$ & 4 & Europe \\
Pigments & Glass fiber tissue & 2 & Netherlands/ Germany \\
& Titanium Dioxide (main & & \\
Finish & pigment), plus others & 0.5 & Europe \\
Recycle & polyurethane lacquer & $<0.5$ & Europe \\
\hline & Post production waste & 15 & Internal \\
\hline
\end{tabular}

The U.S. LCI database provided data for the vinyl as polyvinyl chloride resin, polyester, as PET resin, and wood flour, as sawdust. The calcium carbonate, or limestone, titanium dioxide, lacquer finish, modeled as an acrylic binder in water, dolomite, glass fiber, and polyurethane lacquer data were provided by ecoinvent.

The DINP and dibenzoates plasticizers are based on a dataset averaging three common phthalate esters (DEHP/DINP/DIDP). ${ }^{21}$ This data set was used as a proxy to represent common plasticizers and may not be reflective of the current products used. The other pigments used are assumed to be mineral pigments. These pigments are modeled as a red iron oxide, which is an internally-produced dataset.

19 Table 2 in Forbo (2013a)

20 Table 2 in Forbo (2013b)

${ }^{21}$ PricewaterhouseCoopers/Ecobilan (2001) 
Epoxidized ester is modeled as an epoxidized methyl soyate. For this analysis, ecoinvent data sets were used for soybean upstream data and internally-produced datasets for methyl ester and epoxidation were used. Tall oil rosin is a distillation product of crude tall oil; its production is based on an internally-produced data set. The data for linseed oil, from flax seed, is also based on internally-produced data sets, as is gum rosin, assumed to be pine rosin from tapped pine trees. The carbon in these biomass materials is modeled as sequestered except for the portion that is assumed to decompose in a landfill (see End of Life section).

Table 5-15 and Table 5-16 provide the sourcing locations for materials used. Table 10 and Table 5 of the Forbo LCA reports located at the end of the Marmoleum and Eternal EPDs, respectively, list the specific transport distances of each material to the Forbo facilities. Transportation taking place outside North America was modeled using ecoinvent transportation data, while in the U.S., the U.S. LCI database was used.

Packaging is included in BEES. Both Marmoleum products use corrugated board boxes $\left(0.051 \mathrm{~kg} / \mathrm{m}^{2}\right)$, and polyethylene film $\left(0.0004 \mathrm{~kg} / \mathrm{m}^{2}\right)$ (Table 9 in Forbo (2013a)). Eternal uses polyethylene film $\left(0.002 \mathrm{~kg} / \mathrm{m}^{2}\right)$, corrugated board $\left(0.055 \mathrm{~kg} / \mathrm{m}^{2}\right)$, and Kraftliner paper $\left(0.011 \mathrm{~kg} / \mathrm{m}^{2}\right)$ (Table 4 of Forbo (2013b)). Ecoinvent provides the data for these products.

\subsubsection{Manufacturing}

Page 5 of Forbo (2013a) describes the production process as follows: "Marmoleum tile is produced in several stages starting with the oxidation of linseed oil mixed with tall oil and rosin. With the influence of oxygen from the atmosphere a tough sticky material is obtained called linoleum cement. The linoleum cement is stored in containers for a few days for further reaction and after this it is mixed with wood flour, calcium carbonate, reused waste (if applicable), titanium dioxide and pigments. This mixture is calendared on a polyester substrate and stored in drying rooms, to cure till the required hardness is reached. After approximately 14 days the material is taken out from the drying room to the trimming department where the factory finish is applied on the surface of the product and the end inspection is done. Finally, the edges are trimmed, and the sheet is cut to length into tiles of $333 \mathrm{~mm}$ x $333 \mathrm{~mm}$ (13.1 in x 13.1 in) or $500 \mathrm{~mm}$ x $500 \mathrm{~mm}$ (19.7 in x 19.7 in). The trimmings and the rejected product are reused."

Table 5-17 provides the inputs and outputs for the Marmoleum products. 
Table 5-17 Production Inputs and Outputs - Marmoleum ${ }^{22}$

\begin{tabular}{lcc}
\hline Input & Quantity per $\mathrm{m}^{2}$ & Quantity per $\mathrm{ft}^{2}$ \\
Electricity (MJ) & 12.911 & 1.199 \\
Natural gas (thermal) (MJ) & 52.13 & 4.843 \\
& & \\
Output & & \\
Waste $(\mathrm{kg})-2 \mathrm{~mm}$ & 0.705 & 0.065 \\
Waste $(\mathrm{kg})-2.5 \mathrm{~mm}$ & 0.844 & 0.078 \\
\hline
\end{tabular}

Data for natural gas comes from ecoinvent for EU production. Data for electricity is based on ecoinvent electricity grid data for the United Kingdom and the Netherlands. No product waste is generated, as trimmings and rejected product is recycled back into the calendered backing layer. Other production waste shown in Table 5-17 is incinerated.

Page 5 of Forbo (2013b) describes the production process as follows: PVC plastisols (mixture of PVC, plasticizer and additives) are prepared. Glass fleece is impregnated with a highly filled plastisol followed by the application of a thin white plastisol coating. Rotogravure printing, if required, is done to produce wood, stone or abstract designs. PVC plastisol topcoat and polyurethane lacquer are applied. After fusion at approximately $195{ }^{\circ} \mathrm{C}$, the topcoat is mechanically embossed to enhance the decorative effect. A calendared back layer is then applied to the product. This layer contains a minimum of $45 \%$ of process waste. The finished product is then trimmed, inspected and cut into saleable rolls (nominal length of $25 \mathrm{~m}$ (1640 ft)).

Table 5-18 provides the inputs and outputs for Eternal vinyl sheet flooring.

\section{Table 5-18 Production Inputs and Outputs for Eternal ${ }^{23}$}

\begin{tabular}{lcc}
\hline Input & Quantity per $\mathrm{m}^{2}$ & Quantity per $\mathrm{ft}^{2}$ \\
Electricity (MJ) & 5.47 & 0.51 \\
Natural gas (thermal) (MJ) & 12.12 & 1.13 \\
Water (kg) & 1.45 & 0.13 \\
& & \\
Output & & \\
Waste (kg) & 0.416 & 0.039 \\
Wastewater (kg) & 0.64 & 0.059 \\
\hline
\end{tabular}

Data for natural gas comes from ecoinvent for EU production. Data for electricity is based on ecoinvent electricity grid data for the Netherlands. No product waste is generated, as trimmings and rejected product is recycled back into the calendared backing layer. Other production waste shown in Table 5-18 is incinerated.

22 Table 8 in Forbo (2013a)

23 Table 3 in Forbo (2013b) 


\subsubsection{Transportation}

Transportation to the building site was modeled as based on transportation from the manufacturing plants to the U.S. The Marmoleum products are modeled as transported $5285 \mathrm{~km}$ (3285 mi) by ocean freighter from the Netherlands to a port in New York. Eternal is transported $6062 \mathrm{~km}$ (3768 mi) by ocean freighter from the Netherlands to New York. Once in the U.S., they are modeled as traveling an average distance of $2414 \mathrm{~km}$ (1500 mi). U.S. LCI database data were used for transportation.

\subsubsection{Installation}

At installation, a layer of a water-based adhesive is applied to both products. For Marmoleum, the amount of adhesive is $0.435 \mathrm{~kg} / \mathrm{m}^{2}\left(0.089 \mathrm{lb} / \mathrm{ft}^{2}\right)$ and for Eternal, the amount is $0.3 \mathrm{~kg} / \mathrm{m}^{2}\left(0.06 \mathrm{lb} / \mathrm{ft}^{2}\right) .{ }^{24}$ Installation is primarily a manual process, so no energy use is modeled for the installation phase. Ecoinvent datasets were used to build the adhesive. The adhesives recommended by Forbo are low (zero)-VOC; as such, this type is what is modeled in BEES. Forbo (2013a) specifies a "conservative" $0.435 \mathrm{~kg} / \mathrm{m}^{2}$ for Marmoleum products and Forbo (2013b) specifies $0.3 \mathrm{~kg}$ adhesive per $\mathrm{m}^{2}$ for Eternal products.

The scrap generated during installation is modeled as $4.5 \% .^{25}$ The installation waste is modeled as transported $48 \mathrm{~km}$ (30 mi) by diesel truck and disposed of in a landfill. While some of the packaging waste at installation can be recycled, it is modeled as disposed of in a landfill.

\subsubsection{Use and Maintenance}

The service life of flooring products will vary depending on the amount of floor traffic and the type and frequency of maintenance. The level of maintenance is also dependent on the actual use and desired appearance of the floor. A lifetime of 30 years has been modeled for the Marmoleum and 35 years for Eternal. Replacement, including production of raw materials, manufacturing, transport to installation, etc., is included to account for the BEES flooring category's operating lifetime of 60 years.

BEES includes cleaning and maintenance of products during their useful lifetime. Because of differing manufacturers' maintenance recommendations, there is no single maintenance regimen that is followed. Cleaning equipment used to maintain floors will depend on the maintenance system selected by the building owner, often based on the desired overall appearance. Frequency of deep cleaning and refinishing or polishing, and types and quantities of these compounds will also depend on the maintenance programs developed by individual building owners. For BEES, cleaning and maintenance is modeled based on industry-wide specifications or recommendations obtained from published EPDs; industry-

\footnotetext{
${ }^{24}$ Forbo (2013a)

${ }^{25}$ Both Forbo EPDs model a 6\% installation scrap waste and this was reduced to $4.5 \%$ to be consistent with similar products in BEES.
} 
or manufacturer-specific maintenance guides published on-line; or in some instances, general internet research on best maintenance practices.

Cleaning and maintenance in BEES is divided into two parts. The first, regular cleaning of dirt and dust (i.e., by way of vacuuming (electrical requirements) or sweeping / dust mopping (non-electrical)) is a variable in BEES. The BEES user chooses the method of regular cleaning along with the frequency per week. The default number for commercial applications is set at four, averaging out the cleaning needs of different volumes of traffic. For residential use the default is set to one time per week. Inputs and outputs per cleaning event of regular maintenance are shown in Table 5-19.

\section{Table 5-19 Inputs and Outputs per Regular Cleaning Event ${ }^{26}$}

\begin{tabular}{lcc}
\hline Vacuum choice & $\boldsymbol{P e r ~ m}^{2}$ & $\boldsymbol{P e r ~ f t}^{2}$ \\
Electricity & $0.014 \mathrm{MJ}$ & $3.70 \mathrm{E}-04 \mathrm{kWh}$ \\
Solid waste & $0.0077 \mathrm{~kg}$ & $0.0016 \mathrm{lb}$ \\
& & \\
Sweep / dry mop choice & $\boldsymbol{P e r ~ ~ ^ { 2 }}$ & $\boldsymbol{P e r ~ \mathrm { ft } ^ { 2 }}$ \\
Solid waste & $0.0077 \mathrm{~kg}$ & $0.0016 \mathrm{lb}$ \\
\hline
\end{tabular}

The solid waste is modeled as being transported by diesel truck and disposed of in a landfill. The second part of cleaning is characterized as intermittent deeper cleaning and other maintenance, and this operation is a non-variable in BEES, although as acknowledged above, itmay vary from building to building. Table 5-20 through Table 5-23 present the intermittent cleaning and maintenance schedules for these flooring products.

\section{Table 5-20 Linoleum Cleaning Processes and Frequency ${ }^{27}$}

\begin{tabular}{lll}
\hline Cleaning Process & Frequency & \multicolumn{1}{c}{ Resources Used } \\
Damp mop / neutral cleaner & 1x per week & Hot water, neutral detergent \\
Deep cleaning (scrub) & 1x per month & Electricity, neutral detergent, water \\
Polish & 6x per year & Floor finish, electricity \\
\hline
\end{tabular}

Table 5-21 Linoleum Intermittent Cleaning Inputs per Year ${ }^{28}$

\begin{tabular}{lcccc}
\hline & \multicolumn{2}{c}{ Commercial } & \multicolumn{2}{c}{ Residential } \\
\hline Cleaning Input & Per $\mathrm{m}^{2}$ & ${\text { Per } \mathrm{ft}^{2}}$ & Per $\mathrm{m}^{2}$ & Per $\mathrm{ft}^{2}$ \\
Detergent (ml) & 124 & 11.5 & 62 & 5.76 \\
Electricity (kWh) & 0.033 & 0.003 & 0.013 & 0.001 \\
Polish/finish (liter) & 0.10 & 0.009 & 0.017 & 0.002 \\
Water (liter) & 6.2 & 0.58 & 3.1 & 0.29 \\
\hline
\end{tabular}

\footnotetext{
${ }^{26}$ Energy input and solid waste quantity based on Tables 8 and 10 of Lu et al. (2008). This is modeled on an assumption that carpet and other floors have attracted similar quantities of dirt and dust.

${ }^{27}$ Based on Table 5 in Armstrong (2014b)

${ }^{28}$ No material or energy usage quantities were provided in the Armstrong EPD, so inputs were modeled using adjusted data from Table 2 in (RFCI, 2013a)
} 
Table 5-22 Vinyl Floor Covering Cleaning Processes and Frequency ${ }^{29}$

\begin{tabular}{lll}
\hline Cleaning Process & Frequency & \multicolumn{1}{c}{ Resources Used } \\
Damp mop / neutral cleaner & 1x per week & Hot water, neutral detergent \\
Deep cleaning (scrub) & 1x per month & Electricity, neutral detergent, water \\
Polish & 6x per year & Floor finish, electricity \\
\hline
\end{tabular}

Table 5-23 Vinyl Intermittent Cleaning Inputs per Year ${ }^{30}$

\begin{tabular}{lcccc}
\hline & \multicolumn{2}{c}{ Commercial } & \multicolumn{2}{c}{ Residential } \\
\hline Cleaning Input & ${\text { Per } \mathrm{m}^{2}}$ & ${\text { Per } \mathrm{ft}^{2}}$ & Per $^{2}$ & ${\text { Per } \mathrm{ft}^{2}}$ \\
Detergent (ml) & 119 & 11.1 & 59.5 & 5.5 \\
Electricity (kWh) & 0.022 & 0.002 & 0.002 & 0.0002 \\
Polish/finish (liter) & 0.12 & 0.011 & 0.010 & 0.001 \\
Water (liter) & 5.8 & 0.54 & 2.9 & 0.270 \\
\hline
\end{tabular}

\subsubsection{End of Life}

End of life modeling of the floor products and adhesive includes transportation of these materials by heavy-duty diesel-fuel powered truck approximately $48 \mathrm{~km}$ (30 mi) to a landfill. Truck transportation is based on the U.S. LCI database and disposal in a landfill is modeled based on ecoinvent end of life waste management process data. Eternal is considered inert and is modeled as inert material in a landfill.

Much of the linoleum product is sourced from biobased materials, so disposal includes data for both inert material in a landfill and disposal of biogenic material in a landfill. Mahalle (2011) and the EPA WARM describe the impacts from biogenic material in a landfill as being made up of $\mathrm{CH}_{4}$ from decomposition of biomass and $\mathrm{CO}_{2}$ emissions associated with flaring these emissions where landfill gas is not recovered for energy; and $\mathrm{CO}_{2}$ emissions avoided through landfill gas-to-energy projects. An assumed $23 \%$ of the wood decomposes, so storage of the remaining biogenic carbon is also accounted for (Section 5.1 in Mahalle (2011)). The data for net GHG emissions from landfill gas management practices comes from Table 31 in Mahalle (2011). For linoleum, this amounts to $0.379 \mathrm{~kg} \mathrm{CO} 2$ per $\mathrm{kg}$ linoleum and $0.017 \mathrm{~kg}$ methane per $\mathrm{kg}$ linoleum.

\subsection{Tandus Centiva Commercial Carpet}

The development of all Tandus Centiva commercial carpet included in BEES Online 2.0 use the same underlying data and methodology as described in this section.

\footnotetext{
${ }^{29}$ Based on Table 5 in Armstrong (2014b)

${ }^{30}$ No material or energy usage quantities were provided in the Armstrong EPD, so inputs were modeled using adjusted data from Table 2 in (RFCI, 2013a)
} 


\subsubsection{Product Description}

Based in Dalton, Georgia, Tandus Centiva, a Tarkett company, offers a unique line of Powerbond, Modular, Broadloom, Woven, and Luxury Vinyl Tile flooring products with a true fit-for-purpose approach to enhance spaces for learning, working, healing, and living. The six Tandus Centiva products listed in Table 5-24 are included in BEES.

\section{Table 5-24 Tandus Centiva Products Included in BEES}

\begin{tabular}{|c|c|c|}
\hline Products & $\begin{array}{c}\text { Mass per Applied Area } \\
\mathrm{kg} / \mathrm{m}^{2}\left(\mathrm{lb} / \mathrm{ft} \mathrm{t}^{2}\right)\end{array}$ & $\begin{array}{c}\text { Density in } \\
\mathrm{kg} / \mathrm{m}^{3}\left(\mathrm{lb} / \mathrm{ft} \mathrm{t}^{3}\right)\end{array}$ \\
\hline ER3 Modular & $4.4(0.91)$ & $567.0(35.0)$ \\
\hline ethos Modular & $3.3(0.68)$ & $550.8(34.0)$ \\
\hline Powerbond ethos Cushion & $3.1(0.63)$ & $396.9(24.5)$ \\
\hline Powerbond Cushion & $2.7(0.56)$ & $220.3(13.6)$ \\
\hline Flex-Aire Cushion Modular & $4.0(0.83)$ & 322.4 (19.9) \\
\hline Powerbond Medfloor & $2.8(0.58)$ & $223.6(13.8)$ \\
\hline
\end{tabular}

Tandus Centiva products in BEES are modeled using an average of $0.68 \mathrm{~kg} / \mathrm{m}^{2}$ $\left(20 \mathrm{oz} / \mathrm{yd}^{2}\right)$ yarn which represents Tandus Centiva's annual nylon 6 and nylon 6,6 (solution and yarn dyed) usage. Powerbond and the modular products are made available by Tandus Centiva as "carbon-free" or "climate neutral”; for an additional cost per square unit to the customer, the GHGs emitted over the carpets' life cycles can be optionally offset or balanced. ${ }^{31}$

\subsubsection{Flow Diagram}

The flow diagrams in Figure 5-6, Figure 5-7, and Figure 5-8 show the major elements of the production of these products as they are modeled for BEES.

\footnotetext{
31 This is done through the Carbonfund.org.
} 


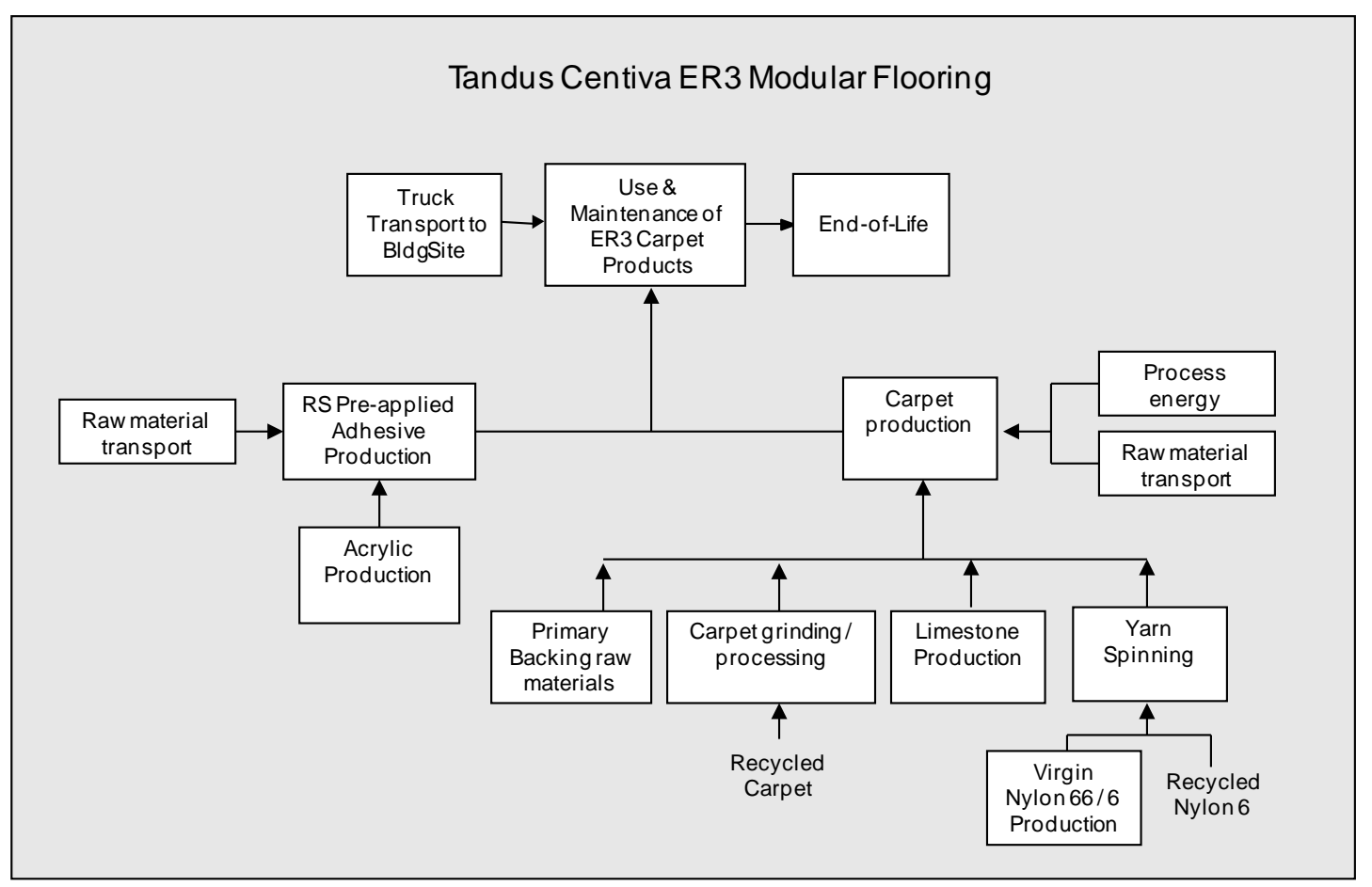

Figure 5-6 Tandus Centiva ER3 Modular RS Flooring System Boundaries

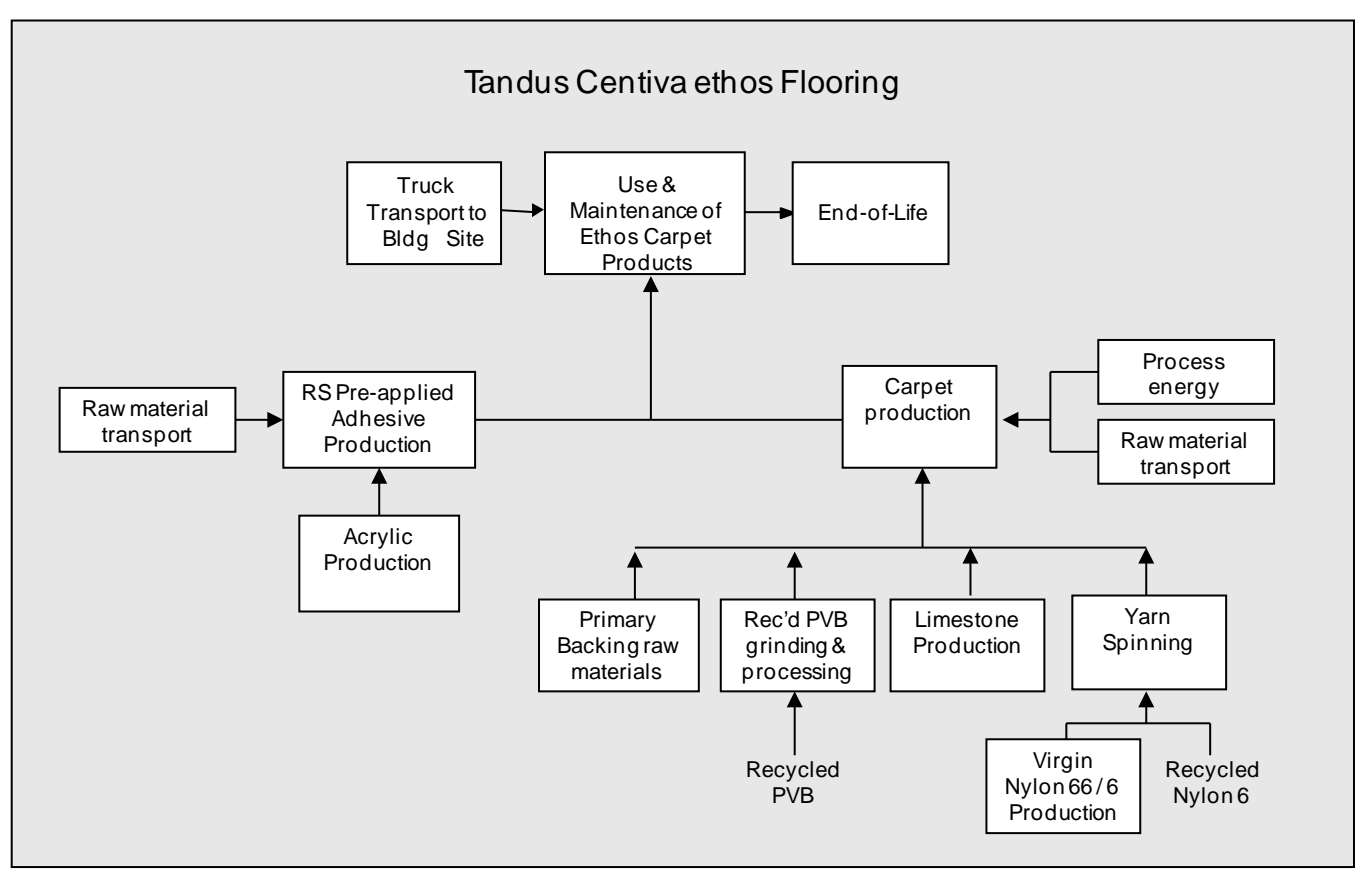

Figure 5-7 Tandus Centiva ethos Flooring System Boundaries 
Tandus Centiva Powerbond Cushion, Powerbond Medfloor \& Flex-Aire Cushion Modular

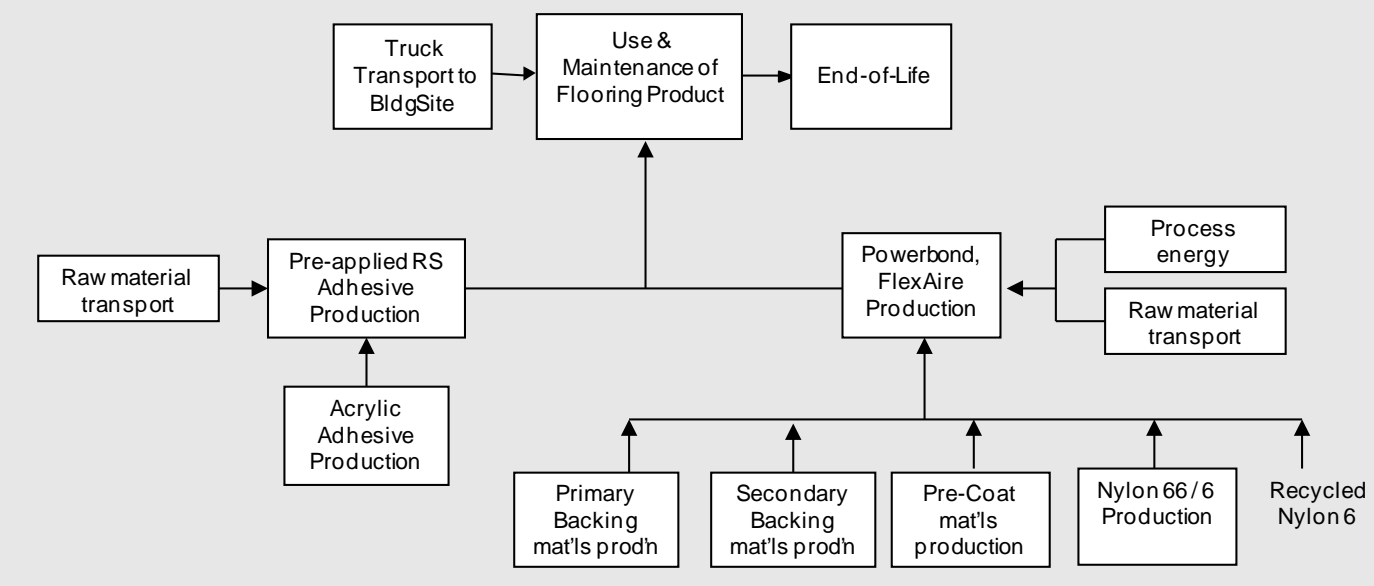

Figure 5-8 Tandus Centiva Powerbond Cushion RS, Powerbond Medfloor RS and Flex-Aire Cushion Modular RS System Boundaries

\subsubsection{Raw Materials}

Table 5-25 and Table 5-26 present the constituents by mass percentage of the Tandus Centiva products.

Table 5-25 Tandus Centiva Flooring Compositions

\begin{tabular}{lrrr}
\hline \multicolumn{1}{c}{ Mass Fraction } & & & \\
\hline Constituent & $\begin{array}{c}\text { ER3 } \\
\text { Modular } \\
\text { RS }\end{array}$ & $\begin{array}{c}\text { Ethos } \\
\text { Modular }\end{array}$ & $\begin{array}{c}\text { Powerbond } \\
\text { ethos } \\
\text { Cushion RS }\end{array}$ \\
\hline Nylon 6,6 Yarn & $8.1 \%$ & $10.9 \%$ & $10.6 \%$ \\
Nylon 6 Yarn & $6.3 \%$ & $8.5 \%$ & $9.9 \%$ \\
Pre-consumer nylon 6 & $0.7 \%$ & $1.0 \%$ & $1.0 \%$ \\
Primary backing & $2.5 \%$ & $3.3 \%$ & $3.6 \%$ \\
Recycled carpet, vinyl, and limestone (filler) & $63.6 \%$ & & \\
Recycled polyvinyl butyral (PVB)/Limestone (filler) & & $51.4 \%$ & $46.1 \%$ \\
Other Additives (precoat, RS adhesive, stabilization fabrics, etc.) & $18.8 \%$ & $24.9 \%$ & $28.8 \%$ \\
\hline Total: & $\mathbf{1 0 0 \%}$ & $\mathbf{1 0 0 \%}$ & $\mathbf{1 0 0} \%$ \\
\hline
\end{tabular}

Tandus Centiva products were modeled based on an average product style representative of the product line. Yarn for Tandus Centiva's products was modeled based on the company's annual usage of nylon 6 and nylon 6,6. The nylon 6 has an average of $10 \%$ pre-consumer content.

The primary backing used is a polyester nonwoven material typical of that utilized in commercial floor coverings. Data for polyester is a U.S. LCI Database data set for PET resin. The secondary backing for ER3 products is made from recycled pre- and post- 
consumer (PC) vinyl backed carpet. No production data are included for recycled vinyl backed carpet, except for data for the materials' transportation to the site and processing into backing. The secondary backing for ethos products is made from postconsumer polyvinyl butyral (PVB) film recovered from windshield and safety glass recycling facilities. The transportation and processing of the PVB are accounted for in the model. Data for the limestone and other additives come from ecoinvent.

Table 5-26 Tandus Centiva Powerbond Cushion RS, Flex-Aire Cushion Modular RS, and Powerbond Medfloor RS Composition

\begin{tabular}{lrrr}
\hline \multicolumn{4}{c}{ Mass Fraction } \\
\hline Constituent & $\begin{array}{c}\text { Powerbond } \\
\text { Cushion } \boldsymbol{R S}\end{array}$ & $\begin{array}{c}\text { Flex-Aire Cushion } \\
\text { Modular RS }\end{array}$ & $\begin{array}{c}\text { Powerbond } \\
\text { Medfloor RS }\end{array}$ \\
\hline Nylon 6,6 Yarn & $12.8 \%$ & $8.9 \%$ & $12.8 \%$ \\
Nylon 6 Yarn & $10.0 \%$ & $6.9 \%$ & $10.0 \%$ \\
Pre-consumer nylon 6 & $1.1 \%$ & $0.7 \%$ & $1.1 \%$ \\
Primary backing & $4.0 \%$ & $2.7 \%$ & $3.9 \%$ \\
Secondary backing & $43.8 \%$ & $60.8 \%$ & $44.6 \%$ \\
Other Additives (precoat, RS & $28.3 \%$ & $20.0 \%$ & $27.6 \%$ \\
adhesive, stabiliz. fabrics, etc.) & & & \\
\hline Total: & $\mathbf{1 0 0} \%$ & $\mathbf{1 0 0} \%$ & $\mathbf{1 0 0 \%}$ \\
\hline
\end{tabular}

Powerbond Cushion and Powerbond Medfloor are flooring products with a heterogeneous construction of nylon and closed cell cushion. The cushion and nylon are fused together with heat and pressure in the Powerbond process creating a floor covering that is integral and inseparable. Flex-Aire Cushion Modular is produced in the same manner except that an intermediate vinyl coating layer along with a nonwoven fiberglass sheet is applied between the precoat and secondary backing. Data for nylon 6,6 and nylon 6 are described above and the primary backing is a polyester nonwoven material. The data sources for these and other materials are described above. The secondary backing is a moisture-impermeable, closed cell vinyl cushion that enhances acoustical and thermal insulation properties as well as ergonomics. Data for vinyl is a polyvinyl chloride resin that comes from the U.S. LCI Database.

Transportation distances for shipment of the raw materials from the suppliers to the manufacturing plant are provided by Tandus Centiva. Most of the materials are transported exclusively by diesel truck, while some are transported by diesel truck and ocean freighter or rail and ocean freighter. All forms of transportation are included in the model, and all data are based on the U.S. LCI Database.

The modeled packaging components, as well as transportation distance and mode to Tandus Centiva's facility have been included in the BEES model. Modular flooring products are packaged in recycled content cardboard boxes, stacked on wooden pallets, and secured with stretch wrap. The roll products are placed on a recycled content cardboard core and secured in plastic. Tandus Centiva encourages installers to recycle packaging materials in local recycling programs. 


\subsubsection{Manufacturing}

The manufacturing process for Tandus Centiva's products consists of tufting the nylon yarn, applying the precoat compound, adhering the secondary backing, and applying Revolutionary System (RS) adhesive. The BEES products have been modeled using an overall facility average of electricity, natural gas used in ovens, and water usage (which includes water for yarn dyeing). These amounts are $9.7 \mathrm{MJ} / \mathrm{m}^{2}\left(2.25 \mathrm{kWh} / \mathrm{yd}^{2}\right)$ of electricity, $16.22 \mathrm{MJ} / \mathrm{m}^{2}\left(0.129 \mathrm{therm} / \mathrm{yd}^{2}\right)$ of natural gas, and $13.6 \mathrm{~L} / \mathrm{m}^{2}\left(3.0 \mathrm{gal} / \mathrm{yd}^{2}\right)$ of water. Although some carbon offsets and Renewable Energy Credits (RECs) are purchased annually, these flows were not considered in the model. The data for the production and use of energy comes from the U.S. LCI Database.

Waste to landfill accounts for $0.020 \mathrm{~kg} / \mathrm{m}^{2}\left(0.036 \mathrm{lb} / \mathrm{yd}^{2}\right)$. Product-specific waste generated during manufacturing is recycled back into new carpet products as part of Tandus Centiva's in-house third party certified recycling process. Transportation to the landfill by diesel truck is accounted for.

\subsubsection{Transportation}

The distance for transport by diesel truck from the Tandus Centiva manufacturing plant in Dalton, Georgia to installation is modeled based on the weighted average transportation distance for Tandus Centiva's North American customers: 1966 km (1222 mi). Transportation emissions allocated to each product depend on the overall mass, as given in Table 5-25 and Table 5-26.

\subsubsection{Installation}

Most Tandus Centiva products are produced with RS pre-applied adhesive, which provides a "peel and stick" installation system. It eliminates the need for wet adhesive, simplifies installation, and reduces VOC emissions and odors. According to Tandus Centiva, $2 \%$ waste is generated during installation of modular and Powerbond products. This waste percentage was incorporated into the production and manufacturing aspects of the model. Scraps are typically kept at the building site for future repairs. While much of the packaging waste at installation can be recycled, it is modeled as transported $48 \mathrm{~km}$ (30 mi) by diesel truck and disposed of in a landfill.

\subsubsection{Use and Maintenance}

Tandus Centiva's Powerbond products are assumed to be replaced after 25 years, and modular products at 15-year intervals. Replacement, including producing raw materials, manufacturing, transport to installation, installation, etc., is included to account for the BEES flooring category's operating lifetime of 60 years.

BEES includes cleaning and maintenance of the floor covering products during their useful lifetime. Because of maintenance programs developed by individual building owners and different manufacturers' maintenance recommendations, there is no single maintenance regimen that is always followed. For example, frequency of deep cleaning 
and types and quantities of cleaning solutions will depend on the maintenance programs at the buildings. For BEES, cleaning and maintenance is modeled of the floor products based on industry-wide specifications or recommendations obtained from published EPDs; industry- or manufacturer-specific maintenance guides published on-line; or in some instances, general internet research on best maintenance practices.

Cleaning and maintenance in BEES is divided into two parts. The first, regular vacuuming of dirt and dust is a variable in BEES. The BEES user chooses the vacuuming frequency per week. The second part of cleaning is characterized as intermittent deeper cleaning - for carpets, this activity is extraction cleaning. Deep-cleaning is a non-variable in BEES, although as acknowledged above, frequency may vary from building to building.

The carpet cleaning data are based on recommendations in the Carpet and Rug Institute (CRI) Carpet Maintenance Guidelines for Commercial Applications for regular vacuuming and intermittent extraction cleaning (CRI, 2014). For BEES, the number of vacuum cleaning events per week is chosen by the user; the default number for commercial carpets is four times per week, averaging out the vacuuming needs of different traffic volumes. (CRI (2014), p.18/30) Commercial carpet is modeled as deep cleaned two times per year. Specific input and output data for vacuuming and deep cleaning come from a carpet cleaning and maintenance report prepared by the Consortium on Competitiveness for the Apparel, Carpet, and Textile Industries (CCACTI) through the Carpet and Rug Institute, Academic Institutions and funded by the State of Georgia (Lu et al., 2008).

Table 5-27 through Table 5-29 provide the energy and other inputs and outputs used for carpet care.

\section{Table 5-27 Energy per Cleaning Event ${ }^{32}$}

\begin{tabular}{lcc}
\hline Electrical energy & ${\text { MJ per } \boldsymbol{y d}^{2}}^{2}$ & $\boldsymbol{k W h}$ per $\boldsymbol{f t}^{2}$ \\
Vacuum & 0.012 & $3.70 \mathrm{E}-04$ \\
Agitator (deep clean) & 0.009 & $2.78 \mathrm{E}-04$ \\
Heat for 120F hot water (deep clean) & 0.144 & $4.44 \mathrm{E}-03$ \\
Extractor (deep clean) & 0.023 & $7.10 \mathrm{E}-04$ \\
Fan drying (deep clean) & 0.087 & $2.69 \mathrm{E}-03$ \\
\hline
\end{tabular}

\section{Table 5-28 Inputs per Cleaning Event ${ }^{33}$}

\begin{tabular}{lcc}
\hline Input & $\boldsymbol{k g}$ per $\boldsymbol{y d}^{\mathbf{2}}$ & $\boldsymbol{l b}$ per $\boldsymbol{f t}^{\mathbf{2}}$ \\
Water & 0.034 & $8.33 \mathrm{E}-03$ \\
Detergent & 0.0012 & $2.94 \mathrm{E}-04$ \\
Hot water & 1.44 & 0.353 \\
\hline
\end{tabular}

32 Based on Table 8 in Lu et al. (2008).
33 Based on Table 6 in Lu et al. (2008) 
Table 5-29 Outputs per Cleaning Event ${ }^{34}$

\begin{tabular}{lcc}
\hline Output & $\boldsymbol{k g}$ per $\boldsymbol{y d}^{2}$ & $\boldsymbol{I b ~ p e r ~ f t ~}^{\mathbf{2}}$ \\
Solid waste from the vacuum & 0.0064 & $1.57 \mathrm{E}-03$ \\
Water output after extraction & 1.44 & 0.353 \\
Detergent effluents & 0.00085 & $2.08 \mathrm{E}-04$ \\
Solid waste from extraction & 0.012 & $2.94 \mathrm{E}-03$ \\
\hline
\end{tabular}

\subsubsection{End of Life}

Tandus Centiva products are 100 \% recyclable in Tandus Centiva's in-house closed-loop recycling process. Tandus Centiva annually recycles over 10 million pounds of postconsumer carpet, a rate of $12.8 \%$. Carpet that is not recycled is modeled as disposed of in a landfill. A diesel-powered truck is modeled as transporting the product $48 \mathrm{~km}$ (30 mi) to its destination. The recycled percentage of Tandus Centiva products are accounted for as being diverted from the landfill, but no other credits in the BEES system boundaries are given to the recycled products.

\subsection{Average Ceramic Tile}

The development of the industry average ceramic tile included in BEES Online 2.0 uses the underlying data and methodology as described in this section.

\subsubsection{Product Description}

Ceramic tile produced in North America is described in a 2014 industry-average EPD as a mixture of multiple mineral-based natural materials including clay, sand, feldspar, talc, nepheline, and shale. The tiles are either pressed or extruded into the desired shape and fired in kilns at high temperatures. Ceramic tile is fire resistant, non-combustible, durable, and easy to maintain.

The ceramic tile covered in the $2014 \mathrm{EPD}$ comprises tile sizes between $12.7 \mathrm{~mm} \mathrm{x}$ $12.7 \mathrm{~mm}$ ( 0.5 in x 0.5 in) and $609.6 \mathrm{~mm}$ x $609.6 \mathrm{~mm}$ (24 in x 24 in), and thicknesses between $7.3 \mathrm{~mm}(0.29 \mathrm{in})$ and $11 \mathrm{~mm}(0.43 \mathrm{in})$. Tile weight ranges from $17.0 \mathrm{~kg} / \mathrm{m}^{2}$ (3.48 lb/ft $\left.{ }^{2}\right)$ to $34.2 \mathrm{~kg} / \mathrm{m}^{2}\left(7.0 \mathrm{lb} / \mathrm{ft}^{2}\right)$; the industry average weight used in the EPD - and thus for BEES - is $18.1 \mathrm{~kg} / \mathrm{m}^{2}\left(3.7 \mathrm{lb} / \mathrm{ft}^{2}\right)$. The functional unit used for BEES is a flooring covering of $0.093 \mathrm{~m}^{2}\left(1 \mathrm{ft}^{2}\right)$ used over the building's operating lifetime of 60 years. Data for BEES were furnished by the Tile Council of North America, Inc. (TCNA) and are based on the LCA performed by TCNA and its member companies, whose results were used in the ceramic tile EPD. Ceramic tile for BEES is applicable to the commercial and residential markets.

\footnotetext{
${ }^{34}$ Based on Table 10 in Lu et al. (2008)
} 


\subsubsection{Flow Diagram}

The flow diagram in Figure 5-9 shows the major elements of the production of this product, as it is currently modeled for BEES.

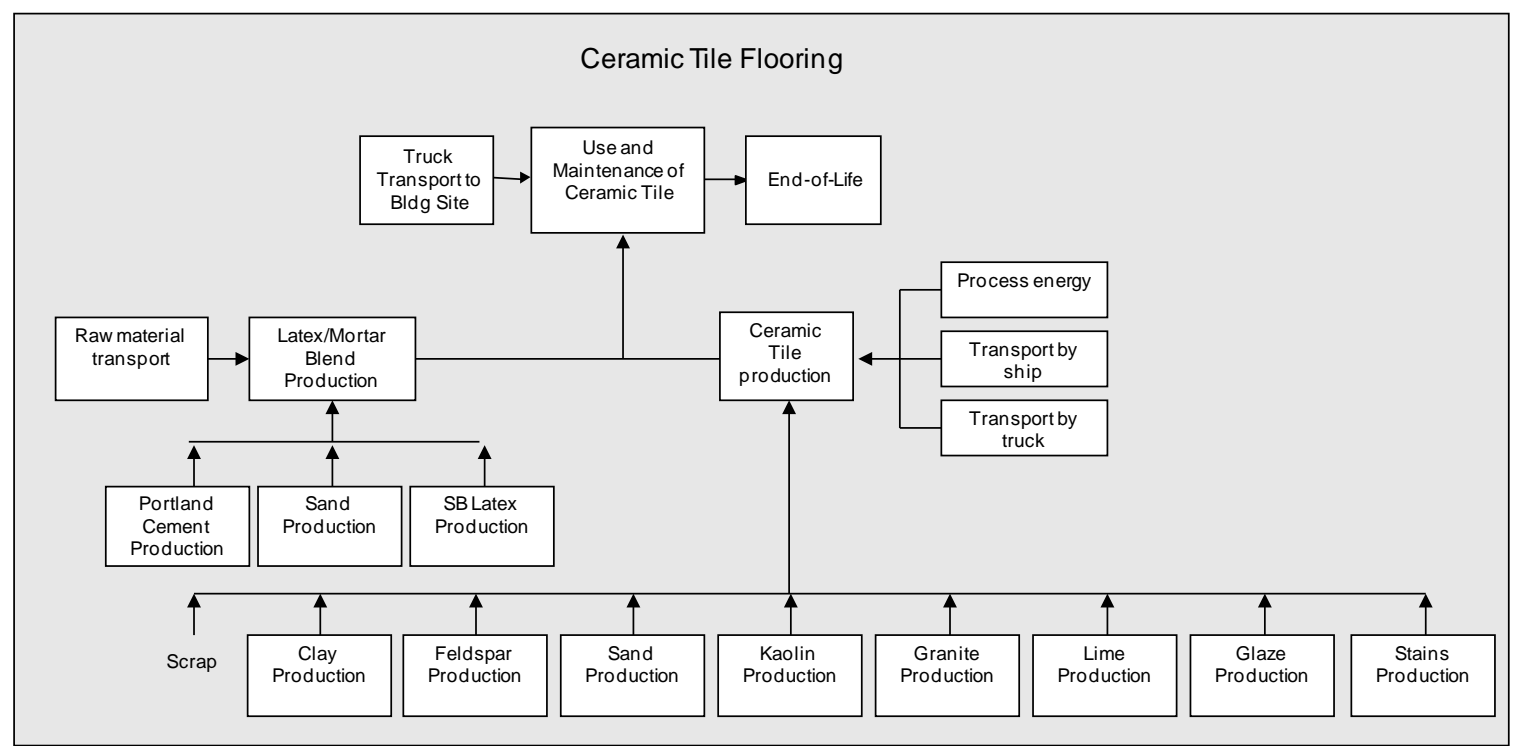

Figure 5-9 Ceramic Tile System Boundaries

\subsubsection{Raw Materials}

The material content of the ceramic tile floor is provided in Table 5-30.

Table 5-30 Ceramic Tile Composition ${ }^{35}$

\begin{tabular}{lccc}
\hline \multicolumn{1}{c}{ Constituent } & $\begin{array}{c}\text { Mass } \\
\text { Fraction (\%) }\end{array}$ & $\begin{array}{c}\text { Mass } \\
\left(\mathbf{k g} / \mathbf{m}^{\mathbf{2}}\right)\end{array}$ & $\begin{array}{c}\text { Mass } \\
\left(\mathbf{l b} / \mathbf{f t}^{2}\right)\end{array}$ \\
\hline Body: & & & \\
Clay & 70.3 & 12.72 & 2.61 \\
Feldspar & 5.3 & 0.96 & 0.20 \\
Sand & 4.8 & 0.87 & 0.18 \\
Scrap (pre, post-consumer) & 4.2 & 0.76 & 0.16 \\
Kaolin & 3.2 & 0.58 & 0.12 \\
Granite & 1.3 & 0.24 & 0.05 \\
Lime & 1.1 & 0.20 & 0.04 \\
Other additives & 4.0 & 0.72 & 0.15 \\
Surface: & & & \\
Glaze \& stain (mineral-based) & 5.4 & 0.98 & 0.20 \\
\hline Total & $\mathbf{1 0 0}$ & $\mathbf{1 8 . 1}$ & 3.7 \\
\hline
\end{tabular}

The origin of the materials is designated as coming from the U.S., Mexico, and/or Europe. The ecoinvent database provided data for the specified materials in Table 5-30, except the scrap. For granite, ecoinvent's basalt quarrying was used as a proxy. The PC

35 Table 2 in TCNA (2014) 
scrap does not have upstream inputs except the transportation of material to manufacturing; it is assumed that processing of the scrap is included in the manufacturing energy.

It should be noted that the non-specified additives and glazes and stains in Table 5-30 were included in the inventory modeling but are not provided in this documentation, consistent with the level of detail released in the EPD. Production of these inventories comes mainly from ecoinvent and U.S. LCI databases.

Ceramic tile manufacturers are located throughout North America. Much of the product weight is made up of materials typically located near manufacturing sites. Except for some of the European-sourced inputs which are shipped by ocean freighter, the raw materials used in the manufacture of the tile are assumed to be transported to the production facility via diesel truck within $805 \mathrm{~km}$ (500 mi). Transportation of the installation materials to the end user is assumed to be $241 \mathrm{~km}(150 \mathrm{mi})$ via diesel truck.

Ceramic tile flooring is packaged primarily in cardboard boxes, placed on pallets, and wrapped in plastic film. Packaging materials and their transportation to ceramic tile facilities have been included in the BEES model.

\subsubsection{Manufacturing}

Page 10 of the ceramic tile EPD (2014) describes manufacturing as follows: "Tile body ingredients are combined with water, mixed, and milled into the desired consistency. The resulting slurry is then spray dried to achieve the optimal moisture content. The milled and dried ingredient, called 'body material' or 'prill', is then pressed to the desired shape. Glaze is applied, as well as decorative treatment, and fired in a high temperature kiln.”

Detailed data on the energy requirements (including electricity, natural gas, diesel fuel, and propane); water use; air emissions; wastewater; and waste generated during production of ceramic tiles were provided to Four Elements, and these data were included in the model. These data are not provided in this documentation, consistent with the level of detail released in the 2014 EPD. Data for the energy sources come from the U.S. LCI database.

Most manufacturers' products' scrap and waste are reincorporated into tile manufacturing; this waste reclamation minimizes waste and maximizes resources. For the EPD and BEES, between $0 \mathrm{~kg} / \mathrm{m}^{2}\left(0 \mathrm{lb} / \mathrm{ft}^{2}\right)$ and $1 \mathrm{~kg} / \mathrm{m}^{2}\left(0.2 \mathrm{lb} / \mathrm{ft}^{2}\right)$ of waste per of tile is generated as waste during production. This waste is modeled as transported and disposed of as inert waste in a landfill.

\subsubsection{Transportation}

Transportation of ceramic tile by heavy-duty truck to the building site is modeled as 805 km (500 mi). 


\subsubsection{Installation}

Mortar in the amount of $4.1 \mathrm{~kg} / \mathrm{m}^{2}\left(0.833 \mathrm{lb} / \mathrm{ft}^{2}\right)$ and sanded grout in the amount of $0.21 \mathrm{~kg} / \mathrm{m}^{2}\left(0.043 \mathrm{lb} / \mathrm{ft}^{2}\right)$ are needed to install ceramic tile. ${ }^{36}$ The mortar is modeled as a latex/mortar blend; its constituents are provided in Table 5-31.

\section{Table 5-31 Latex/Mortar Blend Composition}

\begin{tabular}{lc}
\hline \multicolumn{1}{c}{ Constituent } & Mass Fraction \\
\hline Mortar & $\mathbf{7 0} \%$ \\
Portland Cement & $17 \%$ \\
Sand & $83 \%$ \\
Styrene-Butadiene Latex & $\mathbf{3 0} \%$ \\
\hline
\end{tabular}

The sanded grout is modeled as a mixture of Portland cement and sand with smaller amounts of titanium dioxide as pigment and other additives. The installation materials were modeled using ecoinvent and U.S. LCI database data. Installation of tile and mortar is assumed to be a manual process, so there are no emissions or energy inputs.

The scrap generated during installation is estimated to be $4.5 \%$ of the total flooring material. While the ceramic material could be recycled, it is modeled as transported 48 $\mathrm{km}$ (30 mi) by diesel truck and disposed of in a landfill. Packaging waste is also modeled as disposed of in a landfill, although it is acknowledged that it could be recycled.

\subsubsection{Use and Maintenance}

A 60-year service life is given to the ceramic tile flooring as it is expected to last at least as long as the building itself.

BEES includes cleaning and maintenance of products during their useful lifetime. Because of differing building maintenance recommendations, there is no single maintenance regimen that is followed. Cleaning equipment used to maintain floors will depend on the maintenance system selected by the building owner, often based on the desired overall appearance. For all flooring products in BEES, cleaning and maintenance is modeled based on industry-wide specifications or recommendations obtained from published EPDs; industry- or manufacturer-specific maintenance guides published on-line; or in some instances, general internet research on best maintenance practices.

Cleaning and maintenance in BEES is divided into two parts. The first, regular cleaning of dirt and dust (i.e., by way of vacuuming (electrical requirements) or sweeping / dust mopping (non-electrical)) is a variable in BEES. The BEES user chooses the method of regular cleaning along with the frequency per week. The default number for commercial applications is set at four, averaging out the cleaning needs of different volumes of traffic. For residential use, the default is set to one time per week. The second part of cleaning is characterized as intermittent deeper cleaning and other maintenance where

${ }^{36}$ Ceramic Tile EPD. 
applicable, and this cleaning regimen is a non-variable in BEES, although as acknowledged above, it may vary from building to building. For commercial applications, a damp mop is used to clean the floor one time per week, and this amounts to $1.13 \mathrm{~L} / \mathrm{m}^{2}\left(0.03 \mathrm{gal} / \mathrm{ft}^{2}\right)$ per year. For residential applications, a damp mop is used to clean the floor one time every two weeks, amounting to 0.57 liters $/ \mathrm{m}^{2}\left(0.014 \mathrm{gal} / \mathrm{ft}^{2}\right)$ per year. ${ }^{37}$

\subsubsection{End of Life}

Ceramic tile is modeled as landfilled at end of life. End of life modeling includes transportation of the ceramic tile flooring and the installation material by heavy-duty diesel-fuel powered truck approximately $48 \mathrm{~km}$ (30 mi) to a landfill, plus impacts of a landfill. Truck transportation is based on the U.S. LCI database and disposal in a landfill is modeled based on ecoinvent end of life waste management process data.

\subsection{Average Vinyl Composition Tile (VCT)}

The development of the industry average vinyl composition tile included in BEES Online 2.0 uses the underlying data and methodology as described in this section.

\subsubsection{Product Description}

VCT is a resilient floor covering made primarily from calcium carbonate (limestone) with smaller amounts of polyvinyl chloride, plasticizers, and additives (i.e., pigments and stabilizers). VCT is one of the most widely used resilient flooring materials in commercial interiors with a smaller amount being used residentially. Because of its low cost and wide variety of visuals available, VCT is recognized for its cost-effective performance, durability, and quality. Data for BEES were furnished by the Resilient Floor Covering Institute (RFCI) and are based on the LCA performed by RFCI and its member companies, whose results were used in the North American industry-average VCT EPD (RFCI, 2013a). Industry-average tile thickness ranged from $2.4 \mathrm{~mm}$ to $3.2 \mathrm{~mm}$ (0.094 in to $0.126 \mathrm{in})$. The industry-average product weight, $6.79 \mathrm{~kg} / \mathrm{m}^{2}\left(1.39 \mathrm{lb} / \mathrm{ft}^{2}\right)$, that corresponds with the weighted average thickness is used for BEES (RFCI, 2013a). The functional unit used in BEES for VCT of $0.093 \mathrm{~m}^{2}\left(1 \mathrm{ft}^{2}\right)$ used over the building's operating lifetime of 60 years. This product in the BEES model is applicable to the commercial market.

\subsubsection{Flow Diagram}

The flow diagram in Figure 5-10 shows the major elements of the production of this product, as it is currently modeled for BEES.

\footnotetext{
${ }^{37}$ Based partially on information from Table 3 in TCNA (2014) of the Ceramic Tile EPD
} 


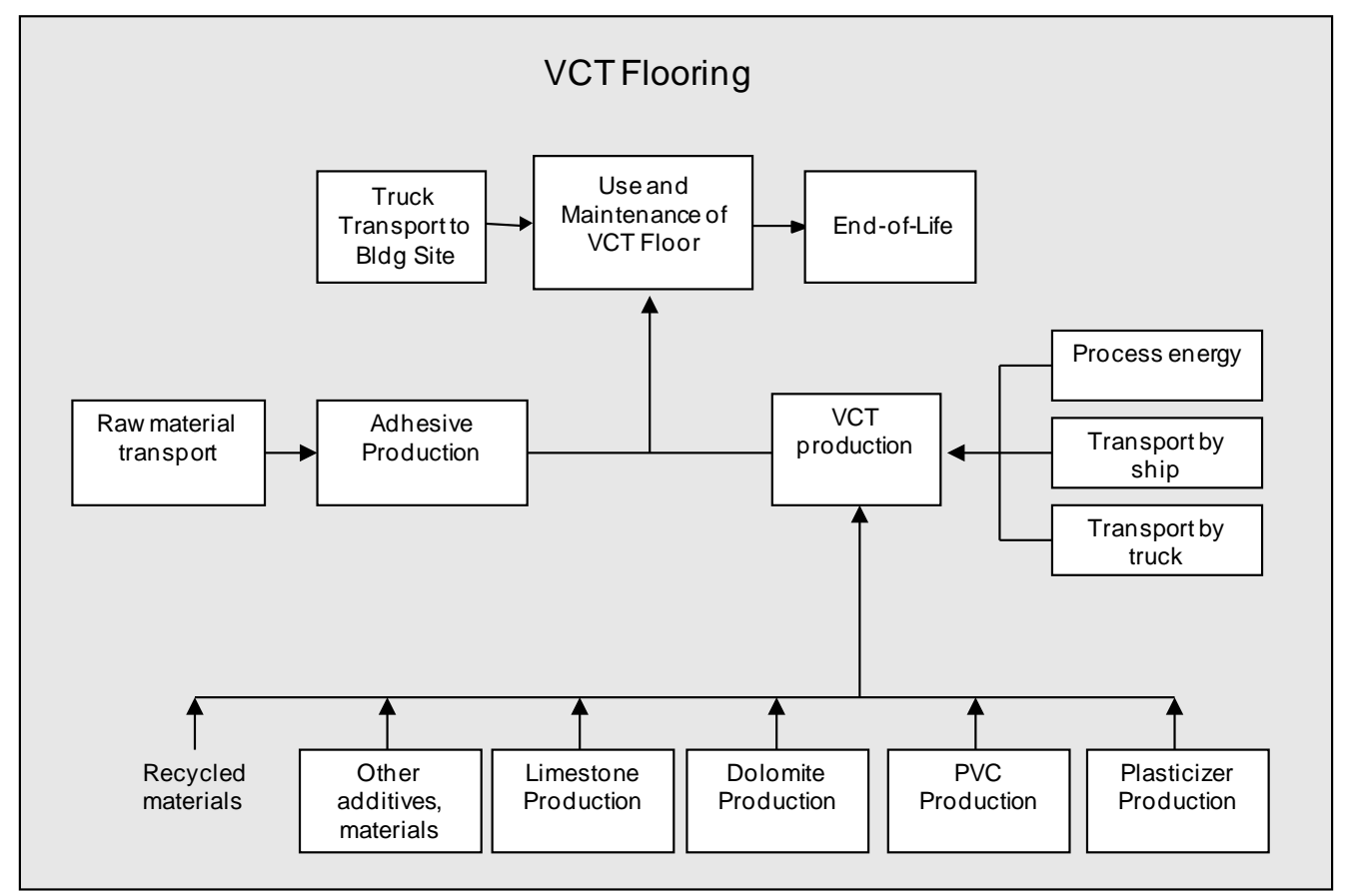

Figure 5-10 Vinyl Composition Tile System Boundaries

\subsubsection{Raw Materials}

The material content of the VCT floor is provided in Table 5-32 (Page 4 in RFCI (2013a)).

\section{Table 5-32 Vinyl Composition Tile Composition ${ }^{38}$}

\begin{tabular}{lccc}
\hline \multicolumn{1}{c}{ Constituent } & $\begin{array}{c}\text { Mass } \\
\text { Fraction } \mathbf{( \% )}\end{array}$ & $\begin{array}{c}\text { Mass } \\
\left(\mathbf{k g} / \mathbf{m}^{2}\right)\end{array}$ & $\begin{array}{c}\text { Mass } \\
\left(\mathbf{l b} / \mathbf{f t}^{2}\right)\end{array}$ \\
\hline Fillers: limestone \& dolomite (fillers) & 84.1 & 5.71 & 1.17 \\
Resin: polyvinyl chloride & 11.3 & 0.77 & 0.16 \\
Plasticizer: DOTP & 3.5 & 0.24 & 0.05 \\
Additives: various & 0.8 & 0.05 & 0.01 \\
Other components: various & 0.3 & 0.02 & 0.00 \\
\hline Total & $\mathbf{1 0 0}$ & $\mathbf{6 . 7 9}$ & $\mathbf{1 . 3 9}$ \\
\hline
\end{tabular}

The U.S. LCI database provided data for the polyvinyl chloride resin. The limestone and dolomite data were provided by ecoinvent. The DOTP data are a confidential data set based on one U.S. manufacturer's late 2010's primary data. It is representative technology. Additives include pigments and stabilizers. Other components include the finish coat applied to the tile at manufacture. Internal recycling is quite common; most scrap and rejected materials are reused in the manufacturing process for VCT and ends up in the finished product. The EPD reports that on average, recycled materials make up $6.9 \%$ of this product and are a combination of one or more ingredients including binder,

${ }^{38}$ Table 2 in TCNA (2014) 
fillers, plasticizer, and additives. It should be noted that the non-specified additives and other materials in Table 5-32, as well as recycled materials, were included in the inventory modeling but are not provided in this documentation, consistent with the level of detail released in the EPD. Production of these inventories is based mainly on the ecoinvent database and some U.S. LCI data.

VCT producers are located throughout the country. The bulk of the product weight is limestone, a readily-available and plentiful filler typically located near manufacturing sites. The raw materials used in the manufacture of the tile are all assumed to be transported to the production facility via diesel truck within $805 \mathrm{~km}$ (500 mi). Transportation distance of adhesive to the end user is assumed to be $241 \mathrm{~km}$ (150 mi) via diesel truck.

Packaging materials and their transportation to VCT manufacturing facilities have been included in the BEES model. VCT flooring is packaged in cardboard boxes, stacked on wooden pallets, and secured with stretch wrap.

\subsubsection{Manufacturing}

VCT is produced in several stages beginning with the mixing of the raw materials including limestone, polyvinyl chloride, plasticizer, stabilizers, and pigments. Once thoroughly mixed, the material is fed into a mill and formed into a sheet. The sheet is then punched into tiles, cooled, and finally packaged in cartons. Detailed data on the energy requirements (electricity and natural gas), water use, air emissions, and waste generated during production of VCT were provided to Four Elements, and these data were included in the model. These data are not provided in this documentation, consistent with the level of detail released in the EPD. Data for electricity and natural gas come from the U.S. LCI database.

$1.5 \%$ by weight of the VCT materials is generated as waste during production. This waste is usually comprised of granulated VCT and VCT dust, and modeling for this waste includes transportation to and disposal in a landfill.

\subsubsection{Transportation}

Transportation distance of VCT by heavy-duty truck to the building site is modeled as 805 km (500 mi).

\subsubsection{Installation}

At installation, a layer of a water-based styrene-butadiene adhesive is applied in the amount of $0.3 \mathrm{~kg} / \mathrm{m}^{2}\left(0.06 \mathrm{lb} / \mathrm{ft}^{2}\right)$ (RFCI, 2013a). Installation is primarily a manual process, so no energy use is modeled for the installation phase. Ecoinvent datasets were used to build the adhesive.

Water-based adhesive formulations today are used far more often than conventional solvent-based adhesives which are known to emit higher levels of VOCs. Because of the 
broad selection of adhesives on the market and, thus, varying levels of VOCs that could be emitted after installation, the VOC emissions limits for sealants and adhesives, set out in Table 1 in SCAQMD (2011), have been used for the baseline tile adhesive used in BEES, or $50 \mathrm{~g} / \mathrm{l}(0.4 \mathrm{lb} / \mathrm{gal})$. A "low-VOC" alternative is also offered for the BEES user; here, the adhesive is modeled as having a negligible VOC content. The adhesive offgassing is included for each installation.

Installation scrap varies depending on the job size. It is estimated that, on average, the scrap generated during installation is $4.5 \%$ of installed product (RFCI, 2013a).

Installation waste is modeled as being transported $48 \mathrm{~km}$ (30 mi) by diesel truck and disposed of in a landfill. While some of the packaging waste at installation can be recycled, it is modeled as disposed of in a landfill.

\subsubsection{Use and Maintenance}

The service life of VCT will vary depending on the amount of floor traffic and the type and frequency of maintenance. The level of maintenance is also dependent on the actual use and desired appearance of the floor. For BEES, consistent with the VCT EPD, a lifetime of 25 years has been modeled. Replacement, including production of raw materials, manufacturing, transport to installation, etc., is included to account for the BEES flooring category's operating lifetime of 60 years.

BEES includes cleaning and maintenance of products during their useful lifetime. Because of differing manufacturers' maintenance recommendations, there is no single maintenance regimen that is followed. Cleaning equipment used to maintain floors will depend on the maintenance system selected by the building owner, often based on the desired overall appearance. Frequency of deep cleaning and refinishing or polishing, and types and quantities of these compounds will also depend on the maintenance programs developed by individual building owners. For BEES, cleaning and maintenance is modeled based on industry-wide specifications or recommendations obtained from published EPDs; industry- or manufacturer-specific maintenance guides published online; or in some instances, general internet research on best maintenance practices.

Cleaning and maintenance in BEES is divided into two parts. The first, regular cleaning of dirt and dust (i.e., by way of vacuuming (electrical requirements) or sweeping / dry mopping (non-electrical)) is a variable in BEES. The BEES user chooses the method of regular cleaning along with the frequency per week. The default number for commercial applications is set at four, averaging out the cleaning needs of different volumes of traffic. Inputs and outputs per cleaning event of regular maintenance are shown Table 5-33. 
Table 5-33 Inputs and Outputs per Regular Cleaning Event ${ }^{39}$

\begin{tabular}{|c|c|c|}
\hline Vacuum choice & Per $\mathrm{m}^{2}$ & Per $\mathrm{ft}^{2}$ \\
\hline Electricity & $0.014 \mathrm{MJ}$ & $3.70 \mathrm{E}-04 \mathrm{kWh}$ \\
\hline Solid waste & $0.0077 \mathrm{~kg}$ & $0.0016 \mathrm{lb}$ \\
\hline $\begin{array}{l}\text { Sweep / dry mop choice } \\
\text { Solid waste }\end{array}$ & $\begin{array}{c}\text { Per m² } \\
0.0077 \mathrm{~kg}\end{array}$ & $\begin{array}{c}P e r \mathrm{ft}^{2} \\
0.0016 \mathrm{lb}\end{array}$ \\
\hline
\end{tabular}

The solid waste is modeled as being transported by diesel truck and disposed of in a landfill. The second part of cleaning is characterized as intermittent deeper cleaning and other maintenance, and this activity is a non-variable in BEES, although as acknowledged above, it may vary from building to building. Table 5-34 and Table 5-35 present the intermittent cleaning and maintenance schedule for VCT flooring and cleaning inputs, respectively (Table 1 in RFCI (2013a)).

\section{Table 5-34 Cleaning Processes and Frequency}

\begin{tabular}{lcc}
\hline Cleaning Process & Frequency & Resources Used \\
Damp mop / neutral cleaner & 1x per week & Hot water, neutral detergent \\
Spray buff / finish restorer & 1x per month & Floor finish, electricity \\
Strip and 2 coats finish & 1x per year & Finish remover, floor finish, electricity \\
\hline
\end{tabular}

Table 5-35 VCT Intermittent Cleaning Inputs per Year ${ }^{40}$

\begin{tabular}{lcc}
\hline Cleaning Input & Per $^{2}$ & ${\text { Per } \mathrm{ft}^{2}}$ \\
Detergent (ml) & 124 & 11.5 \\
Electricity (kWh) & 0.025 & 0.002 \\
Finish (liter) & 0.22 & 0.02 \\
Finish remover (liter) & 0.041 & 0.004 \\
Water (liter) & 6.2 & 0.58 \\
\hline
\end{tabular}

\subsubsection{End of Life}

While VCT can be recycled, it is modeled as landfilled at end of life. End of life modeling includes transportation of the VCT and adhesive by heavy-duty diesel-fuel powered truck approximately $48 \mathrm{~km}$ (30 mi) to a landfill, plus impacts of the materials in a landfill. Truck transportation is based on the U.S. LCI database and disposal in a landfill is modeled based on ecoinvent end of life waste management process data.

\footnotetext{
${ }^{39}$ Energy input and solid waste quantity based on Tables 8 and 10 of Lu et al. (2008). This is modeled on an assumption that carpet and other floors have attracted similar quantities of dirt and dust.

${ }^{40}$ Table 2 in (RFCI, 2013a)
} 


\subsection{Cork Flooring}

The development of the cork flooring included in BEES Online 2.0 uses the underlying data and methodology as described in this section.

\subsubsection{Product Description}

For the BEES analysis, cork floating floor plank has been included. The functional unit for this BEES category is floor covering of $0.09 \mathrm{~m}^{2}\left(1 \mathrm{ft}^{2}\right)$ used over the building's operating lifetime of 60 years. The mass of the product in BEES is $8.0 \mathrm{~kg} / \mathrm{m}^{2}\left(1.64 \mathrm{lb} / \mathrm{ft}^{2}\right)$ (Amorim EPD, 2013). Most cork flooring is manufactured in Europe, but some is manufactured in the U.S. This product can be used in both residential and commercial applications.

\subsubsection{Flow Diagram}

The flow diagram in Figure 5-11 shows the major elements of the production of this product as it is modeled for BEES.

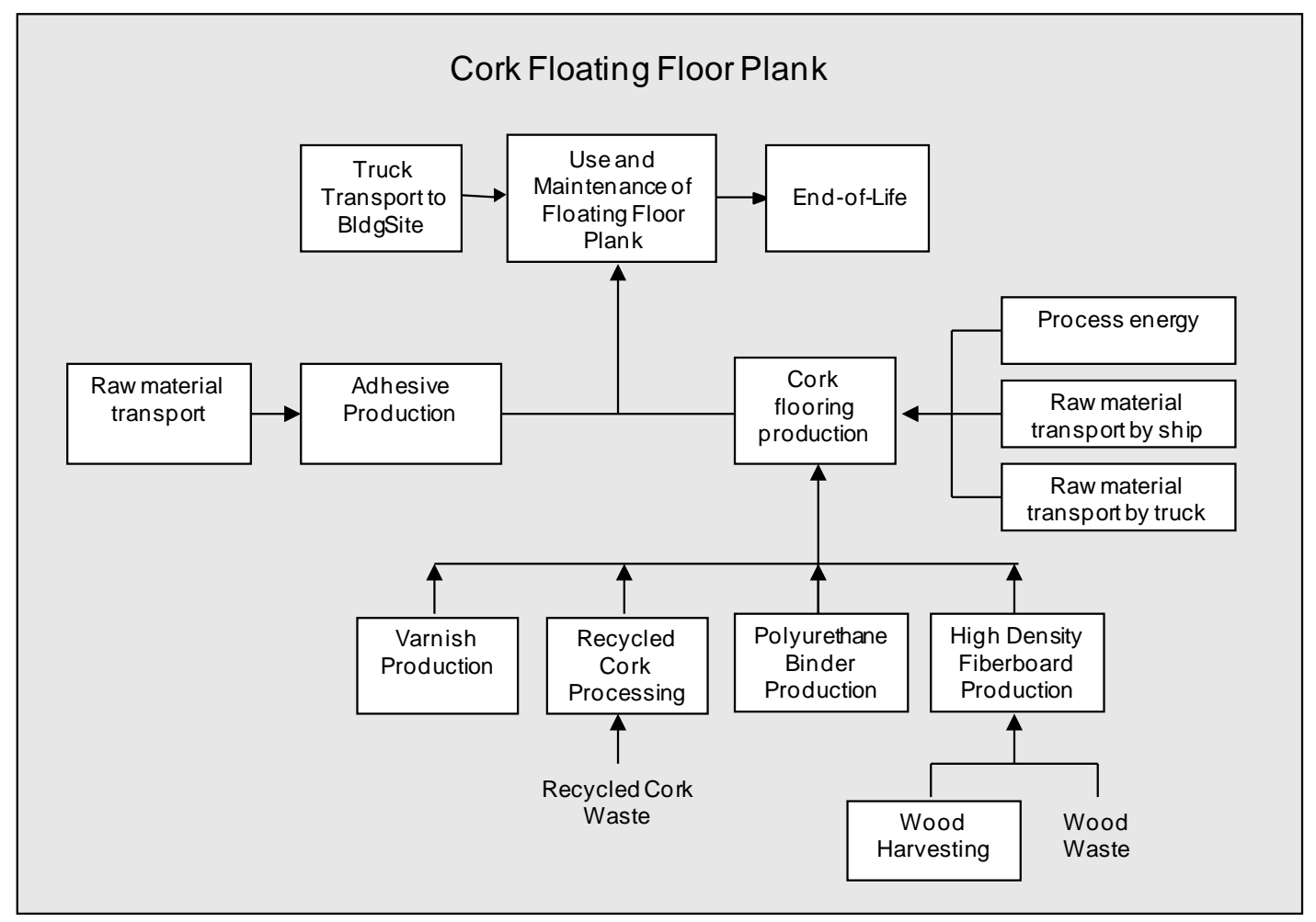

Figure 5-11 Cork Floating Plank Floor System Boundaries

\subsubsection{Raw Materials}

Floating floor plank is made up of two layers of cork veneer, which is made from a combination of recycled cork waste and urethane binder, with a layer of High Density Fiberboard (HDF) sandwiched in between. The cork veneer has a varnish coating. Data 
for the bill of materials is based on the materials listed in Sec. 2.6 of the Amorim EPD (2013), which is shown in Table 5-36.

\section{Table 5-36 Cork Floating Plank Floor Composition}

\begin{tabular}{lccc}
\hline Constituent & Mass Fraction & Mass $\left(\mathbf{k g} / \mathrm{m}^{2}\right)$ & Mass $\left(\mathbf{l b} / \mathrm{ft}^{2}\right)$ \\
\hline HDF & $70.7 \%$ & 5.66 & 1.16 \\
Polyurethane (PUR) binder & $7.3 \%$ & 0.58 & 0.12 \\
Cork & $19.7 \%$ & 1.58 & 0.32 \\
Varnish & $2.3 \%$ & 0.18 & 0.04 \\
Total & $\mathbf{1 0 0} \%$ & $\mathbf{8 . 0 0}$ & $\mathbf{1 . 6 4}$ \\
\hline
\end{tabular}

The cork constituent is a waste byproduct, so the environmental burdens from virgin production of cork are not included. The energy used to grind the cork is included, as is its transport to the manufacturing facility. The binder for the cork is a moisture-cured urethane, and an ecoinvent data set for polyurethane (for flexible foam) is used. HDF is produced mostly from recovered wood waste. HDF and acrylic varnish production, modeled as $87.5 \%$ water content, come from ecoinvent. The ecoinvent data are customized to U.S. energy.

The biomass carbon in the cork and fiberboard was modeled as sequestered except for the portion that is assumed to decompose in a landfill (see End of Life section). The carbon content of the cork is assumed to be $56 \%$, and the carbon content of HDF is assumed to be $48 \%$ of the wood residue in the material.

Transportation distances for shipment of the raw materials from the suppliers to the manufacturing plant is assumed to be $805 \mathrm{~kg}(500 \mathrm{mi})$. The materials were transported by diesel truck, based on the U.S. LCI Database.

\subsubsection{Manufacturing}

Data for manufacturing this cork floor product is based on the data previously in BEES. Cork waste is ground and blended with the urethane binder, then cured. The cork-HDFcork layers are cured. Electricity and an on-site boiler are used for blending and curing. The boiler uses cork powder generated during the production process to produce steam and electricity. Manufacturing the floating floor plank requires approximately $1 \mathrm{MJ}$ $(0.28 \mathrm{kWh})$ of electricity and $0.9 \mathrm{MJ}(0.25 \mathrm{kWh})$ of thermal energy per $1 \mathrm{ft}^{2}{ }^{41}$ Water is also used in the production process. At some facilities, it is recycled and recovered by the plant. Most of the waste generated from manufacturing is used to produce energy.

\subsubsection{Transportation}

For the U.S. market, the BEES model assumes $90 \%$ production in Europe and $10 \%$ in the U.S. Thus, $90 \%$ of the finished cork floor product is modeled as transported $6020 \mathrm{~km}$ (3742 mi) by ocean freighter from Portugal to a port in New York. Once in the U.S., it is

\footnotetext{
${ }^{41}$ Natural Cork Floor data from Lippiatt (2007)
} 
modeled as transported an average distance of $2414 \mathrm{~km}$ (1500 mi). This distance is the same amount assumed for the product manufactured in the U.S. U.S. LCI database was used for transportation.

\subsubsection{Installation}

Due to the construction of the product, the floating floor planks require only a minimal amount of tongue-and-groove adhesive to bond the individual planks together. Installation waste of $2 \%$ of product is assumed. The installation waste is modeled as transported $48 \mathrm{~km}$ (30 mi) by diesel truck and disposed of in a landfill. While some of the packaging waste at installation can be recycled, it is modeled as disposed of in a landfill.

\subsubsection{Use and Maintenance}

The service life of flooring products will vary depending on the amount of floor traffic and the type and frequency of maintenance. The level of maintenance is also dependent on the actual use and desired appearance of the floor. A lifetime of 30 years has been assumed for the cork floor product. Replacement, including production of raw materials, manufacturing, transport to installation, etc., is included to account for the BEES flooring category's operating lifetime of 60 years.

BEES includes cleaning and maintenance of products during their useful lifetime. Because of differing manufacturers' maintenance recommendations, there is no single maintenance regimen that is followed. Cleaning equipment used to maintain floors will depend on the maintenance system selected by the building owner, often based on the desired overall appearance. Frequency of deep cleaning and refinishing or polishing, and types and quantities of these compounds will also depend on the maintenance programs developed by individual building owners. For BEES, cleaning and maintenance is modeled based on industry-wide specifications or recommendations obtained from published EPDs; industry- or manufacturer-specific maintenance guides published online; or in some instances, general internet research on best maintenance practices.

Cleaning and maintenance in BEES is divided into two parts. The first, regular cleaning of dirt and dust (i.e., by way of vacuuming (electrical requirements) or sweeping / dry mopping (non-electrical)) is a variable in BEES. The BEES user chooses the method of regular cleaning along with the frequency per week. The default number for commercial applications is set at four, averaging out the cleaning needs of different volumes of traffic. For residential use the default is set to one time per week. Inputs and outputs per cleaning event of regular maintenance are shown in Table 5-37. 
Table 5-37 Inputs and Outputs per Regular Cleaning Event ${ }^{42}$

\begin{tabular}{|c|c|c|}
\hline Vacuum choice & Per $\mathrm{m}^{2}$ & Per $\mathrm{ft}^{2}$ \\
\hline Electricity & $0.014 \mathrm{MJ}$ & 3.70E-04 kWh \\
\hline Solid waste & $0.0077 \mathrm{~kg}$ & $0.0016 \mathrm{lb}$ \\
\hline $\begin{array}{l}\text { Sweep / dry mop choice } \\
\text { Solid waste }\end{array}$ & $\begin{array}{c}\text { Per m }{ }^{2} \\
0.0077 \mathrm{~kg}\end{array}$ & $\begin{array}{c}\text { Per ft }{ }^{2} \\
0.0016 \mathrm{lb}\end{array}$ \\
\hline
\end{tabular}

The solid waste is modeled as being transported by diesel truck and disposed of in a landfill. The second part of cleaning is characterized as intermittent deeper cleaning and other maintenance, and this activity is a non-variable in BEES, although as acknowledged above, it may vary from building to building. In general, cleaning frequency is based on similar data for other resilient floor coverings. Table 5-38 presents the intermittent cleaning and maintenance schedules for cork.

\section{Table 5-38 Cork Flooring Covering Cleaning Processes and Frequency}

\begin{tabular}{|c|c|c|c|}
\hline $\begin{array}{l}\text { Cleaning Process } \\
\text { Damp mop / neutral cleaner }\end{array}$ & $\begin{array}{l}\text { Frequency- } \\
\text { Commercial } \\
\text { 1x per week }\end{array}$ & $\begin{array}{r}\text { Frequency- } \\
\text { Residential } \\
\text { 1x per } 2 \text { week }\end{array}$ & $\begin{array}{l}\text { Resources Used } \\
\text { Hot water, neutral detergent }\end{array}$ \\
\hline Buff / finish sealer & $1 x$ per 2 years ${ }^{43}$ & $1 \mathrm{x}$ per 9 years ${ }^{44}$ & $\begin{array}{l}\text { Polyurethane sealant, } \\
\text { Electricity }\end{array}$ \\
\hline
\end{tabular}

The energy, material, and water inputs for this product are presented in Table 5-39. The quantities of detergent, water, and electricity come from the Average Homogeneous Vinyl EPD (RFCI, 2013b), with usage amounts adjusted. The sealant application rate is based on product data for a specific coating. ${ }^{45}$

\footnotetext{
${ }^{42}$ Energy input and solid waste quantity based on Tables 8 and 10 of Lu et al. (2008). This is modeled on an assumption that carpet and other floors have attracted similar quantities of dirt and dust.

${ }^{43}$ Polyurethane sealer commercial application timing based on Duro-design cork flooring (http://www.duro-design.com/index.cfm/page/cork.maintenanceWarranty/)

${ }^{44}$ Polyurethane sealer residential application timing based on http://www.usfloorsllc.com/productdisplay/natural-cork-5/why-natural-cork/ "Under normal use in a residential environment, a urethane finish should last between $8-10$ years between refinishing."

${ }^{45}$ DuraSeal water-based PUR specification data, retrieved from http://www.duraseal.com/products/finishes/water-based-polyurethane/.
} 
Table 5-39 Total Inputs for Intermittent Cleaning per Year ${ }^{46,47}$

\begin{tabular}{lcccc}
\hline & \multicolumn{2}{c}{ Commercial } & \multicolumn{2}{c}{ Residential } \\
\hline Cleaning Input & ${\text { Per } \mathrm{m}^{2}}$ & ${\text { Per } \mathrm{ft}^{2}}$ & Per $^{2}$ & ${\text { Per } \mathrm{ft}^{2}}$ \\
Detergent (ml) & 119 & 11.1 & 59.5 & 5.5 \\
Electricity (kWh) & 0.0009 & $9 \mathrm{E}-5$ & 0.0002 & $2 \mathrm{E}-5$ \\
Sealant (kg) & $0.086^{48}$ & 0.007 & 0.022 & 0.001 \\
Water (liter) & 5.8 & 0.54 & 2.9 & 0.270 \\
\hline
\end{tabular}

\subsubsection{End of Life}

End of life modeling of the cork flooring includes transportation by heavy-duty dieselfuel powered truck approximately $48 \mathrm{~km}$ (30 mi) to a landfill. Truck transportation is based on the U.S. LCI database and disposal in a landfill is modeled based on ecoinvent end of life waste management process data.

Much of this floor product is sourced from biobased materials, so disposal includes data for both inert material in a landfill and biogenic material in a landfill. Mahalle (2011) and the EPA WARM (WARM, 2015) describe the impacts from biogenic material in a landfill as being made up of $\mathrm{CH}_{4}$ from decomposition of biomass and $\mathrm{CO}_{2}$ emissions associated with flaring these emissions where landfill gas is not recovered for energy; and $\mathrm{CO}_{2}$ emissions avoided through landfill gas-to-energy projects. An assumed $23 \%$ of the wood decomposes, so storage of the remaining biogenic carbon is also accounted for in Section 5.1 of Mahalle (2011). The data for net GHG emissions from landfill gas management practices comes from Table 31 in Mahalle (2011). For cork flooring, this amounts to $0.393 \mathrm{~kg} \mathrm{CO} 2$ per $\mathrm{kg}$ cork floor and $0.018 \mathrm{~kg}$ methane per kg cork floor.

\subsection{Generic Composite Marble Tile}

The development of the generic composite marble tile included in BEES Online 2.0 uses the underlying data and methodology as described in this section.

\subsubsection{Product Description}

Composite marble tile is a type of composition flooring. It is a mixture of polyester resin and matrix filler, colored for a marble effect and poured into a mold to form tiles. The mold is then vibrated to release air and level the matrix. After curing and shrinkage, the tile is removed from the mold, trimmed, and polished if necessary. The functional unit used for BEES is flooring of $0.093 \mathrm{~m}^{2}\left(1 \mathrm{ft}^{2}\right)$ used over the building's operating lifetime of 60 years. The composite marble tile is modeled as $30 \mathrm{~cm} \mathrm{x} 30 \mathrm{~cm}$ x $0.95 \mathrm{~cm}$ (12 in x

\footnotetext{
${ }^{46}$ Inputs based on RFCI (2013a), Table 2 (with usage adjusted).

${ }^{47}$ Based on RFCI (2013a), Table 2 (with usage adjusted).

${ }^{48}$ Sealant application rate based on a DuraSeal water-based PUR application rate of $8.81 \mathrm{lb} / \mathrm{gal}, 500 \mathrm{sf} / \mathrm{gal}$, with 2 coats. http://www.duraseal.com/products/finishes/water-based-polyurethane/
} 
12 in $x$ 3/8 in), installed using a latex-cement mortar. It is used in commercial and residential markets.

It should be noted that most of the information described herein is carried over from the previous BEES data.

\subsubsection{Flow Diagram}

The flow diagram in Figure 5-12 shows the major elements of the production of composite marble tile as modeled in BEES.

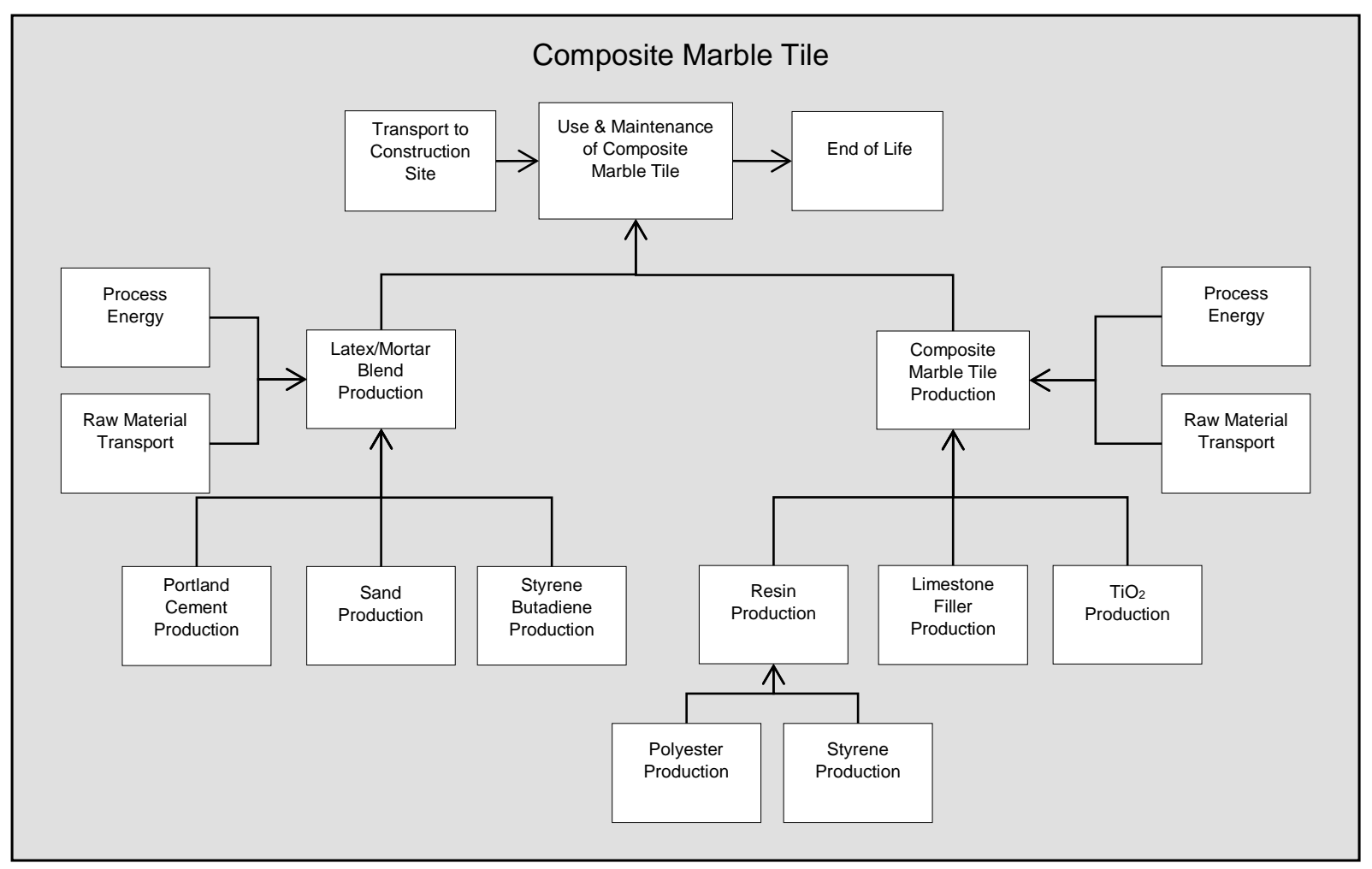

Figure 5-12 Composite Marble Tile System Boundaries

\subsubsection{Raw Materials}

Table 5-40 gives the constituents included in the marble matrix and their proportions.

\section{Table 5-40 Composite Marble Tile Matrix Composition}

\begin{tabular}{lc}
\hline \multicolumn{1}{c}{ Constituent } & Mass Fraction (\%) \\
\hline Filler - $\mathrm{CaCO}_{3}$ & 78.25 \\
Resin - PET \& styrene & 20.0 \\
Pigment $\left(\mathrm{TiO}_{2}\right)$ & 1.50 \\
Catalyst $(\mathrm{MEKP})$ & 0.24 \\
\hline
\end{tabular}

The resin used in the matrix is an unsaturated polyester resin cross-linked with styrene monomer. The styrene content can range from $35 \%$ to $55 \%$. An average value of $45 \%$ 
is used for the model. The resin percentage of $20 \%$ in Table 5-40 is a weighted average, based on data from four sources ranging from $19 \%$ to $26 \%$ resin content. Data for polyester is based on the U.S. LCI database data for PET resin. Styrene data come from ecoinvent. The cross-linking operation is not included in the model due to lack of available data. The filler is assumed to be calcium carbonate $\left(\mathrm{CaCO}_{3}\right)$. It is composed of coarse and fine particles in a combination of two parts coarse to one part fine, and filler production involves the mining and grinding of $\mathrm{CaCO}_{3}$. Data for $\mathrm{CaCO}_{3}$ comes from ecoinvent.

The main catalyst in the matrix is modeled as methyl ethyl ketone peroxide (MEKP). This catalyst is used as a solvent in the mixture of resin and filler so is consumed in the process; however, approximately $1 \%$ of the catalyst is composed of unreacted methyl ethyl ketone (MEK), which is assumed to be released during the reaction. The amount of catalyst is assumed to be about $1 \%$ of the resin content, or $0.24 \%$ of the total marble matrix. MEKP is built using ecoinvent data sets for MEK and peroxide. A pigment or colorant may be used if necessary, and the quantity depends on the color required. The colorant is usually added to the mixture before all the filler has been mixed. For the BEES study, titanium dioxide at $1.5 \%$ of the matrix is assumed, and this constituent is modeled using ecoinvent data.

The raw materials are assumed to be transported on average $402 \mathrm{~km}$ (250 mi) by truck.

The product is modeled as packaged in cardboard boxes, placed on pallets and wrapped in plastic film. Packaging materials and their transportation to composite marble tile facilities have been included in the BEES model.

\subsubsection{Manufacturing}

Electricity is the only energy source involved in producing and casting the resin-filler mixture for composite marble tile. The tile is cured at room temperature. Table 5-41 shows electricity use for composite marble tile manufacturing. It is assumed that $1.5 \%$ of the material is lost at manufacture from the trimming process.

\section{Table 5-41 Energy Requirements for Composite Marble Tile Manufacturing}

\begin{tabular}{lc}
\hline Energy Carrier & MJ/kg (Btu/lb) \\
\hline Electricity & $0.047(20.3)$ \\
\hline
\end{tabular}

Two emissions from composite marble tile manufacturing are fugitive styrene and MEK air emissions. The styrene emissions come from the resin constituent and are assumed to be $2 \%$ of the resin input. The MEK emissions come from the $1 \%$ un-reacted MEK in the catalyst blend. Emissions of styrene from the matrix are assumed to be $0.047 \mathrm{~kg} / \mathrm{m}^{2}$ $\left(9.6 \mathrm{E}-3 \mathrm{lb} / \mathrm{ft}^{2}\right)$, and MEK emissions $0.0005 \mathrm{~kg} / \mathrm{m}^{2}\left(1.0 \mathrm{E}-4 \mathrm{lb} / \mathrm{ft}^{2}\right)$. 


\subsubsection{Transportation}

Transportation distance of the tile product by heavy-duty truck to the building site is modeled as $805 \mathrm{~km}$ (500 mi). Shipping the installation materials to the building site cement, sand, and latex - is assumed to cover $322 \mathrm{~km}$ (200 mi) via diesel truck. Transportation data come from the U.S. LCI database.

\subsubsection{Installation}

Installing composite marble tile requires a sub-floor of a compatible type, such as concrete. Installation data for ceramic tile in BEES was used for composite marble tile. An EPD for ceramic tile (TCNA, 2014) provided data for amounts of materials needed: mortar in the amount of $4.1 \mathrm{~kg} / \mathrm{m}^{2}\left(0.833 \mathrm{lb} / \mathrm{ft}^{2}\right)$ and sanded grout in the amount of 0.21 $\mathrm{kg} / \mathrm{m}^{2}\left(0.043 \mathrm{lb} / \mathrm{ft}^{2}\right)$ are thus used to install composite marble tile. The mortar is modeled as a latex/mortar blend; its constituents are provided in Table 5-42.

\section{Table 5-42 Latex/Mortar Blend Constituents}

\begin{tabular}{cc}
\hline Constituent & Mass Fraction \\
\hline Mortar & $\mathbf{7 0} \%$ \\
Portland Cement & $17 \%$ \\
Sand & $83 \%$ \\
Styrene-Butadiene Latex & $\mathbf{3 0} \%$ \\
\hline
\end{tabular}

The sanded grout is modeled as a mixture of Portland cement and sand with smaller amounts of titanium dioxide as pigment and other additives. The installation materials were modeled using ecoinvent and U.S. LCI database data. Installation of tile and mortar is assumed to be a manual process, so no there are no emissions or energy inputs.

The scrap generated during installation is assumed to be $4.5 \%$ of the total flooring material (TCNA, 2014). While the flooring material could be recycled, it is modeled as transported $48 \mathrm{~km}$ (30 mi) by diesel truck and disposed of in a landfill. Packaging waste is also modeled as disposed of in a landfill, although it is acknowledged that it could be recycled.

\subsubsection{Use and Maintenance}

With proper maintenance and installation, A 60-year service life is given to the composite marble tile flooring as it is expected to last at least as long as the building itself.

BEES includes cleaning and maintenance of products during their useful lifetime. Because of differing manufacturers' maintenance recommendations, there is no single maintenance regimen that is followed. Cleaning equipment used to maintain floors will depend on the maintenance system selected by the building owner, often based on the desired overall appearance. Frequency of deep cleaning and refinishing or polishing, and types and quantities of these compounds will also depend on the maintenance programs developed by individual building owners. For BEES, cleaning and maintenance is 
modeled based on industry-wide specifications or recommendations obtained from published EPDs; industry- or manufacturer-specific maintenance guides published online; or in some instances, general internet research on best maintenance practices.

Cleaning and maintenance in BEES is divided into two parts. The first, regular cleaning of dirt and dust (i.e., by way of vacuuming (electrical requirements) or sweeping / dry mopping (non-electrical)) is a variable in BEES. The BEES user chooses the method of regular cleaning along with the frequency per week. The default number for commercial applications is set at four, averaging out the cleaning needs of different volumes of traffic. For residential applications, this default value is one time per week. Inputs and outputs per cleaning event of regular maintenance are shown in Table 5-43.

\section{Table 5-43 Inputs and Outputs per Regular Cleaning Event ${ }^{49}$}

\begin{tabular}{lcc}
\hline Vacuum choice & Per m $^{2}$ & Per $\mathrm{ft}^{2}$ \\
Electricity & $0.014 \mathrm{MJ}$ & $3.70 \mathrm{E}-04 \mathrm{kWh}$ \\
Solid waste & $0.0077 \mathrm{~kg}$ & $0.0016 \mathrm{lb}$ \\
& & \\
Sweep / dry mop choice & $\boldsymbol{P e r ~ \mathrm { m } ^ { 2 }}$ & $\boldsymbol{P e r ~ \mathrm { ft } ^ { 2 }}$ \\
Solid waste & $0.0077 \mathrm{~kg}$ & $0.0016 \mathrm{lb}$ \\
\hline
\end{tabular}

The solid waste is modeled as being transported by diesel truck and disposed of in a landfill. The second part of cleaning is characterized as intermittent deeper cleaning and other maintenance, and this activity is a non-variable in BEES, although as acknowledged above, it may vary from building to building. Table 5-44 and Table 5-45 present the intermittent cleaning and maintenance schedule and inputs for composite marble tile, respectively; composite marble tile flooring was assumed to have similar maintenance requirements as VCT, so Table 1 in RFCI (2013a) was consulted.

\section{Table 5-44 Cleaning Processes and Frequency}

\begin{tabular}{|c|c|c|c|}
\hline Cleaning Process & $\begin{array}{l}\text { Frequency- } \\
\text { Commercial }\end{array}$ & $\begin{array}{c}\text { Frequency - } \\
\text { Residential }\end{array}$ & Resources Used \\
\hline Damp mop / neutral cleaner & $1 \mathrm{x}$ per week & $1 \mathrm{x}$ per 2 weeks & Hot water, neutral detergent \\
\hline Spray buff / finish restorer & $1 \mathrm{x}$ per month & $1 \mathrm{x}$ per 6 months & $\begin{array}{c}\text { Floor finish, } \\
\text { Electricity }\end{array}$ \\
\hline Strip and two coats finish & $1 \mathrm{x}$ per year & $1 \mathrm{x}$ per 2 years & $\begin{array}{l}\text { Finish remover, floor finish, } \\
\text { Electricity }\end{array}$ \\
\hline
\end{tabular}

\footnotetext{
${ }^{49}$ Energy input and solid waste quantity based on Tables 8 and 10 of Lu et al. (2008). This is modeled on an assumption that carpet and other floors have attracted similar quantities of dirt and dust.
} 
Table 5-45 Composite Marble Tile Intermittent Cleaning Inputs per Year ${ }^{50}$

\begin{tabular}{lcccc}
\hline & \multicolumn{2}{c}{ Commercial } & \multicolumn{2}{c}{ Residential } \\
\hline Cleaning Input & ${\text { Per } \mathrm{m}^{2}}^{\text {Per } \mathrm{ft}^{2}}$ & Per $\mathrm{m}^{2}$ & ${\text { Per } \mathrm{ft}^{2}}$ \\
Detergent (ml) & 124 & 11.5 & 62 & 5.8 \\
Electricity (kWh) & 0.025 & 0.002 & 0.01 & 0.001 \\
Finish (liter) & 0.22 & 0.02 & 0.07 & 0.007 \\
Finish remover (liter) & 0.041 & 0.004 & 0.01 & 0.001 \\
Water (liter) & 6.2 & 0.58 & 3.1 & 0.29 \\
\hline
\end{tabular}

\subsubsection{End of Life}

Composite marble tile is modeled as being landfilled at end of life. End of life modeling includes transportation of the flooring and installation materials by heavy-duty diesel-fuel powered truck approximately $48 \mathrm{~km}$ (30 mi) to a landfill, plus impacts of a landfill. Truck transportation is based on the U.S. LCI database and disposal in a landfill is modeled based on ecoinvent end of life waste management process data.

\subsection{Generic Hardwood Flooring}

The development of the generic hardwood flooring included in BEES Online 2.0 uses the underlying data and methodology as described in this section.

\subsubsection{Product Description}

Solid hardwood and engineered wood floors have been included in the floor coverings category of BEES. The solid hardwood floor data in BEES are based on an average of solid strip hardwood flooring and solid plank hardwood flooring. Hubbard and Bowe (2008) provides the range of dimensions for solid strip and solid plank hardwood: solid strip has face widths of $38.1 \mathrm{~mm}$ (1.5 in), $57.2 \mathrm{~mm}$ (2.25 in) and $82.5 \mathrm{~mm}$ (3.25 in), and solid plank has face widths of $76.2 \mathrm{~mm}$ (3.0 in) to $203 \mathrm{~mm}$ (8.0 in) and higher. Typical thicknesses are $7.62 \mathrm{~mm}$ (1/3 in), $12.7 \mathrm{~mm}$ (0.5 in), and $19 \mathrm{~mm}(0.75 \mathrm{in})$. For BEES, $0.093 \mathrm{~m}^{2}\left(1 \mathrm{ft}^{2}\right)$ with the most common thickness of $19 \mathrm{~mm}(0.75 \mathrm{in})$ is used over the building's operating lifetime of 60 years.

Engineered wood flooring consists of several sheets of solid wood (veneer) bonded together with an adhesive under heat and/or pressure. Engineered wood floors are available in plies, or layers, ranging from 2 to 9 sheets, and 3 and 5 plies are most common. The engineered wood LCA supplies typical thicknesses, which range from 6.4 to $14.3 \mathrm{~mm}$ (1/4 to 9/16 in) (Bergman \& Bowe, 2011). For BEES, $0.093 \mathrm{~m}^{2}\left(1 \mathrm{ft}^{2}\right)$ of engineered wood flooring with $9.5 \mathrm{~mm}$ (3/8 in) thick floor planks is used over the building's operating lifetime of 60 years.

Both products in BEES are modeled as factory-finished, or pre-finished. Prefinishing at the factory keeps the application of all the coatings and sealants in the manufacturing

\footnotetext{
50 Table 2 (with quantities adjusted for residential) in RFCI (2013a)
} 
setting, avoiding excess volatile emissions at the installation site. The trade-off is that prefinishing operations use a large amount of electricity to capture and destroy the emissions from the coating operations, so from a resources point of view, the environmental impacts are greater (Mahalle, 2011). Wood flooring in BEES is applicable to the commercial and residential markets. Table 5-46 provides the thickness and mass per area of each product.

\section{Table 5-46 Wood Flooring Products in BEES}

\begin{tabular}{lcc}
\hline Products & $\begin{array}{c}\text { Nominal } \\
\text { Thickness } \mathbf{~ m m} \text { (in) }\end{array}$ & $\begin{array}{c}\text { Mass per Applied } \\
\text { Area } \mathbf{~ k g} / \mathbf{m}^{\mathbf{2}}\left(\mathbf{l b} / \mathbf{f t}^{2}\right)\end{array}$ \\
\hline Solid Hardwood & $19(0.75)$ & $12.5(2.56)^{51}$ \\
Engineered wood & $9.5(0.375)$ & $6.24(1.28)^{52}$ \\
\hline
\end{tabular}

\subsubsection{Flow Diagram}

The flow diagram in Figure 5-13 and Figure 5-14 presents the major elements of the production of these products, as they are modeled for BEES.

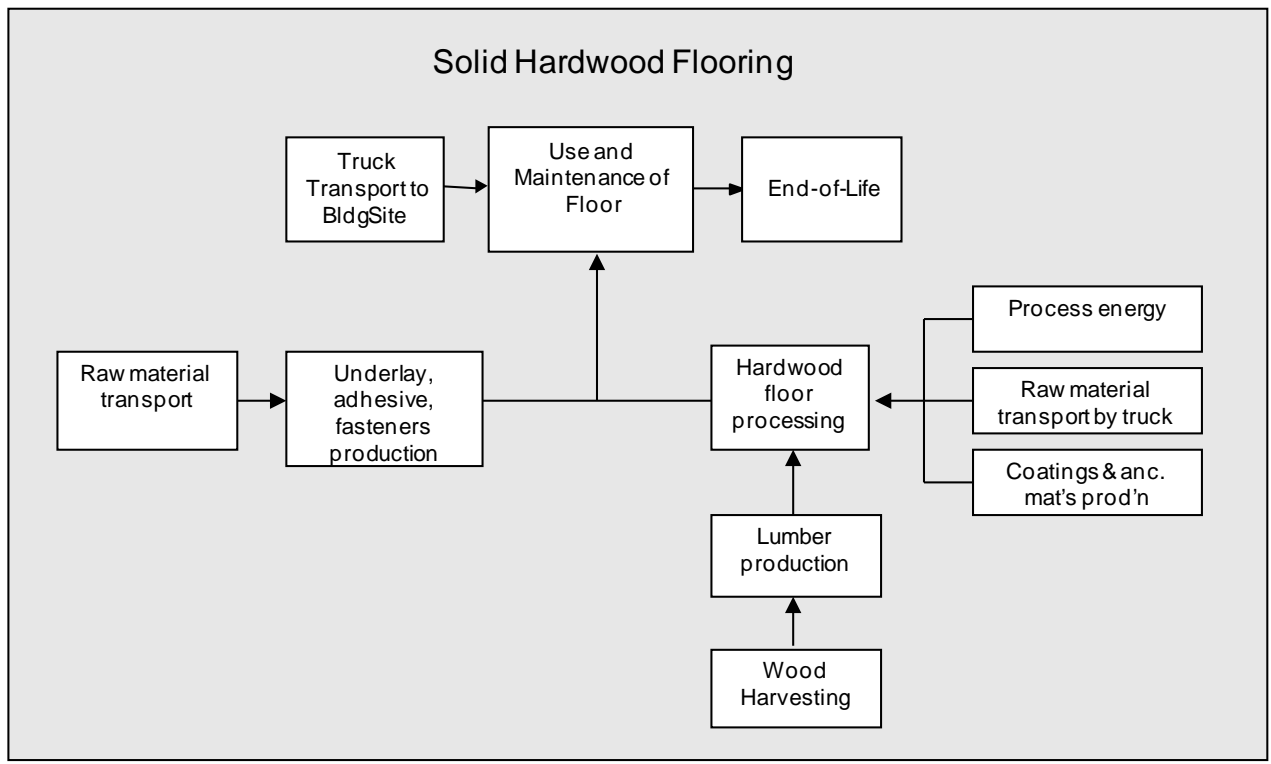

Figure 5-13 Solid Hardwood Flooring System Boundaries

\footnotetext{
${ }^{51}$ Hubbard and Bowe (2008), p. 13.

${ }^{52}$ Based on an oven-dry density provided in Bergman and Bowe (2011) of $656 \mathrm{~kg} / \mathrm{m} 3$ (40.9 lb/ft3) of engineered floor.
} 


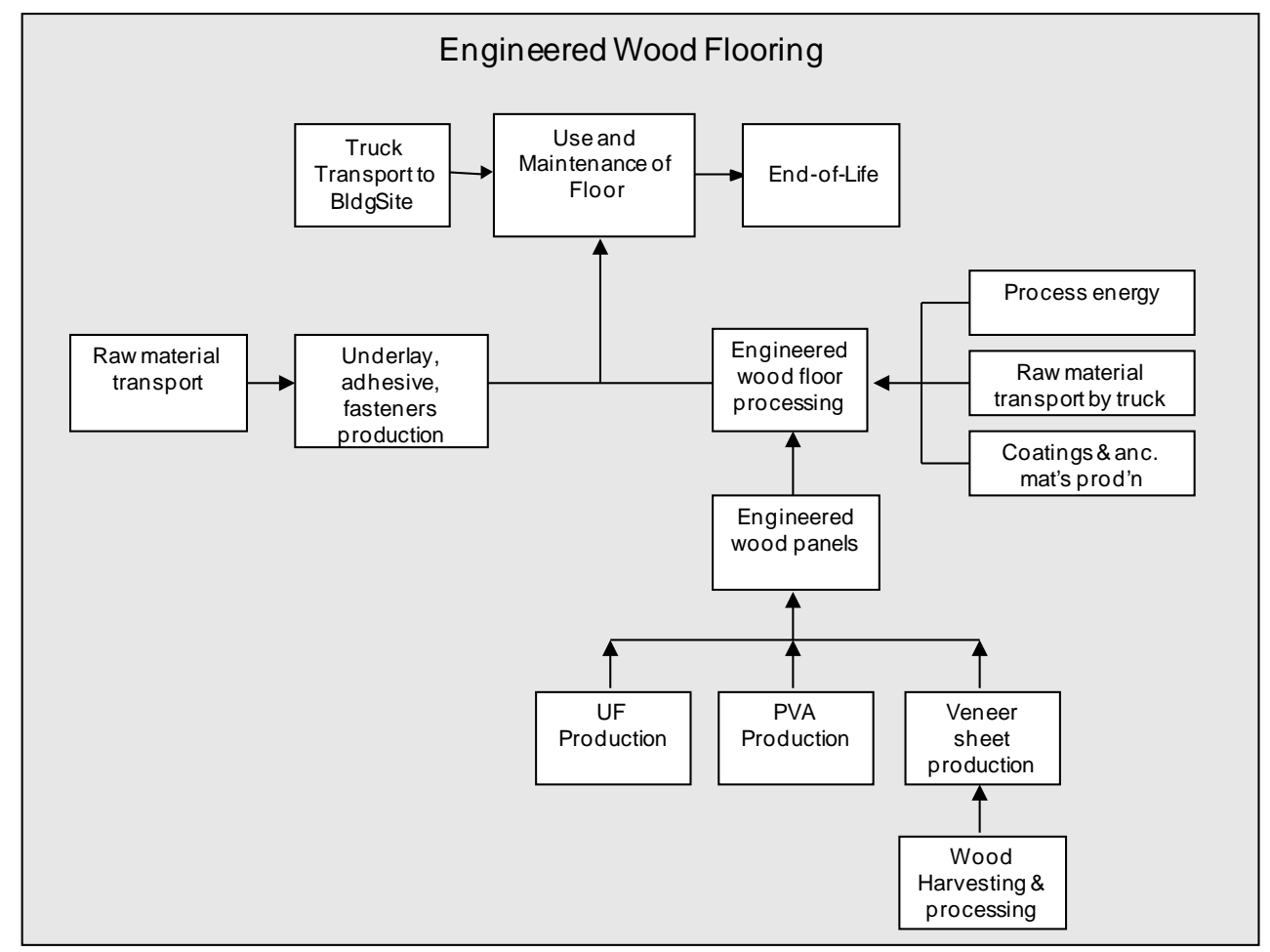

Figure 5-14 Engineered Wood Flooring System Boundaries

\subsubsection{Raw Material Production \& Manufacturing}

The data for the cradle to gate production of solid hardwood floors is taken from Mahalle (2011), which took their data directly from Athena (2010). The unit processes included are described as follows and shown in Figure 5-15.

- Drying. Rough green lumber is dried in kilns fueled by wood waste. The lumber is typically dried to a final moisture content of between $6 \%$ and $9 \%$ (oven dry basis).

- $\quad$ Milling. At the mill, dried lumber is planed, ripped, trimmed, and moulded. Planing puts the lumber into more even thicknesses (into uniform tolerance limits) while also producing smooth face surfaces which aid visual grading and sorting. Ripping involves feeding dry, planed, random width lumber along its length through a rip-saw to create uniform widths. Trimming is done to eliminate lumber defects while crosscutting the lumber into desired lengths using a chop saw. The output of this process is stock of desired lengths within defect tolerances required of the final flooring product. Finally, moulding is done to create fitting pieces (i.e., tongue and grooves) and to generally aid in seamless installation.

- Finishing and packaging. The product is prefinished with application of stains and coatings, then cured, and finally packaged. 


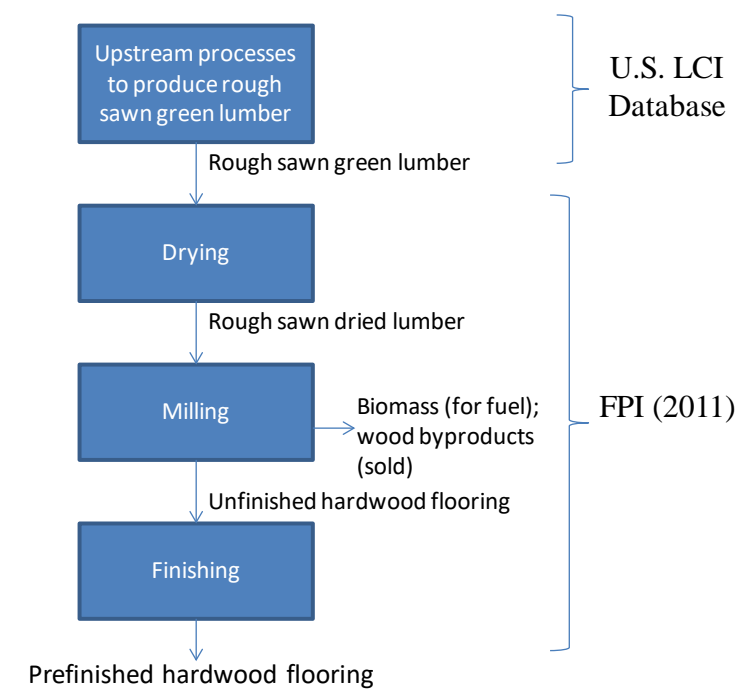

\section{Figure 5-15 Solid Hardwood Flooring Unit Processes}

Table 8 through Table 10 in Mahalle (2011) provide the detailed data used to model the product in BEES, including material inputs, energy, waste flows, and packaging. Data are from manufacturing facilities in eastern Canada for the production year 2008. Data for lumber production come from the U.S. LCI database. The data, despite being Canadian, still represent a good portion (40 \%) of North American hardwood flooring production. For purposes of the BEES system boundaries, the lumber that makes up the flooring is considered the upstream raw material input.

The milling process produces an extensive amount of wood co-products, including wood waste used for fuel or biomass byproducts. BEES used the same co-product allocation modeling as that used by Athena (2010): all inputs and outputs were fully allocated to the primary product - lumber used for solid hardwood flooring. Even though the co-products account for approximately $60 \%$ of the mass of outputs, Athena estimated that the coproducts accounted for no more than $5 \%$ of the revenue to the manufacturer, so most, if not all the environmental inputs and outputs should be carried with the main product. This modeling is conservative to the flooring product.

The biomass carbon in the hardwood floor was modeled as sequestered except for the portion that is assumed to decompose in a landfill (see End of Life section). The carbon content of the wood is modeled at $48 \%$, based on a survey of lumber mills (Section 3.1.1.4 in Mahalle (2011)).

The data for the cradle to gate production of engineered wood floors is taken from Bergman and Bowe (2011) and shown in Figure 5-16. Sec 14.1 in this study provides the detailed data tables that were used to model the product in BEES, and the three unit processes included are: (Bergman and Bowe (2011), Sections 3.6 through 3.8)

- Lay up: involves bonding thin veneer sheets or plies together with urea-formaldehyde (UF) and polyvinyl acetate (PVA) resin to form panels. 
- Trimming, sanding, sawing, and moulding. Veneer panels are trimmed to standard

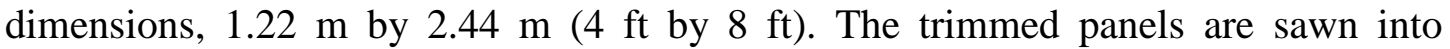
individual boards and sanded. After sanding, the boards are moulded (profiled) into tongue and groove flooring of random lengths.

- Prefinishing is the set of processes aimed at finishing and protecting the unfinished surface. These processes include sanding, priming, staining, filling, curing, sealing, and topcoating.

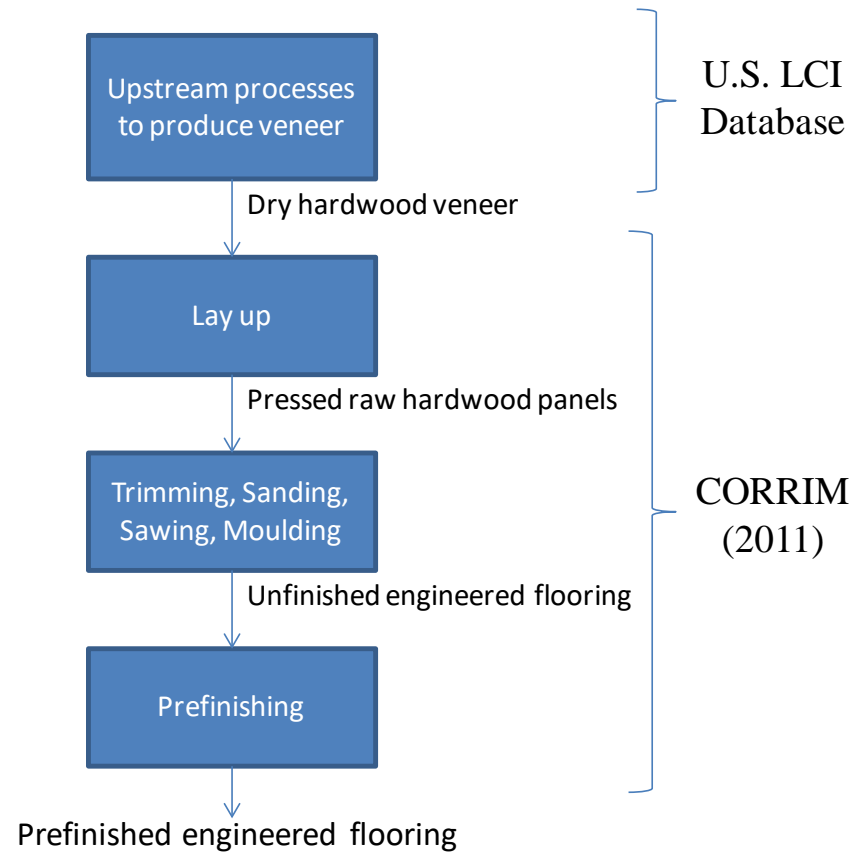

\section{Figure 5-16 Engineered Wood Flooring Unit Processes}

The data tables list out material, energy, and water inputs, plus air emissions and waste flows. The data sets are primary data collected from facilities in the Eastern U.S. for the production year 2007. For purposes of the BEES system boundary, veneer production and drying are considered the raw material input. Data for these processes come from the U.S. LCI database.

Co-product allocation is modeled consistent with the approach taken for hardwood flooring, in which the main wood-based products (e.g., unfinished engineered flooring) carry the full burden of the inputs and outputs, and the co-products (e.g., sawdust, shavings, and sanding dust) are assigned a value of zero due to disproportionately less value. The biomass carbon in the engineered wood floor was modeled as sequestered except for the portion that is assumed to decompose in a landfill (see End of Life section). The wood component of the engineered floors is $88.2 \%$ of the final product mass and carbon content of the wood is modeled at 51.7 \% (Bergman \& Bowe, 2011).

The upstream wood and lumber production comes from the U.S. LCI database. UF and PVA resin, the two other main components making up the engineered wood panel, were 
based on ecoinvent. For coatings, ancillary materials and other inputs, ecoinvent data, customized to U.S. energy, were used. In the few cases where U.S. LCI database data was available, this data set was used. The data representing transportation of the materials to manufacturing are included in the detailed data sets in the reports.

Packaging materials and their transportation to wood flooring facilities have been included in the BEES model. Packaging includes shrink wrap, plastic and steel strapping, corrugated cardboard, and wood pallets. Quantities for these materials are included in the detailed data sets in the referenced reports.

\subsubsection{Transportation}

Transportation distance of wood floors by heavy-duty truck to the building site is modeled as 805 km (500 mi). Data come from the U.S. LCI Database.

\subsubsection{Installation}

Data for installation of materials for both products is based on page 1 of the Quebec Wood Export Bureau EPD on solid strip hardwood flooring, and these quantities are presented in Table 5-47. Both a plywood underlay and a polyethylene vapor barrier, which prevents moisture from coming through the floor, are installed under the products. The solid hardwood floor uses nails as fasteners, while the engineered wood floor assumes staples as its fasteners.

\section{Table 5-47 Installation Materials - Wood Flooring}

\begin{tabular}{lcc}
\hline \multicolumn{1}{c}{ Constituent } & $\begin{array}{c}\text { Quantity } \\
\left(\mathbf{k g} / \mathrm{m}^{2}\right)\end{array}$ & $\begin{array}{c}\text { Quantity } \\
\left(\mathbf{l b}_{\mathrm{ft}} \mathbf{2}^{\mathbf{}}\right)\end{array}$ \\
\hline Plywood underlay (16 mm) & 10.8 & 2.2 \\
Polyethylene vapor barrier (0.15 mm) & 0.14 & 0.029 \\
Carpenter’s glue & 0.07 & 0.014 \\
Solid hardwood fasteners: galvanized steel nails (4 nails, 2 in, 18 gauge) & 0.0018 & 0.0004 \\
Engineered wood fasteners: galvanized steel staples (4 staples, 1.25 in, 18 gauge) $)^{53}$ & 0.0025 & 0.0005 \\
\hline
\end{tabular}

An ecoinvent dataset on vinyl acetate was used for the carpenter's glue, and the other installation materials came from the U.S. LCI database. Installation is primarily a manual process, so no energy use is modeled for the installation phase. The plywood is modeled as having $49.9 \%$ biomass carbon (UL Environment, 2013a).

The scrap generated during installation is estimated to be $0.5 \%$ of the total flooring material (Table 10 in Mahalle (2011)). The wood flooring is modeled as transported 48 km (30 mi) by diesel truck and disposed of in a landfill. Packaging waste is also modeled as disposed of in a landfill, although it is acknowledged that much of these could be recycled.

\footnotetext{
${ }^{53}$ Data from Hosking (2012)
} 


\subsubsection{Use and Maintenance}

A 60-year service life is given to these flooring products as they are expected to last at least as long as the building itself.

BEES includes cleaning and maintenance of products during their useful lifetime. Because of differing building maintenance recommendations, there is no single maintenance regimen that is followed. Cleaning equipment used to maintain floors will depend on the maintenance system selected by the building owner, often based on the desired overall appearance. For all flooring products in BEES, cleaning and maintenance is modeled based on industry-wide specifications or recommendations obtained from published EPDs; industry- or manufacturer-specific maintenance guides published online; or in some instances, general internet research on best maintenance practices.

Cleaning and maintenance in BEES is divided into two parts. The first, regular cleaning of dirt and dust (i.e., by way of vacuuming (electrical requirements) or sweeping / dust mopping (non-electrical)) is a variable in BEES. The BEES user chooses the method of regular cleaning along with the frequency per week. The default number for commercial applications is set at four, averaging out the cleaning needs of different volumes of traffic. For residential use, the default is set to one time per week. The second part of cleaning is characterized as intermittent deeper cleaning and other maintenance where applicable, and this activity is a non-variable in BEES, although as acknowledged above, it may vary from building to building. Inputs and outputs per regular maintenance cleaning event are shown in Table 5-48.

\section{Table 5-48 Inputs and Outputs per Regular Cleaning Event ${ }^{54}$}

\begin{tabular}{lcc}
\hline Vacuum choice & Per m & Per ft \\
Electricity & $0.014 \mathrm{MJ}$ & $3.70 \mathrm{E}-04 \mathrm{kWh}$ \\
Dust \& dirt removed & $0.0077 \mathrm{~kg}$ & $0.0016 \mathrm{lb}$ \\
& & \\
Sweep / dry mop choice & $\boldsymbol{P e r ~ \mathrm { m } ^ { 2 }}$ & $\boldsymbol{P e r} \mathrm{ft}^{2}$ \\
Dust \& dirt removed & $0.0077 \mathrm{~kg}$ & $0.0016 \mathrm{lb}$ \\
\hline
\end{tabular}

The dust and dirt removed is modeled as being transported by diesel truck and disposed of in a landfill.

Guidelines for intermittent cleaning processes come from Armstrong commercial flooring maintenance guide's section on hardwood flooring (Armstrong Maintenance, 2014). The frequency of commercial cleaning is based loosely on these guidelines so assumptions have been made for BEES, as has been done for residential cleaning frequency. The recoating with sealant is based on manufacturer and finish product recommendations but it is reminded that variability from one building to the next could

\footnotetext{
${ }^{54}$ Energy input and solid waste quantity based on Tables 8 and 10 of Lu et al. (2008). This is modeled on
} an assumption that carpet and other floors have attracted similar quantities of dirt and dust. 
be great. Table 5-49 presents the intermittent cleaning and maintenance schedules and Table 5-50 presents the energy and material inputs to clean the products over the course of 1 year.

\section{Table 5-49 Hardwood and Engineered Wood Floor Cleaning Processes and Frequency}

Cleaning Process

Neutral hardwood floor cleaner with micro-fiber mop

Buffing with hardwood floor cleaner

Recoating and resurfacing with sealant

\begin{tabular}{|c|c|c|}
\hline $\begin{array}{l}\text { Frequency- } \\
\text { Commercial } \\
\text { 1x per week }\end{array}$ & $\begin{array}{c}\text { Frequency- } \\
\text { Residential } \\
\text { 1x per } 2 \text { weeks }\end{array}$ & $\begin{array}{l}\text { Resources Used } \\
\text { Floor cleaner }\end{array}$ \\
\hline $1 \mathrm{x}$ per month & 1x per year & Floor cleaner, electricity \\
\hline $1 \mathrm{x}$ per 7 years & $1 \mathrm{x}$ per 7 years & $\begin{array}{l}\text { Electricity, } \\
\text { polyurethane finish }\end{array}$ \\
\hline
\end{tabular}

Frequency- Frequency-

1x per week $1 x$ per 2 weeks

$1 \mathrm{x}$ per month $\quad 1 \mathrm{x}$ per year polyurethane finish

Table 5-50 Intermittent Cleaning Inputs per Year

\begin{tabular}{lcccc}
\hline & \multicolumn{2}{c}{ Commercial } & \multicolumn{2}{c}{ Residential } \\
\hline Cleaning Input & ${\text { Per } \mathrm{m}^{2}}^{2}$ & ${\text { Per } \mathrm{ft}^{2}}^{2}$ & Per $\mathrm{m}^{2}$ & ${\text { Per } \mathrm{ft}^{2}}$ \\
Detergent $(\mathrm{ml})$ & 119 & 11.1 & 59.5 & 5.5 \\
Electricity $(\mathrm{kWh})$ & 0.023 & 0.002 & 0.002 & 0.0002 \\
Polyurethane sealant $(\mathrm{kg})$ & 0.023 & 0.002 & 0.022 & 0.002 \\
\hline
\end{tabular}

Due to lack of available data on actual usage quantities for hardwood floors, data come from an EPD on resilient flooring, with the data adjusted on a per-event basis (RFCI, 2013b). The sealant application rate is based on product literature on application rates. ${ }^{55}$

\subsubsection{End of Life}

End of life modeling of the wood flooring, plywood underlayment, and other installation materials includes transportation of these materials by heavy-duty diesel-fuel powered truck approximately $48 \mathrm{~km}$ (30 mi) to a landfill. Truck transportation is based on the U.S. LCI database, and disposal in a landfill is modeled based on ecoinvent end of life waste management process data. The mass that is not biobased (e.g., nails) is assumed to be inert material in a landfill. The rest of the mass is modeled as biogenic material disposed of in a landfill. Mahalle (2011) and EPA's WARM describe the impacts from biogenic material in a landfill as being made up of $\mathrm{CH}_{4}$ from decomposition of biomass and $\mathrm{CO}_{2}$ emissions associated with flaring these emissions where landfill gas is not recovered for energy; and $\mathrm{CO}_{2}$ emissions avoided through landfill gas-to-energy projects. An assumed $23 \%$ of the wood decomposes, so storage of the remaining biogenic carbon is also accounted for in Section 5.1 of Mahalle (2011). The data for net GHG emissions from landfill gas management practices comes from FPI (2011) Table 31. For the wood

\footnotetext{
${ }^{55}$ DuraSeal water-based PUR application data retrieved from http://www.duraseal.com/products/finishes/water-based-polyurethane/.
} 
flooring, these emissions amount to $0.3607 \mathrm{~kg} \mathrm{CO} 2$ per $\mathrm{kg}$ wood and $0.0166 \mathrm{~kg}$ methane per kg wood (Table 31 in Mahalle (2011)).

\subsection{Generic Nylon Carpet}

The development of the generic nylon carpet included in BEES Online 2.0 uses the underlying data and methodology as described in this section.

\subsubsection{Product Description}

For the BEES analysis, a broadloom carpet with a nylon face weight of $1.0 \mathrm{~kg} / \mathrm{m}^{2}$ $\left(30 \mathrm{oz} / \mathrm{yd}^{2}\right)$ and modular carpet, or carpet tile, with nylon face weight of $0.81 \mathrm{~kg} / \mathrm{m}^{2}$ $\left(24 \mathrm{oz} / \mathrm{yd}^{2}\right)$ were studied. The functional unit used for this BEES category is a flooring covering of $0.09 \mathrm{~m}^{2}\left(1 \mathrm{ft}^{2}\right)$ used over the building's operating lifetime of 60 years. The mass for the $0.09 \mathrm{~m}^{2}\left(1 \mathrm{ft}^{2}\right)$ nylon broadloom carpet in BEES is $2.2 \mathrm{~kg} / \mathrm{m}^{2}\left(0.45 \mathrm{lb} / \mathrm{ft}^{2}\right)$ and the mass for $0.09 \mathrm{~m}^{2}\left(1 \mathrm{ft}^{2}\right)$ of nylon carpet tile is $4.8 \mathrm{~kg} / \mathrm{m}^{2}\left(0.98 \mathrm{lb} / \mathrm{ft}^{2}\right)$. The broadloom carpet can be used in both residential and commercial applications. The modular carpet is applicable for commercial use in BEES.

\subsubsection{Flow Diagram}

The flow diagrams in Figure 5-17 and Figure 5-18 show the major elements of the production of this product, as it is currently modeled for BEES.

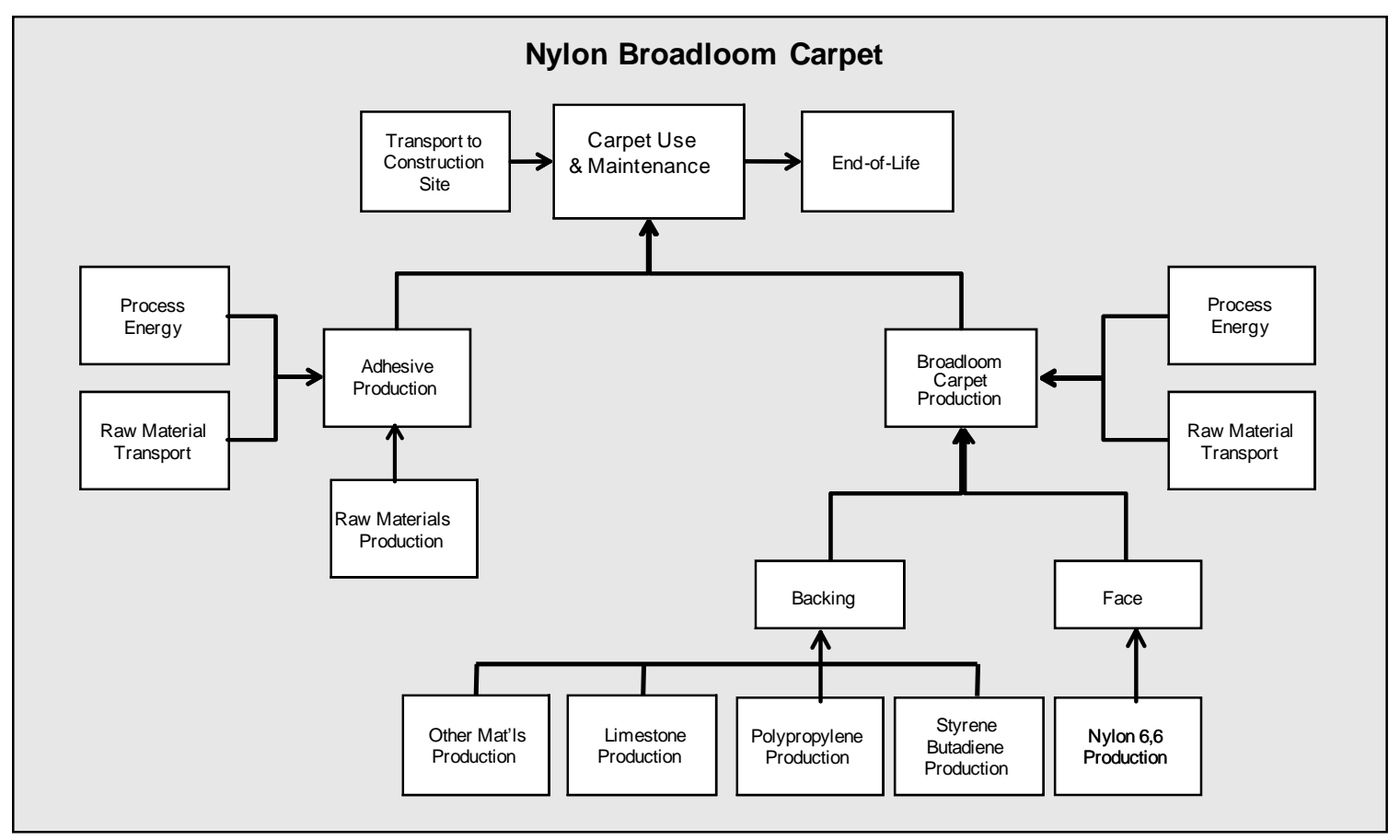

Figure 5-17 Nylon Broadloom Carpet System Boundaries 


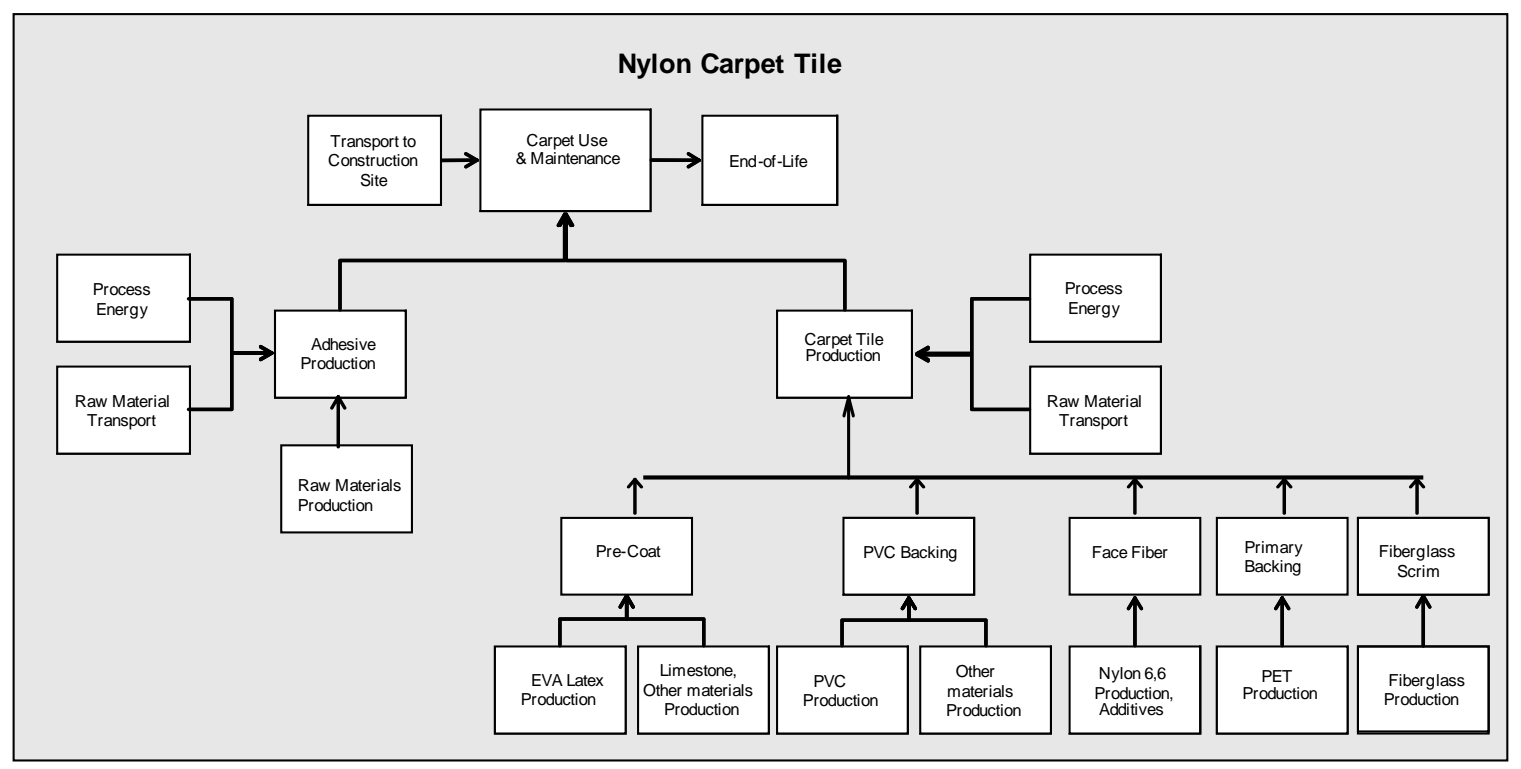

Figure 5-18 Nylon Carpet Tile System Boundaries

\subsubsection{Raw Materials}

The composition of broadloom carpet and carpet tiles differs significantly. Broadloom carpeting consists of the face and a mix of materials that make up the backing of the product. Modular carpet consists of the face and a mix of materials making up several functional layers of the product; specifications are provided in Table 5-51. 
Table 5-51 Nylon Carpet Constituents

\begin{tabular}{llrr}
\hline Constituent & Material & $\mathrm{g} / \mathrm{m}^{2}$ & $\mathrm{oz} / \mathrm{yd}^{2}$ \\
\hline Broadloom & & & \\
Face Fiber & Nylon 6,6 & 1016 & 30 \\
Backing & Limestone & 610 & 18 \\
& Polypropylene (PP) & 237 & 7 \\
& Styrene butadiene (SB) latex & 373 & 11 \\
& Aluminum trihydrate & 203 & 6 \\
& Stainblocker & 0.3 & 0.01 \\
& Other additives & 1.7 & 0.05 \\
\hline & Total & 2442 & 72 \\
\hline Tile & & & \\
Face Fiber & Nylon 6,6 & 814 & 24 \\
Primary backing & PET woven & 119 & 3.5 \\
Pre-coat & EVA latex & 288 & 8.5 \\
& Limestone & 85 & 2.5 \\
& Aluminum hydroxide & 475 & 14 \\
& Other additives & 17 & 0.5 \\
Vinyl Backing & PVC resin & 610 & 18 \\
& Limestone & 1831 & 54 \\
& DOTP plasticizer (replacing DINP) & 644 & 19.0 \\
& Lime & 34 & 1.0 \\
& Other additives & 85 & 2.5 \\
Fiberglass & Fiberglass & 68 & 2.0 \\
\hline & Total & 5070 & 149.5 \\
\hline
\end{tabular}

Data for the materials in the nylon face carpets are generally derived from either U.S. LCI database or ecoinvent data sets. Polypropylene (PP), PET, and PVC resins come from the U.S. LCI database. An acrylonitrile-butadiene-styrene copolymer resin data set, also from U.S. LCI database, was used as a proxy for the Styrene butadiene (SB) latex. Ecoinvent datasets, customized to U.S. energy, were used for the remainder of the materials, except for the plasticizer, which is a confidential data set based on one U.S. manufacturer's late 2010's primary data. Also, aluminum hydroxide (ecoinvent) was used as a proxy for aluminum trihydrate. No data were available to include the stainblocker or other additives in the products, but these constituents make up $0.1 \%$ and $1.6 \%$ of the broadloom and tile carpet bills of materials, respectively.

Transport distance of raw materials to the carpet manufacturing plant is assumed to be $402 \mathrm{~km}$ (500 mi) on average by truck. Data are based on the U.S. LCI database.

Production of product packaging components, as well as their transport to carpet manufacturing facilities, has been included in the BEES model. Broadloom carpet is modeled as rolled onto a recycled content cardboard core and secured in plastic. Carpet tiles are modeled as packaged in recycled content cardboard boxes, stacked on wooden pallets, and secured with stretch wrap. These data are based on the measured quantities provided by Tandus Centiva for their roll and modular products in BEES. 


\subsubsection{Manufacturing}

Carpet manufacturing consists of several steps, including formation of the synthetic fibers; dyeing of the fibers; and construction, treatment, and finishing of the carpet. For both nylon carpet types, the nylon material is made into fibers and then 'tufted' to produce the carpet face. The face yarn is attached, using a primary coating and tufting needles, to the polymer backing. The energy requirements for these process steps are provided in Table 5-52. ${ }^{56}$

Table 5-52 Energy Requirements for Nylon Carpet Manufacturing

\begin{tabular}{lcc}
\hline Energy Carrier & $\begin{array}{c}\text { Broadloom } \\
\text { per } \boldsymbol{~ m}^{2}\left(\text { per } \mathbf{f t}^{2}\right)\end{array}$ & $\begin{array}{c}\text { Tile } \\
\left.\text { per }^{2} \text { per ft }^{2}\right)\end{array}$ \\
\hline Electricity & $0.61 \mathrm{kWh}(0.06 \mathrm{kWh})$ & $0.61 \mathrm{kWh}(0.06 \mathrm{kWh})$ \\
Fuel Oil & $5.0 \mathrm{MJ}(437 \mathrm{Btu})$ & $3.5 \mathrm{MJ}(306 \mathrm{Btu})$ \\
Heating Steam & $1.67 \mathrm{MJ}(145 \mathrm{Btu})$ & $2.4 \mathrm{MJ}(207 \mathrm{Btu})$ \\
\hline
\end{tabular}

Emissions associated with the manufacturing process arise from the production of electricity and the combustion of fuel oil and natural gas, and are based on the U.S. LCI database.

Approximately $4 \%$ waste is generated from the production of nylon broadloom carpet and carpet tile, and this may include trim waste, customer returns, off-specification production, and sew off. All waste is assumed to be disposed of in a landfill; transportation to the landfill by diesel truck and management of the waste in a landfill is accounted for.

\subsubsection{Transportation}

Transportation of the products to the building site is done by heavy-duty truck, and 805 $\mathrm{km}(1500 \mathrm{mi})$ was modeled as the default distance, assuming the majority of carpets are being transported from the Southeast U.S. to various parts of the U.S. Data are based on the U.S. LCI database.

\subsubsection{Installation}

Nylon broadloom carpet and nylon carpet tiles are installed using either standard latex glue or a low-VOC latex glue. For the tile, typical glue application is $0.129 \mathrm{~kg} / \mathrm{m}^{2}(0.026$ $\left.\mathrm{lb} / \mathrm{ft}^{2}\right)$ of installed tile. For the broadloom carpet, $0.63 \mathrm{~kg} / \mathrm{m}^{2}\left(0.129 \mathrm{lb} / \mathrm{ft}^{2}\right)$ is applied to the product. Water-based adhesive formulations today are used far more often than conventional solvent-based adhesives which are known to emit higher levels of VOCs. Because of the broad selection of adhesives on the market and, thus, varying levels of VOCs that could be emitted after installation, the VOC emissions limits for sealants and adhesives, set out in SCAQMD (2011), have been used for the baseline carpet adhesive

\footnotetext{
${ }^{56}$ Data carried over from previous version of BEES.
} 
used in BEES, or $50 \mathrm{~g} / \mathrm{l}$ (0.4 lb/gal) (Table 1 in SCAQMD (2011)). A “low-VOC” alternative is also offered for the BEES user; here, the adhesive is modeled as having a negligible VOC content. Adhesive off-gassing is included for each installation.

For the broadloom carpet used for residential applications, a rubber slab underlayment of $0.058 \mathrm{~kg} / \mathrm{ft}^{2}\left(0.128 \mathrm{lb} / \mathrm{ft}^{2}\right)$ is installed (Table 28 in Mahalle (2011)). Since the rubber slab is considered a durable underlayment material, it is modeled as being replaced at every other new carpet installation.

Installation is primarily a manual process, so no energy use is modeled for the installation phase. Ecoinvent datasets were used to build the adhesive and for the rubber underlayment. Installation scrap varies depending on the job size. It is estimated that, on average, the scrap generated during installation is $4.5 \%$ of the broadloom carpet and $2 \%$ of the carpet tile. Installation waste is modeled as being transported $48 \mathrm{~km}$ (30 mi) by diesel truck and disposed of in a landfill. While some of the packaging waste at installation can be recycled, it is modeled as disposed of in a landfill. No glue is assumed to be wasted during the installation process.

\subsubsection{Use and Maintenance}

The service life of carpets varies depending on the amount of floor traffic and the type and frequency of maintenance. The level of maintenance is also dependent on the actual use and desired appearance of the floor. For BEES, the nylon face broadloom and tile carpets are modeled as having lifetimes of 11 and 15 years, respectively. Replacement, including production of raw materials, manufacturing, transport to installation, etc., is included to account for the BEES flooring category's operating lifetime of 60 years.

BEES includes cleaning and maintenance of the floor covering products during their useful lifetime. Because of maintenance programs developed by individual building owners and different manufacturers' maintenance recommendations, there is no single maintenance regimen that is always followed. For example, frequency of deep cleaning and types and quantities of cleaning solutions will depend on the maintenance programs at the buildings. For BEES, cleaning and maintenance of the floor products is modeled based on industry-wide specifications or recommendations obtained from published EPDs; industry- or manufacturer-specific maintenance guides published on-line; or in some instances, general internet research on best maintenance practices.

Cleaning and maintenance in BEES is divided into two parts. The first, regular vacuuming of dirt and dust is a variable in BEES. The BEES user chooses the vacuuming frequency per week. The second part of cleaning is characterized as intermittent deeper cleaning - for carpets, this activity is extraction cleaning. This deep cleaning is a nonvariable in BEES, although as acknowledged above, frequency may vary from building to building.

The carpet cleaning data are based on recommendations in the CRI Carpet Maintenance Guidelines for Commercial Applications for regular vacuuming and intermittent 
extraction cleaning (CRI, 2014). For BEES, the default number for commercial carpets is 4 times per week, averaging out the vacuuming needs of different traffic volumes (CRI (2014), p.18/30). Residential vacuuming occurs one time per week (default). The commercial carpet is modeled as being deep cleaned two times per year while the residential carpet is modeled as being deep cleaned one time per year. Specific input and output data for vacuuming and deep cleaning come from a carpet cleaning and maintenance report prepared by the CCACTI. Table 5-53 through Table 5-55 provide the energy and other inputs and outputs used for carpet care. Data are from Table 6, Table 8, and Table 10 in Lu et al. (2008).

Table 5-53 Energy per Cleaning Event

\begin{tabular}{lcc}
\hline Electrical energy & MJ per sy & kWh per sf \\
Vacuum & 0.012 & $3.70 \mathrm{E}-04$ \\
Agitator (deep clean) & 0.009 & $2.78 \mathrm{E}-04$ \\
Heat for $120^{\circ} \mathrm{F}$ hot water (deep clean) & 0.144 & $4.44 \mathrm{E}-03$ \\
Extractor (deep clean) & 0.023 & $7.10 \mathrm{E}-04$ \\
Fan drying (deep clean) & 0.087 & $2.69 \mathrm{E}-03$ \\
\hline
\end{tabular}

Table 5-54 Inputs per Cleaning Event

\begin{tabular}{lcc}
\hline Input & kg per $\boldsymbol{s y}$ & $\boldsymbol{l b}$ per $\boldsymbol{s f}$ \\
Water & 0.034 & $8.33 \mathrm{E}-03$ \\
Detergent & 0.0012 & $2.94 \mathrm{E}-04$ \\
Hot water & 1.44 & 0.353 \\
\hline
\end{tabular}

Table 5-55 Outputs per Cleaning Event

\begin{tabular}{lcc}
\hline Output & $\boldsymbol{k g}$ per $\boldsymbol{s y}$ & $\boldsymbol{l b}$ per $\boldsymbol{s f}$ \\
Solid waste from the vacuum & 0.0064 & $1.57 \mathrm{E}-03$ \\
Water output after extraction & 1.44 & 0.353 \\
Detergent effluents & 0.00085 & $2.08 \mathrm{E}-04$ \\
Solid waste from extraction & 0.012 & $2.94 \mathrm{E}-03$ \\
\hline
\end{tabular}

\subsubsection{End of Life}

While there are recycling programs in place for carpets, the products are modeled as landfilled at end of life. End of life modeling includes transportation of the products, their underlayment (where applicable), and adhesive by heavy-duty diesel-fuel powered truck approximately $48 \mathrm{~km}$ (30 mi) to a landfill, plus impacts of the materials in a landfill. Truck transportation is based on the U.S. LCI database and disposal in a landfill is based on ecoinvent end of life waste management process data.

\subsection{Generic Polyester (PET) Broadloom Carpet}

The development of the generic PET broadloom carpet included in BEES Online 2.0 uses the underlying data and methodology as described in this section. 


\subsubsection{Product Description}

For the BEES analysis, a broadloom carpet with a PET face weight of $1.12 \mathrm{~kg} / \mathrm{m}^{2}$ (35 $\mathrm{oz} / \mathrm{yd}^{2}$ ) is included. The functional unit used for this BEES category is floor covering of $0.09 \mathrm{~m}^{2}\left(1 \mathrm{ft}^{2}\right)$ used over the building's operating lifetime of 60 years. The mass modeled for $0.09 \mathrm{~m}^{2}\left(1 \mathrm{ft}^{2}\right)$ PET carpet in BEES is $2.6 \mathrm{~kg} / \mathrm{m}^{2}\left(0.53 \mathrm{lb} / \mathrm{ft}^{2}\right)$. The PET broadloom carpet is used in a residential application.

\subsubsection{Flow Diagram}

The flow diagram in Figure 5-19 shows the major elements of the production of this product, as it is currently modeled for BEES.

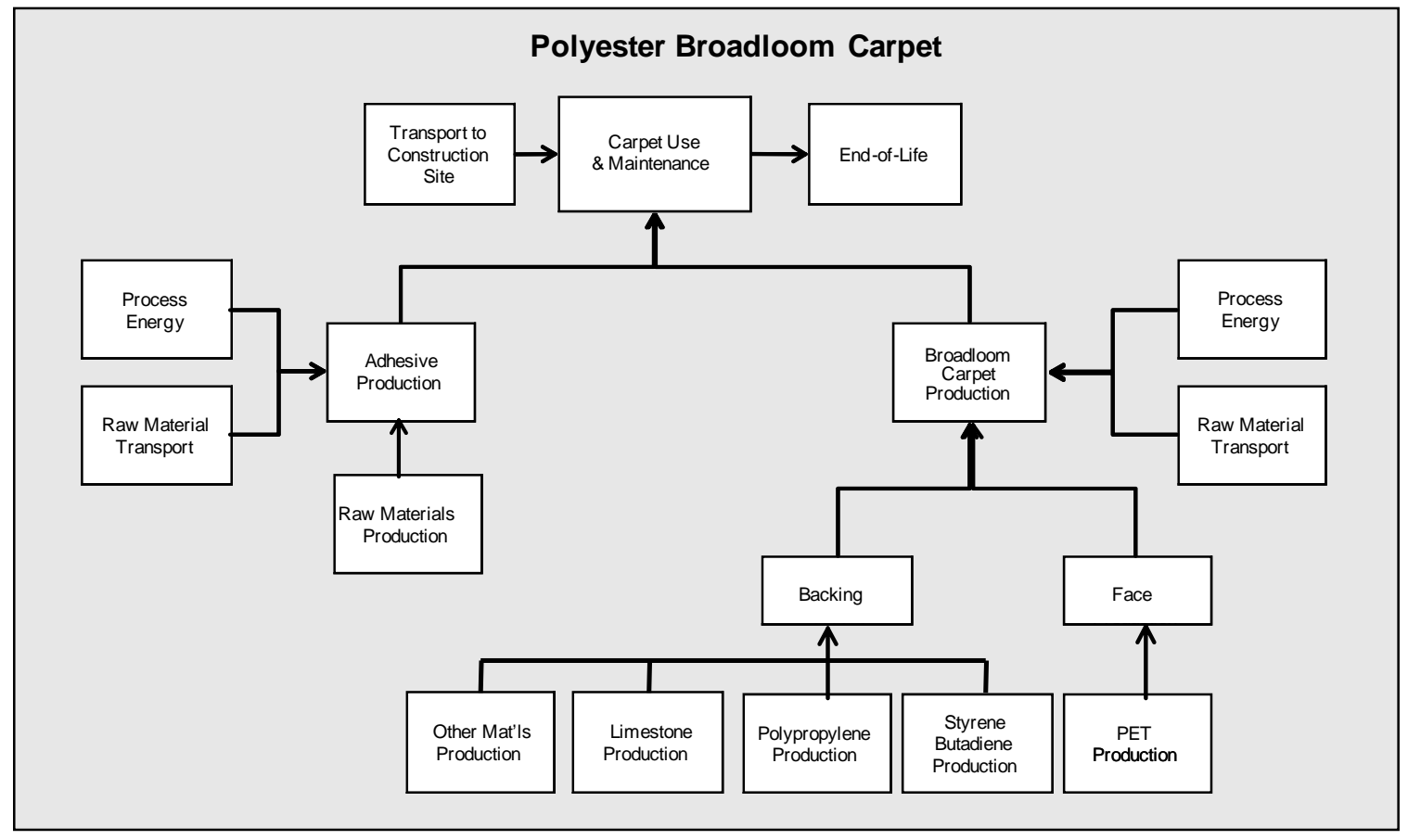

Figure 5-19 PET Broadloom Carpet System Boundaries

\subsubsection{Raw Materials}

PET broadloom carpet consists of the PET face and a mix of materials that make up the backing of the product. Materials are provided in Table 5-56. 
Table 5-56 Polyester Broadloom Carpet Constituents

\begin{tabular}{clcc}
\hline Constituent & \multicolumn{1}{c}{ Material } & $\mathbf{g} / \mathbf{m}^{\mathbf{2}}$ & $\boldsymbol{o z} / \mathbf{y d}^{\mathbf{2}}$ \\
\hline Face Fiber & PET (Polyester) & 1187 & 35 \\
Backing & Limestone & 610 & 18 \\
& Polypropylene (PP) & 237 & 7 \\
& Styrene butadiene (SB) latex & 373 & 11 \\
& Aluminum trihydrate & 203 & 6 \\
& Stainblocker & 0.3 & 0.01 \\
& Other additives & 1.7 & 0.05 \\
\hline & Total & $\mathbf{2 6 1 3}$ & $\mathbf{7 7}$ \\
\hline
\end{tabular}

Data for the materials in this product are from the U.S. LCI database or ecoinvent database. PET and PP resins come from the U.S. LCI database. An acrylonitrilebutadiene-styrene copolymer resin data set, also from U.S. LCI database, was used as a proxy for the SB latex. Ecoinvent datasets, customized to U.S. energy, were used for the remainder of the materials. Aluminum hydroxide, an ecoinvent data set, was used as a proxy for aluminum trihydrate. No data were available to include the stainblocker or other additives in the products, but these make up less than $0.1 \%$ of the mass of the materials.

Transport of raw materials to the carpet manufacturing plant is assumed to be $402 \mathrm{~km}$ (500 mi) on average by truck. Data are based on the U.S. LCI database.

Production of product packaging components, as well as their transport to carpet manufacturing facilities, has been included in the BEES model. Broadloom carpet is modeled as rolled onto a recycled content cardboard core and secured in plastic. This data are based on the measured quantities provided by Tandus Centiva for their roll products in BEES.

\subsubsection{Manufacturing}

Carpet manufacturing consists of several steps, including formation of the synthetic fibers; dyeing of the fibers; and construction, treatment, and finishing of the carpet. No data were available for PET carpet manufacturing, so nylon face carpet manufacturing data were used, ${ }^{57}$ as shown in Table 5-57.

\section{Table 5-57 Energy Requirements for PET Carpet Manufacturing}

\begin{tabular}{lc}
\hline Energy Carrier & Quantity per $\boldsymbol{~ m}^{2}\left(\right.$ per $\left.\boldsymbol{f t}^{2}\right)$ \\
\hline Electricity & $0.61 \mathrm{kWh}(0.06 \mathrm{kWh})$ \\
Fuel Oil & $5.0 \mathrm{MJ}(437 \mathrm{Btu})$ \\
Heating Steam & $1.67 \mathrm{MJ}(145 \mathrm{Btu})$ \\
\hline
\end{tabular}

${ }^{57}$ Data carried over from previous version of BEES. 
Emissions associated with the manufacturing process arise from the production of electricity and the combustion of fuel oil and natural gas, and are based on the U.S. LCI Database.

Approximately $4 \%$ waste is generated from the production of PET broadloom carpet, and this waste may include trim waste, customer returns, off-specification production, and sew off. All waste is assumed to be disposed of in a landfill; transportation to the landfill by diesel truck and management of the waste in a landfill is accounted for.

Assuming a similar quantity of water use as the nylon broadloom operations, approximately $0.96 \mathrm{~kg} / \mathrm{m}^{2}\left(0.20 \mathrm{lb} / \mathrm{ft}^{2}\right)$ of water is modeled as consumed during the manufacture of PET broadloom carpet.

\subsubsection{Transportation}

Transportation of the products to the building site is done by heavy-duty truck, and 805 $\mathrm{km}$ (1500 mi) was modeled as the default distance, assuming the majority of carpets are being transported from the Southeast U.S. to various parts of the U.S. Data are based on the U.S. LCI database.

\subsubsection{Installation}

PET carpet is installed using either standard latex glue or a low-VOC latex glue. The amount of adhesive used for the broadloom carpet is $0.63 \mathrm{~kg} / \mathrm{m}^{2}\left(0.129 \mathrm{lb} / \mathrm{ft}^{2}\right)$. Waterbased adhesive formulations today are used far more often than conventional solventbased adhesives which are known to emit higher levels of VOCs. Because of the broad selection of adhesives on the market and, thus, varying levels of VOCs that could be emitted after installation, the VOC emissions limits for sealants and adhesives, set out in SCAQMD (2011), have been used for the baseline carpet adhesive used in BEES, or 50 g/l (0.4 lb/gal) (Table 1 in SCAQMD (2011)). A “low-VOC” alternative is also offered for the BEES user; here, the adhesive is modeled as having a negligible VOC content. Adhesive off-gassing is included for each installation.

A rubber slab underlayment of $0.058 \mathrm{~kg} / \mathrm{ft}^{2}\left(0.128 \mathrm{lb} / \mathrm{ft}^{2}\right)$ is installed for this residential use (Table 28 in Mahalle (2011)). Since the rubber slab is considered a durable underlayment material, it is modeled as being replaced at every other new carpet installation.

Installation is primarily a manual process, so no energy use is modeled for the installation phase. Ecoinvent datasets were used to build the adhesive and for the rubber underlayment. Installation scrap varies depending on the job size. It is estimated that, on average, the scrap generated during installation is $4.5 \%$ of the broadloom carpet. Installation waste is modeled as being transported $48 \mathrm{~km}$ (30 mi) by diesel truck and disposed of in a landfill. While some of the packaging waste at installation can be recycled, it is modeled as disposed of in a landfill. No glue is assumed to be wasted during installation. 


\subsubsection{Use and Maintenance}

The service life of carpets varies depending on the amount of floor traffic and the type and frequency of maintenance. The level of maintenance is also dependent on the actual use and desired appearance of the floor. For BEES, the PET broadloom carpet is modeled as having a lifetime of 11 years. Replacement, including production of raw materials, manufacturing, transport to installation, etc., is included to account for the BEES flooring category's operating lifetime of 60 years.

BEES includes cleaning and maintenance of the floor covering products during their useful lifetime. Because of maintenance programs developed by individual building owners and different manufacturers' maintenance recommendations, there is no single maintenance regimen that is always followed. For example, frequency of deep cleaning and types and quantities of cleaning solutions will depend on the maintenance programs at the buildings. For BEES, cleaning and maintenance of the floor products is modeled based on industry-wide specifications or recommendations obtained from published EPDs; industry- or manufacturer-specific maintenance guides published on-line; or in some instances, general internet research on best maintenance practices.

Cleaning and maintenance in BEES is divided into two parts. The first, regular vacuuming of dirt and dust is a variable in BEES. The BEES user chooses the vacuuming frequency per week. The second part of cleaning is characterized as intermittent deeper cleaning - for carpets, this activity is extraction cleaning. This cleaning is a non-variable in BEES, although as acknowledged above, frequency may vary from building to building.

The carpet cleaning data are based on recommendations in the CRI Carpet Maintenance Guidelines for Commercial Applications for regular vacuuming and intermittent extraction cleaning (CRI, 2014). For BEES, the default number for residential carpets is once per week, averaging out the vacuuming needs of different traffic volumes (CRI (2014), p.18/30). Residential carpet is modeled as deep cleaned one time per year. Specific input and output data for vacuuming and deep cleaning come from a carpet cleaning and maintenance report prepared by the CCACTI. Table 5-58 through Table 5-60 provide the energy and other inputs and outputs used for carpet care. Data are from Table 6, Table 8, and Table 10 in Lu et al. (2008).

\section{Table 5-58 Energy per Cleaning Event}

\begin{tabular}{lcc}
\hline Electrical energy & MJ per sy & $\boldsymbol{k W h}$ per $\boldsymbol{s} \boldsymbol{f}$ \\
Vacuum & 0.012 & $3.70 \mathrm{E}-04$ \\
Agitator (deep clean) & 0.009 & $2.78 \mathrm{E}-04$ \\
Heat for 120F hot water (deep clean) & 0.144 & $4.44 \mathrm{E}-03$ \\
Extractor (deep clean) & 0.023 & $7.10 \mathrm{E}-04$ \\
Fan drying (deep clean) & 0.087 & $2.69 \mathrm{E}-03$ \\
\hline
\end{tabular}


Table 5-59 Inputs per Cleaning Event

\begin{tabular}{lcc}
\hline Input & $\boldsymbol{k g}$ per $\boldsymbol{s y}$ & $\boldsymbol{l b}$ per $\boldsymbol{s f}$ \\
Water & 0.034 & $8.33 \mathrm{E}-03$ \\
Detergent & 0.0012 & $2.94 \mathrm{E}-04$ \\
Hot water & 1.44 & 0.353 \\
\hline
\end{tabular}

Table 5-60 Outputs per Cleaning Event

\begin{tabular}{lcc}
\hline Output & kg per sy & lb per $\boldsymbol{s f}$ \\
Solid waste from the vacuum & 0.0064 & $1.57 \mathrm{E}-03$ \\
Water output after extraction & 1.44 & 0.353 \\
Detergent effluents & 0.00085 & $2.08 \mathrm{E}-04$ \\
Solid waste from extraction & 0.012 & $2.94 \mathrm{E}-03$ \\
\hline
\end{tabular}

\subsubsection{End of Life}

While there are recycling programs in place for carpets, the PET carpet is modeled as landfilled at end of life. End of life modeling includes transportation of the product, underlayment, and adhesive by heavy-duty diesel-fuel powered truck approximately 48 $\mathrm{km}(30 \mathrm{mi})$ to a landfill, plus impacts of the materials in a landfill. Truck transportation is based on the U.S. LCI database and disposal in a landfill is based on ecoinvent end of life waste management process data.

\subsection{Generic Terrazzo}

The development of the generic terrazzo included in BEES Online 2.0 uses the underlying data and methodology as described in this section.

\subsubsection{Product Description}

Terrazzo is a type of composition flooring. It consists of a mix of marble, granite, onyx, or glass chips in Portland cement, modified Portland cement, or a resinous (epoxy) matrix that is poured, cured, ground, and polished. The BEES model includes a terrazzo floor with epoxy resin, containing a high proportion of inorganic filler (principally marble dust and chips) and a pigment for aesthetic purposes. The materials are mixed and installed directly on site and, when dry, are polished. The functional unit used for BEES is 0.093 $\mathrm{m}^{2}\left(1 \mathrm{ft}^{2}\right)$ of $9.5 \mathrm{~mm}$ (3/8 in) thick terrazzo, used over the building's operating lifetime of 60 years. This product can be used for the residential and commercial markets.

It should be noted that a portion of the information described herein is carried over from the previous BEES model and data.

\subsubsection{Flow Diagram}

The flow diagram in Figure 5-20 shows the major elements of this product as it is modeled for BEES. 


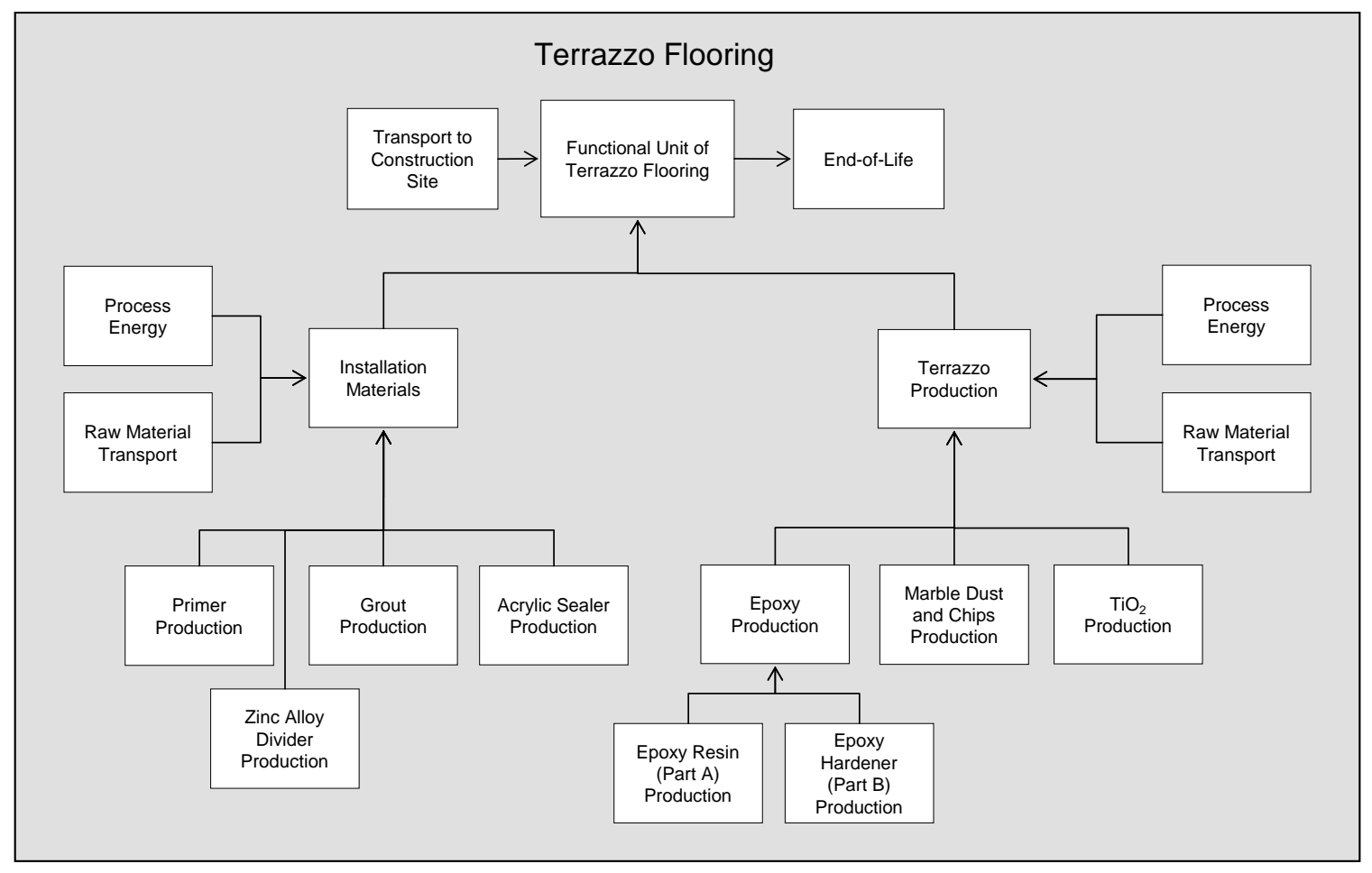

Figure 5-20 Terrazzo System Boundaries

\subsubsection{Raw Materials}

According to the National Terrazzo and Mosaic Association (NTMA), epoxy terrazzo ranges from 14.6 to $19.5 \mathrm{~kg} / \mathrm{m}^{2}$ (3 to $4 \mathrm{lb} / \mathrm{ft}^{2}$ ); the product modeled for BEES is $17 \mathrm{~kg} / \mathrm{m}^{2}$ $\left(3.5 \mathrm{lb} / \mathrm{ft}^{2}\right)$. Table 5-61 lists the constituents of epoxy terrazzo and their proportions.

\section{Table 5-61 Terrazzo Carpet Constituents}

\begin{tabular}{lccc}
\hline Terrazzo Constituents & $\begin{array}{c}\text { Mass } \\
\text { Fraction (\%) }\end{array}$ & $\begin{array}{c}\text { Mass } \\
\left(\mathbf{k g} / \mathrm{m}^{2}\right)\end{array}$ & $\begin{array}{c}\text { Mass } \\
\left(\mathbf{l b} / \mathrm{ft}^{2}\right)\end{array}$ \\
\hline Marble dust and chips & 75 & 12.8 & 2.63 \\
Epoxy resin & 24 & 4.1 & 0.84 \\
Pigment (titanium dioxide) & 1.0 & 0.17 & 0.04 \\
Total & $\mathbf{1 0 0}$ & $\mathbf{1 7 . 0}$ & $\mathbf{3 . 5}$ \\
\hline
\end{tabular}

The term "marble” refers to all calcareous rocks capable of taking a polish (e.g., onyx, travertine, and some serpentine rocks). Marble is quarried, selected to avoid off-color or contaminated material, crushed, washed, and sized to yield marble chips for Terrazzo. ${ }^{58}$ Note that because marble dust is assumed to be a co-product rather than a waste byproduct of marble production, a portion of the burdens of marble quarrying is allocated to marble dust production. An ecoinvent data set for basalt quarry was used as a proxy for marble quarrying.

\footnotetext{
58 Phone conversation with NMTA representative, February 2006.
} 
The epoxy resin consists of two parts: the epoxy resin and the epoxy hardener which initiates the curing. The epoxy resin within the terrazzo is mixed at a ratio of 5:1 resin to hardener. The epoxy resin is based on an ecoinvent data set; the hardener is built using ecoinvent data sets. Depending on customer selection, the terrazzo could have a pigment content of from $1 \%$ to $15 \%$. The pigment is modeled as titanium dioxide, and ecoinvent is used.

The terrazzo constituents are assumed to be transported $402 \mathrm{~km}$ ( $250 \mathrm{mi}$ ) by diesel truck to the terrazzo supplier.

\subsubsection{Manufacturing}

Terrazzo is "manufactured" at the site of installation. The energy requirements for the onsite process include mixing the primer, mixing the terrazzo, grinding the surface (both before and after the application of grout), controlling the dust from grinding, mixing grout, and polishing the floor. The only energy data available are for mixing the terrazzo, which is assumed to require a $5.97 \mathrm{~kW}$ (8 hp) gasoline-powered mixer running for five minutes. Data in Table 5-62 are from U.S. LCI database.

\section{Table 5-62 Energy Requirements for Terrazzo Manufacturing}

\begin{tabular}{lc}
\hline Energy Carrier & $\mathbf{M J} / \mathbf{k g}(\mathrm{Btu} / \mathbf{l b})$ \\
\hline Gasoline & $0.003(1.17)$ \\
\hline
\end{tabular}

\subsubsection{Transportation}

Transportation distance of terrazzo by heavy-duty truck to the building site is modeled as $805 \mathrm{~km}$ (500 mi).

\subsubsection{Installation}

Installing epoxy terrazzo requires a sub-floor of a compatible type, such as cement board, exterior grade plywood, concrete block, concrete, or cement plaster. Most systems adhere to concrete slab subfloors that are level and surface-prepared. Zinc alloy divider strips, epoxy resin (A) and (B), and acrylic sealer are used during installation.

To prevent the terrazzo from cracking, dividers are placed precisely above any concrete joints. Back-to-back "L" strip dividers are recommended for construction joints. Standard dividers are a $9.5 \mathrm{~mm}$ (3/8 in) wide, 16-gauge white zinc alloy, and weigh approximately $0.177 \mathrm{~kg} / \mathrm{m}(0.119 \mathrm{lb} / \mathrm{ft})$. A $10 \mathrm{~cm}(4 \mathrm{in})$ thick concrete slab should have concrete joints at a maximum spacing of $3.7 \mathrm{~m}(12 \mathrm{ft})$; therefore, $29 \mathrm{~m}(96 \mathrm{ft})$ of divider are required for every $13.4 \mathrm{~m}^{2}\left(144 \mathrm{ft}^{2}\right)$. The divider is modeled as aluminum (from U.S. LCI database) with zinc (from ecoinvent). Manufacturer specifications suggest bonding the divider strips to the floor using $100 \%$ solid epoxy resin. The BEES model does not account for the bonding material as the amount is assumed to be negligible relative to the mass of the flooring. 
Prior to applying the terrazzo mixture, the sub-floor must be primed. The primer is made by mixing the epoxy resin components at a lower ratio than that used for the epoxy terrazzo, and two parts epoxy resin to one part hardener has been assumed. Typical coverage is approximately $18.6 \mathrm{~m}^{2}$ to $23.2 \mathrm{~m}^{2}$ (200 $\mathrm{ft}^{2}$ to $250 \mathrm{ft}^{2}$ ) per blended gal of primer, or $0.18 \mathrm{~L} / \mathrm{m}^{2}\left(0.0044 \mathrm{gal} / \mathrm{ft}^{2}\right)$. After the terrazzo mixture has been applied and the surface has been ground, the surface is grouted to fill and seal any voids. An epoxy grout is made by mixing the epoxy resin components in the same ratio used in the epoxy terrazzo. Typical coverage is approximately $46.5 \mathrm{~m}^{2}$ to $65.0 \mathrm{~m}^{2}\left(500 \mathrm{ft}^{2}\right.$ to $\left.700 \mathrm{ft}^{2}\right)$ per blended gal of grout, or $0.068 \mathrm{~L} / \mathrm{m}^{2}\left(0.0017 \mathrm{gal} / \mathrm{ft}^{2}\right)$. The dust after grinding the surfaces (before and after application of grout) is collected and modeled as sent to and disposed of in a landfill.

After the floor has been grouted and polished, two coats of acrylic sealer are applied at an approximate thickness of one to two mils. Typical coverage for a single coat is approximately $74.3 \mathrm{~m}^{2}$ to $92.9 \mathrm{~m}^{2}$ (800 to $1000 \mathrm{ft}^{2}$ ) per gal of sealer. ${ }^{59} \mathrm{With}$ a density of approximately $3.4 \mathrm{~kg} / \mathrm{gal}$, two coats come out to $0.08 \mathrm{~kg} / \mathrm{m}^{2}\left(0.017 \mathrm{lb} / \mathrm{ft}^{2}\right)$. The impact of the acrylic sealer is based on ecoinvent data.

\subsubsection{Use and Maintenance}

With proper maintenance and installation, a 60-year service life is given to the composite marble tile flooring as it is expected to last at least as long as the building itself.

BEES includes cleaning and maintenance of products during their useful lifetime. Because of differing manufacturers' maintenance recommendations, there is no single maintenance regimen that is followed. Cleaning equipment used to maintain floors will depend on the maintenance system selected by the building owner, often based on the desired overall appearance. Frequency of deep cleaning and refinishing or polishing, and types and quantities of these compounds will also depend on the maintenance programs developed by individual building owners. For BEES, cleaning and maintenance is modeled based on industry-wide specifications or recommendations obtained from published EPDs; industry- or manufacturer-specific maintenance guides published online; or in some instances, general internet research on best maintenance practices.

Cleaning and maintenance in BEES is divided into two parts. The first, regular cleaning of dirt and dust (i.e., by way of vacuuming (electrical requirements) or sweeping / dry mopping (non-electrical)) is a variable in BEES. The BEES user chooses the method of regular cleaning along with the frequency per week. The default number for commercial applications is set at four, averaging out the cleaning needs of different volumes of traffic. For residential applications, the cleaning frequency is one time per week. Inputs and outputs per cleaning event of regular maintenance are shown in Table 5-63.

\footnotetext{
59 Terroxy Acrylic Sealer Product Data Sheet, dated June 2015. Retrieved from http://www.tmsupply.com/TMSupply/files/35/35285bb6-3bec-4d42-8c84-03daf456d1ae.pdf.
} 
Table 5-63 Inputs and Outputs per Regular Cleaning Event ${ }^{60}$

\begin{tabular}{lcc}
\hline Vacuum choice & Per m $^{2}$ & Per ft $^{2}$ \\
Electricity & $0.014 \mathrm{MJ}$ & $3.70 \mathrm{E}-04 \mathrm{kWh}$ \\
Solid waste & $0.0077 \mathrm{~kg}$ & $0.0016 \mathrm{lb}$ \\
& & \\
& & Per ft $^{2}$ \\
Sweep / dry mop choice & Per m & $0.0016 \mathrm{lb}$ \\
\hline
\end{tabular}

The solid waste is modeled as being transported by diesel truck and disposed of in a landfill. The second part of cleaning is characterized as intermittent deeper cleaning and other maintenance, and this activity is a non-variable in BEES, although as acknowledged above, it may vary from building to building. Table 5-64 and Table 5-65 present the intermittent cleaning and maintenance schedules and inputs for these flooring products.

Table 5-64 Terrazzo Cleaning Processes and Frequency ${ }^{61,62}$

\begin{tabular}{|c|c|c|c|}
\hline Cleaning Process & $\begin{array}{l}\text { Frequency- } \\
\text { Commercial }\end{array}$ & $\begin{array}{l}\text { Frequency- } \\
\text { Residential }\end{array}$ & Resources Used \\
\hline Damp mop / neutral cleaner & 1x per week & $1 \mathrm{x}$ per 2 week & Hot water, neutral detergent \\
\hline Deep cleaning (scrub) & $1 \mathrm{x}$ per month & $1 \mathrm{x}$ per 2 month & Electricity, neutral detergent, water \\
\hline Polish & $6 \mathrm{x}$ per year & $1 \mathrm{x}$ per year & Floor finish, electricity \\
\hline
\end{tabular}

Table 5-65 Terrazzo Intermittent Cleaning Inputs per Year ${ }^{63}$

\begin{tabular}{lcccc}
\hline & \multicolumn{2}{c}{ Commercial } & \multicolumn{2}{c}{ Residential } \\
\hline Cleaning Input & Per $\mathrm{m}^{2}$ & Per $\mathrm{ft}^{2}$ & Per $\mathrm{m}^{2}$ & Per $\mathrm{ft}^{2}$ \\
Detergent (ml) & 124 & 11.5 & 62 & 5.76 \\
Electricity (kWh) & 0.033 & 0.003 & 0.013 & 0.001 \\
Polish/finish (liter) & 0.10 & 0.009 & 0.017 & 0.002 \\
Water (liter) & 6.2 & 0.58 & 3.1 & 0.29 \\
\hline
\end{tabular}

\subsubsection{End of Life}

Terrazzo is modeled as landfilled at end of life. End of life modeling includes transportation of the terrazzo and installation materials by heavy-duty diesel-fuel powered truck approximately $48 \mathrm{~km}$ (30 mi) to a landfill, plus impacts of the materials in

\footnotetext{
${ }^{60}$ Energy input and solid waste quantity based on Tables 8 and 10 of Lu et al. (2008). This is modeled on an assumption that carpet and other floors have attracted similar quantities of dirt and dust.

61 Terrazzo is assumed to have similar maintenance requirements as linoleum floor products, so maintenance was modeled the same as linoleum in BEES.

${ }^{62}$ Commercial cleaning frequency was modeled based on Armstrong Linoleum EPD (2014), Table 5.

Residential frequency: assumed.

63 No material or energy usage quantities were provided in the Armstrong Linoleum EPD (2014), so inputs were modeled using adjusted data from Table 2 in (RFCI, 2013a).
} 
a landfill. Truck transportation is based on the U.S. LCI database and disposal in a landfill is modeled based on ecoinvent end of life waste management process data.

\subsection{Generic Wool Carpet}

The development of the generic wool carpet included in BEES Online 2.0 uses the underlying data and methodology as described in this section.

\subsubsection{Product Description}

For the BEES analysis, a broadloom carpet and modular carpet tile with wool face fiber weight of $1.36 \mathrm{~kg} / \mathrm{m}^{2}\left(40 \mathrm{oz} / \mathrm{yd}^{2}\right)$ have been included. The functional unit used for this BEES category is a flooring covering of $0.09 \mathrm{~m}^{2}\left(1 \mathrm{ft}^{2}\right)$ used over the building's operating lifetime of 60 years. The mass for the $0.09 \mathrm{~m}^{2}\left(1 \mathrm{ft}^{2}\right)$ wool broadloom carpet in BEES is $2.8 \mathrm{~kg} / \mathrm{m}^{2}\left(0.57 \mathrm{lb} / \mathrm{ft}^{2}\right)$ and the mass for $0.09 \mathrm{~m}^{2}\left(1 \mathrm{ft}^{2}\right)$ of wool carpet tile is $5.6 \mathrm{~kg} / \mathrm{m}^{2}$ $\left(1.15 \mathrm{lb} / \mathrm{ft}^{2}\right)$. The broadloom carpet can be used in both residential and commercial applications. The modular carpet is applicable for commercial use in BEES.

\subsubsection{Flow Diagram}

The flow diagrams in Figure 5-21 and Figure 5-22 show the major elements of the production of this product, as it is currently modeled for BEES.

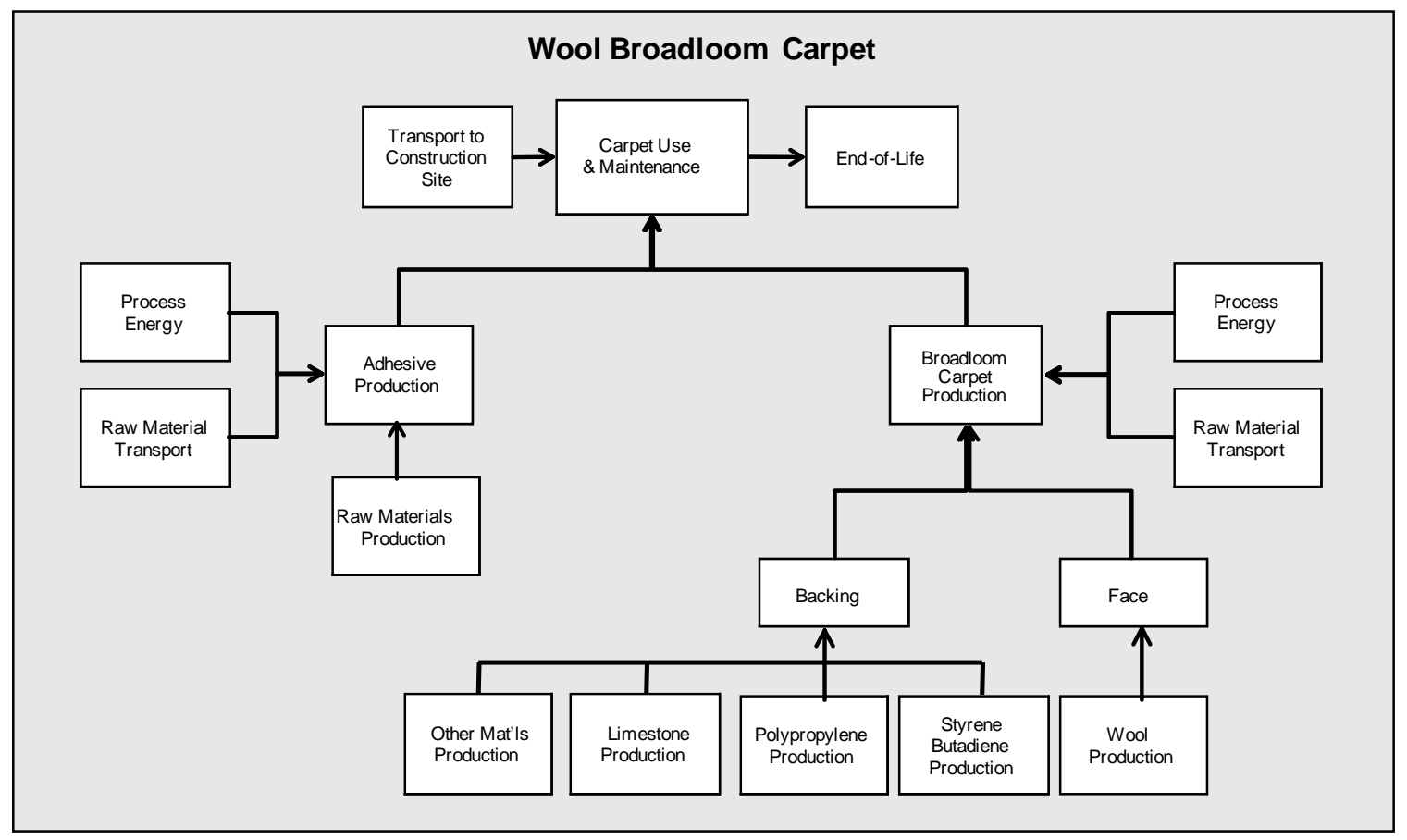

Figure 5-21 Wool Broadloom Carpet System Boundaries 


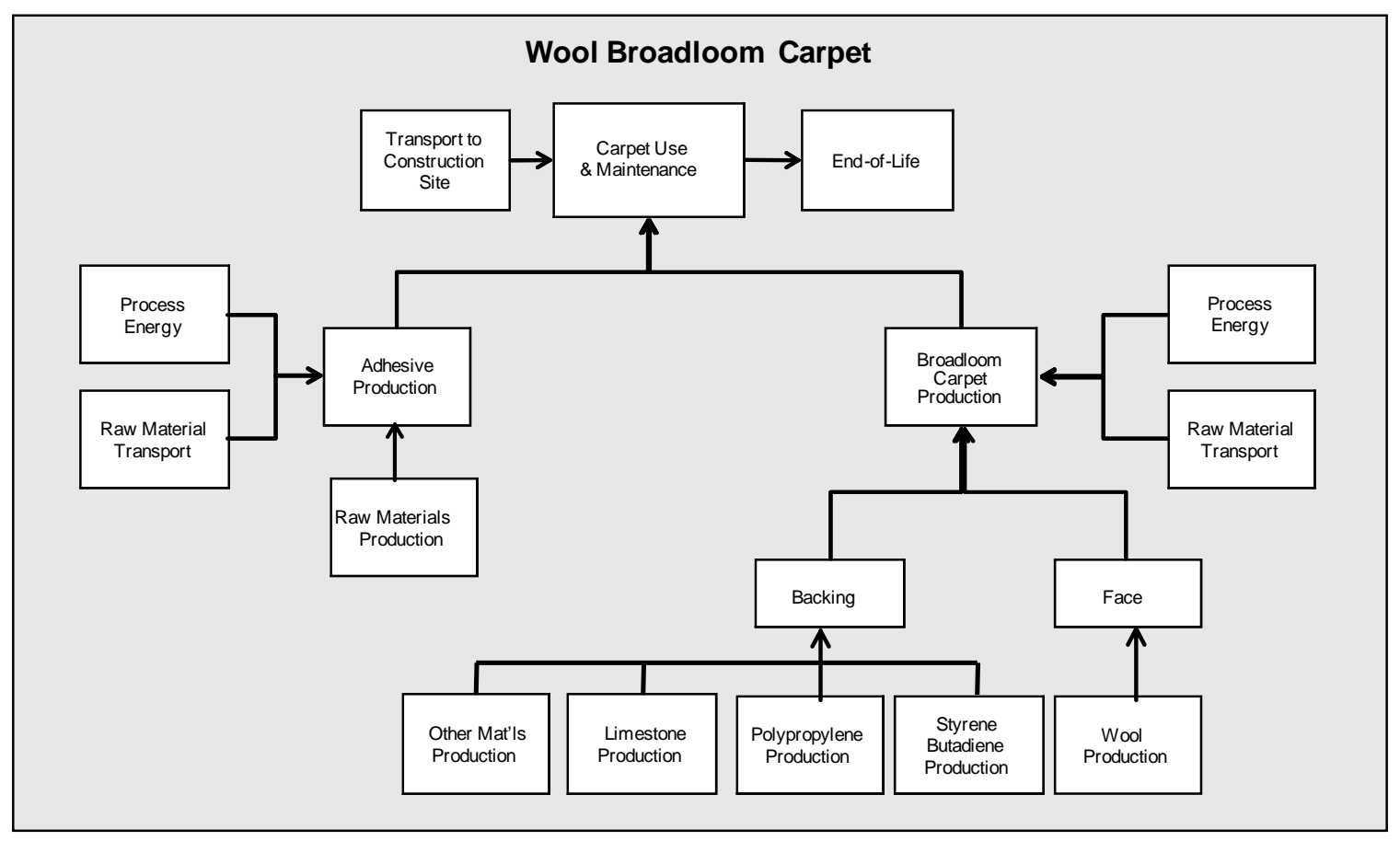

Figure 5-22 Wool Carpet Tile System Boundaries

\subsubsection{Raw Materials}

The composition of broadloom carpet and carpet tiles differs significantly. Broadloom carpeting consists of the face and a mix of materials that make up the backing of the product. Modular carpet consists of the face and a mix of materials making up several functional layers of the product; specifications are provided in Table 5-66. 


\section{Table 5-66 Wool Carpet Constituents}

\begin{tabular}{llll}
\hline Constituent & Material & $\mathrm{g} / \mathrm{m}^{2}$ & $\mathrm{oz} / \mathrm{yd}^{2}$ \\
\hline Broadloom & & & \\
Face Fiber & Wool & 1356 & 40 \\
Backing & Limestone & 610 & 18 \\
& Polypropylene (PP) & 237 & 7 \\
& Styrene butadiene (SB) latex & 373 & 11 \\
& Aluminum trihydrate & 203 & 6 \\
& Stainblocker & 0.3 & 0.01 \\
& Other additives & 1.7 & 0.05 \\
\hline Tile & Total & 2783 & 82 \\
Face Fiber & & & \\
Primary backing & Pool & 1356 & 40 \\
Pre coat & EVA laster (PET) woven & 119 & 3.5 \\
& Limestone & 288 & 8.5 \\
& Aluminum hydroxide & 85 & 2.5 \\
Vinyl Backing & Other additives & 475 & 14 \\
& Polyvinyl chloride (PVC) resin & 17 & 0.5 \\
& Limestone & 610 & 18 \\
& DOTP plasticizer (that has replaced DINP) & 1831 & 54 \\
& Lime & 34 & 1.0 \\
& Other additives & 85 & 2.5 \\
Fiberglass & Fiberglass & 68 & 2.0 \\
\hline & Total & 5612 & 165.5 \\
\hline
\end{tabular}

Data for the materials in the wool face carpets are generally either U.S. LCI database or ecoinvent data sets. PP, PET, and PVC resins come from the U.S. LCI database. An acrylonitrile-butadiene-styrene copolymer resin data set, also from U.S. LCI database, was used as a proxy for the SB latex. Ecoinvent datasets, customized to U.S. energy, were used for the remainder of the materials, with the exception of the plasticizer, which is a confidential data set based on one U.S. manufacturer's late 2010's primary data. Also, aluminum hydroxide (ecoinvent) was used as a proxy for aluminum trihydrate. No data were available to include the stainblocker or other additives in the products, but these make up $0.1 \%$ and $1.6 \%$ of the broadloom and tile carpet bills of materials, respectively.

Data for wool comes from ecoinvent's data sets related to sheep husbandry on pasture land and for wool cleaning and preparation for fiber production. Sheep-related inputs include but are not limited to fertilizer, feed production, and irrigation; wool impacts are based on an ecoinvent-calculated allocation of $22 \%$ (by economic value) of the total sheep. The wool preparation and fiber data were taken from the previous version of BEES. Raw wool is greasy and carries debris that needs to be washed off in a process called "scouring." The amount of washed wool per kg of raw wool is $80 \%$, as shown in Table 5-67 along with mass fractions for other raw wool constituents reported by the Wool Research Organization of New Zealand (WRONZ). 
Table 5-67 Raw Wool Constituents

\begin{tabular}{lc}
\hline \multicolumn{1}{c}{ Constituent } & $\begin{array}{c}\text { Mass } \\
\text { Fraction (\%) }\end{array}$ \\
\hline Clean fiber (ready to be carded and spun) & 80 \\
Grease & 6 \\
Suint salts & 6 \\
Dirt & 8 \\
\hline
\end{tabular}

Grease is recovered at an average rate of $40 \%$, and the non-recovered grease exits the system (e.g., as sludge from water effluent treatment). The scoured fiber is then dried, carded, and spun. Table 5-68 lists the main inflows and outflows for the production of wool yarn from raw wool as reported by WRONZ.

\section{Table 5-68 Wool Yarn Production Requirements}

\begin{tabular}{|c|c|}
\hline Flow & Amount per kg (per lb) wool yarn \\
\hline \multicolumn{2}{|l|}{ Input } \\
\hline Natural Gas & 5.375 MJ (3.29 kWh) \\
\hline Electricity & $0.70 \mathrm{MJ}(0.43 \mathrm{kWh})$ \\
\hline Lubricant & 0.063 kg (0.31 lb) \\
\hline Water & 37.5 l (21.79 gal) \\
\hline \multicolumn{2}{|l|}{ Output } \\
\hline Wool yarn ${ }^{64}$ & $1 \mathrm{~kg}(4.85 \mathrm{lb})$ \\
\hline \multicolumn{2}{|l|}{ Water emissions due to scouring: } \\
\hline Biochemical Oxygen Demand & $4.125 \mathrm{~g}(0.02 \mathrm{lb})$ \\
\hline Chemical Oxygen Demand & $11.625 \mathrm{~g}(0.06 \mathrm{lb})$ \\
\hline
\end{tabular}

Most of the required energy is used at the scouring step. Since grease is a co-product of the scouring process, a mass-based allocation is used to determine how much of the energy entering this process is due exclusively to the production of washed wool. Onefourth of the required energy is used for drying. Lubricant is added for blending, carding, and spinning, and some lubricant is incorporated into the wool. Approximately $6 \%$ of the wool is lost during the blending, carding, and spinning processes of yarn production; this waste is accounted for in the BEES data for the manufacturing lifecycle stage.

Truck transport of raw materials to the manufacturing plant is assumed to be $402 \mathrm{~km}$ (500 mi) on average by truck. Wool, most of which is assumed to come from New Zealand, is transported $14688 \mathrm{~km}$ (9129 mi). Data are based on the U.S. LCI database.

Production of product packaging components, as well as their transport to carpet manufacturing facilities, has been included in the BEES model. Broadloom carpet is modeled as rolled onto a recycled content cardboard core and secured in plastic. Carpet tiles are modeled as packaged in recycled content cardboard boxes, stacked on wooden

\footnotetext{
${ }^{64}$ Accounts for the loss due to the $80 \%$ mass fraction of clean fiber in raw wool.
} 
pallets, and secured with stretch wrap. These data are based on the measured quantities provided by Tandus Centiva for their roll and modular products in BEES.

\subsubsection{Manufacturing}

Wool yarn production into carpet fiber requires additional steps including bleaching, dyeing, and finishing. The inputs to the bleaching process, provided in Table 5-69, are based on a Best Available Techniques document for the textile industry (European Commission (2003), p.135). No energy data are available for bleaching, and information for dyeing and finishing is not sufficient to permit inclusion in the BEES model.

\section{Table 5-69 Wool Yarn Bleaching Inputs}

\begin{tabular}{lc}
\hline \multicolumn{1}{c}{ Input } & $\begin{array}{c}\mathbf{k g} / \mathbf{k g}(=\mathbf{l b} / \mathbf{l b}) \\
\text { Wool Yarn }\end{array}$ \\
\hline Stabilizer & 0.030 \\
Sodium Tri-Polyphosphate & 0.015 \\
Hydrogen Peroxide (35\%) & 0.200 \\
Formic Acid (85\%) & 0.002 \\
Sodium Hydrosulphite & 0.008 \\
\hline
\end{tabular}

For both wool carpet types, the wool must be "tufted" to produce the carpet face. The face yarn is attached, using a primary coating and tufting needles, to the carpet backing. The energy requirements for this process step are provided in Table 5-70.

\section{Table 5-70 Energy Requirements for Wool Carpet Tufting}

\begin{tabular}{lc}
\hline Energy Carrier & $\mathbf{M J} / \mathbf{m}^{2}\left(\mathbf{k W h} / \mathbf{f t}^{2}\right)$ \\
\hline Electricity & $1.79(0.05)$ \\
Natural Gas (industrial boiler) & $8.13(0.21)$ \\
\hline Total & $9.92(0.26)$ \\
\hline
\end{tabular}

Emissions associated with the manufacturing process arise from the production of electricity and the combustion of natural gas, and are based on the U.S. LCI Database. Approximately $0.01 \mathrm{~kg}(0.02 \mathrm{lb})$ of waste is generated from the production of $0.09 \mathrm{~m}^{2}$ $\left(1 \mathrm{ft}^{2}\right)$ of wool broadloom and tile carpeting. The waste is assumed to be disposed of in a landfill; transportation to the landfill by diesel truck and management of the waste in a landfill is accounted for.

\subsubsection{Transportation}

Transportation of the products to the building site is done by heavy-duty truck, and $805 \mathrm{~km}$ (1500 mi) was modeled as the default distance, assuming the majority of carpets are being transported from the Southeast U.S. to various parts of the U.S. Data are based on the U.S. LCI database. 


\subsubsection{Installation}

Wool broadloom carpets and carpet tiles are installed using either standard latex glue or a low-VOC latex glue. For the tile, typical glue application is $0.129 \mathrm{~kg} / \mathrm{m}^{2}\left(0.026 \mathrm{lb} / \mathrm{ft}^{2}\right)$ of installed tile. For the broadloom carpet, $0.63 \mathrm{~kg} / \mathrm{m}^{2}\left(0.129 \mathrm{lb} / \mathrm{ft}^{2}\right)$ is applied to the product. Water-based adhesive formulations today are used far more often than conventional solvent-based adhesives which are known to emit higher levels of VOCs. Because of the broad selection of adhesives on the market and, thus, varying levels of VOCs that could be emitted after installation, the VOC emissions limits for sealants and adhesives, set out in SCAQMD (2011), have been used for the baseline carpet adhesive used in BEES, or 50 g/l (0.4 lb/gal) (Table 1 in SCAQMD (2011)). A “low-VOC” alternative is also offered for the BEES user; here, the adhesive is modeled as having a negligible VOC content. Adhesive off-gassing is included for each installation.

For the broadloom carpet used for residential applications, a rubber slab underlayment of $0.058 \mathrm{~kg} / \mathrm{ft}^{2}\left(0.128 \mathrm{lb} / \mathrm{ft}^{2}\right)$ is installed (Table 28 in Mahalle (2011)). Since the rubber slab is considered a durable underlayment material, it is modeled as being replaced at every other new carpet installation.

Installation is primarily a manual process, so no energy use is modeled for the installation phase. Ecoinvent datasets were used to build the adhesive and for the rubber underlayment. Installation scrap varies depending on the job size. It is estimated that, on average, the scrap generated during installation is $4.5 \%$ of the broadloom carpet and $2 \%$ of the carpet tile. Installation waste is modeled as being transported $48 \mathrm{~km}$ (30 mi) by diesel truck and disposed of in a landfill. While some of the packaging waste at installation can be recycled, it is modeled as being disposed of in a landfill. No glue is assumed to be wasted during the installation process.

\subsubsection{Use and Maintenance}

The service life of carpets varies depending on the amount of floor traffic and the type and frequency of maintenance. The level of maintenance is also dependent on the actual use and desired appearance of the floor. For BEES, the wool face carpets are modeled as having lifetimes of 25 years. Replacement, including production of raw materials, manufacturing, transport to installation, etc., is included to account for the BEES flooring category's operating lifetime of 60 years.

BEES includes cleaning and maintenance of the floor covering products during their useful lifetime. Because of maintenance programs developed by individual building owners and different manufacturers' maintenance recommendations, there is no single maintenance regimen that is always followed. For example, frequency of deep cleaning and types and quantities of cleaning solutions will depend on the maintenance programs at the buildings. For BEES, cleaning and maintenance of the floor products is modeled based on industry-wide specifications or recommendations obtained from published EPDs; industry- or manufacturer-specific maintenance guides published on-line; or in some instances, general internet research on best maintenance practices. 
Cleaning and maintenance in BEES is divided into two parts. The first, regular vacuuming of dirt and dust is a variable in BEES. The BEES user chooses the vacuuming frequency per week. The second part of cleaning is characterized as intermittent deeper cleaning - for carpets, this activity is extraction cleaning. This deep cleaning is a nonvariable in BEES, although as acknowledged above, frequency may vary from building to building.

The carpet cleaning data are based on recommendations in the Carpet and Rug Institute Carpet Maintenance Guidelines for Commercial Applications for regular vacuuming and intermittent extraction cleaning (CRI, 2014). For BEES, the default number for commercial carpets is 4 times per week, averaging out the vacuuming needs of different traffic volumes (CRI (2014), p.18/30). Residential vacuuming occurs one time per week (default). The commercial carpet is modeled as deep cleaned two times per year while the residential carpet is modeled as deep cleaned one time per year. Specific input and output data for vacuuming and deep cleaning come from a carpet cleaning and maintenance report prepared by the CCACTI. Table 5-71 through Table 5-73 provide the energy and other inputs and outputs used for carpet care. Data are from Table 6, Table 8, and Table 10 in Lu et al. (2008).

\section{Table 5-71 Energy per Cleaning Event ${ }^{65}$}

\begin{tabular}{lcc}
\hline Electrical energy & MJ per sy & $\boldsymbol{k W h}$ per $\boldsymbol{s}$ \\
Vacuum & 0.012 & $3.70 \mathrm{E}-04$ \\
Agitator (deep clean) & 0.009 & $2.78 \mathrm{E}-04$ \\
Heat for 120F hot water (deep clean) & 0.144 & $4.44 \mathrm{E}-03$ \\
Extractor (deep clean) & 0.023 & $7.10 \mathrm{E}-04$ \\
Fan drying (deep clean) & 0.087 & $2.69 \mathrm{E}-03$ \\
\hline
\end{tabular}

\section{Table 5-72 Inputs per Cleaning Event}

\begin{tabular}{lcc}
\hline Input & kg per $\boldsymbol{s y}$ & $\boldsymbol{l b}$ per $\boldsymbol{s} \boldsymbol{f}$ \\
Water & 0.034 & $8.33 \mathrm{E}-03$ \\
Detergent & 0.0012 & $2.94 \mathrm{E}-04$ \\
Hot water & 1.44 & 0.353 \\
\hline
\end{tabular}

Table 5-73 Outputs per Cleaning Event

\begin{tabular}{lcc}
\hline Output & $\boldsymbol{k g}$ per $\boldsymbol{s y}$ & $\boldsymbol{l b}$ per $\boldsymbol{s} \boldsymbol{f}$ \\
Solid waste from the vacuum & 0.0064 & $1.57 \mathrm{E}-03$ \\
Water output after extraction & 1.44 & 0.353 \\
Detergent effluents & 0.00085 & $2.08 \mathrm{E}-04$ \\
Solid waste from extraction & 0.012 & $2.94 \mathrm{E}-03$ \\
\hline
\end{tabular}

\subsubsection{End of Life}

\footnotetext{
${ }^{65}$ Energy input and solid waste quantity based on Tables 8 and 10 of Lu et al. (2008). This is modeled on an assumption that carpet and other floors have attracted similar quantities of dirt and dust.
} 
While there are recycling programs in place for carpets, the products are modeled as landfilled at end of life. End of life modeling includes transportation of the products, their underlayment (where applicable), and adhesive by heavy-duty diesel-fuel powered truck approximately $48 \mathrm{~km}(30 \mathrm{mi})$ to a landfill, plus impacts of the materials in a landfill. Truck transportation is based on the U.S. LCI database and disposal in a landfill is based on ecoinvent end of life waste management process data. 


\section{Exterior Wall Finish Category}

The exterior wall finish category covers both residential and commercial products.

\subsection{Exterior Wall Finish Types}

There are a range of exterior wall finish types included in the exterior wall finish category as shown in Table 6-1.

\section{Table 6-1 Exterior Wall Finish Types and Subtypes}

\begin{tabular}{ll}
\multicolumn{2}{c}{ Exterior Wall Finish } \\
Types & Subtypes \\
\hline Siding & Vinyl \\
& Insulated Vinyl \\
& Cedar \\
& Aluminum \\
\hline Stucco & N/A \\
\hline Brick & N/A \\
\hline
\end{tabular}

\subsection{Exterior Wall Finish Characteristics and Certifications}

BEES Online 2.0 has added a feature to filter/restrict products selected based on product characteristics, such as fraction recycled materials, and product certifications, such as U.S. Department of Agriculture (USDA) Certified Biobased. The current list of characteristics and certifications provided in BEES 2.0 are listed in Table 6-2.

\section{Table 6-2 Exterior Wall Finish Characteristics and Certifications}

\begin{tabular}{ll}
\hline \multicolumn{2}{c}{ Characteristics and Certifications } \\
\hline Federal Agency Certifications & None \\
\hline Standard Certification & None \\
\hline NGO Certification & None \\
\hline Characteristics & $25 \%$ Recycled Content \\
& $35 \%$ Recycled Content \\
& $50 \%$ Recycled Content \\
& $75 \%$ Recycled Content \\
\hline
\end{tabular}

\subsection{Exterior Wall Finish Installation, Service Life, and Use Phase}

To evaluate the life cycle impacts of exterior wall finishes, it is necessary to consider the installation and use phase impacts, both of which could vary depending on decisions outside the product manufacturer's control. It is assumed there are no use phase impacts while installation impacts are incorporated into the products embodied impacts. The 
default assumed service life is defined for each BEES product in its associated documentation.

\subsection{Generic Stucco Cladding}

Stucco is typically a mixture of sand, cement, and lime applied to masonry or framed walls. Stucco is desired for aesthetics, integral colors, fire ratings, high abuse resistance, and low maintenance. BEES covers two types of stucco. Traditional three-coat stucco is made up of two base coats and a finish coat of Portland cement and/or masonry cement. One coat stucco, an alternative to traditional stucco, is made up of one base coat and one finish coat of plaster cement, using almost half the cement of three coat, and a rigid foam sheathing layer.

\subsubsection{Product Description}

The BEES model assumes a functional unit of $0.09 \mathrm{~m}^{2}\left(1 \mathrm{ft}^{2}\right)$ of stucco applied to a frame construction, i.e., stucco applied over expanded metal lath or woven wire, for 60 years. Three coat stucco is used for residential and commercial applications, while one-coat may be used in residential and light commercial applications. ${ }^{66}$

In BEES, three-coat stucco totals $2.22 \mathrm{~cm}$ (7/8 in) in thickness. Coats one and two are each nominally $0.95 \mathrm{~cm}$ (3/8 in) thick and the finish coat is $0.32 \mathrm{~cm}(1 / 8 \mathrm{in})$ thick. The base and finish coat densities for Portland cement and masonry cement stuccos are shown in Table 6-3. Since no specific data were available on overall North America market share of Portland cement and masonry cement stucco, life cycle data for the two cement types were averaged (50-50) for use in the BEES model.

One-coat stucco in BEES is modeled as having one base coat of $0.95 \mathrm{~cm}(3 / 8$ in) thick and a finish coat of $0.32 \mathrm{~cm}(1 / 8 \mathrm{in})$ (ORNL, 2012). The rigid foam insulation is $2.54 \mathrm{~cm}$ (1 in) expanded polystyrene (EPS). While three-coat stucco preparation is prescriptive (i.e., specified amounts of Portland cement and/or masonry cement), one coat, not currently written into building code or explicitly covered by ASTM standards, must use formulation(s) that adhere to the performance requirements set out in the code bodies.

Table 6-3 Density of Stucco by Plaster Cement Type

\begin{tabular}{lc}
\hline \multicolumn{1}{c}{ Type of Stucco } & $\begin{array}{c}\text { Density } \\
\mathbf{k g} / \mathbf{m}^{3}\left(\mathbf{l b} / \mathbf{f t}^{3}\right)\end{array}$ \\
\hline Portland Cement Base Coat (Type C plaster) & $1830(114)$ \\
Portland Cement Finish Coat (Type F plaster) & $1971(123)$ \\
Masonry Cement Base Coat (Type MS plaster) & $1907(119)$ \\
Masonry Cement Finish Coat (Type FMS plaster) & $2175(136)$ \\
\hline
\end{tabular}

\footnotetext{
${ }^{66}$ Code prohibits one coat on Type I and Type II buildings. For BEES, this is designated only as a
} residential product. 


\subsubsection{Flow Diagram}

The flow diagrams in Figure 6-1 through Figure 6-3 show the major elements of Portland cement three-coat stucco, masonry cement three-coat stucco, and one-coat stucco exterior sidings.

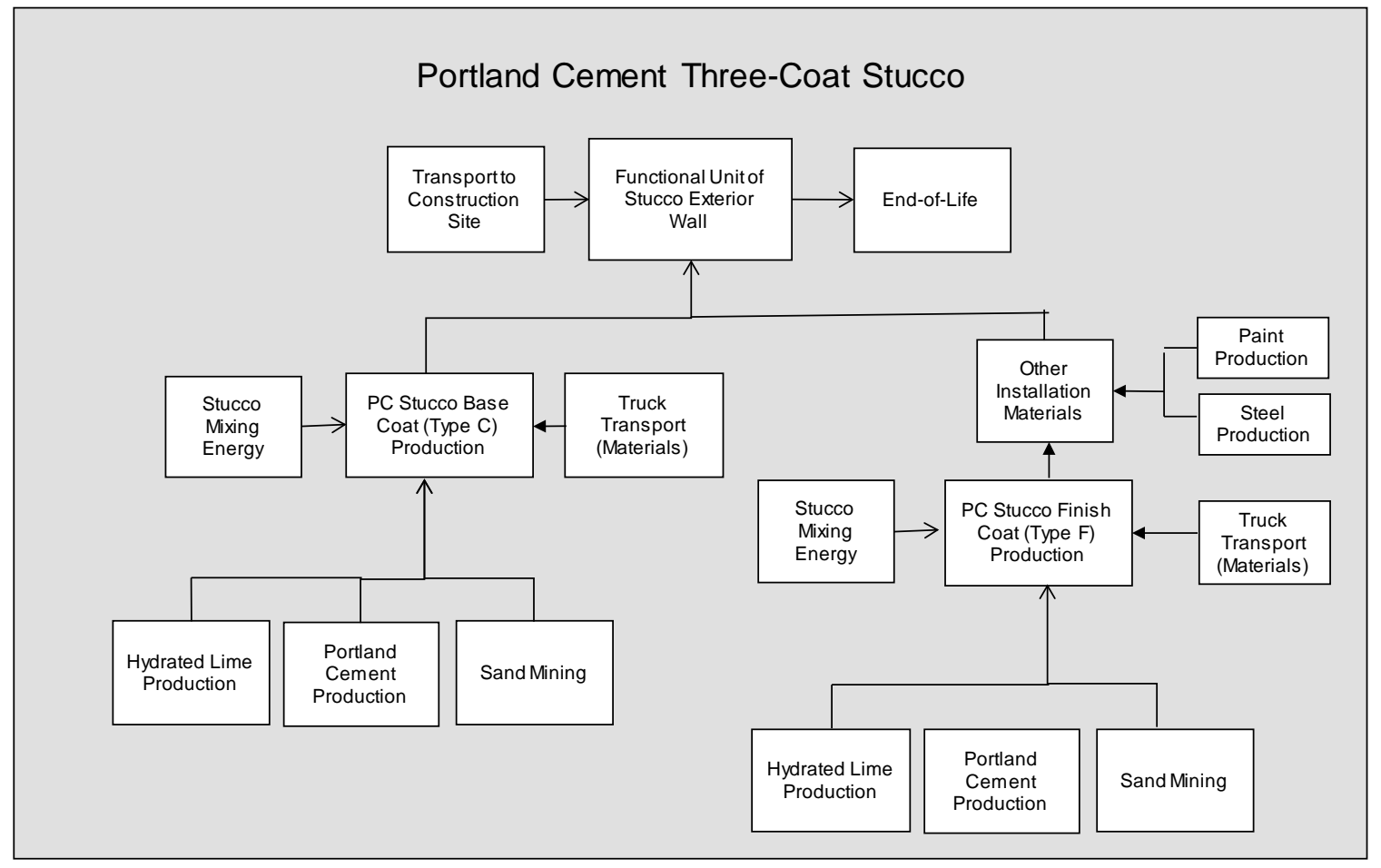

Figure 6-1 Portland Cement Three-Coat Stucco System Boundaries 


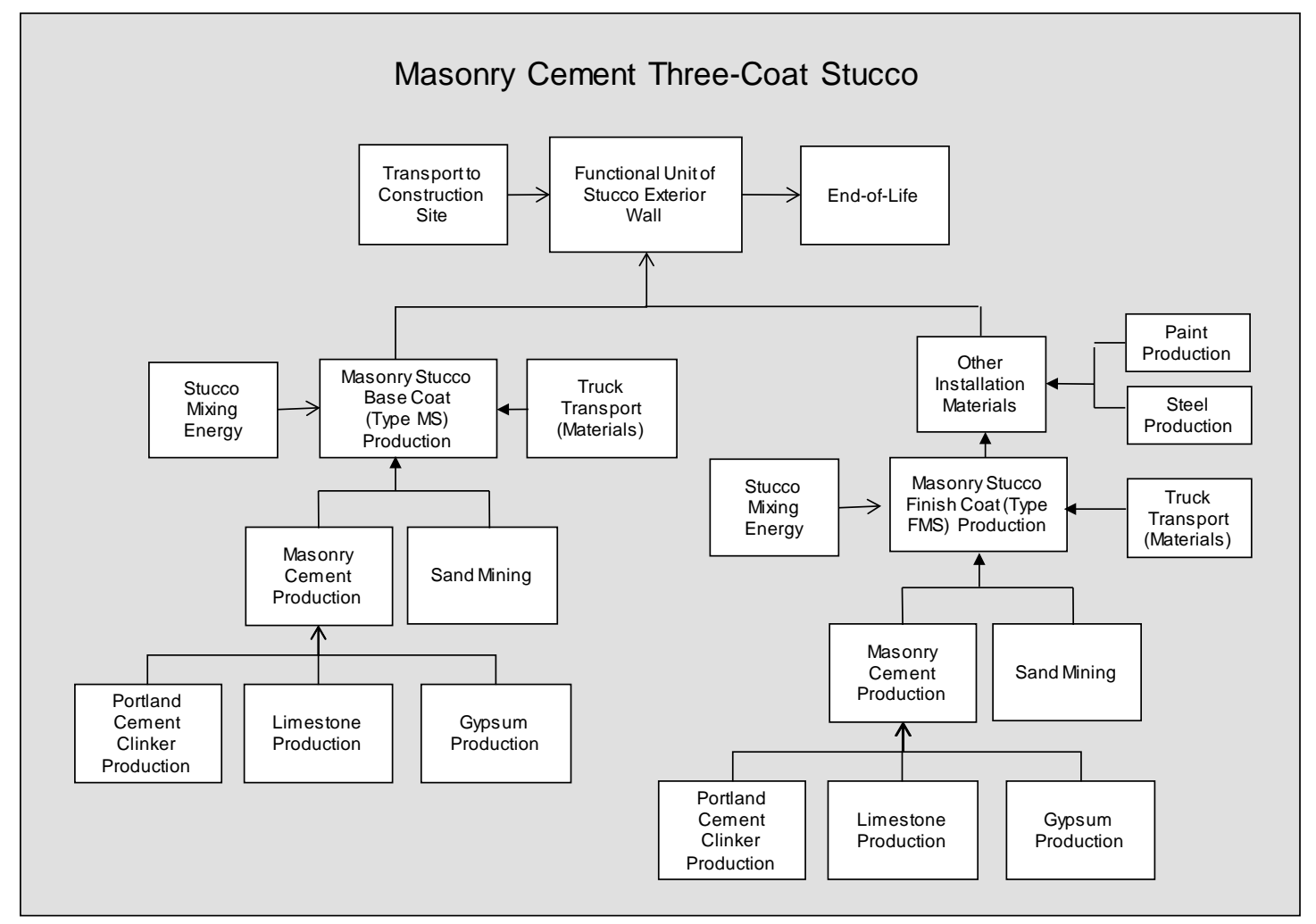

Figure 6-2 Masonry Cement Three-Coat Stucco System Boundaries

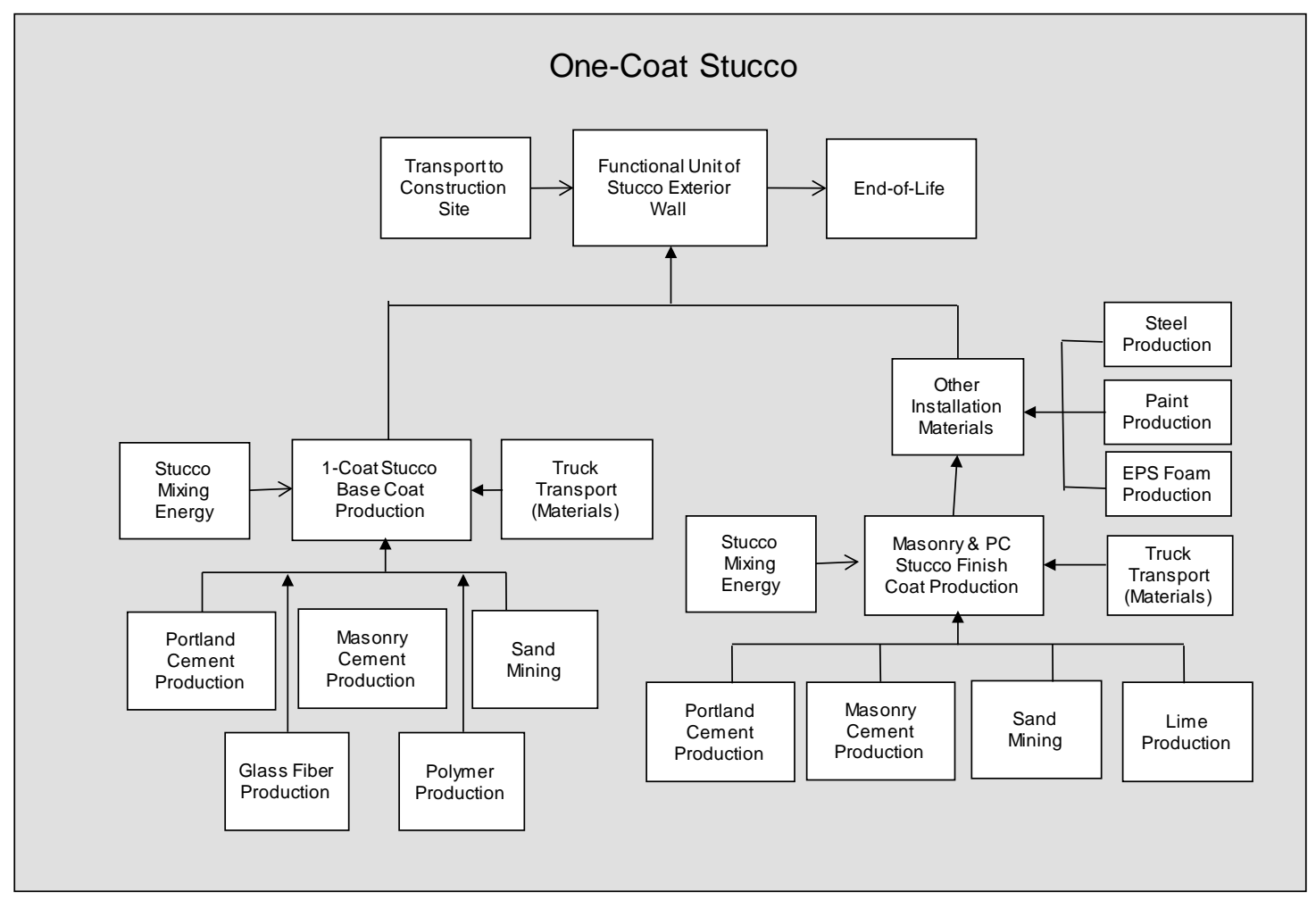

Figure 6-3 One-Coat Stucco System Boundaries 


\subsubsection{Raw Materials}

The material compositions of three coat stucco using Portland cement and masonry cement base coat and finish coats are shown in Table 6-4. ${ }^{67}$

\section{Table 6-4 Three Coat Stucco Constituents}

\begin{tabular}{|c|c|c|c|c|}
\hline \multirow{2}{*}{ Constituent } & \multicolumn{3}{|c|}{$\begin{array}{c}\text { Cementitious Materials } \\
\text { (volume fraction) }\end{array}$} & \multirow{2}{*}{$\begin{array}{l}\text { Sand (volume } \\
\text { fraction of } \\
\text { cementitious } \\
\text { material) }\end{array}$} \\
\hline & $\begin{array}{c}\text { Portland } \\
\text { Cement }\end{array}$ & $\begin{array}{l}\text { Masonry } \\
\text { Cement }\end{array}$ & Lime & \\
\hline Base Coat C & 1 & & 1.125 & 3.25 \\
\hline Finish Coat F & 1 & & 1.125 & 3 \\
\hline Base Coat MS & & 1 & & 3.25 \\
\hline Finish Coat FMS & & 1 & & 3 \\
\hline
\end{tabular}

The base coat cement for one coat stucco is a proprietary blend of sand, cement, lime, fiber for reinforcement, and additives. The constituents and their mass fractions vary across manufacturers, but a generic formulation is presented in Table 6-5.

Table 6-5 One Coat Stucco Constituents

\begin{tabular}{lc}
\hline Constituent & Mass Fraction (\%) \\
\hline Sand & 70.0 \\
Cement & 25.0 \\
Glass fiber & 2.0 \\
Polymers & 3.0 \\
\hline
\end{tabular}

The cement is modeled as an average of masonry and Portland cements, described below. The polymer is assumed to be acrylic polymer. One coat stucco's top coat is identical to the top coat used for three coat stucco (both in composition and thickness).

Portland and Masonry Cement Production: The Portland cement data come from Portland Cement Association's (PCA's) U.S. industry-average data (PCA, 2016a). The raw material use for masonry cement is based on Type $\mathrm{N}$ masonry cement, and its constituents are shown in Table 6-6 (PCA, 2016b).

\section{Table 6-6 Masonry Cement Constituents}

\begin{tabular}{lc}
\hline \multicolumn{1}{c}{ Constituent } & Mass Fraction (\%) \\
\hline Portland cement clinker & $57.5 \%$ \\
Limestone & $36.1 \%$ \\
Gypsum & $4.9 \%$ \\
Dust (e.g., bypass dust) & $1.1 \%$ \\
Other inputs & $0.5 \%$ \\
Total & $\mathbf{1 0 0 . 0} \%$ \\
\hline
\end{tabular}

${ }^{67}$ Based on ASTM Specification C926-94. 
The contents of materials above are based on ecoinvent customized to U.S. conditions. Other Three-Coat and One-Coat Stucco Constituents: Data for the lime, sand, acrylic binder, and glass fiber come from the ecoinvent database customized to U.S. conditions.

Transportation of raw materials: Many of the raw materials used for stucco are locally sourced; an assumed $90 \%$ of materials is modeled as being transported $322 \mathrm{~km}$ (200 mi) by truck. The remaining materials are transported an average of $3219 \mathrm{~km}$ (2 $000 \mathrm{mi})$, assumed to be by rail.

\subsubsection{Manufacturing}

Stucco is "manufactured" and assembled at the point of installation. See the section below on "Installation."

\subsubsection{Transportation}

The stucco raw materials are transported to the building site via diesel truck an average distance of $805 \mathrm{~km}$ (500 mi). The BEES user can change this default distance within BEES.

\subsubsection{Installation}

Stucco is commonly delivered to a job site in one-cubic yard bags (approximately $42.6 \mathrm{~kg}$ (94 lb)). Gasoline, diesel, or electric mixers can prepare up to thirty bags per day of stucco. Large pumps may also be used at job sites; these can pump approximately 200 bags per day, dramatically increasing production time and efficiency. According to Stucco Manufacturers Association (SMA), pumps account for approximately $75 \%$ of the bagged plastic cement used, and BEES models this preparation method. The pumping motor is a four-cylinder pump which uses about $37.8 \mathrm{l}$ to $45.4 \mathrm{l}$ (10 gal to 12 gal) gasoline or diesel fuel per day, amounting to $2.2 \mathrm{l}$ (0.585 gal) of fuel per $454 \mathrm{~kg}$ (1000 lb) stucco prepared.

Stucco may be installed onto expanded metal lath or woven wire, a lighter steel product, on wood and steel frame materials. While metal lath can be used for all the applications, nowadays it is most commonly used for three coat commercial applications. It is typically $0.15 \mathrm{~kg}(0.33 \mathrm{lb})$ per $\mathrm{ft}^{2}$ of wall area. Woven wire is primarily used for residential applications. For three coat stucco, woven wire is modeled at approximately $0.113 \mathrm{~kg}$ $(0.25 \mathrm{lb})$ per $0.09 \mathrm{~m}^{2}\left(1 \mathrm{ft}^{2}\right)$ of wall area. For one coat stucco, a lighter gauge woven wire is used with the foam sheathing - approximately $0.057 \mathrm{~kg}(0.125 \mathrm{lb})$ woven wire per 0.09 $\mathrm{m}^{2}\left(1 \mathrm{ft}^{2}\right)$ of wall area is used. For all of these materials, the typical recycled content in steel used for building materials is used.

EPS rigid foam sheathing is included in the one coat stucco system boundaries. One-inch EPS foam board is modeled at $0.057 \mathrm{~kg}(0.125 \mathrm{lb})$. Data for EPS resin blown into foam boards is based on industry average primary data and comes from the U.S. LCI database. 
The foam is typically grooved on the back side to allow for drainage. While the EPS foam provides some insulating benefits, building code still requires additional insulation (consistent with other products in this category, this extra insulation is not included in the analysis of the stucco). Building code does not require sheathing for three coat stucco even though it is common. To be consistent with other products in BEES, sheathing is not included in the three coat stucco system boundaries for BEES. For both products, weather resistive barriers and other ancillary materials that may be required to complete the exterior wall system are not included in the system boundaries for BEES exterior wall finishes. A small amount of waste, approximately $1 \%$, is assumed to be generated during the installation process. Scrap EPS generated at installation is assumed to be $2 \%$ of the total.

Stucco buildings are assumed to be painted. After installation, the siding is modeled as painted with two coats of acrylic paint. Due to lack of data for exterior acrylic paint, it is modeled as a solvent based paint modeled for BEES in the amount of $0.0175 \mathrm{~kg}$ (0.0079 lb) per $0.09 \mathrm{~m}^{2}\left(1 \mathrm{ft}^{2}\right)$.

\subsubsection{Use}

The stucco siding is modeled as being repainted with one coat of paint every fifteen years, for a total of three additional paint coatings over the course of 60 years. A properly installed stucco exterior will have a useful life of 100 years. Maintenance can vary greatly with weather conditions but is usually minimal. Crack repairs are done manually. Besides painting, other maintenance is not included within the boundaries of the BEES model.

\subsubsection{End of Life}

At end of life of the building, it is assumed that stucco and lath or woven wire are sent to a construction \& demolition landfill. End of life modeling includes transportation of these materials by heavy-duty diesel-fuel powered truck approximately $48 \mathrm{~km}$ (30 mi) to a landfill, plus impacts of the materials in a landfill. Truck transportation is based on the U.S. LCI database and disposal in a landfill is modeled based on ecoinvent end of life waste management process data.

\subsection{Dryvit Systems Cladding Products}

In 1969, Dryvit Systems, Incorporated, currently owned by RPM International Inc. of Medina, $\mathrm{OH}$, introduced North America to its exterior wall cladding system with insulation installed as part of the outside wall. Since that time, Dryvit's Exterior Insulation and Finish Systems (EIFS) have been used on commercial and residential buildings in the United States.

Dryvit operates four manufacturing plants in the U.S., including one at its headquarters in West Warwick, RI, and has subsidiary operations in Canada, Poland, and China. The data 
for the Outsulation systems are based on the West Warwick, RI facility while the data for the Canada systems are based on the Stouffville, Ontario, Canada facility.

\subsubsection{Product Description}

Siding is generally specified in terms of 'squares' of siding, or $9.29 \mathrm{~m}^{2}\left(100 \mathrm{ft}^{2}\right)$ of siding. For BEES, the functional unit is $0.09 \mathrm{~m}^{2}\left(1 \mathrm{ft}^{2}\right)$ of siding used in a building for 60 years. All the Dryvit EIFS cladding systems are installed onto sheathing and are evaluated in BEES with the other exterior wall covering products on the functional basis of one square foot of exterior wall area covered. Even though these products are thermally efficient, a building still requires additional insulation to meet code. According to Dryvit, the EIFS systems provide a thermal resistance value of about R-6. Thermal performance differences among exterior wall finish alternatives are not accounted for in BEES but should be considered when interpreting BEES results.

Four of the most widely used Dryvit EIFS cladding systems are evaluated in BEES:

Outsulation and Outsulation Plus for the U.S. market, and Outsulation Plus and Outsulation MD, produced by Dryvit Systems Canada for the Canada market. The Outsulation cladding systems are comprised of an EPS insulation board, a fiberglass mesh which is used for reinforcement, a polymer-modified cement-based adhesive/basecoat, and a polymer-based textured finish used as a top coat. Outsulation Plus has an added layer of air and moisture barrier which is intended to protect the wall from accidental moisture and provide better insulation by stopping air infiltration. All of these cladding systems can be installed in new and existing buildings.

\subsubsection{Flow Diagram}

The flow diagrams in Figure 6-4 and Figure 6-5 show the major elements of the production of these products as they are currently modeled for BEES. 


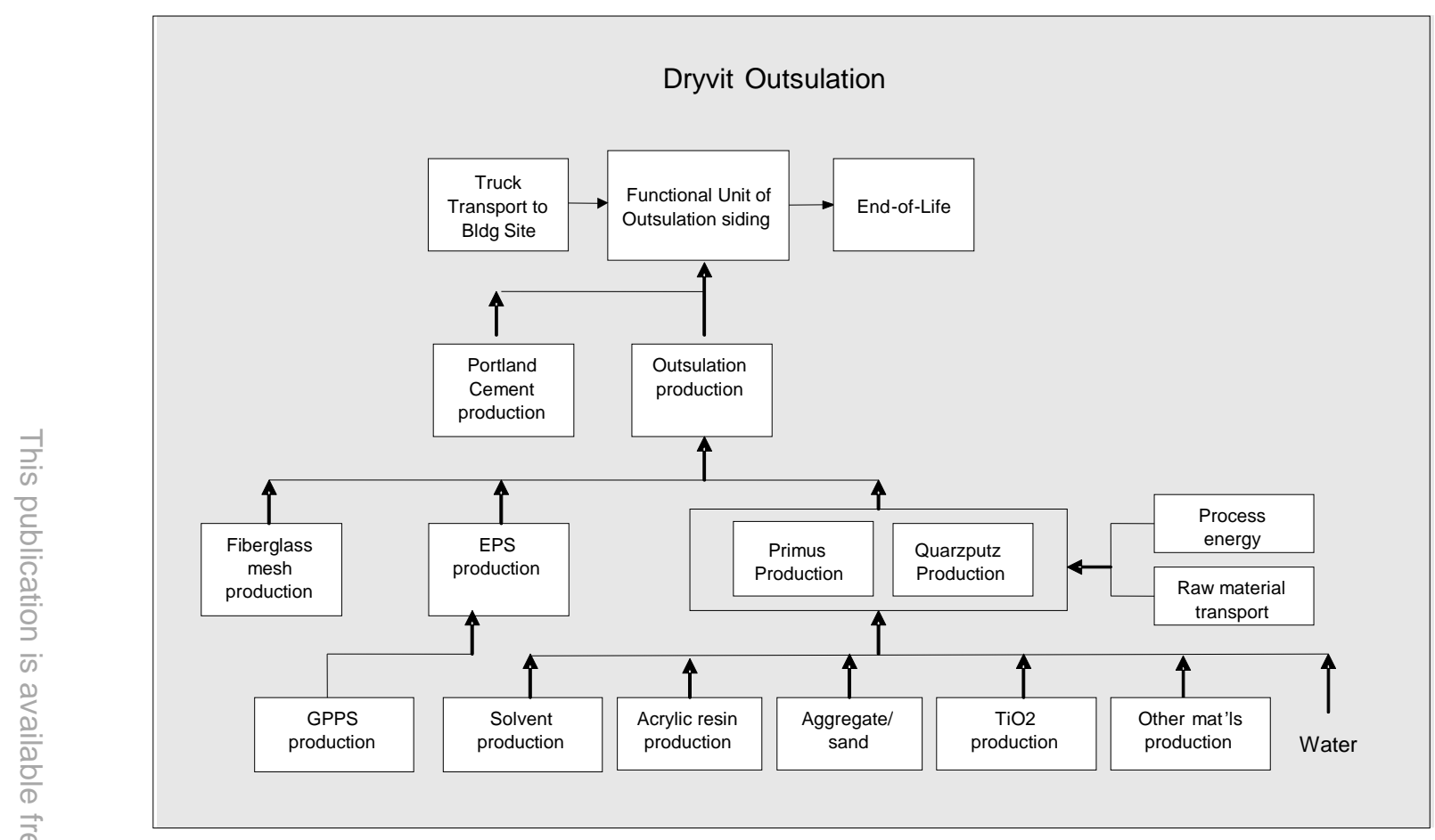

Figure 6-4 Dryfit Outsulation System Boundaries

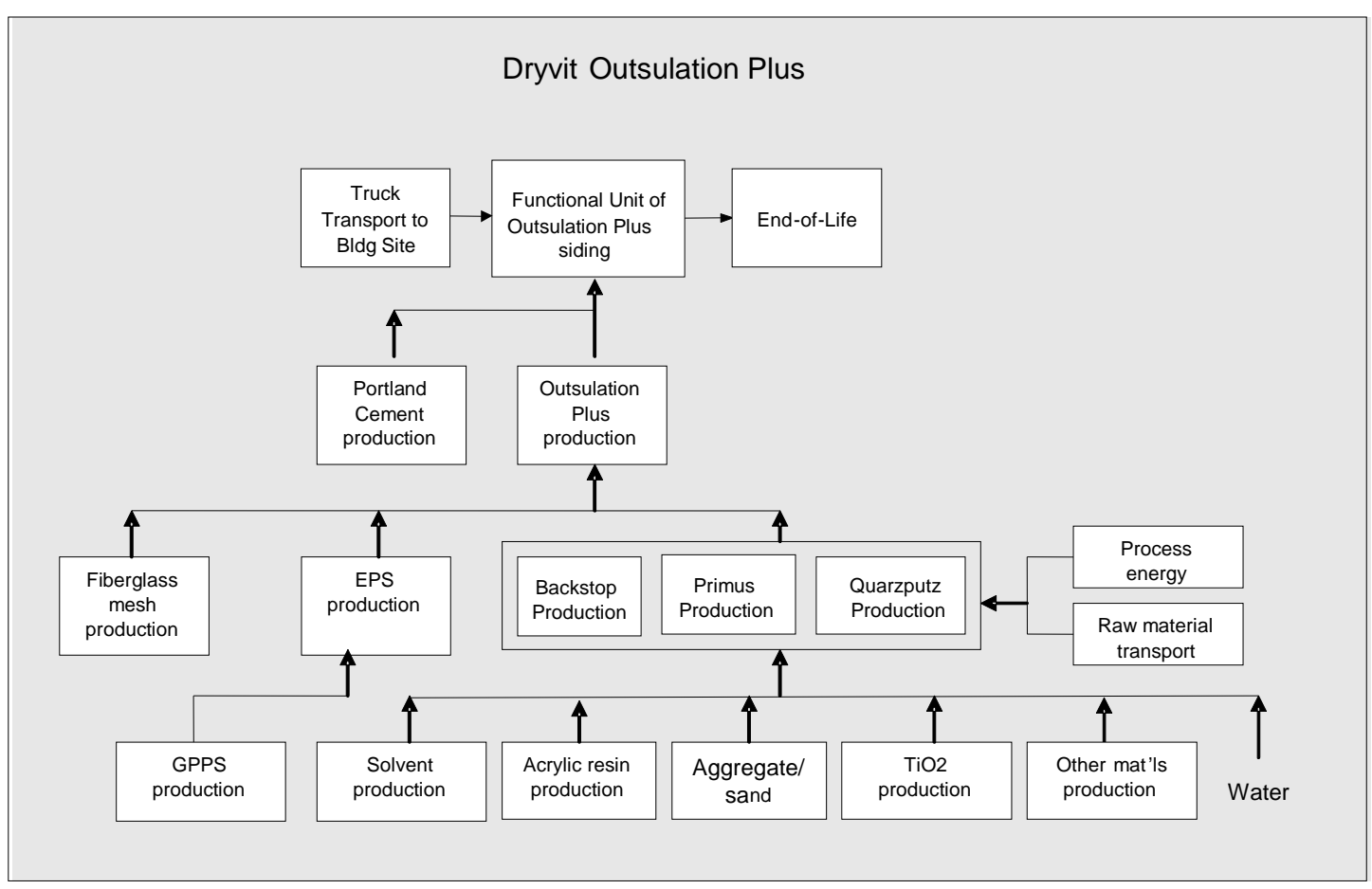

Figure 6-5 Dryfit Outsulation System Boundaries 


\subsubsection{Raw Materials}

Product Constituents: Outsulation and Outsulation Plus for U.S. and Canada.

Outsulation's basecoat, the textured finish top coat, and the barrier layer offered as part of Outsulation Plus are mixed and packaged at Dryvit's facilities. The Outsulation layers modeled for BEES are presented in Table 6-7 along with a listing of their materials:

Table 6-7 Outsulation and Outsulation Plus Product Constituents

\begin{tabular}{lccc}
\hline \multicolumn{1}{c}{ Constituent } & $\begin{array}{c}\text { Adhesive / Basecoat } \\
\text { (Primus) }\end{array}$ & $\begin{array}{c}\text { Topcoat } \\
\text { (Quarzputz) }\end{array}$ & $\begin{array}{c}\text { Barrier } \\
\text { (Backstop) }\end{array}$ \\
\hline Solvent & Yes & Yes & Yes \\
Resins & Yes & Yes & Yes \\
Aggregate & Yes & Yes & Yes \\
Fine filler & & Yes & Yes \\
Titanium dioxide (TiO2) slurry & & Yes & Yes \\
Other materials & Yes & Yes & Yes \\
Water & Yes & Yes & Yes \\
\hline
\end{tabular}

Product Constituents: Outsulation MD. The material constituents in Outsulation MD are mixed and packaged at Dryvit's Ontario facility. The Outsulation MD layers modeled for BEES are presented in Table 6-8 along with a listing of their materials:

Table 6-8 Outsulation MD Product Constituents

\begin{tabular}{lccccc}
\hline Constituent & $\begin{array}{c}\text { Barrier } \\
\text { (Backstop NT } \\
\text { Texture) }\end{array}$ & $\begin{array}{c}\text { Adhesive/ } \\
\text { Basecoat } \\
\text { (Primus) }\end{array}$ & $\begin{array}{c}\text { Flashing } \\
\text { (AquaFlash) }\end{array}$ & $\begin{array}{c}\text { Primer } \\
\text { (Color } \\
\text { Prime) }\end{array}$ & $\begin{array}{c}\text { Topcoat } \\
\text { (Sand-pebble) }\end{array}$ \\
\hline Solvent & Yes & Yes & Yes & Yes & Yes \\
Resins & Yes & Yes & Yes & Yes & Yes \\
Aggregate & Yes & Yes & Yes & Yes & Yes \\
Fine filler & Yes & & Yes & Yes & Yes \\
TiO2 slurry & Yes & Yes & Yes & Yes & Yes \\
Water & Yes & & & & \\
\hline
\end{tabular}

Materials Data and Modeling. Ecoinvent data are used for the solvent (modeled as naphtha) and the fine filler, modeled as lime. The resin is modeled as an acrylic-based resin. Data for this resin, plus the aggregate and titanium dioxide slurry, are also based on ecoinvent. Water makes up much of these products: it is over $23 \%$ of Quarzputz and Backstop, nearly $25 \%$ of the Sandpebble topcoat, nearly $30 \%$ of Primus, and $40 \%$ Color Prime. Packaging for these products (18.9 l (5 gal) PP pails) is included in the model. Data for PP comes from the U.S. LCI database.

\subsubsection{Manufacturing}

Energy Requirements and Emissions. Energy use at the Dryvit plants is primarily electricity to blend the systems’ constituents in large vessels and package them into 18.91 
(5 gal) pails. The quantity of electricity for each product produced in Rhode Island is provided in Table 6-9.

\section{Table 6-9 Energy Requirements for Mixing Dryvit Outsulation and Outsulation Plus Materials}

\begin{tabular}{lcc}
\hline Outsulation Products & $\boldsymbol{k W h} / \boldsymbol{l} \boldsymbol{b}$ & $\boldsymbol{k W h} / \mathrm{ft}^{2}$ \\
\hline Primus & $7.47 \mathrm{E}-4$ & $4.21 \mathrm{E}-4$ \\
Quarzputz & $6.26 \mathrm{E}-4$ & $3.45 \mathrm{E}-4$ \\
Backstop & $1.28 \mathrm{E}-3$ & $2.86 \mathrm{E}-4$ \\
\hline Total & $\mathbf{2 . 6 5} \mathrm{E}-\mathbf{3}$ & $\mathbf{1 . 0 5} \mathrm{E}-\mathbf{3}$ \\
\hline
\end{tabular}

No data were available to disaggregate electricity data for the Outsulation MD or Outsulation Plus constituents that are blended at the Ontario facility, so average blending energy there was used: $5.6 \mathrm{E}-4 \mathrm{kWh}$ per pound of product, or 7.1 E-4 kWh per square foot. Electricity production fuels and burdens come from the U.S. LCI database, using a Canada electricity grid mix. Any fine material particulates released during blending is captured by a dust collection system, so no particulates or other emissions are assumed to be released. No manufacturing waste is produced.

\subsubsection{Transportation}

Transportation distances of the product components were provided by both Dryvit plants. The distances to Warwick, RI range from $1770 \mathrm{~km}(1100 \mathrm{mi})$ for the fillers and $1086 \mathrm{~km}$ (675 mi) for the aggregate, down to $80 \mathrm{~km}(50 \mathrm{mi})$ for the solvent. For Outsulation MD and Outsulation Plus (Canada), all the materials except the aggregates are transported 26 $\mathrm{km}(16 \mathrm{mi})$ to Stouffville, Ontario. The aggregates are transported $363 \mathrm{~km}$ (227 mi) to Stouffville, Ontario. These materials are transported by diesel truck, as modeled in the U.S. LCI database.

The Outsulation U.S. products are modeled as being transported an average of $402 \mathrm{~km}$ ( $250 \mathrm{mi}$ ) by diesel truck to the building site. The Canadian products are transported by both diesel truck (average of $143 \mathrm{~km}$, or $89 \mathrm{mi}$ ) and rail (average of $3444 \mathrm{~km}$, or 2150 mi). When factoring the quantity transported by truck and rail (84 \% and $16 \%$, respectively), the weighted average transported comes to $721 \mathrm{~km}$ (450 mi). These numbers are based on customer transportation records. EPS and fiberglass mesh are assumed to be transported $400 \mathrm{~km}$ ( $250 \mathrm{mi}$ ) by diesel truck to the building site.

\subsubsection{Installation}

Dryvit's components described above, plus the EPS and fiberglass mesh, are installed together at the building site to produce the Outsulation, Outsulation Plus, and Outsulation MD products. These materials are specified in Table 6-10. 
Table 6-10 Dryvit EIFS Constituents

\begin{tabular}{|c|c|c|c|}
\hline Constituent & $\begin{array}{l}\text { Quantity per } 9 \mathrm{~m}^{2} \\
\left(100 \mathrm{ft}^{2}\right) \text { of EIFS }\end{array}$ & & \\
\hline & Outsulation & Outsulation Plus & Outsulation MD \\
\hline EPS & $5.67 \mathrm{~kg}(12.5 \mathrm{lb})$ & 5.67 kg (12.5 lb) & 5.67 kg (12.5 lb) \\
\hline Fiberglass Mesh & 1.35 kg (2.98 lb) & 1.35 kg (2.98 lb) & 1.35 kg (2.98 lb) \\
\hline Primus & 25.0 kg (55.1lb) & 25.0 kg (55.1lb) & $25.0 \mathrm{~kg}(55.1 \mathrm{lb})$ \\
\hline Quarzputz & $24.43 \mathrm{~kg}$ (53.85 lb) & $24.43 \mathrm{~kg}$ (53.85 lb) & \\
\hline Backstop NT Texture & & 9.89 kg (21.8lb) & 9.89 kg (21.8lb) \\
\hline Flashing (AquaFlash) & & & $0.302 \mathrm{~kg}(0.665 \mathrm{lb})$ \\
\hline Primer (Color Prime) & & & 1.5 kg (3.33 lb) \\
\hline Topcoat (Sandpebble) & & & $24.43 \mathrm{~kg}(53.85 \mathrm{lb})$ \\
\hline
\end{tabular}

EPS is produced by licensed EPS molders to a specification that has been established by Dryvit and ASTM International. Fiberglass mesh also is produced to Dryvit specification and ASTM International standard. The Dryvit basecoats, weather barriers, and finishes are used on the jobsite by trained plasterers. The process of applying EIFS cladding begins once the stud walls are constructed and sheathing is up. The EPS is applied to the sheathing with Primus as the adhesive and then again coated with Primus for a basecoat. In the field, Primus is mixed with equal amounts of cement. The fiberglass mesh is then embedded into the basecoat. After 24 hours of drying time, the textured finish, Quarzputz or Sandpebble, is placed as the top coat. Outsulation Plus installation includes the layer of Backstop for the added layer of air and moisture barrier. Outsulation MD includes a primer and a layer for flashing. Note that while sheathing, weather resistive barriers, and other ancillary materials are required to complete the exterior wall system, these materials are not included in the system boundaries for BEES exterior wall finishes.

Data for EPS resin and blowing agents for foam insulation is based on industry average primary data and comes from the U.S. LCI database. Fiberglass is based on ecoinvent data. For the BEES system, these products are included with the raw material acquisition stage data since they are considered part of the main product. Portland cement (mixed with Primus) is included with the use stage of the product model. The Portland cement data come from PCA’s U.S. industry-average data (PCA, 2016a).

According to the manufacturer, installation waste can run from $1 \%$ to $5 \%$; $2 \%$ is modeled for BEES, and this waste is modeled as landfilled.

\subsubsection{Use}

Dryvit products are assumed to have useful lives of at least 60 years. Any maintenance or cleaning over the life, if needed, is done manually and with relatively few materials. Because maintenance can vary from owner to owner based on frequency and degree, representative data were neither available nor included in the model. 


\subsubsection{End of Life}

At end of life of the building, it is assumed that these exterior siding products are sent to a construction \& demolition landfill. End of life modeling includes transportation of these materials by heavy-duty diesel-fuel powered truck approximately $48 \mathrm{~km}$ (30 mi) to a landfill, plus impacts of the materials in a landfill. Truck transportation is based on the U.S. LCI database and disposal in a landfill is modeled based on ecoinvent end of life waste management process data.

\subsection{CertainTeed Siding Products}

CertainTeed Corporation manufactures building materials that include roofing, vinyl and fiber cement siding, trim, fence, railing, decking, foundations, insulation, gypsum, ceilings, and pipe products. CertainTeed has approximately 70 facilities throughout the United States and Canada.

\subsubsection{Product Description}

Five of CertainTeed's siding products are evaluated in BEES, with the functional unit of $0.09 \mathrm{~m}^{2}\left(1 \mathrm{ft}^{2}\right)$ used over 60 years:

CertainTeed vinyl siding. CertainTeed's vinyl siding product in BEES is modeled as an average of its vinyl siding product lines manufactured at its Jackson, MI, and Hagerstown, MD, plants. Bills of materials and manufacturing data were collected from these two facilities and averaged on a weighted basis, based on vinyl siding output. This vinyl siding has a nominal thickness of $0.11 \mathrm{~cm}(0.044 \mathrm{in})$ and a mass ranging from 17.83 $\mathrm{kg}$ to $21.79 \mathrm{~kg}$ ( $39.4 \mathrm{lb}$ to $48.2 \mathrm{lb}$ ) per $9.29 \mathrm{~m}^{2}\left(100 \mathrm{ft}^{2}\right)$. Consistent with the generic vinyl siding product in BEES, it is typically installed with galvanized nail fasteners placed 41 cm (16 in) on center.

CertainTeed Recycled Content CedarBoards (D6). The CedarBoards Double 6" Clapboard product is a vinyl siding product with EPS foam backing for added insulation. The vinyl siding, containing both post-industrial and PC content PVC resin, has the semblance of a rough cedar finish, and has a nominal thickness of $0.11 \mathrm{~cm}(0.044 \mathrm{in})$. It is produced at CertainTeed's Jackson, MI, plant, and is sent to another facility to be laminated onto the insulated foam. Its mass ranges from $18.61 \mathrm{~kg}$ to $22.75 \mathrm{~kg}$ (41.0 lb to $50.2 \mathrm{lb})$ per $9.29 \mathrm{~m}^{2}\left(100 \mathrm{ft}^{2}\right)$ and it is typically installed with galvanized nail fasteners placed $41 \mathrm{~cm}$ (16 in) on center. It has a thermal resistance value of $\mathrm{R}_{\mathrm{US}}-2.9$ according to thermal testing results by an independent testing company. Despite the added insulation, the building still requires base insulation. Thermal performance differences among exterior wall finish alternatives are not accounted for in BEES but should be considered when interpreting BEES results.

CertainTeed Cedar Impressions siding is a PP resin-based siding with the semblance and texture of cedar panels. With a mass ranging from $34.4 \mathrm{~kg}$ to $42.0 \mathrm{~kg}$ (75.6 lb to $92.4 \mathrm{lb}$ ) per $9.29 \mathrm{~m}^{2}\left(100 \mathrm{ft}^{2}\right)$ and a thickness of $1.25 \mathrm{~cm}(0.10 \mathrm{in})$, Cedar Impressions is 
manufactured at CertainTeed's McPherson, KS, plant. It is typically installed with galvanized nail fasteners placed $26.7 \mathrm{~cm}$ (10.5 in) on center.

CertainTeed WeatherBoards siding with and without recycled content are two fiber cement-based siding products offered by CertainTeed. WeatherBoards are available in laps, panels, shingles, and individual shakes. The products evaluated in BEES, representing much of the volume of their fiber cement siding sold, are lap siding of 21.96 $\mathrm{cm}$ (8.25 in) wide and $0.79 \mathrm{~cm}$ (0.31 in) thick. Installed, they have a $17.8 \mathrm{~cm}$ (7.0 in) reveal with $3.18 \mathrm{~cm}$ (1.25 in) of overlap. WeatherBoards with recycled content have a density of $12.45 \mathrm{~kg} / \mathrm{m}^{2}\left(2.55 \mathrm{lb} / \mathrm{ft}^{2}\right)$; installed density is $14.89 \mathrm{~kg} / \mathrm{m}^{2}\left(3.05 \mathrm{lb} / \mathrm{ft}^{2}\right)$.

Densities for WeatherBoards without recycled content are about $5 \%$ higher: $13.07 \mathrm{~kg} / \mathrm{m}^{2}$ $\left(2.68 \mathrm{lb} / \mathrm{ft}^{2}\right)$ and $15.63 \mathrm{~kg} / \mathrm{m}^{2}\left(3.20 \mathrm{lb} / \mathrm{ft}^{2}\right)$, respectively. WeatherBoards are typically installed with galvanized nail fasteners placed $41 \mathrm{~cm}$ (16 in) on center and the boards are painted. They are manufactured at CertainTeed's Roaring River, NC, plant.

\subsubsection{Flow Diagram}

The flow diagrams in Figure 6-6 through Figure 6-10 show the major elements of the production of these products as they are currently modeled for BEES.

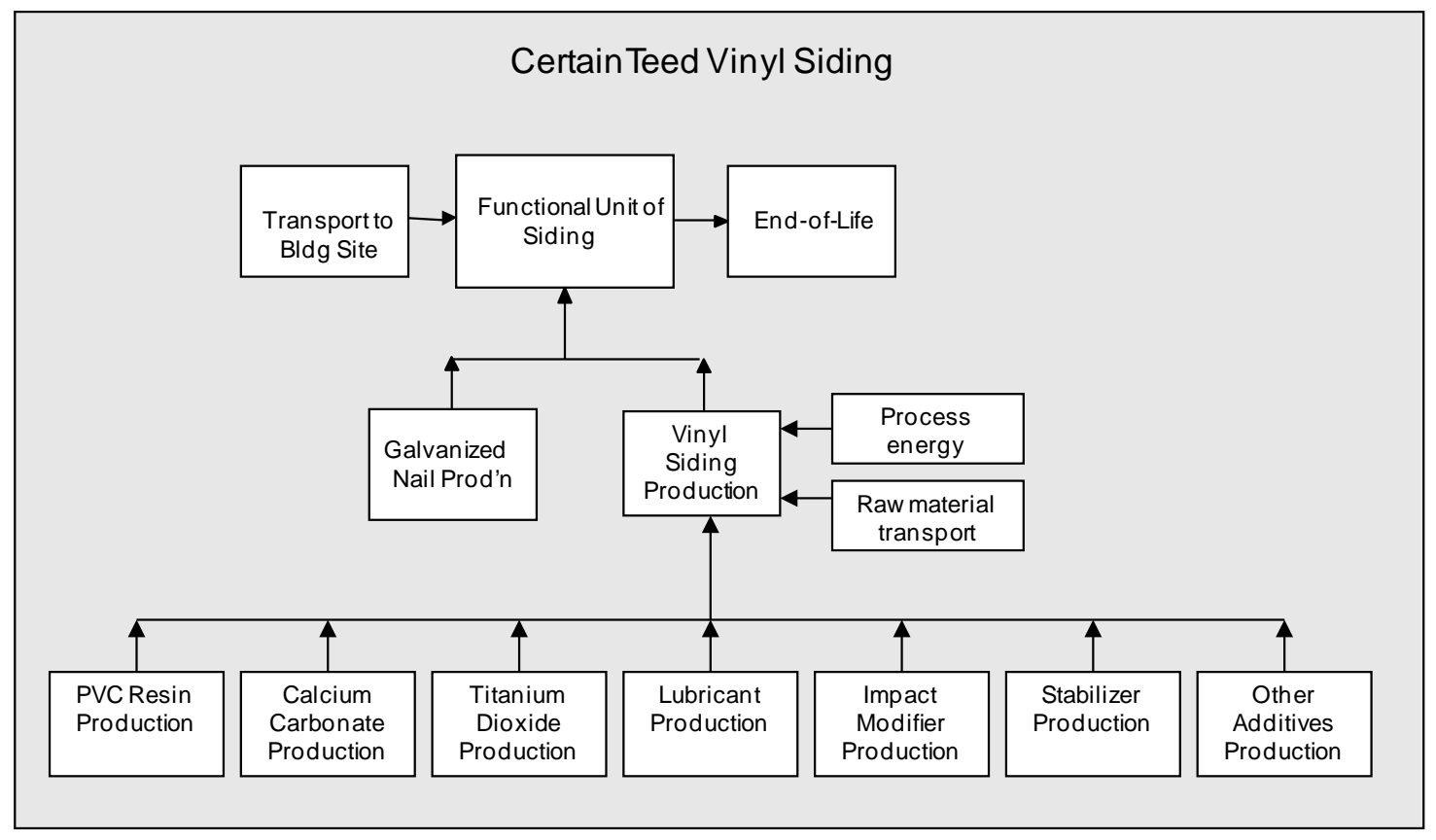

Figure 6-6 CertainTeed Vinyl Siding System Boundaries 


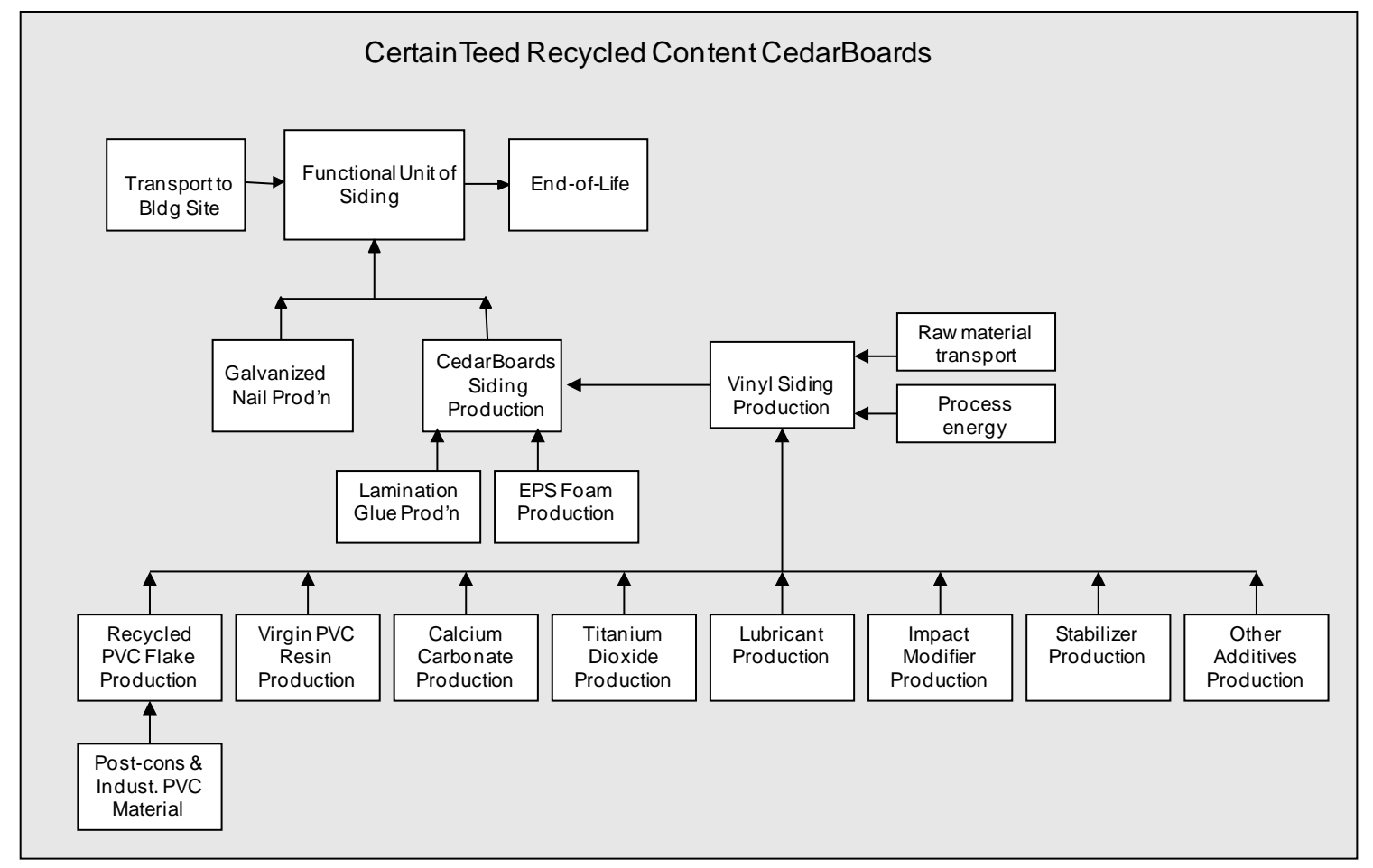

Figure 6-7 CertainTeed Recycled Content CedarBoards System Boundaries

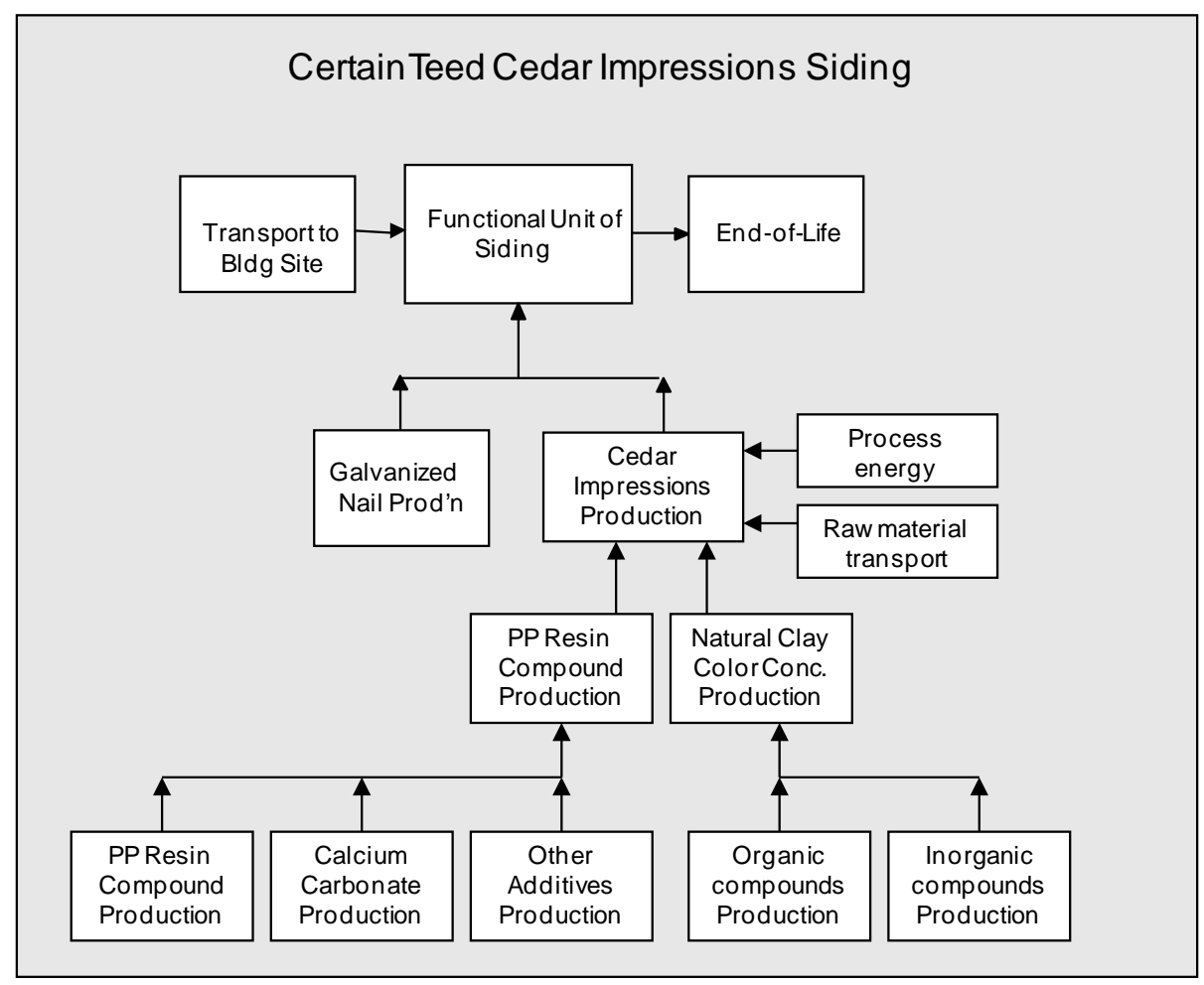

Figure 6-8 CertainTeed Cedar Impressions System Boundaries 


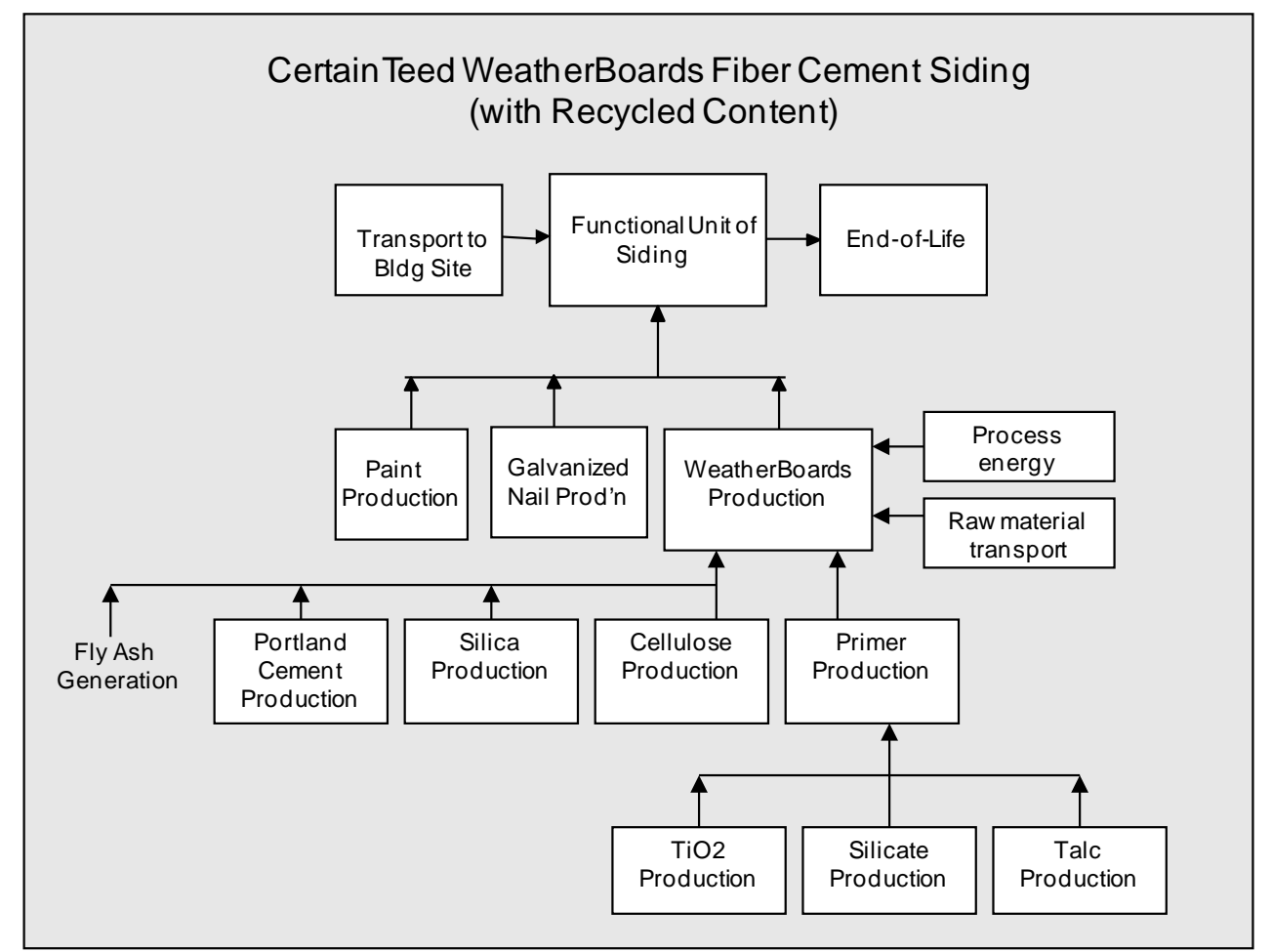

Figure 6-9 CertainTeed WeatherBoards (With Recycled Content) System Boundaries

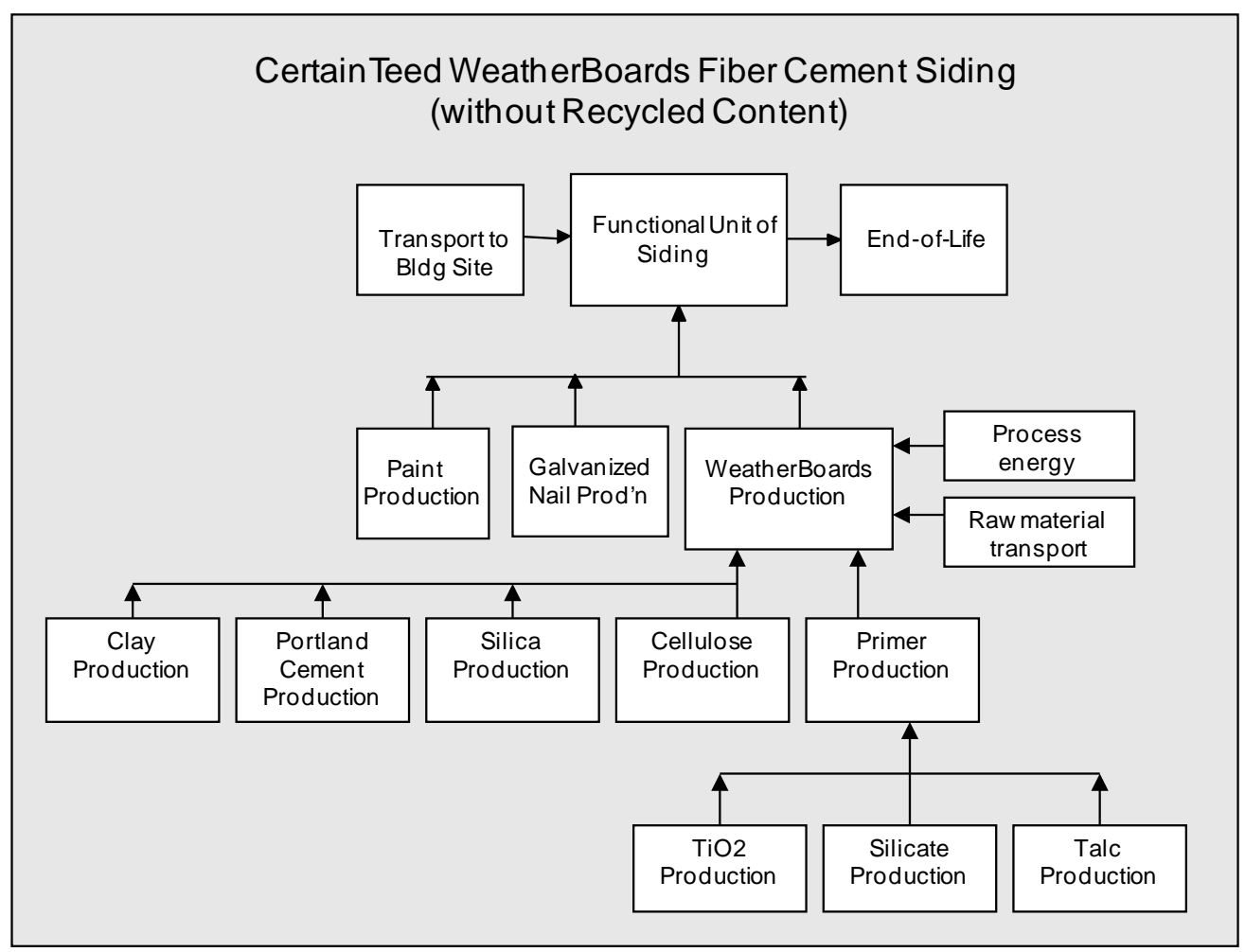

Figure 6-10 CertainTeed WeatherBoards (No Recycled Content) System Boundaries 


\subsubsection{Raw Materials}

CertainTeed Vinyl Siding. The CertainTeed vinyl siding product is made up of the materials shown in Table 6-11.

\section{Table 6-11 Vinyl Siding Constituents (Weighted Average)}

\begin{tabular}{lc}
\hline Constituent & \% in the Siding \\
\hline PVC resin & $73.9 \%-90.3 \%$ \\
Calcium carbonate & $8.6 \%-10.5 \%$ \\
Acrylic-based additives & $2.8 \%-3.4 \%$ \\
Titanium dioxide & $1.5 \%-1.9 \%$ \\
Lubricant & $1.4 \%-1.7 \%$ \\
Other additives & $1.8 \%-2.2 \%$ \\
\hline
\end{tabular}

Total must equal $100 \%$

The PVC resin is based on CertainTeed's own formulation and manufacturing of the resin. Data for the formulation are not provided in this documentation to protect company confidential data but all elements of that model are based on U.S. LCI database and the ecoinvent database. Production data for the other materials in Table 6-12 are based on the same databases. "Other additives" include pigment, impact modifiers, stabilizers, and process aids. Data for all the materials were provided in Material Safety Data Sheets (MSDS); their production data are included in the LCA model but are excluded from this documentation to protect company confidential data.

Recycled Content CedarBoards. Recycled Content CedarBoards are comprised of three main components: EPS foam, vinyl siding, and lamination glue, as shown in the table below.

\section{Table 6-12 Recycled Content CedarBoards Siding Constituents}

\begin{tabular}{lc}
\hline Constituent & \% in the Siding \\
\hline Foam backing & $10.4-12.8 \%$ \\
CertainTeed vinyl siding with recycled content & $78.8-96.3 \%$ \\
Lamination glue & $0.8-1.0 \%$ \\
\hline
\end{tabular}

The foam backing is EPS foam board insulation produced by the same producer as described in the documentation for the Insulated Vinyl Siding BEES product.

The recycled content vinyl siding is produced at the Jackson, MI, plant. Table 6-12 on CertainTeed average vinyl siding provides the main bill of materials for the siding, with one exception: $74.3 \%$ of the PVC resin is recycled. According to CertainTeed's supplier, the recycled content PVC resin comes from both post-industrial (vinyl siding and window manufacturers), and PC (scrap, end of life siding and construction tear-down). The 
recycler cleans and shreds the incoming material and produces recycled PVC flakes. General mass balance data were supplied by the recycler. Since primary data on recycling energy could not be obtained from the supplier, PET bottle recycling process energy was used as a proxy (Franklin Associates, 2010). While the energy to shred and reclaim PET bottles may be very different from PVC reclamation processes, the Franklin data are primary data from four reclamation plants in the U.S., and these data are considered to be of very good quality based on data quality evaluation in the report. Table 6-13 provides the recycling energy assumed for PVC recycling.

\section{Table 6-13 PVC Flake Recycling Energy}

\begin{tabular}{lc}
\hline Energy Source & $\begin{array}{c}\text { Quantity per } \boldsymbol{k g} \\
\text { PVC flake }\end{array}$ \\
\hline Electricity (MJ) & 1.66 \\
Natural Gas (MJ) & 2.88 \\
LPG \& propane (MJ) & 0.0076 \\
\hline
\end{tabular}

Energy data come from the U.S. LCI database. The average distance the post-industrial and PC vinyl feedstock is transported to the recycler is $1609 \mathrm{~km}$ (1000 mi); this transportation impact is included in the model. The lamination glue is made up of the components in Table 6-14, obtained from the MSDS.

\section{Table 6-14 Lamination Glue Constituents}

\begin{tabular}{lc}
\hline Constituent & \% by mass \\
\hline Tackifying Resins & $42.3 \%$ to $51.7 \%$ \\
Mineral Oil & $18.0 \%$ to $22.0 \%$ \\
Polymer Solids & $24.3 \%$ to $29.7 \%$ \\
Carbonic Acid & $2.7 \%$ to $3.3 \%$ \\
Talc & $2.7 \%$ to $3.3 \%$ \\
\hline
\end{tabular}

This glue emits minimal VOCs according to the MSDS. The materials in the glue were modeled based on data in the U.S. LCI database and ecoinvent.

Cedar Impressions Siding. Two material mixes are blended together to form Cedar Impressions siding, as shown in Table 6-15.

\section{Table 6-15 Cedar Impressions Constituents}

\begin{tabular}{lc}
\hline Constituent & \% in the Siding \\
\hline PP resin compound & $88.0 \%$ to $100 \%$ \\
Natural clay color concentrate & $0.0 \%$ to $2.4 \%$ \\
\hline
\end{tabular}


The PP resin compound is made up of PP resin, calcium carbonate filler, and other additives. The natural clay color concentrate is made up of approximately $50 \%$ inorganic, mineral-based compounds and $50 \%$ organic compounds. The full bills of materials for these compounds have been included in the model but are not provided in this documentation to protect company-confidential data. Production data for materials are based on data in the U.S. LCI database and ecoinvent.

Weatherboards Siding. Weatherboards siding constituents with and without recycled content are shown in Table 6-16.

\section{Table 6-16 WeatherBoards Constituents}

\begin{tabular}{lcc}
\hline Constituent & $\begin{array}{c}\text { With Recycled Content } \\
\text { \% by mass }\end{array}$ & $\begin{array}{c}\text { Without Recycled Content } \\
\text { \% by mass }\end{array}$ \\
\hline Portland cement & $30 \%$ to $37 \%$ & $34 \%$ to $39 \%$ \\
Fly ash & $30 \%$ to $50 \%$ & N/A \\
Kaolin clay & N/A & $2 \%$ to $7 \%$ \\
Silica & $14 \%$ to $34 \%$ & $48 \%$ to $53 \%$ \\
Cellulose & $6 \%$ to $10 \%$ & $6 \%$ to $10 \%$ \\
Primer & $0.2 \%$ & $0.2 \%$ \\
\hline
\end{tabular}

The data for pulpwood-based cellulose come from the U.S. LCI database. The Portland cement data come from Portland Cement Association (PCA) U.S. industry-average data (PCA, 2016a). Fly ash is a waste material that results from burning coal to produce electricity which could also be a byproduct of coal combustion. Because it would be disposed of if not used beneficially elsewhere, fly ash is assumed to be an environmentally “free” input material. Transport of the fly ash to CertainTeed has been included in the model. The kaolin clay data come from ecoinvent. The silica - silicic acid/calcium salt, or calcium silicate - has been modeled based on stoichiometry of the reactants water glass and slaked lime, which come from ecoinvent data. The primer consists of titanium dioxide, sodium potassium/aluminum silicate, and talc - whose data come from ecoinvent. A loss rate of $6.4 \%$ of all materials except for the primer has been accounted for in the modeling.

\subsubsection{Manufacturing}

\subsubsection{CertainTeed Vinyl Siding, Recycled Content CedarBoards, and Cedar Impressions}

The manufacturing energy for CertainTeed's vinyl siding, recycled content CedarBoards, and Cedar Impressions is presented in Table 6-17. 
Table 6-17 Energy Requirements for CertainTeed Vinyl- and PP-based Products

\begin{tabular}{lccc}
\hline & \multicolumn{3}{c}{ Quantity per functional unit of product } \\
\hline Energy source & Average vinyl siding & Recycled Content Cedarboards & Cedar Impressions \\
\hline Electricity (MJ) & $0.282-0.344$ & $0.376-0.460$ & $0.041-0.051$ \\
Natural Gas (MJ) & $0.028-0.034$ & $0.324-0.396$ & $0.225-0.275$ \\
Propane (MJ) & $0.009-0.011$ & $0.077-0.094$ & $0.020-0.024$ \\
\hline
\end{tabular}

Electricity is used to blend the ingredients in the products, propane is used for forklifts, and natural gas is used for plant heating. Electricity production fuels, natural gas, and propane production and combustion come from the U.S. LCI database. Table 6-18 summarizes other manufacturing-related data:

Table 6-18 Other Process Data for CertainTeed Vinyl- and PP-based Products

\begin{tabular}{lccc}
\hline & \multicolumn{3}{c}{ Quantity per functional unit of product } \\
\hline Process Input or Output & Average vinyl siding & Recycled Content Cedarboards & Cedar Impressions \\
\hline Input: Water use (L) & $0.317-0.387$ & $0.559-0.683$ & $0.706-0.862$ \\
Output: Wastewater (L) & $0.214-0.262$ & $0.409-0.499$ & $0.599-0.733$ \\
Output: Waste (kg) & $0.010-0.012$ & $0.005-0.007$ & $0.002-0.002$ \\
\hline
\end{tabular}

The water is used for product cooling and to run the cooling towers. The wastewater, discharged to the sewer, comes directly from the cooling water use; the discrepancy between the reported water in and out is due to evaporation losses. This water is assumed to be uncontaminated.

There are no manufacturing/product losses; the CertainTeed facilities have systems in place to recycle or recover and use all the floor sweepings and product scrap. For example, the Cedar Impressions scrap is recycled into a part of packaging pallets used throughout CertainTeed plants. The solid waste is non-hazardous material composed of unrecyclable packaging, cafeteria trash, and other miscellaneous trash, and it is landfilled.

Combustion-related air emissions are accounted for in upstream energy use data sets (e.g., natural gas use in a boiler). According to CertainTeed, no other process-related air emissions are generated from these processes.

Lamination of Recycled Content CedarBoards. After the CedarBoards vinyl siding has been manufactured, it is sent to Beach $\mathrm{City}, \mathrm{OH}$, to be laminated. The vinyl siding sheets and EPS foam board are hand fed onto a table of rollers. Lines of glue are applied to the foam and then the foam and vinyl are run through a compression roller sealing the foam to the vinyl. The final product is boxed and shipped. The whole process relies primarily on human labor, with only a small amount of electricity being used for the roller machine. This electricity is included as part of the foam production process described in the insulated 
vinyl siding Raw Materials section. Transportation by heavy-duty diesel truck from Jackson, MI to Beach City, OH (394 km (245 mi)) is included in the model.

Transportation of CertainTeed Vinyl Siding constituents. Transportation of the raw materials in CertainTeed's average vinyl siding to the two manufacturing locations has been accounted for, and a weighted average taken based on total production. The PVC resin is transported by rail less than $2500 \mathrm{~km}$ (1553 mi) to both locations. The remaining materials are transported by heavy-duty diesel truck, and transportation distances are up to $3000 \mathrm{~km}$ (1864 mi). All transportation modes are modeled based on the U.S. LCI database.

Transportation of Recycled Content CedarBoards constituents. Transportation of the raw materials in the recycled content vinyl siding to the Jackson plant has been accounted for. Once manufactured, the siding is transported $394 \mathrm{~km}$ (245 mi) by heavy-duty diesel truck from Jackson, MI, to Beach City, $\mathrm{OH}$, to be laminated. The lamination glue is transported less than $1000 \mathrm{~km}$ (621 mi) to Beach City. The transportation of the raw materials to Beach City to produce EPS foam is included in the foam production model. All transportation modes are modeled based on the U.S. LCI database.

Transportation of Cedar Impressions constituents. Transportation of the raw materials to CertainTeed has been accounted for. The PP resin compound is transported by rail less than $1500 \mathrm{~km}(932 \mathrm{mi})$ and the natural clay color concentrate is transported by heavy-duty truck less than $1000 \mathrm{~km}(621 \mathrm{mi})$. All transportation modes are modeled based on the U.S. LCI database.

\subsubsection{CertainTeed WeatherBoards With and Without Recycled Content}

WeatherBoards are produced by creating a slurry with water and the raw materials. Electricity is used for this blending. The slurry is then shaped into the WeatherBoards boards which are subsequently dried in the "kiln" using natural gas heat. Gasoline, diesel, and propane fuels are used in various facility vehicles, including forklifts. A summary of the manufacturing energy for CertainTeed WeatherBoards is presented in Table 6-19.

\section{Table 6-19 Energy Requirements for WeatherBoards}

\begin{tabular}{lcc}
\hline Energy source & \multicolumn{2}{c}{ MJ per functional unit } \\
\hline With Recycled & Content & $\begin{array}{c}\text { No Recycled } \\
\text { Content }\end{array}$ \\
\hline Electricity & $0.810-1.07$ & $0.857-1.12$ \\
Natural Gas & $2.12-2.16$ & $2.23-2.26$ \\
Diesel Oil & 0.036 & 0.038 \\
Gasoline & 0.002 & 0.002 \\
Propane & $0.014-0.017$ & $0.014-0.017$ \\
\hline
\end{tabular}


Electricity production fuels, natural gas, and the other fuels' production and combustion come from the U.S. LCI database. Table 6-20 summarizes other manufacturing-related data:

\section{Table 6-20 Other Process Data for WeatherBoards}

\begin{tabular}{lcc}
\hline & \multicolumn{2}{c}{ Quantity per functional unit } \\
\hline Process Input or Output & $\begin{array}{c}\text { With Recycled } \\
\text { Content }\end{array}$ & $\begin{array}{c}\text { No Recycled } \\
\text { Content }\end{array}$ \\
\hline Input: Water use (L) & $0.414-0.711$ & $0.442-0.739$ \\
Output: Waste (kg) & $0.086-0.094$ & $0.091-1.000$ \\
\hline
\end{tabular}

Water is used to form the slurry. No water emissions are generated as the water from the slurry evaporates; the Roaring River facility is a zero-discharge facility. Solid waste includes process losses at the plant which are landfilled. Process-related air emissions are generated from processing WeatherBoards. These emissions are included in the model but not in this documentation. Combustion-related air emissions are accounted for in upstream energy use data sets (e.g., from natural gas use in the kiln).

Transportation of CertainTeed WeatherBoards constituents. Transportation of the raw materials to Roaring River, NC have been accounted for, with distances by diesel truck ranging from $290 \mathrm{~km}$ (180 mi) to $724 \mathrm{~km}(450 \mathrm{mi})$. The primer is shipped $434 \mathrm{~km}$ ( $270 \mathrm{mi}$ ) by rail. One of the materials is shipped approximately $5000 \mathrm{~km}$ (3108 mi) by ocean freighter to a port on the U.S. east coast and then trucked the remaining distance. All transportation modes are modeled based on the U.S. LCI database.

\subsubsection{Packaging and Transportation}

Packaging of the final CertainTeed products were included in these BEES models. Data for packaging is based on the industry average vinyl siding and insulated vinyl siding data provided by Sustainable Solutions Corporation for those products in BEES. Packaging includes paper labels, plastic strapping, low-density polyethylene (LDPE) plastic wrap and weather bags, cardboard, and pallets.

Transportation of CertainTeed Vinyl Siding and Recycled Content Cedarboards to Installation. These finished products are transported an average of $1400 \mathrm{~km}(870 \mathrm{mi})$ by diesel truck to their respective building sites. The nails used at installation are assumed to be transported $241 \mathrm{~km}$ (150 mi) by diesel truck to the building sites. The BEES user may change the default transportation distance for the main products.

Transportation of CertainTeed Cedar Impressions to Installation. The finished Cedar Impressions siding is transported an average of $3620 \mathrm{~km}$ (2250 mi) by diesel truck to the building site. The nails used at installation are assumed to be transported $241 \mathrm{~km}$ (150 mi) by diesel truck to the building site. The BEES user may change the default transportation distance for the main product. 
Transportation of CertainTeed WeatherBoards to Installation. The finished WeatherBoards siding is transported an average of $950 \mathrm{~km}$ (590 mi) by diesel truck to the building site. Both the nails and the paint used at installation are assumed to be transported $241 \mathrm{~km}(150 \mathrm{mi})$ by diesel truck to the building site. The BEES user may change the default transportation distance for the main products.

\subsubsection{Installation}

Installation of the CertainTeed products is done primarily by manual labor. These products are modeled as being installed with nails and a nail gun to be consistent with other siding products in BEES. The CertainTeed products are also commonly installed with a hammer and nails. For the vinyl-based sidings and WeatherBoards, nails are installed $41 \mathrm{~cm}$ (16 in) on center. The nails are modeled as galvanized steel, and for installation $41 \mathrm{~cm}$ (16 in) on center, $0.026 \mathrm{~kg} / \mathrm{m}^{2}\left(0.005 \mathrm{lb} / \mathrm{ft}^{2}\right)$ of siding is used. Cedar Impressions are installed with galvanized steel nails $26.7 \mathrm{~cm}$ (10.5 in) on center. For installation $26.7 \mathrm{~cm}$ (10.5 in) on center, $0.04 \mathrm{~kg} / \mathrm{m}^{2}\left(0.008 \mathrm{lb} / \mathrm{ft}^{2}\right)$ of siding is used. The energy required to operate compressors to power air guns and circular saws for cutting is assumed to be very small and is not included in the analysis. In addition to nails, WeatherBoards require two coats of paint at installation, each coat amounting to $0.094 \mathrm{~kg} / \mathrm{m}^{2}\left(0.019 \mathrm{lb} / \mathrm{ft}^{2}\right)$ on a dry basis. A solvent based paint modeled for BEES is used for the model.

The model assumes an average installation waste of $5 \%$ by mass for each product, and this waste is assumed to go to a landfill. While sheathing, weather resistive barriers, and other ancillary materials may be required to complete the exterior wall system, these materials are not included in the system boundaries for BEES exterior wall finishes.

\subsubsection{Use}

These products are modeled as having useful lives of 60 years. Thus, one initial installation and use period is modeled for the BEES functional lifetime. WeatherBoards are modeled as being repainted with one coat of paint every fifteen years, for a total of three additional paint coatings over the course of 60 years. No other routine maintenance is required to prolong the lifetime of the products, although cleaning is recommended to maintain appearance. Cleaning would normally be done with water and household cleaners. Information on typical cleaning practices (e.g., frequency of cleaning, types and quantities of cleaning solutions used) was not available. Besides paint needed for WeatherBoards, maintenance is not included in the system boundaries.

\subsubsection{End of Life}

Each of these products is assumed to be disposed of in a landfill at end of life. End of life modeling includes transportation of the product and installation materials by heavy-duty diesel-fuel powered truck approximately $48 \mathrm{~km}(30 \mathrm{mi})$ to a landfill, plus impacts of the materials in a landfill. Truck transportation is based on the U.S. LCI database and 
disposal in a landfill is modeled based on ecoinvent end of life waste management process data.

\subsection{Generic Vinyl Siding and Insulated Vinyl Siding}

Vinyl siding is used as an exterior wall finish on new and renovated construction. Since its introduction in the 1960s, vinyl siding has become one of the more popular exterior wall finishes for new construction. Vinyl siding is manufactured in a wide variety of profiles, colors, and thicknesses to meet different market applications. Vinyl siding is commonly produced as double units that have the appearance of two overlapping or adjoining $11.4 \mathrm{~cm}$ wide (4.5 in wide) boards. Double 4.5 is the most common profile. The mass of vinyl siding is $19.3 \mathrm{~kg}(42.4 \mathrm{lb})$ per $9.29 \mathrm{~m}^{2}\left(100 \mathrm{ft}^{2}\right)$ for a typical $0.102 \mathrm{~cm}$ (0.040 in) thickness. For the BEES system, $0.102 \mathrm{~cm}$ (0.040 in) thick, $23 \mathrm{~cm}$ (9 in) wide horizontal vinyl siding installed with galvanized nail fasteners is studied. The nails are assumed to be placed $41 \mathrm{~cm}$ (16 in) on center.

Insulated vinyl siding uses an EPS foam-contoured material designed to enhance the performance characteristics of vinyl siding. Compressed EPS beads are expanded into foam board and then laminated onto vinyl siding. The foam contouring characteristic improves the thermal performance of the external wall system by eliminating any voids behind the vinyl's hollow siding, thereby saving energy during its use. It is also intended to discourage mold growth and repel termites with the help of an insecticide.

\subsubsection{Product Description}

Insulated vinyl siding modeled for BEES is $22.4 \mathrm{~kg}(49.3 \mathrm{lb})$ per $9.29 \mathrm{~m}^{2}\left(100 \mathrm{ft}^{2}\right)$ and is typically installed with galvanized nail fasteners placed $41 \mathrm{~cm}$ (16 in) on center. Insulated vinyl siding has thermal resistance values ranging from $\mathrm{R}_{\mathrm{SI}^{-}}-0.35$ to $\mathrm{R}_{\mathrm{SI}}-0.70$ ( $\mathrm{R}_{\mathrm{US}}-2$ to $\left.\mathrm{R}_{\mathrm{US}}-4\right)^{68}$; the product in BEES has a value of RUS-2.57 according to ASTM International Standard 1363 test results. Despite the added insulation and reduced thermal bridging, the building still requires base insulation which is not included in BEES for this category. Thermal performance differences among exterior wall finish alternatives are not accounted for in BEES, but it should be considered when interpreting BEES results.

Data described in this chapter and modeled for BEES are based on the Vinyl Siding Institute's (VSI) LCA covering these two products. Data are primarily from North American facilities and manufacturers, collected for the year 2015. While siding is generally specified in terms of 'squares' of siding, or $9.29 \mathrm{~m}^{2}\left(100 \mathrm{ft}^{2}\right)$, for BEES, the functional unit is $0.09 \mathrm{~m}^{2}\left(1 \mathrm{ft}^{2}\right)$ of siding used in a building for 60 years.

\subsubsection{Flow Diagram}

${ }^{68}$ Units for RsI and $\mathrm{R}_{\mathrm{Us}}$ are ${ }^{\circ} \mathrm{C}-\mathrm{m}^{2}$-sec/J and ${ }^{\circ} \mathrm{F}-\mathrm{ft}^{2}-\mathrm{s} / \mathrm{BTU}$, respectively. 
The flow diagrams in Figure 6-11 and Figure 6-12 show the major elements of the production of these products as they are currently modeled for BEES.

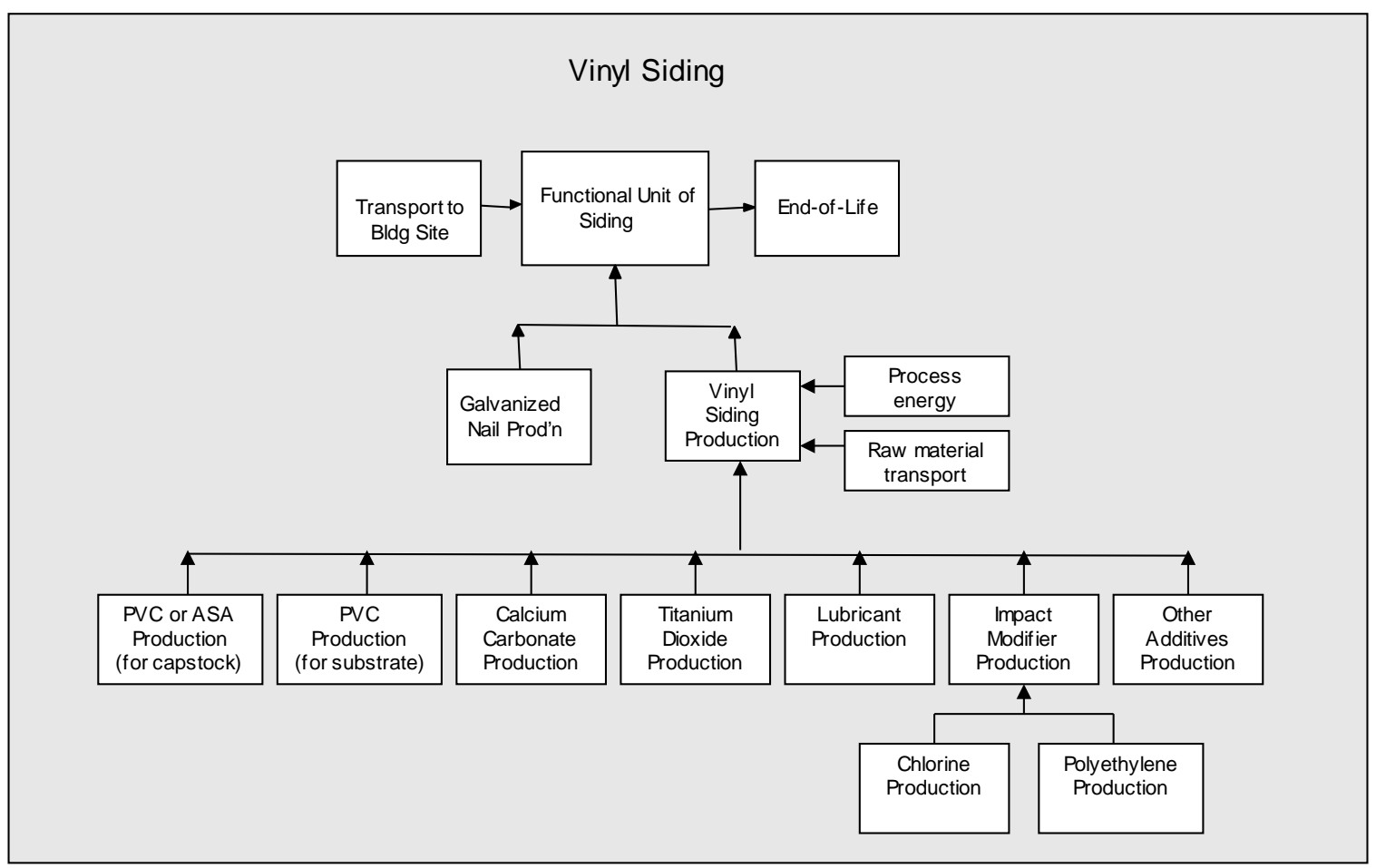

Figure 6-11 Vinyl Siding System Boundaries

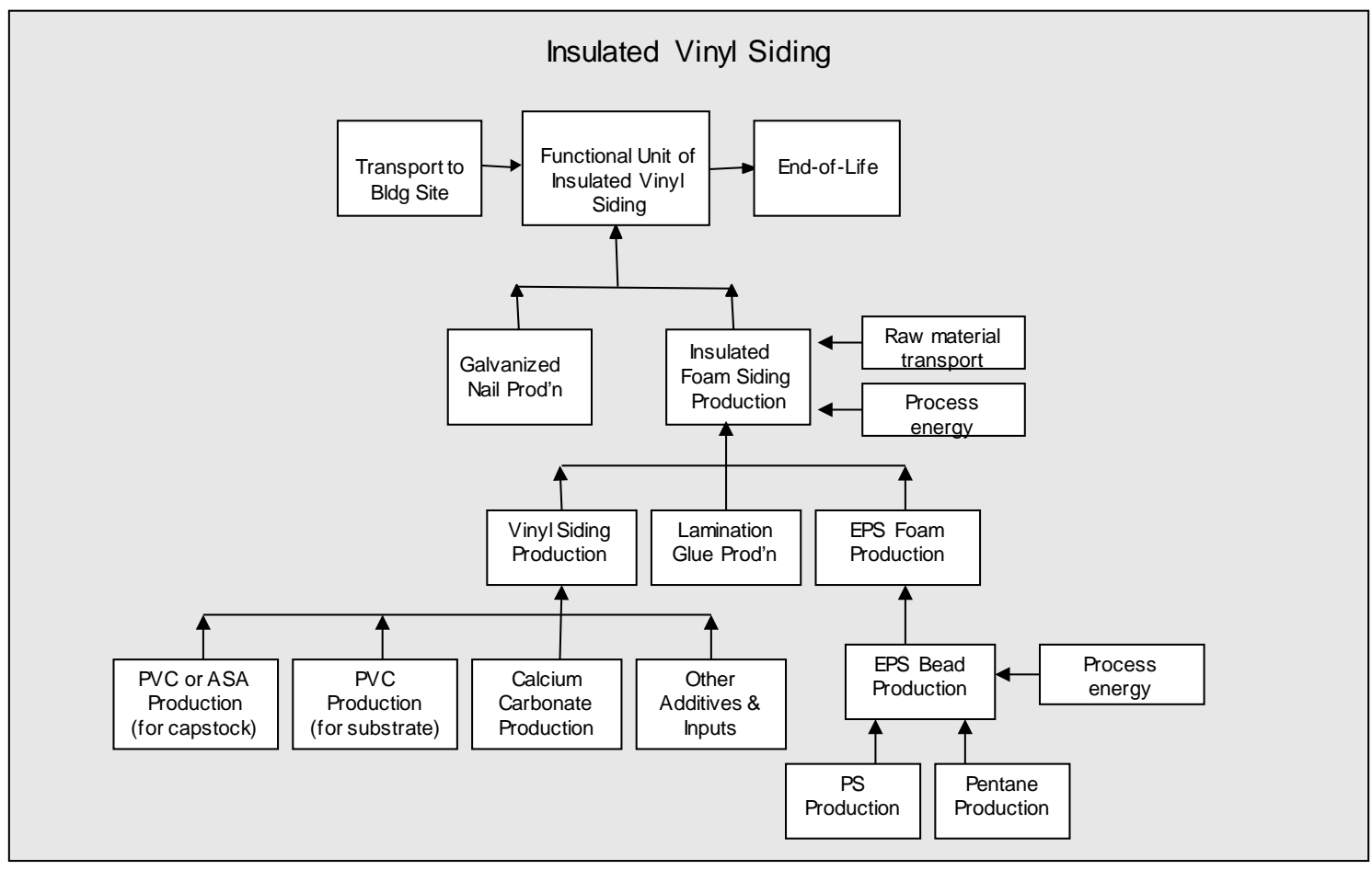

Figure 6-12 Insulated Vinyl Siding System Boundaries 


\subsubsection{Raw Materials}

Vinyl siding is composed of two layers: the substrate and the capstock, which is the surface exposed to the outside and formulated to be more weather resistant. The vinyl siding product in BEES represents $50 \%$ siding made with PVC capstock and $50 \%$ made with acrylonitrile styrene acrylate (ASA) capstock. ${ }^{69}$ The formulation in Table 6-21 presents the average of the these two formulations by mass percentage (Sustainable Solutions Corporation, 2016):

\section{Table 6-21 Vinyl Siding Constituents}

\begin{tabular}{lc}
\hline Constituent & Average of the PVC and ASA Capstocks \\
\hline PVC & $74 \%$ \\
ASA & $6.0 \%$ \\
Calcium carbonate (limestone) & $10 \%$ \\
Impact modifier & $2.0 \%$ \\
Titanium dioxide & $1.6 \%$ \\
Lubricants & $1.8 \%$ \\
Other additives & $4.6 \%$ \\
Total & $\mathbf{1 0 0} \%$ \\
\hline
\end{tabular}

The PVC resin comes from the U.S. LCI database. The impact modifier, a chlorinated polyethylene, is produced from the chlorination of polyethylene. Data for both chlorine and polyethylene used to build the impact modifier come from the U.S. LCI database. ASA is modeled as acrylonitrile-butadiene-styrene copolymer resin, from the U.S. LCI database. Titanium dioxide and calcium carbonate come from ecoinvent. "Other additives” include pigment, stabilizer, process aids, and sealant; production data for these substances are based on materials in the U.S. LCI and ecoinvent databases. Some of the additives’ data sets were built using Material Data Sheets and/or stoichiometry.

\subsubsection{Manufacturing}

\subsubsection{Vinyl Siding}

According to Sustainable Solutions Corporation (2016), vinyl siding manufacturing is a very efficient extrusion process requiring relatively low inputs of energy and water. The ability to immediately return scrap and off-specification materials (regrind) directly into the manufacturing process results in minimal manufacturing waste. Technological advances have allowed for vinyl siding to be co-extruded with a substrate and a capstock. As described in Sustainable Solutions Corporation (2016), “Co-extrusion allows for a

\footnotetext{
${ }^{69}$ Note: PVC capstock currently has a slightly higher market share but siding with ASA capstock is expected to become more dominant in the coming years.
} 
more durable product, enabling colors and textures to retain their original appearance and performance capabilities over time.”

Energy and other inputs. Manufacturing energy and water use are presented in Table 6-22.

\section{Table 6-22 Energy and Water Requirements for Vinyl Siding}

\begin{tabular}{lc}
\hline Fuel Use & Quantity per $\boldsymbol{k g}$ Siding \\
Electricity MJ (kWh) & $0.896(0.249)$ \\
Natural Gas m3 (scf) & $0.003(0.110)$ \\
Propane l (gal) & $2.3 \mathrm{E}-3(6.2 \mathrm{E}-4)$ \\
Gasoline l (gal) & $1.6 \mathrm{E}-6(4.0 \mathrm{E}-7)$ \\
\hline Water Use I (gal) & $0.829(0.219)$ \\
\hline
\end{tabular}

The electricity is used for raw materials mixing, extrusion, machining, lighting, air compressors, cooling water pumps, grinding operations, and other miscellaneous equipment. The natural gas is used for space heating, and the propane and gasoline are used in mobile equipment. Electricity production sources and the fuels production and combustion come from the U.S. LCI database. Water is make-up for process cooling, and to a small extent, cleaning and domestic use.

Manufacturing outputs. The amount of wastewater generated is $0.54 \mathrm{~L} / \mathrm{kg}(0.065 \mathrm{gal} / \mathrm{lb})$ siding. The difference between the reported water in and out is mainly due to evaporation losses in the closed loop cooling water systems utilized by most of the plants. The BEES model includes treatment with water treatment chemicals so this water is assumed to be uncontaminated. A small quantity of inert waste which includes some PVC, $0.027 \mathrm{~kg}$ per $\mathrm{kg}$ siding, is generated and landfilled. Combustion-related air emissions are accounted for in upstream energy use data sets (e.g., natural gas use in a boiler). Process-related air emissions reported for BEES are shown in Table 6-23.

\section{Table 6-23 Air Emissions Data for Vinyl Siding}

\begin{tabular}{lc}
\hline Emission & Quantity $(\mathbf{k g}$ per functional unit) \\
\hline Dichloroethene & $1.31 \mathrm{E}-10$ \\
Vinyl Chloride & $1.24 \mathrm{E}-05$ \\
\hline
\end{tabular}

Transportation of vinyl siding constituents. Transportation of the raw materials to siding facilities has been quantified in Sustainable Solutions Corporation (2016) and accounted for in BEES. For vinyl siding, materials are transported an average of $170 \mathrm{~kg}-\mathrm{km}$ (603 lb-mile) by truck and 150 kg-km (532 lb-mile) by train. Train and diesel-powered combination trucks are modeled based on the U.S. LCI database.

Packaging. Industry-average packaging data were provided by Sustainable Solutions and includes paper labels, plastic strapping, LDPE plastic wrap and weather bags, cardboard, and wood pallets. 


\subsubsection{Insulated Vinyl Siding}

The three main components of insulated vinyl siding are shown in Table 6-24.

Table 6-24 Insulated Vinyl Siding Constituents

\begin{tabular}{lcc}
\hline Constituent & Kg per $\mathrm{ft}^{2}$ & \% by mass \\
\hline Foam backing & 0.028 & $12.5 \%$ \\
Vinyl siding & 0.193 & $86.0 \%$ \\
Lamination glue & 0.0033 & $1.5 \%$ \\
\hline
\end{tabular}

The insulated vinyl siding facility first makes EPS foam board by compressing EPS foam beads and expanding them using steam from a natural gas-fired steam generator. Insulated vinyl siding is produced when the EPS foam board and a sheet of vinyl siding are hand fed onto a table of rollers. Lines of glue are applied to the foam and then the foam and vinyl are run through a compression roller, sealing the foam to the vinyl. Prior to lamination, the foam is trimmed to match the vinyl profile. These pieces are then boxed and shipped. The whole process relies primarily on human labor, with a small amount of electricity for the roller machine. Foam trim, $0.29 \mathrm{~kg} / \mathrm{kg}$ foam, is recovered and sent to a recycler.

VSI through Sustainable Solutions supplied the energy use, water use, and emissions, including pentane release, at the foam production and siding lamination plant but these data cannot be released since they are proprietary and not averaged with other facilities' production data. Electricity production, fuels, and combustion come from the U.S. LCI Database.

Data for the vinyl siding has been described above. The lamination glue used is made up of the components shown in Table 6-25.

\section{Table 6-25 Laminated Glue Constituents}

\begin{tabular}{lc}
\hline Constituent & \% by mass \\
\hline Tackifying Resins & $47.0 \%$ \\
Mineral Oil & $20.0 \%$ \\
Polymer Solids & $27.0 \%$ \\
Carbonic Acid & $3.0 \%$ \\
Talc & $3.0 \%$ \\
\hline
\end{tabular}

These materials are modeled based on elements of the U.S. LCI database and ecoinvent.

Transportation of insulated vinyl siding constituents. Transportation of the raw materials to siding facilities has been quantified in Sustainable Solutions Corporation (2016) and accounted for in BEES. For insulated vinyl siding, vinyl siding and the lamination glue 
are transported an average of $420 \mathrm{~kg}-\mathrm{km}$ (1490 lb-mile) by truck and $150 \mathrm{~kg}-\mathrm{km}$ (532 lb-mile) by train. ${ }^{70}$ The EPS foam beads come from domestic and foreign suppliers; the distances and modes of transportation, including ocean freighter, rail, and dieselpowered combination truck, are included in the model. The transportation data are based on the U.S. LCI database.

Packaging. Industry-average packaging data were provided by Sustainable Solutions and includes paper labels, plastic strapping, LDPE plastic wrap and weather bags, cardboard, and wood pallets.

\subsubsection{Transportation}

The finished vinyl siding and insulated vinyl siding products are transported a weighted average distance of $509 \mathrm{~km}$ (316 mi) by diesel truck to the building site. Nails used for installation are assumed to be transported $241 \mathrm{~km}(150 \mathrm{mi})$ by diesel truck to the building site. The BEES user may change the assumed transport distances for the main products.

\subsubsection{Installation}

Installation for both products is done primarily by manual labor. Nails or screws can be used to install the siding; nails are more common and would typically be the type installed with a gun. The energy required to operate compressors to power air guns is assumed to be small and is not included in the analysis. Installation is modeled for nails placed $41 \mathrm{~cm}$ (16 in) on center; nail use is $0.0024 \mathrm{~kg}(0.0053 \mathrm{lb})$ per $0.09 \mathrm{~m}^{2}$ (per $\mathrm{ft}^{2}$ ) of siding. Installation waste with a mass fraction of $5 \%$ is assumed, and this waste is assumed to go to a landfill.

While sheathing, weather resistive barriers, and other ancillary materials may be required to complete the exterior wall system, these materials are not included in the system boundaries for BEES exterior wall finishes.

\subsubsection{Use}

The vinyl siding products have an assumed useful life of 60 years. No routine maintenance is required to prolong the lifetime of the product, although cleaning is recommended to maintain appearance. Cleaning would normally be done with water and household cleaners. Information on typical cleaning practices (e.g., frequency of cleaning, types and quantities of cleaning solutions used) was not available; maintenance was not included in the system boundaries.

\subsubsection{End of Life}

At end of life, these products are assumed to be disposed of in a landfill. End of life modeling includes transportation of these materials by heavy-duty diesel-fuel powered truck approximately $48 \mathrm{~km}$ (30 mi) to a landfill, plus impacts of the materials in a

\footnotetext{
${ }^{70}$ Sustainable Solutions Corporation (2016), Table 4.4
} 
landfill. Truck transportation is based on the U.S. LCI database and disposal in a landfill is modeled based on ecoinvent end of life waste management process data.

\subsection{Generic Aluminum Siding}

Aluminum siding or cladding is a commonly-used exterior wall cladding that is known for its light weight and durability. Aluminum siding typically has an exterior coating to provide color and durability. Common coatings include acrylic, polyester, and vinyl.

\subsubsection{Product Description}

For the BEES system, the functional unit is $0.09 \mathrm{~m}^{2}$ (one $\mathrm{ft}^{2}$ ) of exterior wall area of aluminum siding used for 60 years. The aluminum siding panels in BEES are $20 \mathrm{~cm}(8$ in) wide and 22 gauge or $0.064 \mathrm{~cm}$ (0.025 in) thick. The siding is fastened using aluminum fasteners every $41 \mathrm{~cm}$ to $61 \mathrm{~cm}$ (16 in to $24 \mathrm{in})$.

\subsubsection{Flow Diagram}

The flow diagram in Figure 6-13 shows a simplistic flow diagram of the major elements of the production of this product, as it is currently modeled for BEES.

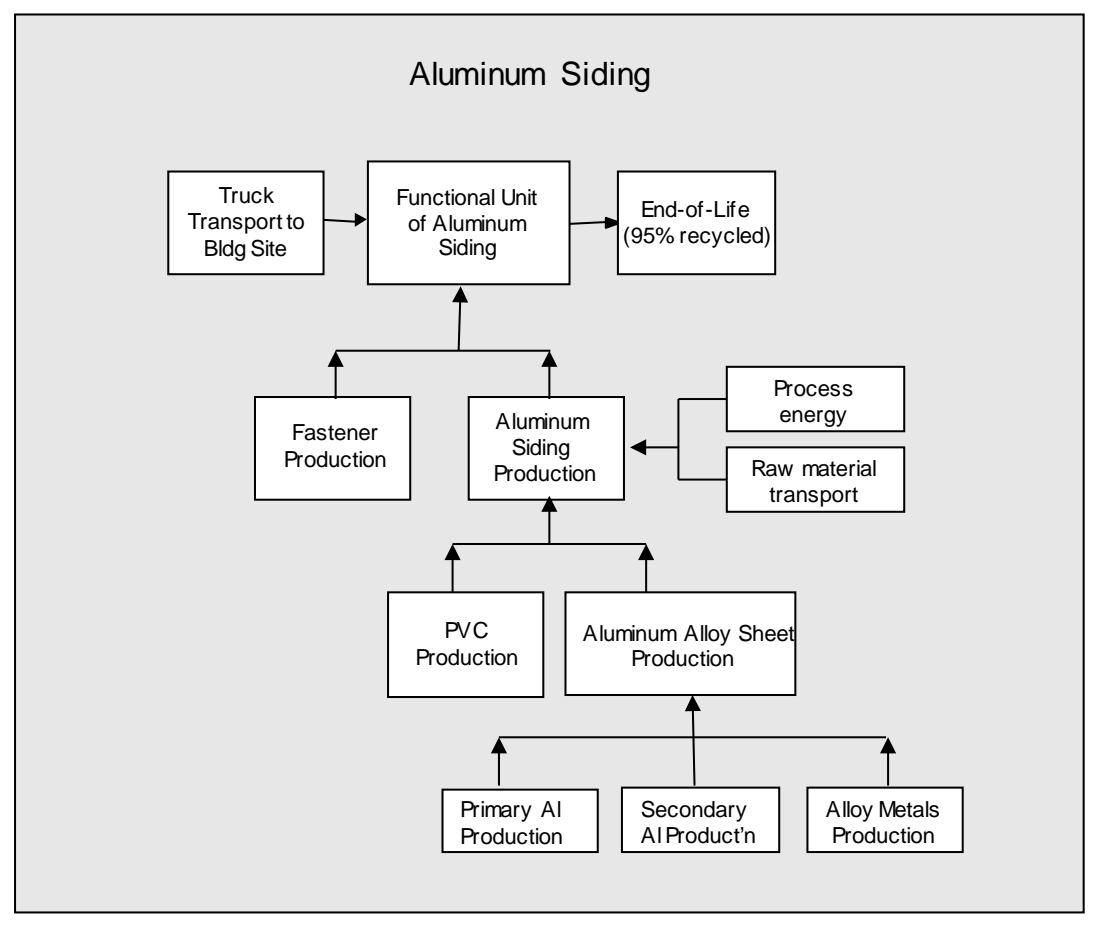

Figure 6-13 Aluminum Siding System Boundaries

\subsubsection{Raw Materials}

There are several aluminum siding products on the market, most of which are manufactured using different combinations of aluminum alloys and coating materials. Coating formulations are generally proprietary; the product studied for the BEES system 
is manufactured as an aluminum sheet with a PVC thermoset topcoat. The installed product is modeled with a mass of $0.19 \mathrm{~kg}(0.42 \mathrm{lb})$ of aluminum siding (PAC-CLAD, 2015), and Table 6-26 presents the major constituents and their percentages.

\section{Table 6-26 Aluminum Siding Constituents}

\begin{tabular}{lcc}
\hline \multicolumn{1}{c}{ Constituent } & $\begin{array}{c}\text { Mass } \\
\mathbf{k g} / \mathbf{m}^{\mathbf{2}}\left(\mathbf{l b} / \mathbf{f t}^{2}\right)\end{array}$ & $\begin{array}{c}\text { Mass Fraction } \\
(\boldsymbol{\%})\end{array}$ \\
\hline Aluminum Alloy Sheet & $2.04(0.419)$ & 99.0 \\
PVC Topcoat & $0.020(0.004)$ & 1.0 \\
\hline
\end{tabular}

Aluminum production. The data for the aluminum in this product come from the Aluminum Association (AA) North American industry average LCA data on semifinished aluminum products (AA, 2013).${ }^{71}$ AA (2013) includes detailed primary (i.e., facility) data for primary aluminum production, including bauxite mining; production of alumina, which converts the mined bauxite into aluminum oxide; production of anode, an auxiliary input; smelting by electrolysis using the Prebake and Söderberg technologies, and primary ingot casting. AA (2013) also includes primary data to produce secondary aluminum, including scrap collection and processing and scrap melting and ingot casting. The flat rolling processes to produce aluminum sheets and coils first undergo hot rolling, which produce hot rolled coils, and then cold rolling, which takes hot-rolled coil or strip and produces cold rolled coil and products. ${ }^{72}$ Aluminum sheet for siding may be produced from hot-rolled or cold-rolled coil. For BEES, it is assumed that $50 \%$ is made up of hot rolled coil and $50 \%$ of cold rolled.

According to the Aluminum Association, the estimated recycled content of aluminum building materials used today is between $50 \%$ and $85 \%{ }^{73}$ For BEES, it is modeled as $67 \%$, based on the modeling and data in AA (2013). Primary data collected from AA (2013) of participating aluminum companies’ North American facilities are representative for the year 2010. Data for the sheet rolling processes are based on years 2008 to 2011.

The aluminum sheet in the BEES model has been modeled using the Substitution Approach, also called the "Avoided Burden Approach", which considers production and end of life recycling loops. According to AA (2013) (p.22-24):

"The recommendation of the Substitution Approach is based on the characteristics of aluminum products and aluminum recycling, which preserves the full physical properties of the metal without losses of quality no matter how many times it is recycled. The aluminum recycling system is a semi-closed-loop system in which the recycled aluminum could end up

\footnotetext{
${ }^{71}$ Note that this source was the most recent available data from AA at the time of this publication

${ }^{72}$ The interested reader is encouraged to go to www.aluminum.org for more information on its LCAs, including detail on process descriptions and unit process inputs and outputs.

${ }^{73}$ Found at: http://www.aluminum.org/product-markets/building-construction
} 
with the same product system, e.g., extruded to extruded products, flatrolled to flat-rolled products, and shape-casted to shape-casted products, or in other cases, the recycled aluminum from one product system could be used for other product systems depending on the efficient allocation of aluminum scraps by market forces... The system flow chart for Substitution Approach is shown in Figure 6-14."

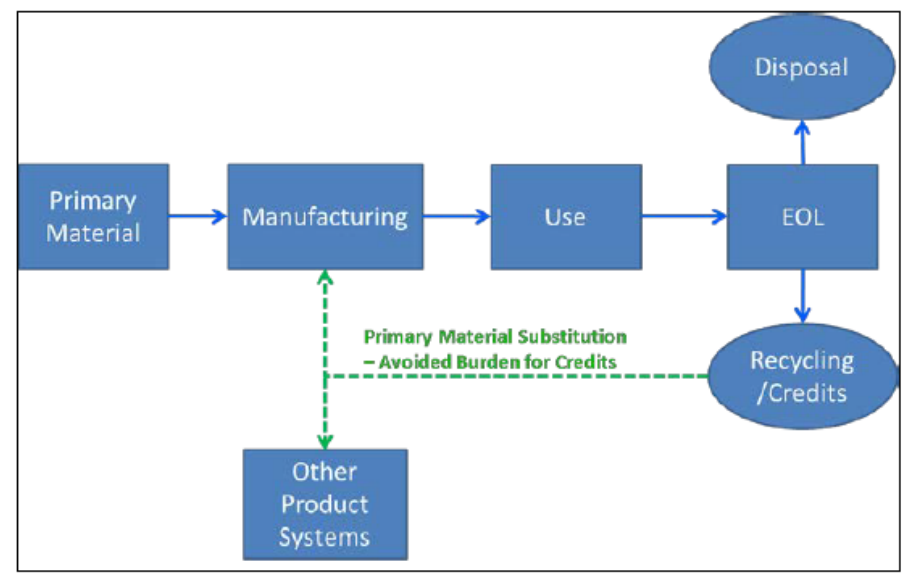

\title{
Figure 6-14 Process Flow Char for a Substitution Approach
}

\begin{abstract}
"Under this framework, the product being examined is completely recycled once it reaches the end-of-life phase. Material losses are considered during the collection and processing of scrap as well as those associated with the production of secondary material (the melting and/or re-melting process). The lost material is replenished with the primary material to keep the system closed. Consistent with ISO 14044, the net recovered metal is a substitution of the same amount of primary metal and therefore help avoid the burdens associated with the primary metal production. A credit is given for such a substitution."
\end{abstract}

Other materials production. The vinyl topcoat is $0.08 \mathrm{~mm}$ to $0.09 \mathrm{~mm}$ ( $3.3 \mathrm{mil}$ to $3.7 \mathrm{mil}$ ) thick. Data to produce PVC come from the U.S. LCI database. Alloys are used in metals to improve their performance characteristics. There are many aluminum alloying designations, and a subset of these alloys can be used in building and construction, depending on the specific needs of the application. Magnesium as a primary alloying agent helps to increase the strength of aluminum. The Aluminum Association classifies the anodized 5005 sheet as a common alloy application for architectural applications. ${ }^{74}$ While other alloy series, including 1xxx, 3xxx, and 6xxx, offer designations that may also be applicable for use in building and construction, we use aluminum 5005 as a general guidance for the alloying composition used for BEES. Namely, a composition of

\footnotetext{
${ }^{74}$ Found at: http://www.aluminum.org/resources/industry-standards/aluminum-alloys-101
} 
$0.8 \%$ magnesium, $0.7 \%$ iron, $0.3 \%$ silicon, $0.25 \%$ zinc, $0.2 \%$ copper, and $0.2 \%$ manganese is assumed. ${ }^{75}$ The data for these elements were provided by ecoinvent.

\subsubsection{Manufacturing}

Energy Requirements and Emissions. Energy requirements and emissions for production of the rolled aluminum alloy and PVC resin are included in the BEES data for the raw material acquisition life cycle stage (described above). The model does not include the energy demands or emissions associated with application of PVC topcoat to the aluminum siding or cutting of the panels at the fabrication plant due to lack of available data.

Packaging. Product packaging data come from the PAC-CLAD EPD due to lack of other packaging data on roll-form aluminum panels. According to the EPD, packaging of aluminum panels per $1000 \mathrm{ft}^{2}$ includes $227 \mathrm{~kg}(500 \mathrm{lb})$ wood, $0.249 \mathrm{~kg}(0.55 \mathrm{lb})$ plastic, assumed to be LDPE packaging film, and $2.13 \mathrm{~kg}(4.7 \mathrm{lb})$ paper. Data for wood comes from the U.S. LCI database and data for LDPE film and paper come from ecoinvent.

Transportation to fabrication plants. Transportation of rolled aluminum and PVC resin to aluminum siding mills is assumed to be $402 \mathrm{~km}$ (250 mi) by truck.

\subsubsection{Transportation}

Transportation of the fabricated aluminum siding to the building site is modeled using heavy-duty truck an average of $805 \mathrm{~km}$ (500 mi) to the building site. The BEES user may change this default distance.

\subsubsection{Installation}

Aluminum siding installation is predominately a manual process - a small amount of energy may be required to operate compressors to power air guns, but this energy use is assumed to be small and is not included in the analysis. Fasteners may be placed every 41 $\mathrm{cm}$ to $61 \mathrm{~cm}$ (16 in to $24 \mathrm{in})$, using an average of $0.006 \mathrm{~kg}(0.013 \mathrm{lb})$ of aluminum fasteners per $\mathrm{ft}^{2}$ of siding. Installation waste with a mass fraction of $5 \%$ is assumed, and all waste is assumed to go to a metals recycler. While sheathing, weather resistive barriers, and other ancillary materials may be required to complete the exterior wall system, these materials are not included in the system boundaries for BEES exterior wall finishes.

\subsubsection{Use}

The product is assumed to have a useful life of 80 years. In some instances, siding without significant corrosion damage can be found after 100 years. However, owners may replace siding for reasons other than corrosion (e.g., to update the home's exterior

\footnotetext{
${ }^{75}$ Alloy percentages found at: https://continentalsteel.com/aluminum/grades/alloy-5005/
} 
appearance or change the color). It is assumed for the model that the siding remains in place over the 60-year study period.

Buildings with aluminum siding are periodically cleaned, usually for aesthetic reasons. Information on typical cleaning practices (e.g., frequency of cleaning, types and quantities of cleaning solutions used) is not available; no use phase impacts from cleaning are included.

\subsubsection{End of Life}

Because aluminum scrap has a significant economic value, the model assumes a $95 \%$ recycling rate for the siding at end of life, which is typical for aluminum products in the construction market sector. This rate is consistent with AA (2013). Recycling at end of life is accounted for in the cradle-to-grave production data for hot rolled and cold rolled coils using the Substitution Approach.

\subsection{Generic Brick}

Brick is a masonry unit of clay or shale, formed into a rectangular shape while plastic, cored, and then fired in a kiln. Mortar is used to bond the bricks into a single element. Facing brick or hollow brick are commonly used in brick veneer as a part of exterior wall assemblies.

\subsubsection{Product Description}

The BEES model for brick and mortar evaluates a modular-sized brick unit that represents fired clay facing brick and hollow brick. The brick unit evaluated has actual dimensions assumed to be $92 \mathrm{~mm} \times 57 \mathrm{~mm} \times 194 \mathrm{~mm}\left(3^{5 / 8} \mathrm{in} . \times 2 \frac{1}{4} \mathrm{in} . \times 75 / 8\right.$ in.). The nominal dimensions of the brick unit including the mortar joint are $102 \mathrm{~mm} \times 68 \mathrm{~mm} \times$ $203 \mathrm{~mm}$ ( 4 in. $\times 2 \frac{2}{3}$ in. $\times 8$ in.). The brick unit is cored prior to being fired, which removes about $25 \%$ to $30 \%$ of the clay or shale material. The cored and fired brick unit weighs $1.7 \mathrm{~kg}(3.7 \mathrm{lb})$.

The brick is assumed to be installed with Type $\mathrm{N}$ mortar, which has a density of 1840 $\mathrm{kg} / \mathrm{m} 3(115 \mathrm{lb} / \mathrm{ft} 3)$ and a maximum air content of $20 \%$. Masonry is typically measured based on wall area $\left(\mathrm{m}^{2}\right.$ or $\left.\mathrm{ft}^{2}\right)$. A brick wall is assumed to be $80 \%$ brick and $20 \%$ mortar by surface area. For BEES, the functional unit is $0.09 \mathrm{~m}^{2}\left(1 \mathrm{ft}^{2}\right)$ of siding used in a building for 60 years.

\subsubsection{Flow Diagram}

The flow diagram in Figure 6-15 shows the major elements of the production of this product, as it is currently modeled for BEES. 


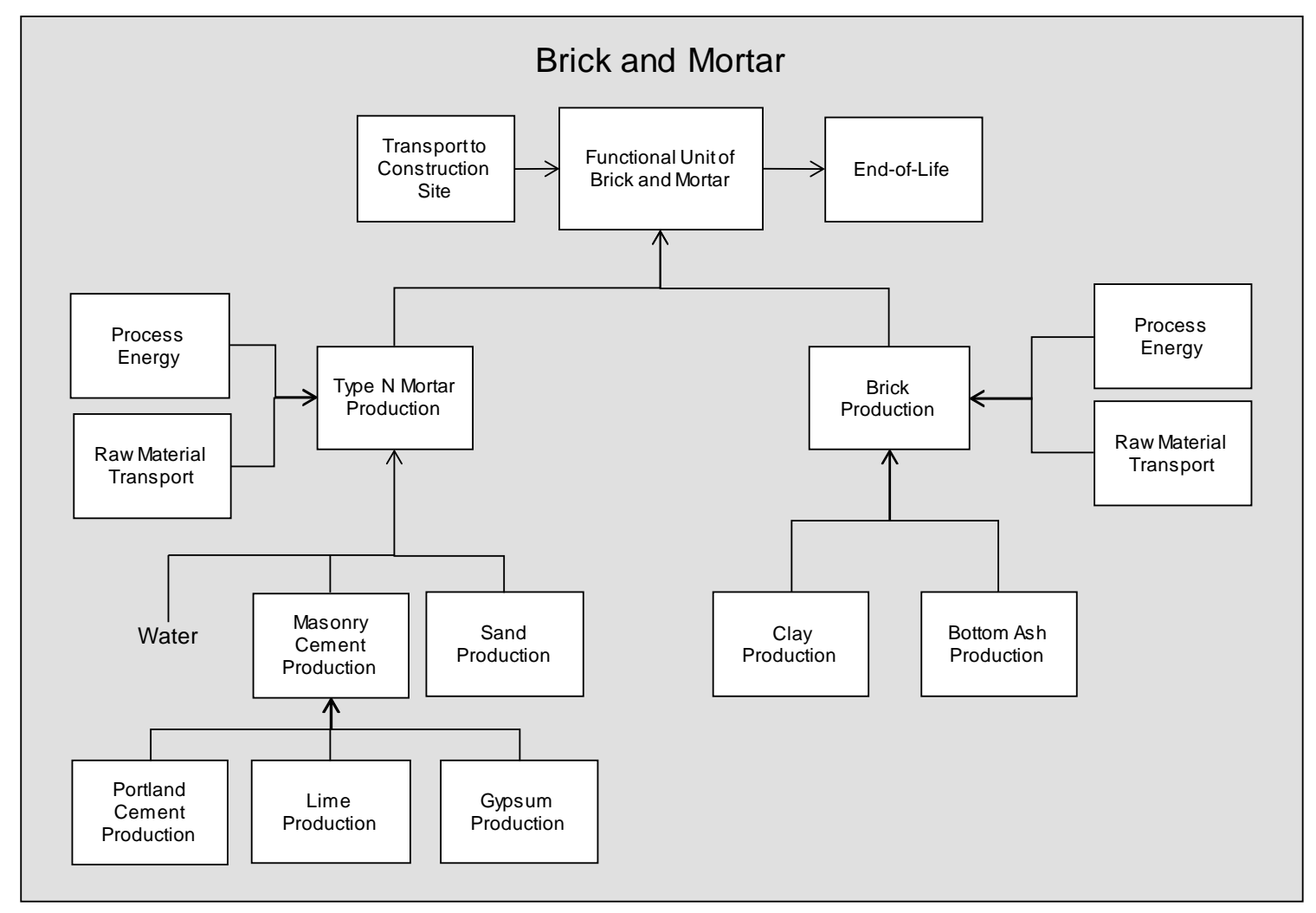

Figure 6-15 Brick \& Mortar System Boundaries

\subsubsection{Raw Materials}

Table 6-27 shows that brick uses virtually $100 \%$ mined clay or shale. Bottom ash, a postindustrial recycled material, is the most widely used recycled material that is added to the clay or shale during brick production. Typical replacement of clay or shale inputs is $0.8 \%$ bottom ash by mass.

\section{Table 6-27 Fired Brick Constituents}

\begin{tabular}{lc}
\hline Constituent & Mass Fraction (\%) \\
\hline Clay & 99.2 \\
Bottom Ash & 0.8 \\
\hline
\end{tabular}

All material removed in the manufacturing process is returned to the manufacturing stream. Fired product that is scrapped is used as grog ${ }^{76}$ in brick manufacturing or for other uses such as landscape chips and roadbed. Type N mortar consists of one-part masonry cement (by volume fraction) and three parts natural or manufactured sand, ${ }^{77}$ and adequate water to achieve the proper consistency. Mixing $0.009 \mathrm{~m}^{3}\left(1 / 3 \mathrm{ft}^{3}\right)$ of masonry

\footnotetext{
${ }^{76}$ Grog is previously-fired ceramic material, typically from ground brick. It is included in the brick body to reduce drying shrinkage or provide a more open texture to the fired brick.

77 Based on ASTM Specification C270-12a.
} 
cement, $0.028 \mathrm{~m}^{3}\left(1 \mathrm{ft}^{3}\right)$ of sand, and approximately $6.3 \mathrm{l}$ (1.7 gal) of water yields about $0.028 \mathrm{~m}^{3}\left(1 \mathrm{ft}^{3}\right)$ of mortar. The raw material used for masonry cement is based on Type $\mathrm{N}$ masonry cement, and its constituents are shown in Table 6-28 (PCA, 2016b).

\section{Table 6-28 Masonry Constituents}

\begin{tabular}{lc}
\hline \multicolumn{1}{c}{ Constituent } & Mass Fraction (\%) \\
\hline Portland cement clinker & $57.5 \%$ \\
Limestone & $36.1 \%$ \\
Gypsum & $4.9 \%$ \\
Dust (e.g., bypass dust) & $1.1 \%$ \\
Other inputs & $0.5 \%$ \\
Total & $\mathbf{1 0 0 . 0}$ \\
\hline
\end{tabular}

The materials for masonry cement are based on ecoinvent customized to U.S. conditions. Some water in mortar is chemically bound, so there is some net consumption of waterbased on $25 \%$ by weight for hydration, approximately $57 \mathrm{~kg}$ (3.5 lb) of water is chemically bound for every $0.028 \mathrm{~m}^{3}\left(1 \mathrm{ft}^{3}\right)$ of mortar produced.

\subsubsection{Manufacturing}

Energy Requirements and Emissions. The energy requirements for brick production are listed in Table 6-29. These values are based on the drying and firing production steps in the manufacturing process, as these processes are the most energy-intensive steps. Although upgraded electrical motors have been incorporated into many plants, the overall horsepower requirements have not changed, so the amount of electricity used remains similar. A blend of grid electricity sources is used to represent the distribution of manufacturing facilities.

Table 6-29 Energy Requirements for Brick Manufacturing ${ }^{78}$

\begin{tabular}{lc}
\hline Energy Carrier & Quantity per $\mathbf{L} \boldsymbol{b}$ \\
\hline Natural Gas & $0.022 \mathrm{~m}^{3}$ to $0.025 \mathrm{~m}^{3}$ \\
& $\left(0.775 \mathrm{ft}^{3}\right.$ to $\left.0.871 \mathrm{ft}^{3}\right)$ \\
Grid Electricity & $0.0810 \mathrm{MJ}(0.0225 \mathrm{kWh})$ \\
\hline
\end{tabular}

Emissions for brick firing and drying are based on AP-42 data for emissions from brick manufacturing for each manufacturing technology and type of fuel burned (EPA, 1997). ${ }^{79}$

Brick production is distributed across U.S. Census Regions as shown in Table 6-30.

\footnotetext{
${ }^{78}$ As determined by the National Brick Research Center based on existing records and data from brick manufacturers and selected equipment vendors.

${ }^{79}$ According to the Brick Industry Association (BIA), AP-42 emissions data are likely to be overstated, as at least 80 brick kilns have added emission control devices in the past ten years. However, EPA has yet to update AP-42 with this additional information.
} 
Table 6-30 U.S. Brick Production by Census Region ${ }^{80}$

\begin{tabular}{lc}
\hline Census Region & Brick Production \\
\hline Pacific & $3.4 \%$ \\
Mountain & $3.3 \%$ \\
West South Central & $29.6 \%$ \\
East South Central & $14.2 \%$ \\
South Atlantic & $28.4 \%$ \\
West North Central & $4.0 \%$ \\
East North Central & $11.8 \%$ \\
Middle Atlantic & $4.1 \%$ \\
New England & $1.2 \%$ \\
\hline
\end{tabular}

Water Consumption. Water is used in the manufacturing process to impart plasticity to the raw materials, which allows the brick to be formed. Although water is used in brick manufacturing, it is not chemically altered or bound but is evaporated into the atmosphere. Approximately $35 \%$ of plants use some amount of recycled water. Approximately $11 \%$ of plants use only recycled water (Ducker, 2008). On average, approximately $20.5 \%$ of the weight of formed brick is water and is returned to the atmosphere during the drying process.

Transportation of Raw Materials. Brick manufacturers often locate their facilities near readily available clay sources to reduce transportation. Brick raw materials are typically transported by truck from the pit to the brick plant. The average distance from the pit to the plant is approximately $24 \mathrm{~km}$ (15 mi) (Brick Industry Association, 2009).

Waste. Brick manufacturing is very efficient. Processed clay and shale removed in the forming process before firing are returned to the production stream. Brick not meeting standards after firing are culled from the process and ground to be used as grog in manufacturing brick or crushed to be used as landscaping material. Scrap loss due to the manufacturing process is only 3 \% (Brick Industry Association, 2017).

\subsubsection{Transportation}

Transportation of brick to the building site is modeled as a variable of the BEES system. Most brick is transported by truck with a much smaller amount shipped by rail (95 \% and $5 \%$, respectively) to the building site. The average distance shipped is $298 \mathrm{~km}$ (185 miles) by truck and $961 \mathrm{~km}$ (597 miles) by rail. The BEES user may change the transportation distance in the tool.

${ }^{80}$ Brick Industry Association (2017) 


\subsubsection{Installation}

Mortar is assumed to be delivered to a job site in $0.76 \mathrm{~m}^{3}\left(1 \mathrm{yd}^{3}\right)$ bags ( $2.7 \mathrm{~kg}$ or $\sim 94 \mathrm{lb}$ ). Installation of brick and mortar primarily consists of manual labor; no energy use is modeled for the installation phase. Losses during the installation phase are estimated to be $5 \%$ of total materials per $\mathrm{ft}^{2}$. Waste from the installation process is typically landfilled. While sheathing, weather resistive barriers, and other ancillary materials may be required to complete the exterior wall system, these materials are not included in the system boundaries for BEES exterior wall finishes.

\subsubsection{Use}

Brick walls are often in service for more than 100 years. Older buildings are adapted to new uses, with the existing brick walls included as a design feature. A useful life of 200 years is assumed. If properly designed, detailed and constructed, brick veneer walls require very little maintenance. Some components within the masonry wall system may require periodic maintenance and repair. For example, repointing mortar joints on portions of the wall may be required after 50 years, but this minor maintenance task was not included within the system boundary of the model.

While buildings with brick and mortar finishes require insulation, the finish itself provides a thermal resistance value of about $\mathrm{R}_{\mathrm{SI}}-0.16$ (Rus-0.9) for a nominal $10.2 \mathrm{~cm}$ (4 in) brick veneer. ${ }^{81}$ Testing has shown that wall assemblies finished with brick veneer have increased thermal performance due to the thermal mass of the veneer and the nominal $2.5 \mathrm{~cm}$ ( 1 in) air space required behind the veneer. Thermal performance differences among exterior wall finish alternatives are not accounted for.

\subsubsection{End of Life}

Demolition of brick walls at end of life is typically not done carefully. The walls are knocked down using equipment such as a wrecking ball or explosives, resulting in some loss of brick. It is estimated that approximately $75 \%$ of brick may be recovered as whole, sound units, free from cracks and other defects that would interfere with their proper laying or use. Brick that are to be reused are required to meet the requirements for new brick units and be cleaned of old mortar before reuse. The mortar is removed by hand labor using chisels and hammers, typically at the demolition site. The cleaned brick is sold for new construction, and the mortar and broken brick are taken to landfills.

\subsection{Generic Cedar Siding}

Cedar wood is a popular exterior siding material because it is lightweight, low-density, and aesthetically-pleasing material and provides adequate weatherproofing.

\subsubsection{Product Description}

${ }^{81}$ Units for $\mathrm{R}_{\mathrm{SI}}$ and $\mathrm{R}_{\mathrm{US}}$ are ${ }^{\circ} \mathrm{C}-\mathrm{m}^{2}$-sec/J and ${ }^{\circ} \mathrm{F}-\mathrm{ft}^{2}$-s/BTU, respectively. 
For the BEES system, beveled cedar siding with planks $1.27 \mathrm{~cm}$ (0.5 in) thick and 15.2 $\mathrm{cm}$ (6 in) wide and a $2.54 \mathrm{~cm}$ (1 in) overlap is modeled. The functional unit is $0.09 \mathrm{~m}^{2}$ $\left(1 \mathrm{ft}^{2}\right)$ of siding used on a building for 60 years. Cedar siding modeled for BEES has a mass of $0.432 \mathrm{~kg}(0.95 \mathrm{lb})$ and is installed with galvanized nails $41 \mathrm{~cm}$ (16 in) on center and finished with one coat of primer and two coats of paint. Paint is reapplied every fifteen years. Much of the data for this product is based on a recent LCA on Western Red Cedar siding. Primary data for the year 2015 were collected from cedar operations and siding manufacturing facilities in the U.S. Pacific Northwest and British Columbia, Canada.

\subsubsection{Flow Diagram}

The flow diagram in Figure 6-16 shows the major elements of the production of this product, as it is currently modeled for BEES.

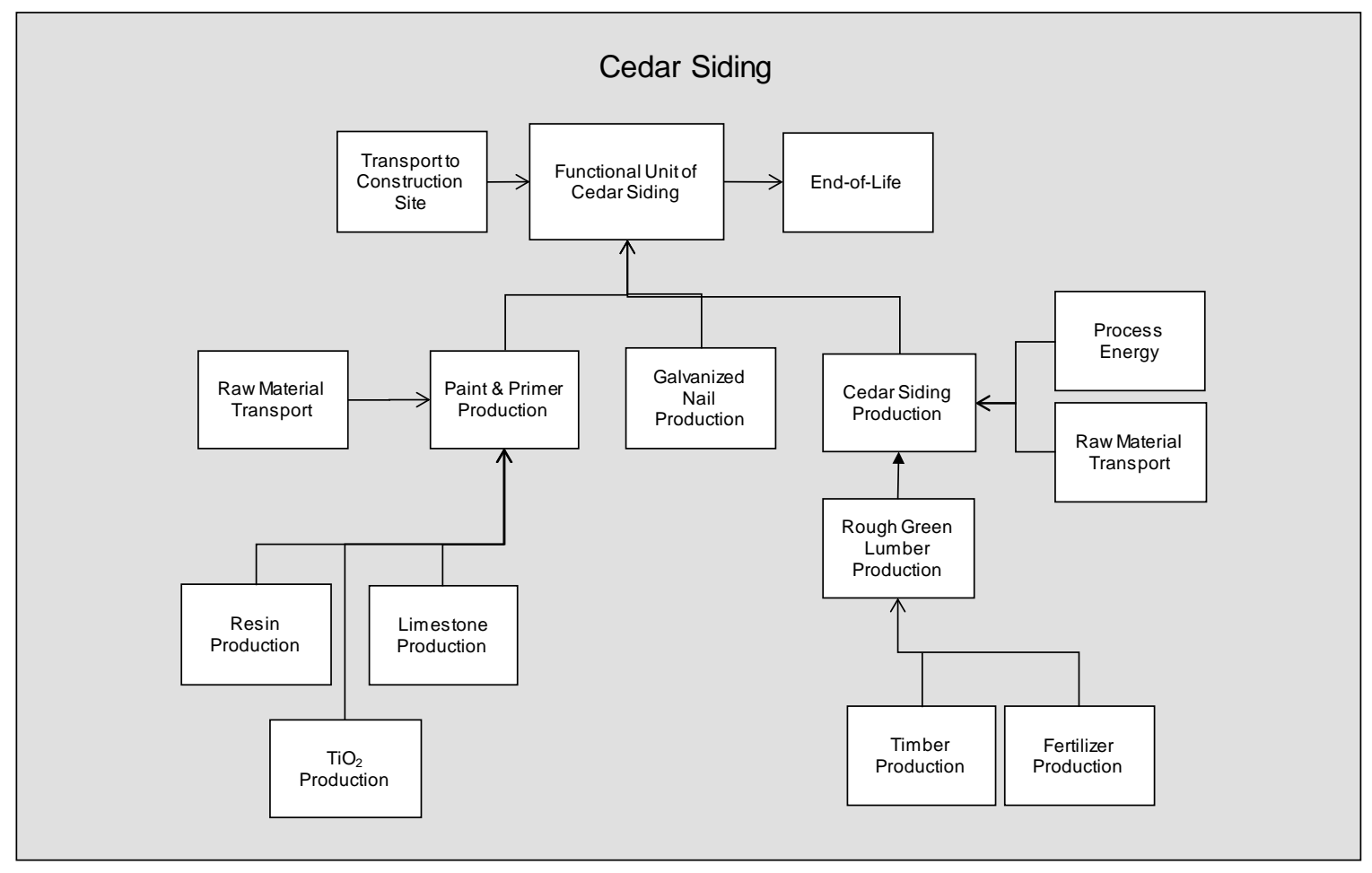

Figure 6-16 Cedar Siding System Boundaries

\subsubsection{Raw Materials}

Cedar siding production starts with growing and harvesting from forests. The data to produce roundwood include harvesting, nursery operations, and forest management (i.e., site preparation, planting, and management related activities, such as thinning). Roundwood production data are based on Table 4 in FPInnovations (2017). Next, the logs are sent to sawmills and planing mills where the logs are washed, debarked, and sawn into planks of rough green lumber. Data for this process comes from Table 7 in 
FPInnovations (2017). Energy use is based on the U.S. LCI database. Fertilizer and other ancillary materials, including lubricants and hydraulic fluids, come from ecoinvent.

It should be noted that the rough green lumber and its co-products, pulp chips and bark, are allocated on an economic basis; this approach is a change from the original Consortium for Research on Renewable Industrial Materials (CORRIM) work done (and on which the U.S. LCI database wood data are based). The mass allocation percentages have been adjusted to economic allocation using the guidance provided in PCRs for North American Structural and Architectural Wood products, and as a result, the green lumber takes approximately $95 \%$ of the share of products and co-products - an adjustment from approximately $50 \%$.

BEES modeling accounts for the absorption of $\mathrm{CO}_{2}$ for longer-life products. As trees grow, the carbon becomes part of the wood, and the oxygen is released to the atmosphere. The "uptake" of $\mathrm{CO}_{2}$ in $929 \mathrm{~cm}^{2}\left(1 \mathrm{ft}^{2}\right)$ installed product is approximately $0.82 \mathrm{~kg}(1.8 \mathrm{lb})$ of $\mathrm{CO}_{2}$, based on a carbon content of $51.54 \%$ for cedar (oven dry weight).

\subsubsection{Manufacturing}

At the cedar siding mill, the green lumber is edged, trimmed, dried in a kiln, and planed. Final trimmed lumber is packaged. Data to manufacture the siding come from Table 12 in FPInnovations (2017). Like previous cedar related operations, data for energy comes from the U.S. LCI database and materials come from ecoinvent. Table 12 also provides the following average packaging for $1000 \mathrm{~kg}$ (2 $205 \mathrm{lb})$ cedar siding: $0.02 \mathrm{~kg}(0.04 \mathrm{lb})$ plastic strapping from U.S. LCI database and $0.37 \mathrm{~kg}(0.82 \mathrm{lb})$ lumber wrap modeled as LDPE film from U.S. LCI database and ecoinvent, and $0.02 \mathrm{~m}^{3}\left(0.7 \mathrm{ft}^{3}\right)$ dunnage. These materials are modeled as landfilled after installation.

\subsubsection{Transportation}

Transportation of cedar siding to the building site is modeled using heavy-duty truck and rail, from Vancouver, Canada, to distribution centers in Seattle, WA, Minneapolis, MN, and New York, NY. Accounting for these locations, on average, the product is shipped approximately $2000 \mathrm{~km}$ (1410 mi) to the building site. The BEES user may change this default distance.

\subsubsection{Installation}

Cedar siding installation is predominately a manual process--a relatively small amount of energy may be required to operate compressors to power air guns, but this amount is assumed to be too small to warrant inclusion in the analysis. Cedar siding panels are attached using galvanized nails. Three nails are required per $0.09 \mathrm{~m}^{2}\left(\mathrm{per} \mathrm{ft}^{2}\right.$ ) of siding. Assuming standard $6 \mathrm{~d} 5 \mathrm{~cm}$ (2 in) nails, installation requires $0.0054 \mathrm{~kg}(0.0119 \mathrm{lb})$ of nails per $\mathrm{ft}^{2}$ of siding. No installation waste is assumed for the nails. After installation, the siding is first primed and then painted with two coats of paint. The primer and paint are 
modeled as a solvent based paint modeled for BEES in the amount of $0.0175 \mathrm{~kg}$ (0.0079 lb) per $0.09 \mathrm{~m}^{2}\left(1 \mathrm{ft}^{2}\right)$. Background data come from ecoinvent.

Installation waste with a mass fraction of $5 \%$ is assumed, and it is assumed to go to landfill, modeled using wood disposal in a landfill from ecoinvent. While sheathing, weather resistive barriers, and other ancillary materials may be required to complete the exterior wall system, these materials are not included in the system boundaries for BEES exterior wall finishes.

\subsubsection{Use}

Cedar siding is modeled as having a useful life of over 60 years. Thus, one initial installation and use period is modeled for the BEES functional lifetime. It is modeled as being repainted with one coat of paint every fifteen years, for a total of three additional paint coatings over the course of 60 years. No other routine maintenance is required to prolong its lifetime, although cleaning is recommended to maintain appearance. Cleaning would normally be done with water and household cleaners. This data has not been modeled due to the broad range of cleaning practices and materials (e.g., frequency of cleaning, types and quantities of cleaning solutions used).

\subsubsection{End of Life}

At end of life, the BEES model assumes that $50 \%$ of the siding is recovered and $50 \%$ is landfilled. The portion that is landfilled is modeled as transported by diesel-fuel powered truck approximately $48 \mathrm{~km}$ (30 mi) to a landfill. Truck transportation is based on the U.S. LCI database, and disposal in a landfill is modeled based on ecoinvent end of life waste management process data for untreated wood. The mass that is not biobased (e.g., nails) is assumed to be inert material in a landfill. The rest of the mass is modeled as biogenic material disposed of in a landfill, and accounts for the $\mathrm{CO}_{2}$ and methane $\left(\mathrm{CH}_{4}\right)$ emissions pertaining to the decomposing biomass. FPInnovations (2017) assumes, after a review of the recent scientific literature, that $10 \%$ of the wood ultimately decomposes, so storage of the remaining biogenic carbon is also accounted for. (FPInnovations (2017), Sec. 5.2) Using data and assumptions on landfill gas collection systems in North America, including the percentage of landfills with capture equipment in place, average capture efficiency, and energy recovery values, cedar siding emissions due to wood decomposition in the landfill amount to $0.0284 \mathrm{~kg}(0.06 \mathrm{lb}) \mathrm{CO}_{2}$ and $0.0036 \mathrm{~kg}(0.008 \mathrm{lb})$ $\mathrm{CH}_{4}$ per $0.09 \mathrm{~m}^{2}$ (one $\mathrm{ft}^{2}$ ). (FPInnovations (2017), Table 35 and Section 5.2).

\subsection{Generic Polypropylene (PP) Siding}

PP siding is used as an exterior wall finish on new and renovated construction. PP siding offers a thick durable profile that can mimic a wide variety of wood shingle and shake patterns. It is manufactured in a range of profiles, colors and thicknesses to meet different architectural and market applications. PP siding typically comes in panels of $3.66 \mathrm{~m} \mathrm{x}$ $17.8 \mathrm{~cm}$ (12 ft x $7 \mathrm{in})$; as installed, 14.29 panels are used per $9.29 \mathrm{~m}^{2}\left(100 \mathrm{ft}^{2}\right)$. The mass 
of PP siding is $32.3 \mathrm{~kg}(71.3 \mathrm{lb})$ per $9.29 \mathrm{~m}^{2}\left(100 \mathrm{ft}^{2}\right)$ for a typical $0.216 \mathrm{~cm}(0.085 \mathrm{in})$ thickness.

\subsubsection{Product Description}

For the BEES system, $0.216 \mathrm{~cm}$ (0.085 in) thick, $17.8 \mathrm{~cm}$ (7 in) wide horizontal PP siding installed with galvanized nail fasteners is studied. The nails are assumed to be placed 41 cm (16 in) on center.

Data described in this chapter and modeled for BEES are based on the VSI's LCA covering PP siding. Data are primary from North American facilities and manufacturers, collected for the year 2015. While siding is generally specified in terms of 'squares' of siding, or $9.29 \mathrm{~m}^{2}\left(100 \mathrm{ft}^{2}\right)$, for BEES, the functional unit is $0.09 \mathrm{~m}^{2}\left(1 \mathrm{ft}^{2}\right)$ of siding used over 60 years.

\subsubsection{Flow Diagram}

The flow diagram in Figure 6-17 presents the major elements of the production of this product as it is currently modeled for BEES.

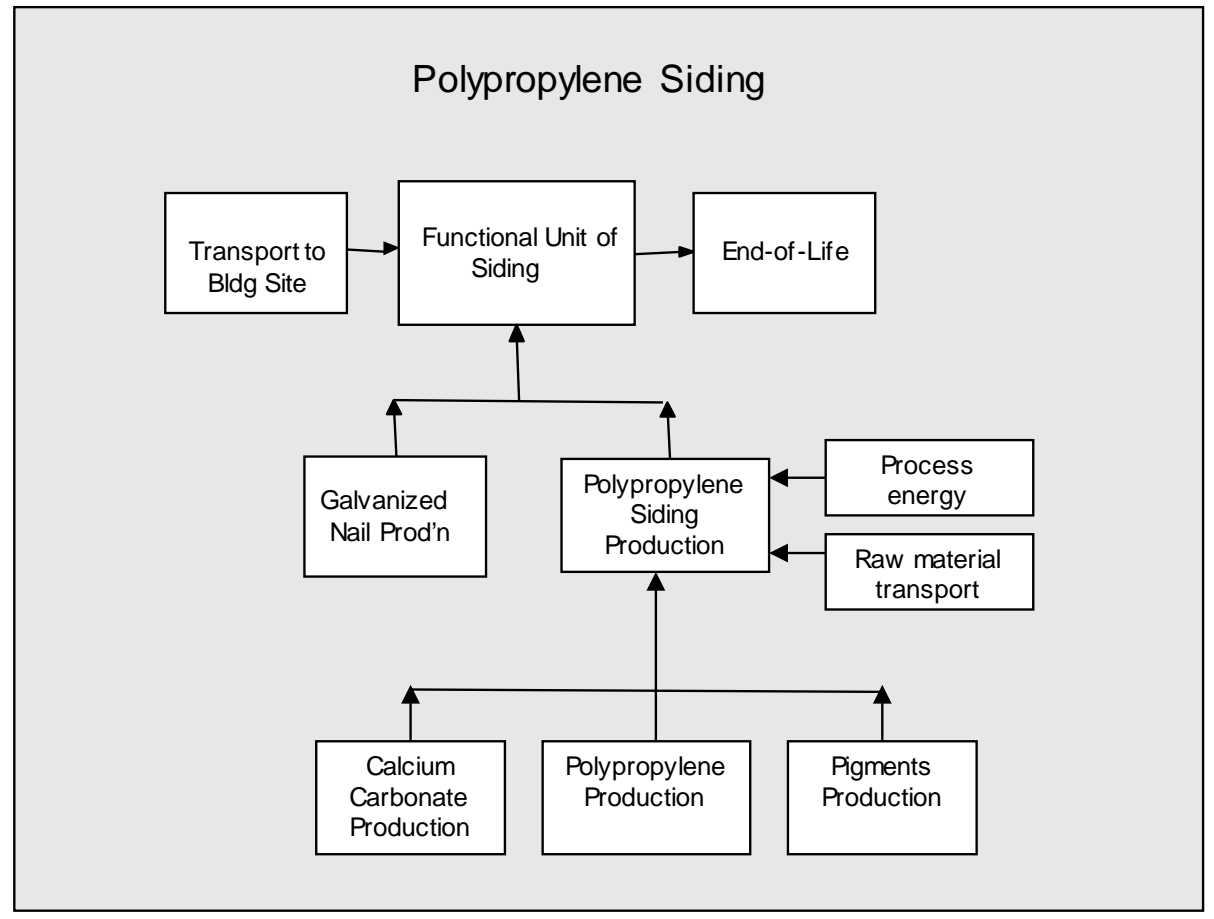

Figure 6-17 Polypropylene Siding System Boundaries

\subsubsection{Raw Materials}

PP siding components are presented in Table 6-31. 
Table 6-31 Polypropylene Siding Constituents ${ }^{82}$

\begin{tabular}{lc}
\hline Constituent & \% in Siding \\
\hline PP & $85 \%$ \\
Calcium carbonate (limestone) & $12 \%$ \\
Pigments & $3.0 \%$ \\
Total & $\mathbf{1 0 0} \%$ \\
\hline
\end{tabular}

The PP resin comes from the U.S. LCI database. Calcium carbonate is based on ecoinvent customized to U.S. conditions. Pigments modeled include chromium- and antimony-based compounds (modeled as chromium and antimony from ecoinvent), and titanium dioxide from ecoinvent.

Transportation of the raw materials to siding facilities has been reported and averaged in Sustainable Solutions Corporation (2016) and is accounted for in BEES. Materials are transported an average of $37 \mathrm{~kg}-\mathrm{km}$ (131 lb-mile) by truck and $1210 \mathrm{~kg}-\mathrm{km}$ (4293 lb mile) by train. ${ }^{83}$ Train and diesel-powered combination trucks are modeled based on the U.S. LCI database.

\subsubsection{Manufacturing}

As described in Sustainable Solutions Corporation (2016), “To produce PP siding, PP compound beads are melted and injected into molds derived from actual cedar shakes. The polymer cures into the shape from the mold. Various pigments can be added for color variations. PP siding manufacturing is an extremely efficient injection molding process requiring relatively low inputs of energy and water and the ability to immediately return scrap and off-specification materials (regrind) directly into the manufacturing process results in [minimal] manufacturing waste." ${ }^{84}$ Manufacturing energy and water use are presented in Table 6-32.

\section{Table 6-32 Energy and Water Requirements for Polypropylene Siding ${ }^{85}$}

\begin{tabular}{lc}
\hline Fuel Use & Quantity per $\boldsymbol{k g}$ Siding \\
Electricity MJ (kWh) & $5.76(1.6)$ \\
Natural Gas m $^{3}(\mathrm{scf})$ & $0.058(2.06)$ \\
Propane I (gal) & $1.3 \mathrm{E}-4(3.5 \mathrm{E}-05)$ \\
\hline Water Use I (gal) & $1.49(0.393)$ \\
\hline
\end{tabular}

The electricity is used for raw materials mixing, extrusion, machining, lighting, air compressors, cooling water pumps, grinding operations, and other miscellaneous equipment. The natural gas is used for space heating, and the propane is used in mobile

\footnotetext{
${ }^{82}$ Sustainable Solutions Corporation (2016), Table 4.3.

${ }^{83}$ Sustainable Solutions Corporation (2016), Table 4.4

${ }^{84}$ Sustainable Solutions Corporation (2016), Section 4.3 A3. Manufacturing Process Overview

85 Sustainable Solutions Corporation (2016), Table 4.5
} 
equipment. Electricity production sources and the fuels production and combustion come from the U.S. LCI database. Water is used for process cooling, and to a small extent, cleaning and domestic use.

The amount of wastewater generated is $0.48 \mathrm{l}$ ( 0.126 gal $)$ per $\mathrm{kg}$ siding. The difference between the reported water in and out is mainly due to evaporation losses in the closed loop cooling water systems utilized by most of the plants. The BEES model includes treatment with water treatment chemicals so this water is assumed to be uncontaminated. A small quantity of inert waste, $5.6 \mathrm{E}-3 \mathrm{~kg}$ per $\mathrm{kg}$ siding, is generated and landfilled, and $2.1 \mathrm{E}-3 \mathrm{~kg}$ per $\mathrm{kg}$ siding is incinerated.

Packaging. Industry-average packaging data for this product were provided by Sustainable Solutions and include paper labels, plastic and metal strapping, LDPE wrap, cardboard, and wood pallets.

\subsubsection{Transportation}

The finished PP siding product is transported a weighted average distance of $1108 \mathrm{~km}$ (689 mi) by diesel truck to the building site. Nails used for installation are assumed to be transported $241 \mathrm{~km}$ (150 mi) by diesel truck to the building site. The BEES user may change the assumed transport distances for the main products.

\subsubsection{Installation}

Installation on the building is done primarily by manual labor. Nails or screws can be used to install the siding; nails are more common and would typically be the type installed with a gun. The energy required to operate compressors to power air guns is assumed to be small and is not included in the analysis. Installation is modeled for nails placed $41 \mathrm{~cm}$ (16 in) on center; nail use is $0.0024 \mathrm{~kg}(0.0053 \mathrm{lb})$ per $0.09 \mathrm{~m}^{2}$ (per $\mathrm{ft}^{2}$ ) of siding. Installation waste with a mass fraction of $5 \%$ is assumed, and this waste is assumed to go to a landfill.

While sheathing, weather resistive barriers, and other ancillary materials may be required to complete the exterior wall system, these materials are not included in the system boundaries for BEES exterior wall finishes.

\subsubsection{Use}

PP siding has an assumed useful life of 60 years. No routine maintenance is required to prolong the lifetime of the product, although cleaning is recommended to maintain appearance. Cleaning would normally be done with water and household cleaners. Information on typical cleaning practices (e.g., frequency of cleaning, types and quantities of cleaning solutions used) was not available; maintenance was not included in the system boundaries. 


\subsubsection{End of Life}

At end of life, the siding is removed and taken to be disposed of in a landfill. End of life modeling includes transportation of the siding and nails by heavy-duty diesel-fuel powered truck approximately $48 \mathrm{~km}$ (30 mi) to a landfill, plus impacts of the materials in a landfill. Truck transportation is based on the U.S. LCI database and disposal in a landfill is modeled based on ecoinvent end of life waste management process data. 


\section{Interior Wall and Ceiling Finish Categories}

The interior wall and ceiling categories cover both residential and commercial finishing products.

\subsection{Interior Wall and Ceiling Finish Types}

There are a range of interior wall and ceiling finish types, but only one product type is currently included in the interior wall finish category, latex paint, as shown in Table 7-1. Conventional paints are generally classified into two basic categories: water-based (in which the solvent is water) and oil- or solvent-based (in which the solvent is an organic liquid, usually derived from petrochemicals). Paints essentially consist of a resin or binder, pigments, and a carrier in which these substances are dissolved or suspended. Once the paint is applied to a surface, the carrier evaporates, leaving behind a solid coating. In oil-based paints the carrier is a solvent consisting of VOCs, which can adversely affect indoor air quality and the environment. Due to increased government regulations and market demand, paint formulations have shifted away from oil-based paints to waterborne or latex paints since these paints emit far fewer VOCs upon application. Furthermore, the market for latex paint has increasingly shifted to low- and zero-VOC emissions formulations, drastically reducing the levels of VOCs emitted during and after application.

\section{Table 7-1 Interior Wall and Ceiling Finish Types and Subtypes}

\begin{tabular}{|ll}
\multicolumn{2}{c}{ Floor Covering } \\
Types & Subtypes \\
\hline Latex Paint & Virgin \\
& Reprocessed \\
& Consolidated \\
\hline
\end{tabular}

\subsection{Interior Wall Finish Characteristics and Certifications}

BEES Online 2.0 has added a feature to filter/restrict products selected based on product characteristics, such as fraction recycled materials, and product certifications, such as USDA Certified Biobased. The current list of characteristics and certifications provided in BEES 2.0 are listed in Table 7-2. 
Table 7-2 Exterior Wall and Ceiling Finish Characteristics and Certifications

\begin{tabular}{ll}
\hline \multicolumn{2}{c}{ Characteristics and Certifications } \\
\hline Federal Agency Certifications & None \\
\hline Standard Certification & None \\
\hline NGO Certification & None \\
\hline Characteristics & $25 \%$ Recycled Content \\
& $35 \%$ Recycled Content \\
& $50 \%$ Recycled Content \\
& $75 \%$ Recycled Content \\
\hline
\end{tabular}

\subsection{Interior Wall and Ceiling Finish Installation, Service Life, and Use Phase}

To evaluate the life cycle impacts of interior wall finishes, it is necessary to consider the installation and use phase impacts, both of which could vary depending on decisions outside the product manufacturer's control. It is assumed there are no use phase impacts while installation impacts are incorporated into the products embodied impacts. The default assumed service life is defined for each BEES product in its associated documentation.

\subsection{Generic Latex Paint}

\subsubsection{Product Description}

BEES includes three neutral-colored, latex-based paint options for interior use: virgin latex paint and recycled content latex paint made by two distinct methods: consolidating and reprocessing (or remanufacturing). These latter paints contain leftover household paint, or PC paint. Consolidated paint facilities are often located at or near county or city recycling and Household Hazardous Waste (HHW) facilities. These facilities generally have relatively small-scale operations in which paint meeting a certain quality is blended and repackaged and sold or given away to the public. In larger consolidating operations, some virgin materials are added to the paint. Reprocessed paint is generally produced in a larger-scale facility and varies by producer and PC paint content; reprocessed paint can contain $50 \%$ to over $90 \%$ PC paint.

The three latex paint alternatives are applied the same way. The surface to be painted is first primed and then painted with two coats of paint. One coat of paint is then applied every 5 years. When considering specific products, quality could vary greatly, depending on specific formulations that will define performance, attributes, physical characteristics, etc. For BEES, however, these three paint options are assumed to be of the same quality, with one gal covering $37.2 \mathrm{~m}^{2}\left(400 \mathrm{ft}^{2}\right)$. Density is modeled at $1.32 \mathrm{~kg} / \mathrm{l}(11.0 \mathrm{lb} / \mathrm{gal})$. For BEES, the functional unit is $0.09 \mathrm{~m}^{2}\left(1 \mathrm{ft}^{2}\right)$ of paint coating used in a building for 60 years. 


\subsubsection{Flow Diagram}

The flow diagrams in Figure 7-1 and Figure 7-2 presents the major elements of the production of this product as it is currently modeled for BEES.

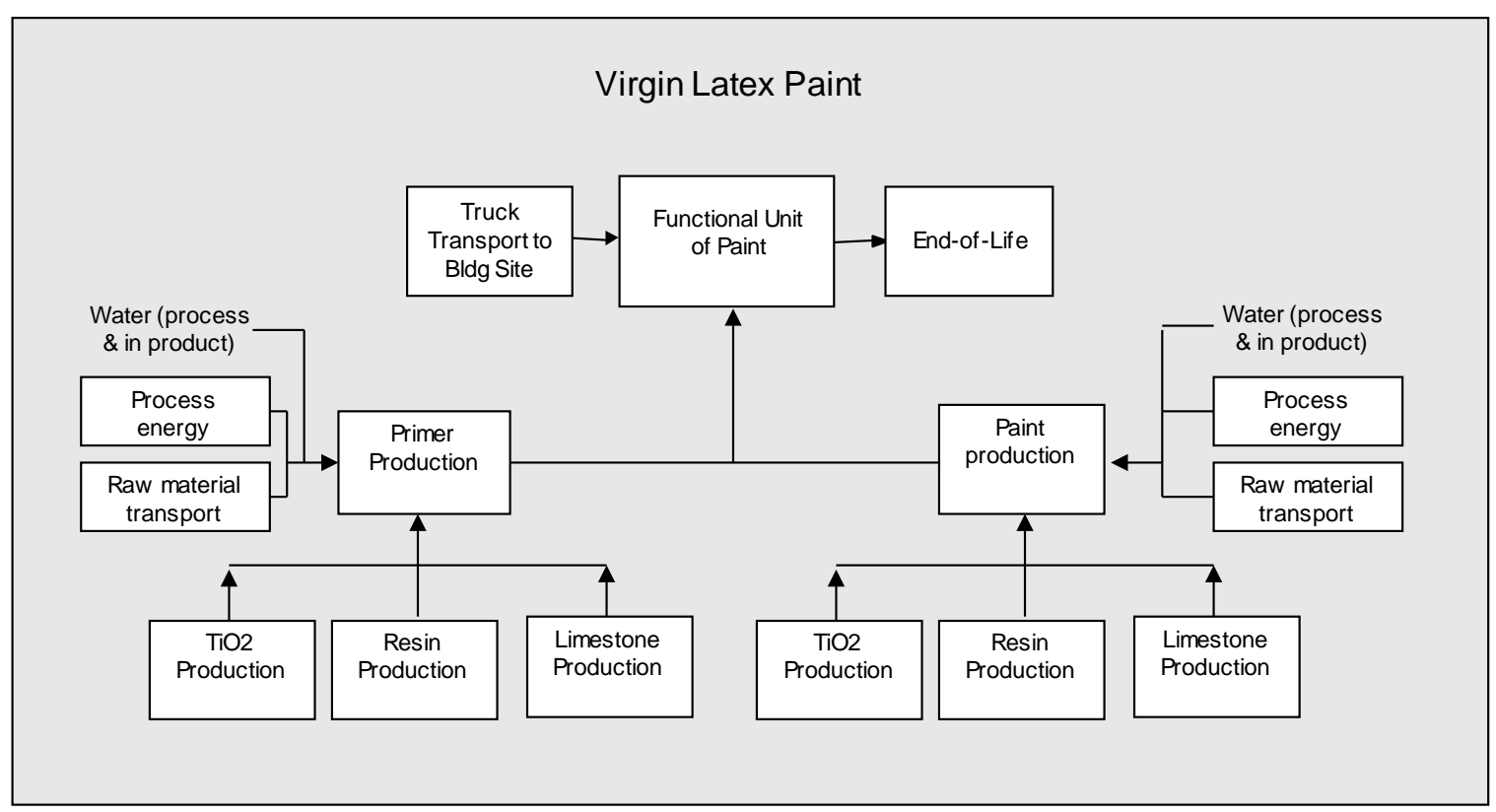

Figure 7-1 Generic Latex Paint System Boundaries

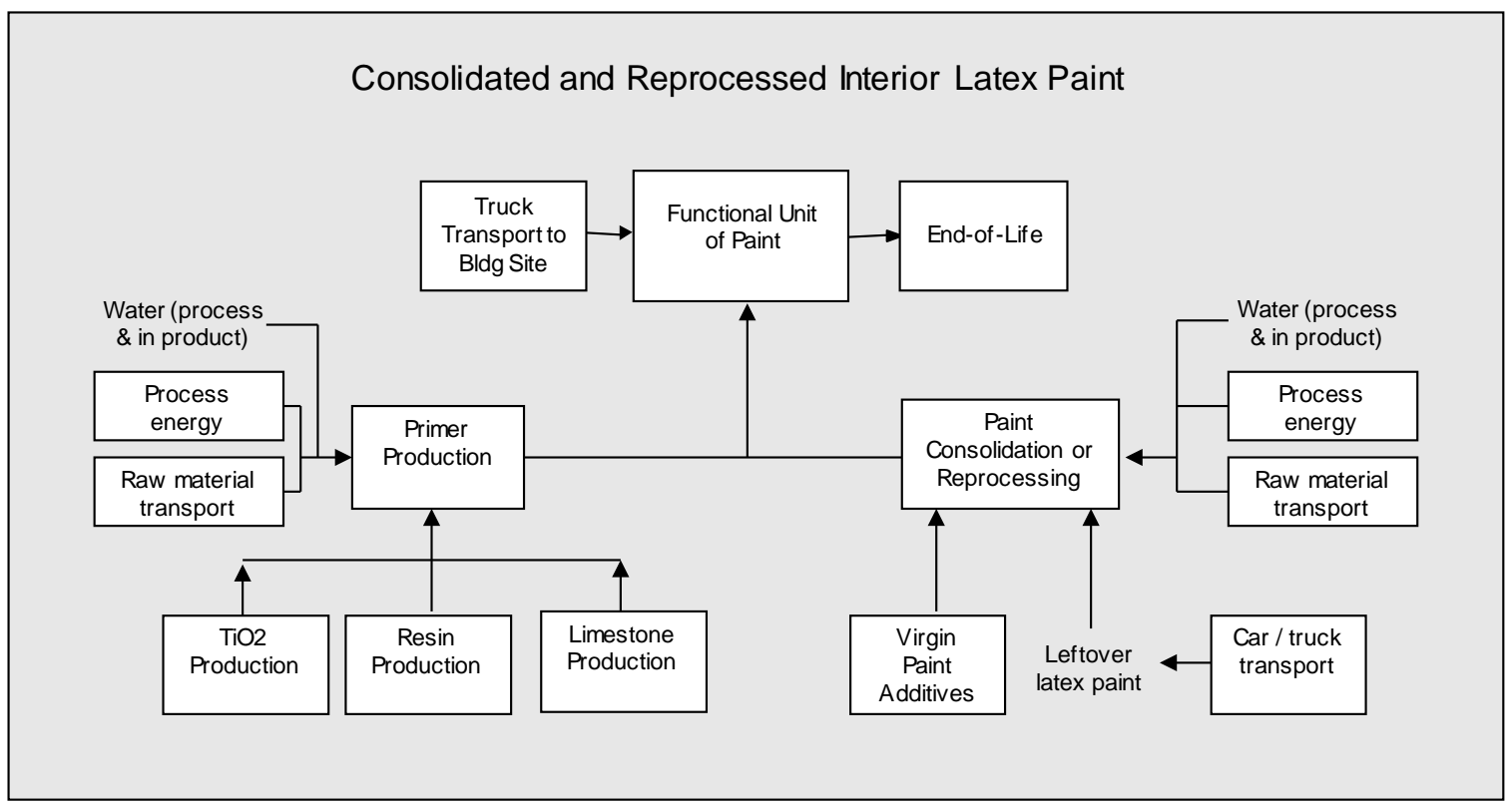

Figure 7-2 Generic Latex Paint System Boundaries 


\subsubsection{Raw Materials}

Virgin latex paint. The major virgin latex paint constituents are binder (resins), pigments (titanium dioxide and other pigments), pigment extender and filler (calcium carbonate), and carrier (water, for latex paint). The binder is synthetic latex made from polyvinyl acetate and/or acrylic polymers and copolymers. Titanium dioxide is one of the primary pigments used and imparts hiding properties in white or light-colored paints. A range of pigment extenders may be added. Other additives include surfactants, defoamers, preservatives, and fungicides. Water has a coalescing agent - typically a glycol or glycol ether. The components are mixed together until they form an emulsion.

The average composition of the virgin latex paint/primer system modeled in BEES is provided in Table 7-3. These compositions are loosely based on data from published manufacturer-specific EPDs and manufacturers' Safety Data Sheets (where ingredients are specified) on latex paint products. BEES users should note that even though BEES presents these very generic formulations, there is actually no such thing as an average paint, given the broad selection of binders, extenders, colorants, and other additives used in a multitude of combinations, depending on performance requirements, product line, intended use, and manufacturer. One might characterize the quantities presented in Table 7-3 as a generic formulation representing a medium-quality interior latex paint and primer.

Table 7-3 Virgin Latex Paint Constituents

\begin{tabular}{lcc}
\hline \multicolumn{1}{c}{ Constituent } & Paint Mass Fraction (\%) & Primer Mass Fraction (\%) \\
\hline Resin (binder) & 15 & 20 \\
Titanium dioxide (pigment) & 15 & 11 \\
Calcium carbonate (limestone) & 16 & 5 \\
Other additives & 4 & 4 \\
Water & 50 & 60 \\
\hline
\end{tabular}

Calcium carbonate, or limestone, is the material used to represent the mineral-based extender pigments and fillers. Data for calcium carbonate and titanium dioxide come from ecoinvent. The resin binder is acrylic-based, and its composition may be a vinyl acrylic polymer, a polyvinyl acrylic polymer, or a styrene acrylic polymer. Table 7-4 presents the assumed market shares for these resin types as they are modeled in BEES.

\section{Table 7-4 Latex Paint Resin Constituents}

\begin{tabular}{lc}
\hline \multicolumn{1}{c}{ Resin Type } & Market Share (\%) \\
\hline Vinyl acrylic & $33.3 \%$ \\
Polyvinyl acetate & $33.3 \%$ \\
Styrene acrylic & $33.3 \%$ \\
\hline
\end{tabular}

The vinyl acrylic impact is built using vinyl acetate, from ecoinvent, and butyl acrylate, a data set built using stoichiometry and ecoinvent inputs. Polyvinyl acetate data comes 
from ecoinvent (as vinyl acetate), and the styrene acrylic is modeled as styreneacrylontrile copolymer from ecoinvent. Often, a colorant is added at the retail store in varying amounts which depend on the desired color and qualities. Due to the range of possible materials and quantities, this colorant is not included in BEES.

Packaging has been included in the model; virgin latex paint is modeled as sold in onegallon steel cans with an empty mass $0.11 \mathrm{~kg} / \mathrm{liter}(0.9 \mathrm{lb} / \mathrm{gal})$.

Consolidated paint. The consolidated paint in BEES is assumed to have a PC paint content of $98.5 \%$, with the remaining constituents being virgin-based. This ratio is based on an LCA study on leftover paint waste management that surveyed paint consolidation plants located throughout the U.S. (Paint Product Stewardship Initiative, 2006). At 1.32 $\mathrm{kg} / \mathrm{l}(11.0 \mathrm{lb} / \mathrm{gal})$, this rate amounts to $0.019 \mathrm{~kg} / \mathrm{l}(0.17 \mathrm{lb} / \mathrm{gal})$ of virgin additives, which are modeled as the paint constituents described above. Consolidated paint is packaged (i.e., repackaged) in a $19 \mathrm{l}$ (5 gal) high density polyethylene (HDPE) plastic bucket having an empty mass of $1.13 \mathrm{~kg}$. Data for HDPE comes from the U.S. LCI database.

Reprocessed paint. The leftover paint waste management study also surveyed paint reprocessing plants. Based on this survey, PC paint content ranged from $55 \%$ to $93 \%$, with a weighted average of $76 \%$. Therefore, the quantity of virgin constituents was modeled as $24 \%$, amounting to $0.32 \mathrm{~kg} / \mathrm{l}(2.64 \mathrm{lb} /$ gal $)$ of virgin additives per gal of reprocessed paint, at the assumed density of $1.32 \mathrm{~kg} / \mathrm{l}(11.0 \mathrm{lb} / \mathrm{gal})$. Reprocessed paint is modeled as packaged in $19 \mathrm{l}$ (5 gal) HDPE plastic buckets and $3.8 \mathrm{l}$ (1 gal) steel containers (assuming a 50/50 share for these).

\subsubsection{Manufacturing}

Virgin latex paint. Paint manufacture consists of combining the ingredients, less some of the solvent, in a steel mixing vessel. In some cases, the mixing is followed by a grinding operation to break up the dry ingredients, which tend to clump during mixing. Then, additional solvents or other liquids are added to achieve final viscosity, and supplemental tinting is added. Finally, the paint is strained, put into steel cans, and packaged for shipping.

The energy to blend and package virgin latex paint and the paint primer is modeled to be $0.084 \mathrm{kWh} / \mathrm{l}(0.32 \mathrm{kWh} / \mathrm{gal})$ of purchased electricity, plus $5.85 \mathrm{MJ} / \mathrm{l}(22.2 \mathrm{MJ} / \mathrm{gal})$ of additional energy. In the absence of data on the source of the additional energy required, it is assumed to be natural gas.

Raw materials are modeled as being transported to the paint manufacturing site by truck. Since no site-specific data have been used for BEES, the default transportation distances in the architectural coatings PCR have been implemented. These distances are to 1207 $\mathrm{km}(750 \mathrm{mi})$ for the raw materials in the paint and $1500 \mathrm{~km}$ (932 mi) for the steel paint cans.

Consolidated latex paint. Before PC paint undergoes consolidation, it is sorted from solvent based paints, contaminated paint, and other HHW materials that come to an 
HHW facility. Once the paint in good condition is separated from other types of paint and HHW, the paint cans are opened manually or electrically and paint is poured into a mixing vessel. The cans are sometimes crushed using electrical equipment. Water is often used to clean facilities, as are absorbents to soak up paint from the floor. Waste is minimized as often the emptied containers are recycled. Table 7-5 provides consolidation plant sorting inputs and outputs.

\section{Table 7-5 Consolidated Paint Sorting Data}

\begin{tabular}{llc}
\hline Flow & \multicolumn{1}{c}{ Units } & Amount \\
\hline Inputs & & \\
Water used & $\mathrm{L} / \mathrm{L}(\mathrm{gal} / \mathrm{gal})$ & $0.22(0.22)$ \\
Absorbent used to absorb paint on floor & $\mathrm{kg} / \mathrm{L}(\mathrm{lb} / \mathrm{gal})$ & $0.0002(0.002)$ \\
Electricity & $\mathrm{J} / \mathrm{L}(\mathrm{kwh} / \mathrm{gal})$ & $310227(0.327)$ \\
Natural gas process fuel & $\mathrm{m} 3 / \mathrm{L}(\mathrm{ft} 3 / \mathrm{gal})$ & $0.0001(0.010)$ \\
Diesel fuel (mobile equipment) & $\mathrm{L} / \mathrm{L}(\mathrm{gal} / \mathrm{gal})$ & $0.0009(0.0009)$ \\
Natural gas (mobile equipment) & $\mathrm{L} / \mathrm{L} \mathrm{(gal/gal)}$ & $0.0003(0.0003)$ \\
Propane (mobile equipment) & $\mathrm{L} / \mathrm{L} \mathrm{(gal/gal)}$ & $0.005(0.005)$ \\
Gasoline (mobile equipment) & $\mathrm{L} / \mathrm{L} \mathrm{(gal/gal)}$ & $0.0002(0.0002)$ \\
used oil & $\mathrm{L} / \mathrm{L}$ (gal/gal) & $0.001(0.001)$ \\
Outputs & & \\
Waste & $\mathrm{kg} / \mathrm{L} \mathrm{(lb/gal)}$ & $0.102(0.850)$ \\
\hline
\end{tabular}

Next, the paint is blended and repackaged. Table 7-6 provides the consolidation process energy and water requirements.

\section{Table 7-6 Consolidated Paint Processing Data}

\begin{tabular}{llc}
\hline Flow & \multicolumn{1}{c}{ Units } & Amount \\
\hline Water used & $\mathrm{L} / \mathrm{L}(\mathrm{gal} / \mathrm{gal})$ & $0.07(0.07)$ \\
Electricity & $\mathrm{J} / \mathrm{L}(\mathrm{kwh} / \mathrm{gal})$ & $55092(0.058)$ \\
Natural gas process fuel & $\mathrm{m} 3 / \mathrm{L}(\mathrm{ft} 3 / \mathrm{gal})$ & $0.00001(0.002)$ \\
Diesel fuel (mobile equipment) & $\mathrm{L} / \mathrm{L}$ (gal/gal) & $0.002(0.002)$ \\
Propane (mobile equipment) & $\mathrm{L} / \mathrm{L}$ (gal/gal) & $0.007(0.007)$ \\
\hline
\end{tabular}

The absorbent used to soak up paint from the facility floor is reported as cat litter, which is modeled as clay. All data on energy use and combustion in mobile equipment and boilers comes from the U.S. LCI Database.

It is assumed that $90 \%$ of the paint comes to a consolidation plant by truck from a HHW facility or a municipal solid waste transfer station. The remaining incoming paint comes directly from households via passenger vehicle. Based on the surveys, truck transportation is on average $161 \mathrm{~km}(100 \mathrm{mi})$ and car transport is on average $15 \mathrm{~km}$ (9.4 mi). The passenger vehicle mileage has been allocated to one-fourth its amount to account for the mass of other HHW drop-off items likely transported in the car plus driving for other errands during the same trip. The passenger vehicle is modeled as $50 \%$ 
gasoline-powered car and 50 \% sport utility vehicle, and these data come from ecoinvent. Truck transportation data comes from the U.S. LCI database.

Reprocessed latex paint. As with consolidated paint, before paint is reprocessed it must be sorted from other incoming materials. Once the PC latex paint appropriate for reprocessing has been sorted from other paints and materials, it is blended with virgin materials and packaged for sale. Table 7-7 provides the inputs and outputs from sorting and reprocessing.

\section{Table 7-7 Reprocessed Paint Sorting and Processing Data}

\begin{tabular}{lc}
\hline Flow & Quantity per I (per gal ) \\
\hline Inputs: & \\
Water used & $0.565 \mathrm{l}(0.565 \mathrm{gal})$ \\
Electricity & $0.425 \mathrm{MJ}(0.447 \mathrm{kWh})$ \\
Propane (mobile equipment) & $0.0023 \mathrm{l}(0.0023 \mathrm{gal})$ \\
Gasoline (mobile equipment) & $0.0009 \mathrm{l}(0.0009 \mathrm{gal})$ \\
Outputs: & \\
Waste & $0.0083 \mathrm{~kg}(0.07 \mathrm{lb})$ \\
\hline
\end{tabular}

Paint reprocessing facilities mostly receive leftover paint via truck from collection sites including HHW facilities. Because there are fewer reprocessing facilities, trucks travel on average a greater distance than to consolidation facilities; this distance is about $885 \mathrm{~km}$ (550 mi) according to the leftover paint study.

\subsubsection{Transportation}

Virgin and reprocessed latex paint. Since precise data on transporting finished paint products is not available, the default transportation distances to the consumer in the architectural coatings PCR have been implemented. These distances are $402 \mathrm{~km}$ (250 mi) to the distribution center and $805 \mathrm{~km}$ (500 mi) from the distribution center to the point of sale. Transportation via heavy-duty truck is modeled as a variable of the BEES system so the BEES user may adjust the transportation distance.

Consolidated paint. Transportation of the consolidated paint, assumed to be purchased by local users, is accomplished by gasoline-powered car and sport utility vehicle, typically traveling a much shorter distance due to the high number of local paint consolidation facilities and markets.

\subsubsection{Installation}

At the beginning of the 60-year BEES use period, one coat of primer is applied under the two coats of paint. According to the architectural coatings PCR, $10 \%$ of the wet mass of the coating remains unused and is disposed of properly, which entails drying the paint and putting it into the municipal solid waste; in this case, it is modeled as going to a landfill. Painters and consumers may also take advantage of a leftover paint management program, such as PaintCare ${ }^{\circledR}$, a program of the American Coatings Association that 
operates paint stewardship programs on behalf of paint manufacturers in states that have passed paint stewardship laws. ${ }^{86}$ For BEES, $90 \%$ of the unused paint is assumed to go to landfill and $10 \%$ is assumed to go to a paint recycler or consolidator.

\subsubsection{Use}

Every five years, the wall is assumed to be painted over with one additional coat, amounting to 11 additional coats over the 60 -year use period. These replacements are accounted for in the model. Virgin latex paint is modeled as having a VOC content of $100 \mathrm{~g} / \mathrm{l}$, considering the low- and zero-VOC paints on the market (light colors, less sheen), and paints with higher VOC content due to higher sheen ingredients, colorants, or other additives containing solvents that would release VOCs during drying. The consolidated and reprocessed paints are assumed to have an average VOC content of $250 \mathrm{~g} / \mathrm{l}$, the limit set by Green Seal GS-43 (Green Seal, 2011b).

\subsubsection{End of Life}

At end of life, all the paint goes into a landfill with the wall on which it is applied. Endof-life modeling includes transportation of the decommissioned walls by heavy-duty diesel-fuel powered truck approximately $48 \mathrm{~km}$ (30 mi) to a landfill, plus impacts of a landfill. Truck transportation is based on the U.S. LCI database and disposal in a landfill is modeled based on ecoinvent end of life waste management process data.

\footnotetext{
${ }^{86}$ For more information, refer to: https://www.paintcare.org/about/\#/overview?paintcare-inc.
} 


\section{Exterior Wall and Ceiling Insulation Category}

The exterior wall and ceiling insulation categories cover both residential and commercial applications.

\subsection{Exterior Wall and Ceiling Insulation Types and Functional Unit}

There are a range of interior wall and ceiling insulation types included in Table 8-1. Use of insulation impacts a building's thermal performance and environmental impacts. The current functional unit is one unit of thermal resistance ( $\mathrm{R}$-value) for $1 \mathrm{ft}^{2}$ of area covered over the 60-year study period. The BEES results currently use R-value in metric units ( $\mathrm{R}_{\mathrm{SI}}$ ), which is in units of ${ }^{\circ} \mathrm{C}-\mathrm{m}^{2}$-sec/J. The R-value in U.S. units (RUS), or better known in the United States as simply "R-value," is in units of ${ }^{\circ} \mathrm{F}-\mathrm{ft}^{2}-\mathrm{s} / \mathrm{Btu}$. The R-value is a factor of $\sim 5.68$ times greater than $\mathrm{R}_{\mathrm{SI}}$.

Insulation is more complex than other BEES products because thermal resistance and associated LCIA results vary by thickness and application for insulation. LCIA results do not increase linearly as R-value increases, which makes it difficult to use one multiplier to scale the results to a desired R-value. For example, the LCIA results for $1 \mathrm{ft}^{2}$ of 3.5 in RUs-13 fiberglass batt insulation cannot be calculated by taking the LCIA results for RSI1 and multiplying by 13 / 5.68. Therefore, it is currently recommended that a BEES user NOT use the "quantity" option and the associated "total” LCIA results for any decision-making for insulation products.

To evaluate the insulation products based on actual R-values installed, the insulation products in BEES Online 2.0 will be updated from $\mathrm{R}_{\mathrm{SI}}-1$ ( $\left.\mathrm{R}_{\mathrm{US}}-5.68\right)$ to installed R-values. These will be added to BEES in 2019. The insulation product options will be added to Table 8-1 once they are finalized, which will cover the most common product options and building code insulation requirements. 
Table 8-1 Interior Wall and Ceiling Insulation Types, Subtypes, and Function Unit Conversion

\begin{tabular}{llcc} 
& & \multicolumn{2}{c}{ Wall and Ceiling Insulation } \\
Types & Subtypes & Current Option & Upcoming R-Value Options \\
\hline Mineral & Loose Fill & $\mathrm{R}_{\mathrm{SI}}-1$ & TBD \\
& Board & $\mathrm{R}_{\mathrm{SI}}-1$ & $\mathrm{TBD}$ \\
Cellulose & Blown-In - Wall & $\mathrm{R}_{\mathrm{SI}}-1$ & $\mathrm{TBD}$ \\
& Blown-In - Ceiling & $\mathrm{R}_{\mathrm{SI}}-1$ & $\mathrm{TBD}$ \\
\multirow{4}{*}{ Fiberglass } & Batt - Wall & $\mathrm{R}_{\mathrm{SI}}-1$ & $\mathrm{TBD}$ \\
& Batt - Ceiling & $\mathrm{R}_{\mathrm{SI}}-1$ & $\mathrm{TBD}$ \\
& Loose Fill & $\mathrm{R}_{\mathrm{SI}}-1$ & $\mathrm{TBD}$ \\
\hline
\end{tabular}

Unit: $\mathrm{R}_{\mathrm{SI}}-1=\mathrm{R}_{\mathrm{US}}-5.67826$

Conversion Factor $\left(\mathrm{R}_{\mathrm{US}}\right.$ to $\left.\mathrm{R}_{\mathrm{SI}}\right)=1 / 5.67826=0.1761$

By controlling for the thermal performance, BEES provides results that are reasonable approximations for the relative environmental impacts across insulation types for given R-values. However, it is important to note that BEES results do not account for framing factor or thermal bridging, which would require whole building energy modeling of the entire assembly. For assembly and building-level LCIA results, see Athena Impact Estimator for Buildings (IE4B) and NIST's Building Industry Reporting and Design for Sustainable Buildings Neutral Environment Software Tool (BIRDS NEST).

\subsection{Exterior Wall and Ceiling Insulation Characteristics and Certifications}

BEES Online 2.0 has added a feature to filter/restrict products selected based on product characteristics, such as fraction recycled materials, and product certifications, such as USDA Certified Biobased. The R-value specific insulation products that are currently under development will introduce R-value as a characteristic. The current and upcoming list of characteristics and certifications provided in BEES 2.0 are listed in Table 8-2.

Table 8-2 Exterior Wall and Ceiling Insulation Characteristics and Certifications

\begin{tabular}{ll}
\hline \multicolumn{2}{c}{ Characteristics and Certifications } \\
\hline Federal Agency Certifications & None \\
\hline Standard Certification & None \\
\hline NGO Certification & None \\
\hline Characteristic - Recycled Content & $25 \%, 35 \%, 50 \%, 75 \%$ \\
\hline Characteristic - R-Value & TBD \\
\hline
\end{tabular}

\subsection{Exterior Wall and Ceiling Insulation Installation, Service Life, and Use Phase}

To evaluate the life cycle impacts of exterior wall and ceiling insulation, it is necessary to consider the installation and use phase impacts, both of which could vary depending on 
decisions outside the product manufacturer's control. It is assumed there are no use phase impacts while installation impacts are incorporated into the products embodied impacts. The default assumed service life is defined for each BEES product in its associated documentation.

\subsection{Generic Mineral Wool Insulation}

Mineral wool insulation is made by spinning fibers from natural rock like diabase or basalt (rock wool) or iron ore blast furnace slag (slag wool). Rock wool and slag wool are manufactured by melting the constituent raw materials in a cupola. A molten stream is created and poured onto a rapidly spinning wheel or wheels. The viscous molten material adheres to the wheels and the centrifugal force throws droplets of melt away from the wheels, forming fibers. For loose fill insulation, the resulting fibers are processed into the final unbonded product and packaged. For mineral wool board, a binder is used to stabilize the fibers. The material is heated to cure the binder and stabilize the material and is then cooled. The blankets are cut to size and packaged.

\subsubsection{Product Description}

BEES includes unfaced, light density mineral wool board and loose fill mineral wool. The insulation products in BEES are based on the thermal resistance $\mathrm{R}_{S I}=1 \quad\left(\mathrm{R}_{\mathrm{US}}=5.68\right)$ over the 60-year study period. ${ }^{87}$ The mass of mineral wool insulation per functional unit is shown in Table 8-3 and Table 8-4.

\section{Table 8-3 Mineral Wool Board Insulation by Application ${ }^{88}$}

\begin{tabular}{lc}
\hline Application & $\begin{array}{c}\text { Mass per } \mathbf{R}=\mathbf{1} \text { Functional Unit } \\
\mathbf{k g} / \mathbf{m}^{\mathbf{2}}\left(\mathbf{l b} / \mathbf{f t}^{2}\right)\end{array}$ \\
\hline Wall & $1.7(0.35)$ \\
Ceiling & \\
\hline Note: $\mathrm{R}_{\mathrm{SI}}-1=\mathrm{R}_{\mathrm{US}}-5.68$ & \\
\hline
\end{tabular}

Table 8-4 Loose Fill Mineral Wool Insulation by Application ${ }^{89}$

\begin{tabular}{lc}
\hline Application & $\begin{array}{c}\text { Mass per } \mathbf{R}=1 \text { Functional Unit } \\
\mathbf{k g} / \mathbf{m}^{2}\left(\mathbf{l b} / \mathbf{f t}^{2}\right)\end{array}$ \\
\hline Wall & $1.1(0.23)$ \\
Ceiling & \\
\hline Note: $\mathrm{R}_{\mathrm{SI}}-1=\mathrm{R}_{\mathrm{US}}-5.68$ & \\
\hline
\end{tabular}

\footnotetext{
${ }^{87}$ Units for $\mathrm{R}_{\mathrm{SI}}$ and $\mathrm{R}_{\mathrm{Us}}$ are ${ }^{\circ} \mathrm{C}-\mathrm{m}^{2}$-sec/J and ${ }^{\circ} \mathrm{F}-\mathrm{ft}^{2}$-s/BTU, respectively.

${ }^{88}$ NAIMA (2013a)

${ }^{89}$ NAIMA (2013b)
} 


\subsubsection{Flow Diagram}

The flow diagrams in Figure 8-1 and Figure 8-2 presents the major elements of the production of this product as it is currently modeled for BEES.

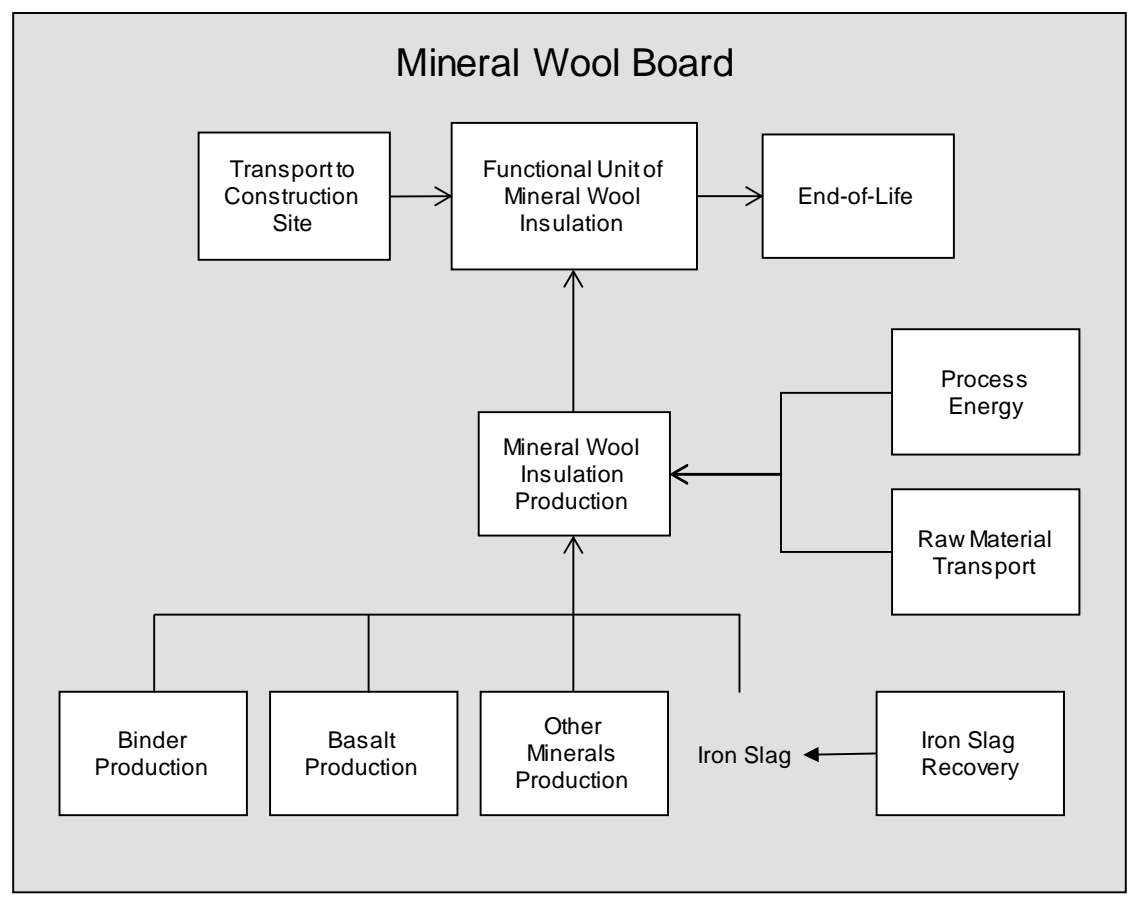

Figure 8-1 Mineral Wool Board Insulation System Boundaries

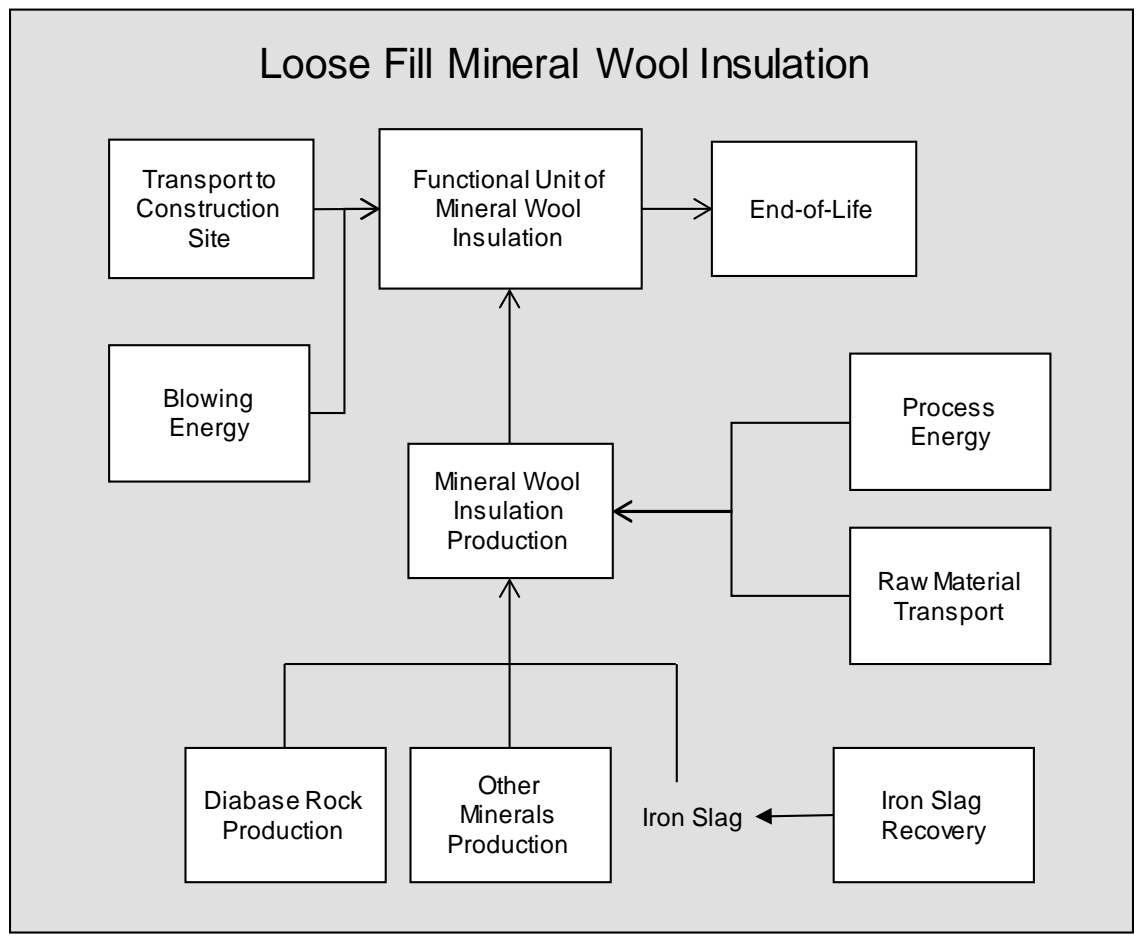

Figure 8-2 Loose Fill Mineral Wool Insulation System Boundaries 


\subsubsection{Raw Materials}

The BEES models for these products represent an industry average mix of the different types of mineral wool insulation used in North America, given in Table 8-5 and Table 8-6. The North American Insulation Manufacturers Association (NAIMA) EPDs provide the detailed material content data. ${ }^{90}$

\section{Table 8-5 Mineral Wool Board Insulation Constituents}

\begin{tabular}{lc}
\hline \multicolumn{1}{c}{ Constituent } & Mass \\
\hline Mineral Wool Batch & \\
Slag & 62.0 \\
Basalt & 25.0 \\
Feldspar & 7.0 \\
Cement & 1.0 \\
Granite & 0.4 \\
Iron Ore & 0.4 \\
Binder & \\
Phenolic resin & 2.0 \\
Urea & 2.0 \\
Other & 0.2 \\
Total & $\mathbf{1 0 0 . 0}$ \\
\hline
\end{tabular}

\section{Table 8-6 Loose Fill Mineral Wool Insulation Constituents}

\begin{tabular}{lc}
\hline \multicolumn{1}{c}{ Constituent } & Mass Fraction (\%) \\
\hline Slag & 86.5 \\
Bauxite & 6.2 \\
Granite & 4.1 \\
Feldspar & 2.9 \\
De-dusting agent & 0.3 \\
Total & $\mathbf{1 0 0 . 0}$ \\
\hline
\end{tabular}

Data for most of the materials come from ecoinvent. The feldspar data set is used as a proxy for granite. Except for its transportation to the manufacturing plant, slag is modeled as an input that is free of environmental burdens since it is a byproduct of iron production. The de-dusting agent, modeled as ethylene glycol, comes from the U.S. LCI database. The Portland cement data come from PCA's U.S. industry-average data (PCA, 2016a).

\subsubsection{Manufacturing}

Energy and water use. The energy requirements for melting the product constituents into fibers and drying of the fibers involve energy for heat and electrical energy. Energy use at manufacturing was based on Primary Energy results for the Production stage in the NAIMA EPDs. Natural gas and electricity were assumed to be the energy sources. The

90 Table 1 in NAIMA (2013a) and NAIMA (2013b). 
industry average process water used during production is also reported in Table 4 of the EPDs and included in BEES: $0.45 \mathrm{~L} / \mathrm{m}^{2}$ for loose fill insulation and $0.87 \mathrm{~L} / \mathrm{m}^{2}$ for light density insulation board.

Transportation. The raw materials are transported to the manufacturing plant via diesel truck. Materials are sourced domestically, and transportation distances range on average from $161 \mathrm{~km}(100 \mathrm{mi})$ to $805 \mathrm{~km}$ (500 mi).

Waste. Much of the waste produced during the production process is either recycled into other insulation materials or added back into the melt. Some non-hazardous waste quantities are generated during production; this data comes from Table 4 of each respective EPD: $0.36 \mathrm{~kg} / \mathrm{m}^{2}\left(0.07 \mathrm{lb} / \mathrm{ft}^{2}\right)$ for loose fill and $0.91 \mathrm{~kg} / \mathrm{m}^{2}\left(0.19 \mathrm{lb} / \mathrm{ft}^{2}\right)$ for light density board.

\subsubsection{Transportation}

Transportation of the insulation to the building site is modeled as an assumed average of $805 \mathrm{~km}$ (500 mi) by heavy-duty diesel-fueled truck based on the U.S. LCI database. The BEES user can revise this distance if customization is necessary.

\subsubsection{Installation}

Installing mineral wool board is primarily a manual process so no energy is included here. The board is modeled as having a $3 \%$ scrap rate. According to the NAIMA 2013 EPD, four $3.85 \mathrm{~cm}$ (1.5 in) fasteners per $\mathrm{m}^{2}\left(\sim 9.3\right.$ per $\left.100 \mathrm{ft}^{2}\right)$ are used and these fasteners are included in the analysis. Blowing machines are used to install loose fill insulation. These machines can vary greatly in power and insulation throughput, based on their size, performance specifications, etc. For BEES, a $18 \mathrm{~kW}$ (25 hp) diesel engine is used to blow $930 \mathrm{~kg}(2050 \mathrm{lb})$ of mineral wool insulation. During the installation of loose fill insulation, any additional material is added into the building shell where the insulation is installed - there is effectively no installation waste.

Mineral wool insulation has a functional lifetime of over 60 years so no replacement is needed during the 60 year study period.

\subsubsection{Use}

While not accounted for in BEES, it is important to consider thermal performance differences when assessing environmental and economic performance for insulation product alternatives. Thermal performance affects building heating and cooling loads, which in turn affect energy-related LCA inventory flows and building energy costs over the 60-year use stage.

\subsubsection{End of Life}

At end of life, it is assumed that the insulation is disposed of in a landfill. End-of-life modeling includes transportation by heavy-duty diesel-fuel powered truck approximately 
$80 \mathrm{~km}$ (50 mi) to a construction \& demolition landfill. Insulation in a landfill is modeled based on ecoinvent end-of-life waste management process data.

\subsection{Generic Cellulose Insulation}

Blown cellulose insulation is produced primarily from PC wood pulp (newspapers), typically accounting for roughly $85 \%$ of the insulation by weight. Cellulose insulation is treated with fire retardant; ammonium sulfate, borates, and boric acid are used most commonly and account for the other $15 \%$ of the cellulose insulation by weight.

\subsubsection{Product Description}

The cellulose insulation product in BEES is a conventional blown cellulose. Two additional categories that may be added to BEES in the future include stabilized cellulose, into which a starch-based adhesive is added to minimize product settling, and spray-applied cellulose into commercial buildings.

The insulation products in BEES are based on the thermal resistance $\mathrm{R}_{S I}=1$ ( $\left.\mathrm{R}_{\mathrm{US}}=5.68\right)$ over the 60 -year study period. ${ }^{91}$ The mass of cellulose insulation per functional unit is shown in Table 8-7.

Table 8-7 Blown Cellulose Insulation by Application

\begin{tabular}{lcc}
\hline Application & $\begin{array}{c}\text { Mass per } \boldsymbol{R}=\mathbf{1} \text { Functional Unit } \\
\mathbf{k g} / \mathbf{m}^{\mathbf{2}}\left(\mathbf{l b} / \mathbf{f t}^{2}\right)\end{array}$ & $\begin{array}{c}\text { Scaling } \\
\text { Factor }\end{array}$ \\
\hline Wall (dense pack) & $2.25(0.46)$ & 2.3 for $\mathrm{R}_{\mathrm{US}}-13$ \\
Ceiling & $1.03(0.21)$ & 6.7 for $\mathrm{R}_{\mathrm{US}}-38$ \\
\hline
\end{tabular}

\subsubsection{Flow Diagram}

The flow diagram in Figure 8-3 presents the major elements of the production of this product as it is currently modeled for BEES.

${ }^{91}$ Units for $\mathrm{R}_{\mathrm{SI}}$ and $\mathrm{R}_{\mathrm{US}}$ are ${ }^{\circ} \mathrm{C}-\mathrm{m}^{2}$-sec/J and ${ }^{\circ} \mathrm{F}-\mathrm{ft}^{2}$-s/BTU, respectively. 


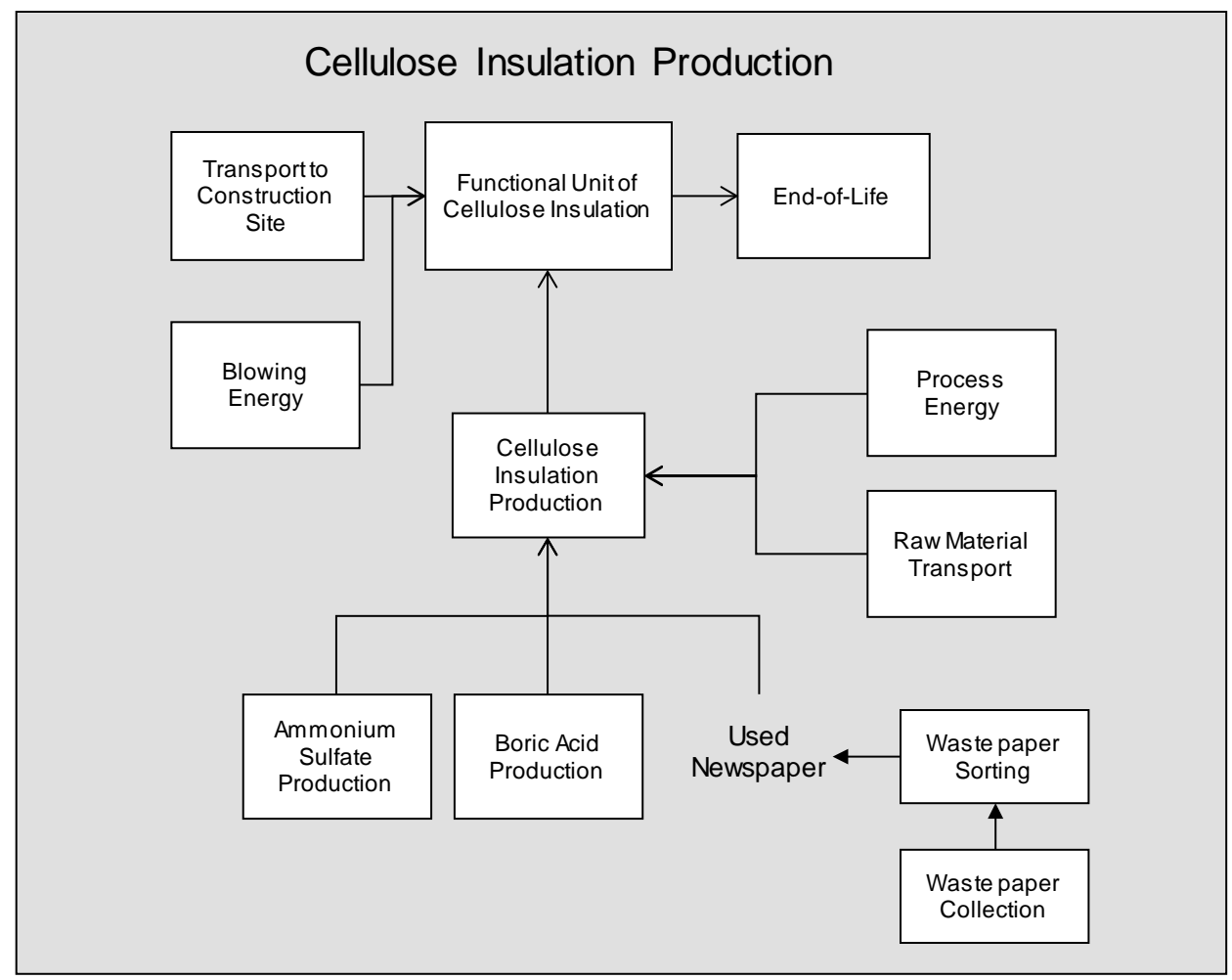

Figure 8-3 Cellulose Insulation System Boundaries

\subsubsection{Raw Materials}

Cellulose insulation is essentially shredded recovered wastepaper that is coated with fire retardants. The mass fraction of these materials is provided in Table 8-8. The relative proportions of fire retardants vary among manufacturers; an ammonium sulfate and boric acid mix of $70 \%$ and $30 \%$, respectively, was modeled in BEES as that mix could be considered characteristic for this use.

\section{Table 8-8 Cellulose Insulation Constituents}

\begin{tabular}{lc}
\hline \multicolumn{1}{c}{ Constituent } & Mass \\
\hline Recoction (\%) \\
Ammonium sulfate & 85 \\
Boric acid & 10.5 \\
\hline
\end{tabular}

Production of the newspaper is not included in the model since it is a recovered product, but the operations around recovering it are, which include wastepaper collection, sorting, and subsequent transportation to the insulation manufacturer. Ammonium sulfate is assumed to be a co-product of nylon (caprolactam) production. The boric acid flame retardant is assumed to be produced from borax. Data for both materials come from ecoinvent. 


\subsubsection{Manufacturing}

Energy Requirements and Emissions. The manufacturing process includes shredding the wastepaper and blending it with the different fire retardants. Manufacturing energy is assumed to be purchased electricity in the amount of $0.35 \mathrm{MJ} / \mathrm{kg}$ (150 Btu/lb). There are no wastes or water effluents from the process of manufacturing cellulose insulation.

Transportation. The recovered newspaper is assumed to be shipped $161 \mathrm{~km}$ (100 mi) to the manufacturing plant via diesel truck. Other materials are assumed shipped by truck an average of $805 \mathrm{~km}$ (500 mi).

Waste. All waste produced during the production process is recycled back into other insulation materials. Therefore, minimal solid waste is generated during the production process.

\subsubsection{Transportation}

Transportation distance of the insulation to the building site is modeled to be an assumed average of $483 \mathrm{~km}$ (300 mi) by heavy-duty diesel-fueled truck, since cellulose insulation is produced regionally. Still, a BEES user can change this distance should customization be desired.

\subsubsection{Installation}

Blowing machines to install loose insulation can vary greatly in power and insulation throughput, based on their size, performance specifications, etc. For BEES, a $18 \mathrm{~kW}$ (25 hp) diesel engine is used to blow $1520 \mathrm{~kg}$ (3350 lb) of cellulose insulation. During the installation of loose fill insulation, any waste material is added into the building shell where the insulation is installed - there is effectively no installation waste.

\subsubsection{Use}

Cellulose insulation has a functional lifetime of over 60 years so no replacement is needed during the 60-year study period. While not accounted for in BEES, it is important to consider thermal performance differences when assessing environmental and economic performance for insulation product alternatives. Thermal performance affects building heating and cooling loads, which in turn affect energy-related LCA inventory flows and building energy costs over the 60-year use stage. Since alternatives for ceiling and wall insulation are all evaluated using the same thermal resistance value, thermal performance differences are not a significant issue here but the scaling should be accounted for.

\subsubsection{End of Life}

While cellulose insulation may be recyclable, it is assumed that all of the insulation is disposed of in a landfill at end-of-life. End-of-life modeling includes transportation approximately $80 \mathrm{~km}$ (50 mi) to a landfill. Cellulose insulation in a landfill is modeled 
using ecoinvent's data set on disposal of newspaper in a landfill, which accounts for partial decomposition of paper.

\subsection{Generic Fiberglass Insulation}

Fiberglass blanket, or batt, insulation is made by forming spun-glass fibers into batts. At an insulation plant, the product feedstock is weighed and sent to a melting furnace. The raw materials are melted in a furnace at very high temperatures. Streams of the resulting vitreous melt are either spun into fibers after falling onto rapidly rotating flywheels or drawn through tiny holes in rapidly rotating spinners. This process shapes the melt into fibers. Glass coatings are added to the fibers that are then collected on conveyers. The structure and density of the product is continually controlled by the conveyer speed and height as it passes through a curing oven. The cured product is then sawn or cut to the required size, such as for a batt. Off-cuts and other scrap material are recycled back into the production process.

\subsubsection{Product Description}

For BEES, the fiberglass batt is modeled with a facing paper. Blown fiberglass insulation, also called loose fill fiberglass insulation, is made by forming spun-glass fibers using the same method as for batts but leaving the insulation loose and unbonded.

The insulation products in BEES are based on the thermal resistance $\mathrm{R}_{\mathrm{SI}}=1\left(\mathrm{R}_{\mathrm{US}}=5.68\right)$ over the 60 -year study period. ${ }^{92}$ The mass of fiberglass insulation per functional unit is shown in Table 8-9 and Table 8-10.

Table 8-9 Fiberglass Batt Insulation by Application ${ }^{93}$

\begin{tabular}{lcc}
\hline Application & $\begin{array}{c}\text { Mass per } \mathbf{R}=1 \text { Functional } \\
\text { Unit } \mathbf{~} \mathbf{g} / \mathbf{m}^{\mathbf{2}}\left(\mathbf{l b} / \mathbf{f t}^{2}\right)\end{array}$ & $\begin{array}{c}\text { Scaling } \\
\text { Factor }\end{array}$ \\
\hline Wall & & 3 for R Rs-13, plus facing \\
Ceiling & $0.44(0.09)$ & 7 for R $\mathrm{US}_{\mathrm{US}}-38$, plus facing \\
\hline
\end{tabular}

Table 8-10 Loose Fill Fiberglass Insulation by Application ${ }^{94}$

\begin{tabular}{lcc}
\hline Application & $\begin{array}{c}\text { Mass per } \mathbf{R}=\mathbf{1} \text { Functional } \\
\text { Unit } \mathbf{~ g} / \mathbf{m} 2 \text { (lb/ft2) }\end{array}$ & $\begin{array}{c}\text { Scaling } \\
\text { Factor }\end{array}$ \\
\hline Ceiling & $0.60(0.12)$ & 4.52 for $R_{U s}-38$ \\
\hline
\end{tabular}

${ }^{92}$ Units for $\mathrm{R}_{\mathrm{SI}}$ and $\mathrm{R}_{\mathrm{Us}}$ are ${ }^{\circ} \mathrm{C}-\mathrm{m}^{2}$-sec/ $\mathrm{J}$ and ${ }^{\circ} \mathrm{F}-\mathrm{ft}^{2}$-s/BTU, respectively.

${ }^{93}$ Quantity per functional unit based on data provided in Owens Corning (2013a) and CertainTeed (2013).

${ }^{94}$ Quantity per functional unit from Owens Corning (2013b) 


\subsubsection{Flow Diagram}

The flow diagrams in Figure 8-4 and Figure 8-5 presents the major elements of the production of this product as it is currently modeled for BEES.

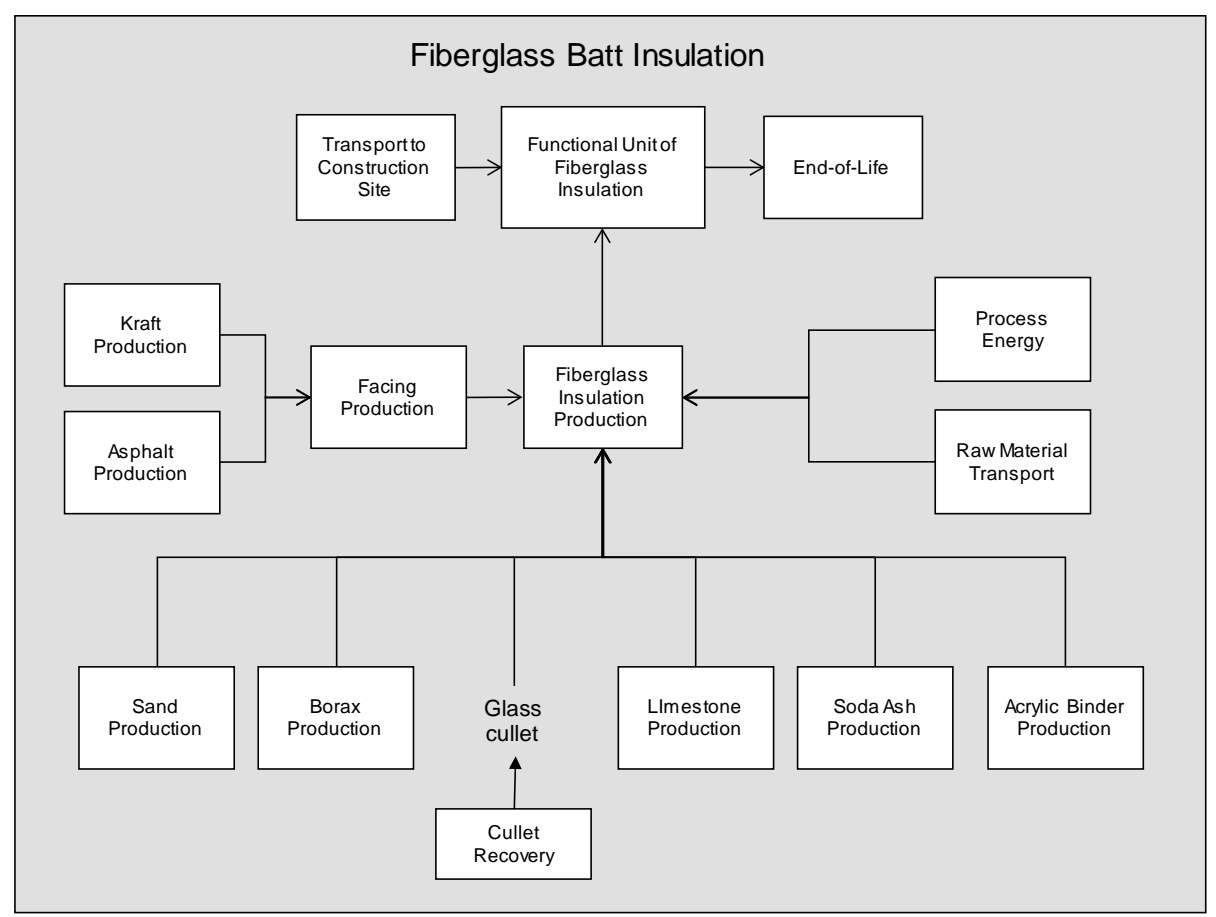

Figure 8-4 Fiberglass Batt Insulation System Boundaries

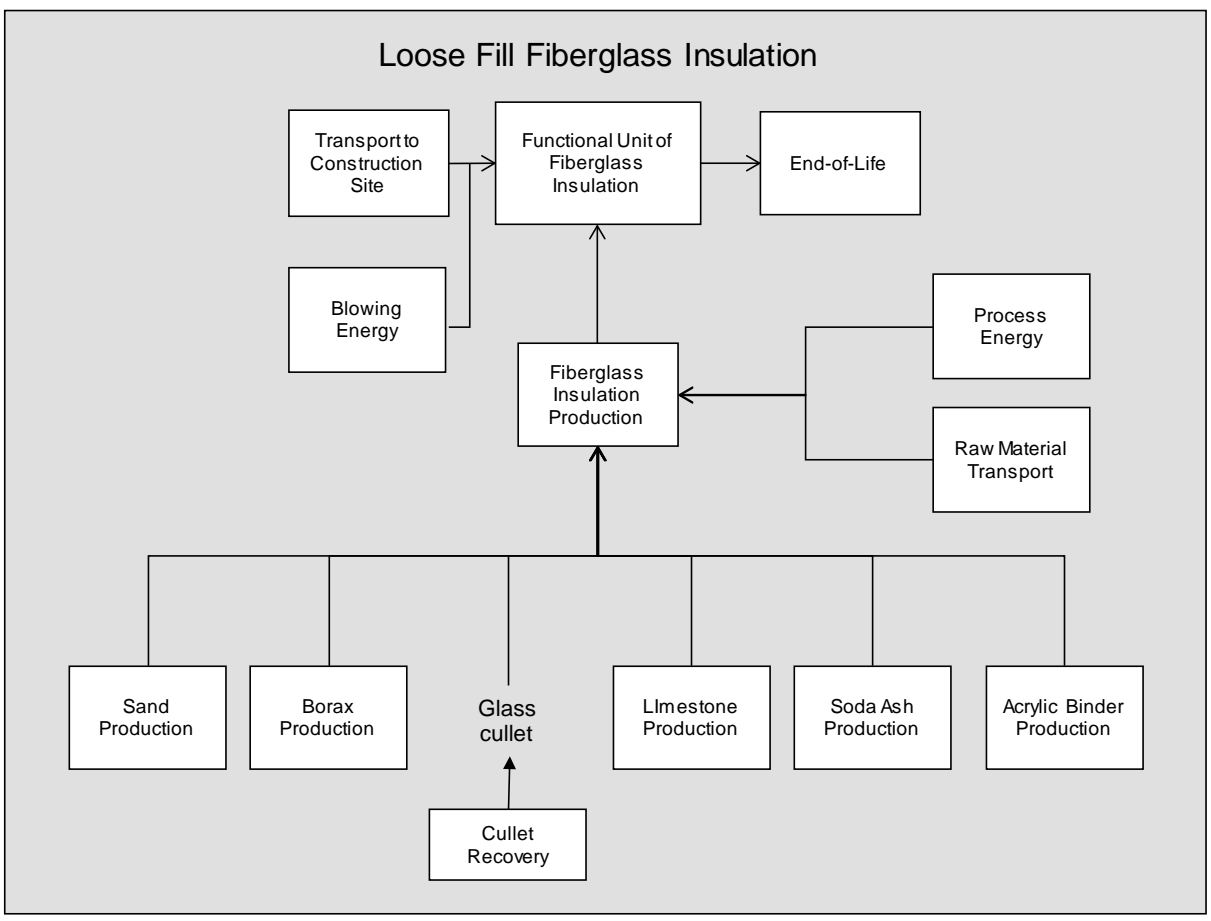

Figure 8-5 Loose Fill Fiberglass Insulation System Boundaries 


\subsubsection{Raw Materials}

Fiberglass insulation is made with a blend of sand, limestone, soda ash, borax, cullet, and coatings materials. The cullet, or recycled window, automotive, or bottle glass, can account for well beyond 50 \% by mass of the raw material input in some products on the market. Glass cullet use could be limited, however, as its use is dependent on availability in the market, and not all glass cullet is of sufficient quality to be used in the glass fiber manufacturing process. Nevertheless, the use of recycled material has helped to steadily reduce the energy required to produce fiberglass insulation products. The raw materials used to produce fiberglass insulation are shown in Table 8-11. These mass fractions are based loosely on ranges of percentages of raw materials data from Owens Corning and CertainTeed published EPDs. These data are not meant to represent any one product on the market.

\section{Table 8-11 Fiberglass Insulation Constituents}

\begin{tabular}{lll}
\hline Constituent & Batt & Loose Fill \\
\hline Glass constituent & Mass Fraction (\%) & Mass Fraction (\%) \\
\hline Soda Ash & 9 & 9 \\
Borax & 12 & 17 \\
Glass Cullet & 38 & 38 \\
Quicklime & 9 & 5 \\
Binder Coatings & 5 & $<1$ \\
Sand & 27 & 27 \\
Feldspar & 0 & 4 \\
Total & 100 & 100 \\
Facing & & \\
Kraft paper & 25 & \\
Asphalt & 75 & \\
Total & 100 & \\
\hline
\end{tabular}

The production data for the soda ash and lime come from the U.S. LCI database. The borax, glass cullet (collection), silica sand, and feldspar come from ecoinvent. For the facing, Kraft paper comes from ecoinvent and the asphalt comes from U.S. LCI database. The binder for fiberglass insulation was traditionally phenol formaldehyde resin but due to indoor air quality issues, this binder has been replaced with other materials. For BEES, the binder has been modeled as an acrylic binder, based on data from ecoinvent.

\subsubsection{Manufacturing}

Energy Requirements and Emissions. The energy requirements for melting the glass constituents into fibers and drying of the completed batt involve the use of electricity and other energy for heat - assumed to be natural gas. Overall energy use was estimated using guidance from the Primary Energy results for Plant Operations in the Owens Corning EPDs. Natural gas and electricity were the assumed energy sources. The manufacturing process generates air emissions from the combustion of the fuels used to melt the raw materials and from the drying of the insulation material prior to cutting and packaging. 
Data for natural gas production and combustion into heat, and electricity are based on the U.S. LCI database.

Transportation. The raw materials are transported to the manufacturing plant via diesel truck. Materials are sourced domestically, and transportation distances range on average from $161 \mathrm{~km}$ (100 mi) to $805 \mathrm{~km}$ (500 mi).

Waste. Much of the waste produced during the cutting and blending process is either recycled into other insulation materials or added back into the glass mix.

\subsubsection{Transportation}

Transportation of the insulation to the building site is modeled as an assumed average of $805 \mathrm{~km}$ (500 mi) by heavy-duty diesel-fueled truck based on the U.S. LCI database. The BEES user can revise this distance if customization is desired.

\subsubsection{Installation}

Installing batt insulation is primarily a manual process; no energy or emissions are included in the model. A blowing machine is used to blow loose insulation into the ceiling space. Blowing machines can vary greatly in power and insulation throughput, based on their size, performance specifications, etc. For BEES, an $18 \mathrm{~kW}$ (25 hp) diesel engine is used to blow $612 \mathrm{~kg}$ (1350 lb) of loose fiberglass insulation. During the installation of the loose fill and batt, any waste material or scrap can be added into the building shell where the insulation is installed so there is effectively no installation waste.

Fiberglass insulation has a functional lifetime of more than 60 years - there is no need to replace or maintain the insulation during normal building use.

\subsubsection{Use}

While not accounted for in BEES, it is important to consider thermal performance differences when assessing environmental and economic performance for insulation product alternatives. Thermal performance affects building heating and cooling loads, which in turn affect energy-related LCA inventory flows and building energy costs over the 60-year use stage.

\subsubsection{End of Life}

At end of life, it is assumed that the insulation is disposed of in a landfill. End-of-life modeling includes transportation by heavy-duty diesel-fuel powered truck approximately $80 \mathrm{~km}(50 \mathrm{mi})$ to a construction \& demolition landfill. Insulation in a landfill is modeled based on ecoinvent end-of-life waste management process data. 


\section{Partitions Category}

The partitions category covers both residential and commercial products.

\subsection{Partition Types}

There are two partition types included in Table 9-1.

Table 9-1 Interior Wall and Ceiling Finish Types and Subtypes

\begin{tabular}{ll}
\multicolumn{2}{c}{ Wall and Ceiling Insulation } \\
Types & Subtypes \\
\hline Gypsum & Board \\
& X Board \\
\hline
\end{tabular}

\subsection{Partition Characteristics and Certifications}

BEES Online 2.0 has added a feature to filter/restrict products selected based on product characteristics, such as fraction recycled materials, and product certifications, such as USDA Certified Biobased. The current list of characteristics and certifications provided in BEES 2.0 are listed in Table 9-2.

Table 9-2 Exterior Wall and Ceiling Finish Characteristics and Certifications

\begin{tabular}{ll}
\hline \multicolumn{2}{c}{ Characteristics and Certifications } \\
\hline Federal Agency Certifications & None \\
\hline Standard Certification & None \\
\hline NGO Certification & None \\
\hline Characteristics & $25 \%$ Recycled Content \\
& $35 \%$ Recycled Content \\
& $50 \%$ Recycled Content \\
& $75 \%$ Recycled Content \\
\hline
\end{tabular}

\subsection{Partition Installation, Service Life, and Use Phase}

To evaluate the life cycle impacts of interior wall finishes, it is necessary to consider the installation and use phase impacts, both of which could vary depending on decisions outside the product manufacturer's control. It is assumed there are no use phase impacts while installation impacts are incorporated into the products' embodied impacts. The default assumed service life is defined for each BEES product in its associated documentation. 


\subsection{Average North American Gypsum Wallboard}

Gypsum wallboard (GWB), also known as "drywall” or "plaster board," consists of a core of gypsum surrounded by a paper covering. Several varieties of GWB products are available; each is comprised of a specially formulated gypsum plaster mix and facing paper specifically developed for the intended application. These gypsum board products include regular GWB, moisture-resistant gypsum board, and Type X fire-resistant gypsum board.

\subsubsection{Product Description}

For BEES, two of the most common GWB products - 1/2” (12.7 mm) Regular and 5/8” (15.9 mm) Type $X$ - are studied. Industry average North American data were used; the cradle-to-gate data for these products is based on a 2011 industry-wide study undertaken by the Gypsum Association (GA) and its member companies (Bushi \& Meil, 2011). As such the industry average use of natural and synthetic gypsums were included. The $1 / 2$ " Regular and 5/8” Type X GWB have a finished density of 7.66 and $10.84 \mathrm{~kg} / \mathrm{m}^{2}(1.57$ $\mathrm{lb} / \mathrm{ft}^{2}$ and $2.22 \mathrm{lb} / \mathrm{ft}^{2}$ ), respectively (including $3.3 \% \mathrm{MC}$ ). These products are installed with joint tape, joint treatment compound, and wallboard screws. GWB is assumed to be screwed to wood studs, $41 \mathrm{~cm}$ (16 in) on center. A functional unit of $92.9 \mathrm{~m}^{2}\left(1000 \mathrm{ft}^{2}\right.$, or MSF) of GWB used in a building for 60 years has been modeled.

\subsubsection{Flow Diagram}

The flow diagram in Figure 9-1 presents the major elements of the production of this product as it is currently modeled for BEES.

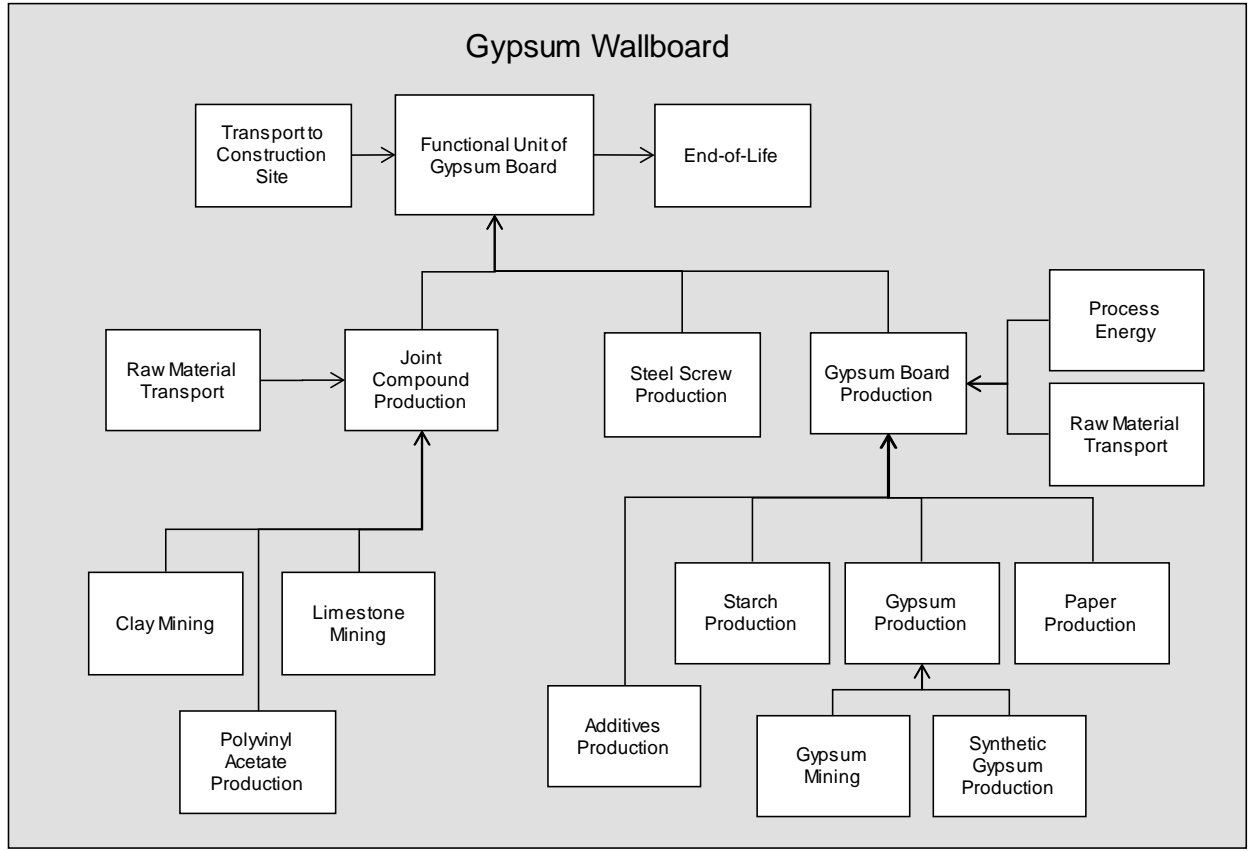

Figure 9-1 Gypsum Board System Boundaries 


\subsubsection{Raw Materials}

GWB primarily consists of gypsum that is mixed with additives and water and backed on both sides with gypsum paper. Gypsum sources include natural gypsum that is quarried or mined, synthetic gypsum resulting from the flue gas desulfurization (FGD) process required for $\mathrm{SO}_{2}$ scrubbing during coal fired power production, and a smaller amount of PC gypsum material. Table 9-3 shows the materials used in producing one MSF of each product.

\section{Table 9-3 GWB Inputs per MSF ${ }^{95}$}

\begin{tabular}{lcc}
\hline & 1/2” Regular & 5/8” Type $\boldsymbol{X}$ \\
\hline \multicolumn{1}{c}{ Constituent } & $\mathbf{k g}(\mathbf{l b})$ & $\mathbf{k g}(\mathbf{l b})$ \\
\hline Gypsum material & $672(1482)$ & $961(2118)$ \\
• Natural (ore) & $41 \%$ & $41 \%$ \\
• Synthetic (FGD) & $57 \%$ & $57 \%$ \\
• Post-consumer (PC) & $2 \%$ & $2 \%$ \\
Gypsum paper & $20.3(44.8)$ & $20.2(44.6)$ \\
Additives & $13.5(29.8)$ & $16.6(36.7)$ \\
Water & $427(942)$ & $595(1312)$ \\
\hline
\end{tabular}

Primary data for natural gypsum extraction were collected for Bushi and Meil (2011) from six gypsum quarries and one mine site covering the U.S., Canada, and Mexico for the reference year 2010. Synthetic gypsum, produced as a co-product from coal-fired power production, was modeled using system expansion to avoid allocation of the "multifunctionality” of coal-fired power generation. FGD gypsum generally undergoes additional secondary drying at the GWB plant; energy for drying is included in the model. PC gypsum data included its collection and use. The data for facing and backing gypsum papers, which are made up of recycled paper sources and additives, comes from primary data for the year 2010 from three gypsum paper plants. Additives include starch, vermiculite, fiberglass, dispersant, retarder, potassium sulfate, dextrose, clay (kaolin), boric acid, land plaster, foaming agent (soap), BM accelerator, ammonium sulfate, edge paste, and shredded paper. Data used for BEES are consistent with data used in the GWB study and include data from U.S. LCI Database and ecoinvent customized to U.S. conditions.

\subsubsection{Manufacturing}

Gypsum board is produced using partially dehydrated or calcinated gypsum. The gypsum is fed into a mixer where it is combined with water and other ingredients to form a slurry or paste. The slurry is spread onto a moving belt of face paper and then covered with a backing paper. As the materials move down the production line, the edges of the face

${ }^{95}$ Bushi and Meil (2011) 
paper are folded over the backing paper to create one of several edge types. The board then progresses down the production line where it is cut into specific lengths. The individual boards are subsequently run through dryers. Once dry, the wallboard moves further down the line where it is trimmed to an exact length, paired with another board, bound on both ends with a labeling tape, and stacked in a bundle. The bundles are taken into the warehouse, where they are selected for shipment to customers. Primary data on GWB manufacturing were collected for Bushi and Meil (2011). Seventeen GWB facilities in the U.S. provided total production 2010 data, including material and energy inputs and process emissions.

Energy use and outflows. Energy used for manufacturing and reported by GWB manufacturers include natural gas used for the drying process, plus electricity, diesel fuel, propane, and gasoline. Manufacturers also reported non-combustion (i.e., process-related) air emissions (including particulate matter and VOCs) and water effluents. These inputs and outputs are included in the model but quantities per MSF are not presented here as the data are proprietary. According to Bushi and Meil (2011), on average, for every MSF of GWB product manufactured, about $0.4 \%$ of all material inputs end up as solid waste. This waste is included in the model, including its deposition in a landfill.

Packaging. Packaging of GWB has been included in the model and is described in the industry-average GWB Type X EPD as “gypsum board end tape (bundling tape) constructed of paper and containing water- and oil-based ink; banding, rail bags and slip sheets; cardboard and metal edge/corner protectors; risers/spacers constructed of gypsum board; and adhesive for risers/spacers” (GA, 2014). Specific materials and quantities were obtained from Bushi and Meil (2011), and data for these materials come from ecoinvent customized to U.S. conditions.

Transportation. The transportation of the gypsum, gypsum paper, and additives to the gypsum board facility has been considered in the models. Transportation data were obtained from Bushi and Meil (2011) and include weighted averages of distances and modes of transportation to manufacturers.

\subsubsection{Transportation}

The participating GWB manufacturers for Bushi and Meil (2011) provided transportation distances and modes to building sites, as shown in Table 9-4.

\section{Table 9-4 Industry-Average Distances to Building Site ${ }^{96}$}

\begin{tabular}{lcc}
\hline Mode of Transport & Regular $1 / 2$ in & Type $\boldsymbol{X}$ 5/8 in \\
\hline Rail - km (mi) & $211(131)$ & $214(133)$ \\
Diesel truck - km (mi) & $449(279)$ & $286(178)$ \\
Barge - km (mi) & $331(206)$ & $331(206)$ \\
\hline
\end{tabular}

\footnotetext{
${ }^{96}$ Bushi and Meil (2011), Table 11.
} 
Transportation data sets are based on U.S. LCI database. While the above data were used in the model, BEES users may input their own transportation distance.

\subsubsection{Use}

Gypsum board is assumed to have a useful life of 75 years, provided it is well maintained and protected. There are no emissions from the use of gypsum board and repairs required to patch holes or tears are not included in the product system boundaries.

\subsubsection{Installation}

Gypsum board may be attached to wood framing, cold-formed steel framing, or existing surfaces using nails, staples, screws, and adhesives appropriate for the application. Joints between gypsum boards may be sealed or finished using paper or glass fiber mesh and one or more layers of joint treatment compound. Joint treatment compound is available in ready-mixed or dry powder form. BEES assumes ready mixed, which is usually a vinylbased, ready-to-use product that contains limestone to provide body. Clay, mica, talc, or perlite are often used as fillers. Ethylene glycol is used as an extender, and antibacterial and anti-fungal agents are also included.

The quantity of joint compound used per MSF was calculated using the PCR for joint compound (UL, 2016). The PCR stipulates a volume of 38.2 liters (10.1 gal) per MSF. For a conventional weight Ready Mixed joint compound with a shrinkage value of $19.2 \%$ and default installation waste factor of $3 \%$ (Drywall Finishing Council, 2017), the volume of joint compound is 48.8 liters (12.9 gallons) per MSF. At a typical density of $1.64 \mathrm{~kg} /$ liter $(13.7 \mathrm{lb} / \mathrm{gal})$, the required weight of Ready Mixed joint compound is 80.3 $\mathrm{kg}$ (177 lb). The joint compound in BEES was modeled based on an MSDS for an allpurpose joint compound. Water and limestone make up the bulk of the volume, with smaller amounts of vinyl acetate polymer, bentonite, and sand. These production data come from ecoinvent.

GWB is modeled as fastened using screw type fasteners at $61 \mathrm{~cm}$ (24 in) on center. The Gypsum Construction Handbook was consulted for data on the fasteners and spacing (USG Corporation, 2014). For $1 \mathrm{MSF}$, assuming $41 \mathrm{~cm}$ (16 in) spacing between screws, 375 screws are needed. A mass of $1.448 \mathrm{~g}$ (3.2 E-3 lb) per screw amounts to $0.543 \mathrm{~kg}$ (1.2 lb) screws per MSF.

Wallboard installation waste is approximated at $10 \%$ and is modeled as being disposed of in a landfill. This value is a conservative modeling decision, but it should be acknowledged that this waste could also be sent to a gypsum recycler who will either provide the clean scrap to a gypsum board manufacturer or process the clean scrap for agricultural use. 


\subsubsection{End of Life}

While gypsum board could be recycled at end of life, the product is modeled as disposed of in a landfill. End of life modeling includes transportation of the GWB and installation materials by heavy-duty diesel-fuel powered truck approximately $48 \mathrm{~km}$ (30 mi) to a landfill, plus impacts of the materials in a landfill. Truck transportation is based on the U.S. LCI database and disposal in a landfill is modeled based on ecoinvent end of life waste management process data. 
10 Wall Sheathing Category (Under Development)

Under Development.

11 Roof Sheathing Category (Under Development)

Under Development.

12 Roof Coverings Category (Under Development)

Under Development.

\author{
13 Parking Lot Paving Category (Under Development) \\ Under Development.
}

14 Beams Category (Under Development)

Under Development.

15 Columns Category (Under Development)

Under Development.

16 Basement Walls Category (Under Development)

Under Development.

17 Slab on Grade Category (Under Development)

Under Development. 


\section{Software Development and Design}

BEES is a data-driven web application that enables access to a NIST-developed building product database based on building product cost and LCA results as described in previous sections of this report. Comparisons of life cycle costs and environmental impacts for similar building products can be evaluated using the data visualization features in the application. Technologies were selected for this project based on their utility in developing this comprehensive system. A summary of each technology is described below.

\subsection{Database}

\subsubsection{Database Management - Sql Server}

Microsoft Sql Server relational database management system is used to store the BEES building product database.

\subsubsection{Database Development - SimaPro and Excel}

Development of the BEES database includes two steps. First, LCA software (SimaPro) is used to generate the LCIA results for each BEES building product. Second, the product characteristics, cost data, and LCIA results are manually compiled into source data tables in a spreadsheet format (Excel). These source data tables are pulled into the BEES application in CSV format.

\subsection{Application}

\subsubsection{Software Programming Language - C\#}

$\mathrm{C \#}$ is an object-oriented programming language developed by Microsoft. It is based on the $\mathrm{C}++$ programming language, has many similarities with Java, and was developed to work with the .Net framework. C\# is used primarily for developing the server-side code of BEES Online 2.0, including modules to process results data for visualization and data retrieval.

\subsubsection{Software Framework - .NET}

The .Net Framework is a Microsoft developed framework, which contains the common language runtime, in addition to several common class libraries. The common language runtime can be thought of as the foundation of the framework that manages processes at execution time. BEES targets the .Net Framework version 4.5.

\subsubsection{Web Development Technologies - HTML, CSS, JavaScript, JQuery, jqChart}

Several web technologies were used in the creation of the user interface. Hypertext Markup Language (HTML) is the primary language used for displaying web content. Cascading Style Sheet (CSS) is the definition file used by web pages for formatting. 
JavaScript is a light-weight scripting language used to programmatically manipulate the input, output or display of a web page. JQuery is a JavaScript library that facilitates Document Object Model (DOM) manipulation and simplifies partial web page data refreshing through asynchronous JavaScript and XML (AJAX) requests. jqChart is a html 5 charting library used to render charts based on the data for specific comparisons in BEES Online 2.0.

\subsubsection{Application Design - Visual Studio}

The BEES application is developed using Visual Studio's MVC 5 project template with the "database first method." Model, view, and controller functions are all placed in different code files to keep each entity separate. The general flow of the application can be seen in Figure 18-1. A user makes a request through the browser. The controller gets the request and passes the request parameters to the model, which retrieves necessary data from the database. The model passes back the data, which is merged with the view and then passed back to the browser by the controller.
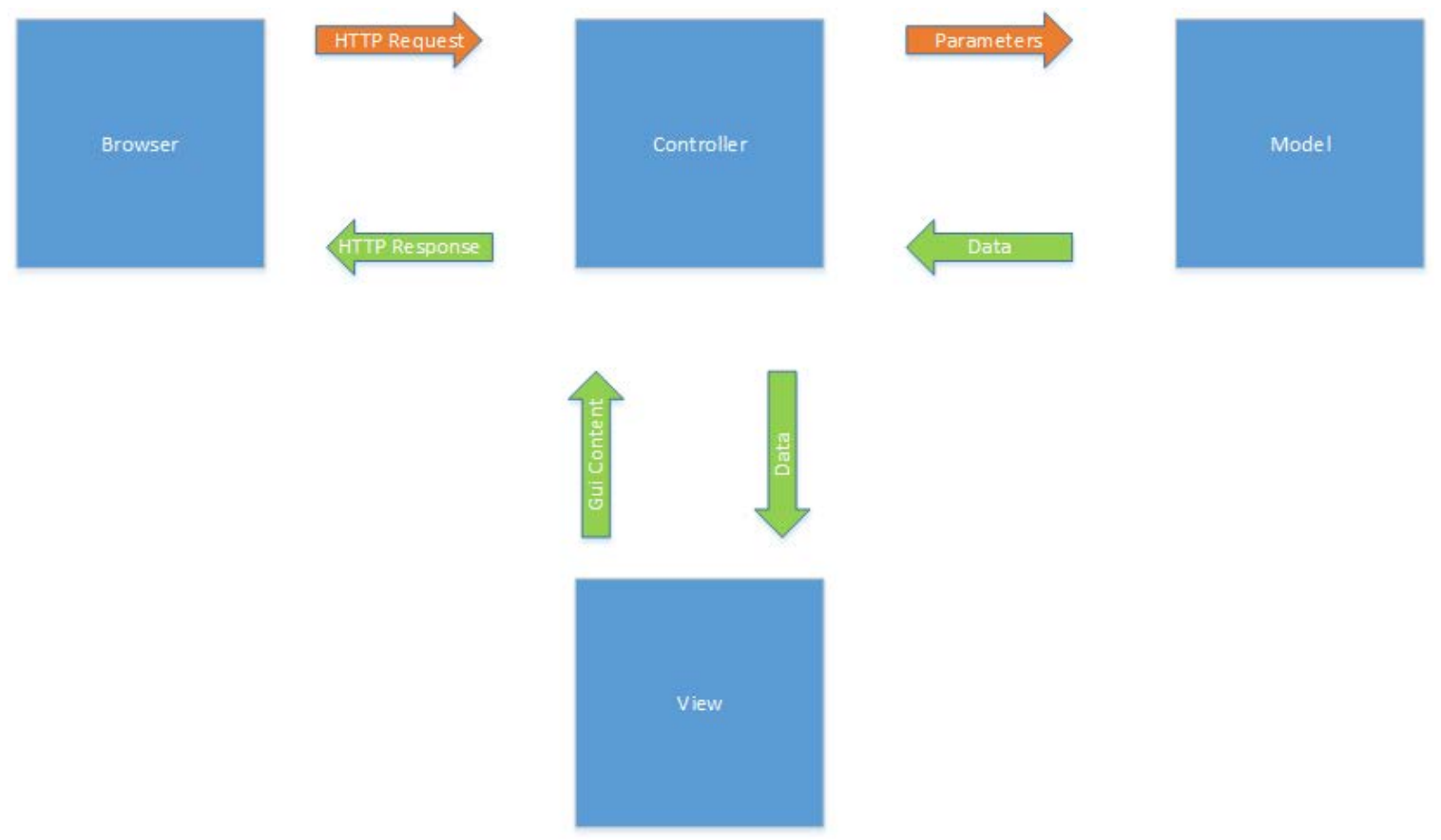

\section{Figure 18-1 Application Information Flow}

In developing the BEES application, the database first method is used because the BEES database had been developed prior to development of the user interface module. The software model containing seven data tables was created based on the database. Controller methods were then developed to retrieve data based on specific parameters from the model, which was then combined with the view and passed back to the browser to be displayed to the user. Comparison results are displayed by the chart module, which contains functions for ordering, formatting, and displaying data visually. The capability 
to download the data in a .csv file is included so that data can be analyzed by the user according to their preferences. 


\section{Limitations and Future Research}

Properly interpreting the BEES environmental performance results requires placing them in perspective. The BEES LCAs use selected inventory flows converted to selected local, regional, and global environmental impacts to assess environmental performance. Those inventory flows which currently do not have scientifically proven or quantifiable impacts on the environment are excluded, such as mineral extraction and wood harvesting, which are qualitatively thought to lead to loss of habitat and an accompanying loss of biodiversity. Any new or improved data and/or modeling approaches should be brought into the interpretation of the BEES results.

The Environmental Problems approach that BEES uses for impact assessment does not offer the same degree of relevance for all environmental impacts. For global and regional effects (e.g., climate change and acidification) the method may result in an accurate description of the potential impact. For impacts dependent upon local conditions (e.g., smog, ecological toxicity, and human health impacts) it may result in an oversimplification of the actual impacts because the indices are not tailored to localities.

During the interpretation step of the BEES LCAs, environmental impact results are optionally combined into a single environmental performance score using relative importance weights. These weights necessarily incorporate values and subjectivity. BEES users should routinely test the effects on the environmental impact scores of changes in the set of importance weights by completing their analysis with more than one weighting approach.

Life cycle impact assessment is a rapidly evolving science. Assessment methods unheard of a decade ago have since been developed and are now being used routinely in LCAs. While BEES incorporates state-of-the-art impact assessment methods, the science will continue to evolve and methods in use today - particularly those for land and water use are likely to change and improve over time. Future versions of BEES should incorporate these improved methods as they become available.

At this time BEES does not include formal uncertainty analysis. Uncertainty exists throughout all levels of LCA, from the background data to impact characterization to normalization factors. NIST is evaluating the inclusion of uncertainty analysis into future releases of BEES.

The BEES overall performance scores do not represent absolute performance. Rather, they represent proportional differences in performance, or relative performance, among competing alternatives. Consequently, the overall performance score for a given product alternative can change if one or more competing alternatives are added to or removed from the set of alternatives under consideration. In rare instances, rank reversal, or a reordering of scores, is possible. Finally, since they are relative performance scores, no conclusions may be drawn by comparing overall scores across building elements. For example, if exterior wall finish Product A has an overall performance score of 30, and roof covering Product D has an overall performance score of 20, Product D does not 
necessarily perform better than Product A (keeping in mind that lower performance scores are better). This limitation does not apply to comparing environmental performance scores across building elements.

There are inherent limits to comparing product alternatives without reference to the whole building design context. Such comparisons may overlook important environmental and cost interactions among building elements. For example, the useful life of one building element (e.g., floor coverings), which influences both its environmental and economic performance scores, may depend on the selection of related building elements (e.g., subflooring). There is no substitute for good building design. Environmental and economic performance are but two attributes of building product performance. The BEES model assumes that competing product alternatives all meet minimum technical performance requirements. However, there may be significant differences in technical performance, such as acoustic or fire performance, which may outweigh environmental and economic considerations. 


\section{References}

AA. (2013). The Environmental Footprint of Semi-Finished Aluminum Products in North America, A Life Cycle Assessment Report. Retrieved from Washington, DC, December 2013:

Alberini, A., \& Chiabai, A. (2007). Discount Rates in Risk Versus Money and Money Versus Money Tradeoffs. Risk Analysis, 27(2), 483-498. doi:https://doi.org/10.1111/i.15396924.2007.00899.x

Alioth. (2018). \$1,000 in $2007 \rightarrow 2018$ | Inflation Calculator. U.S. Official Inflation Data. Armstrong. (2014a). Environmental Product Declaration - Vinyl Composition Tile. Retrieved from Armstrong. (2014b). Environmental Product Declaration - Linoleum. Retrieved from Armstrong. (2014c). Environmental Product Declaration - BioBased Tile. Retrieved from ASTM. (2011). Standard Practice for Applying the Analytic Hiearchy Process Multiattribute Decision Analysis of Investments Related to Buildings and Building Systems, ASTM Designation E1765-11. Retrieved from West Conshohocken, PA:

ASTM. (2014). Asphalt Shingles, Built-up Asphalt Membrane Roofing and Modified Bituminous Membrane Roofing. Retrieved from West Conshohocken, PA:

ASTM. (2015). Standard Practice for Measuring Life-Cycle Costs of Buildings and Building Systems, ASTM Designation E917-15. Retrieved from West Conshohocken, PA:

ASTM. (2015e). Standard Classification for Building Elements and Related SiteworkUNIFORMAT II, ASTM Designation E1557-09. Retrieved from West Conshohocken, PA:

ASTM. (2016). Standard Practice for Applying Analytical Hierarchy Process (AHP) to Multiattribute Decision Analysis of Investments Related to Projects, Products, and Processes, ASTM Designation E1765-16. Retrieved from West Conshohocken, PA:

ASTM. (2017). Standard Practice for Measuring Life-Cycle Costs of Buildings and Building Systems, ASTM Designation E917 - 17. Retrieved from West Conshohocken, PA:

Athena. (2010). A Gate-to-Gate Life Cycle Assessment of Canadian Pre-finished Solid Strip Hardwood Flooring; Drying, Milling and Finishing Unit Process Data and Assessment. Retrieved from Performed for FP Innovations, Forintek Division (Quebec):

Bare, J. (2012). User's Manual: Tool for the Reduction and Assessment of Chemical and other Environmental Impacts (TRACI) version 2.1. Retrieved from

Bare, J., Gloria, T., \& Norris, G. (2006). Development of the method and US normalization database for life cycle impact assessment and sustainability metrics. Environmental science \& technology, 40(16), 5108-5115.

Bare, J., Young, D., QAM, S., Hopton, M., \& Chief, S. A. B. (2012). Tool for the Reduction and Assessment of Chemical and other Environmental Impacts (TRACI).

Bergman, R. D., \& Bowe, S. A. (2011). CORRIM Final Report, Module N, Life-Cycle Inventory of Manufacturing Prefinished Engineered Wood Flooring in the Eastern United States, Section 1.2. Retrieved from

Boulay, A., Bare, J., Benini, L. et al. (2018). Int J Life Cycle Assess, 23(368). doi:https://doi.org/10.1007/s11367-017-1333-8

Brick Industry Association. (2009). The Bottom Line on Brick's Role in Sustainability and Green Building Design. Retrieved from Found at: www.gobrick.com/Resources/Publications/Brick-In-Home-Building:

Brick Industry Association. (2017). The 2016 Brick Industry Association Annual Report 2016. Retrieved from

Bushi, L., \& Meil, J. (2011). A Cradle-to-Gate Life Cycle Assessment of 1/2" Regular and 5/8" Type X Gypsum Wallboard. Retrieved from 
Cameron, T., \& Gerdes, G. (2002). Eliciting Individual-Specific Discount Rates. Paper presented at the Second World Congress of Environmental and Resource Economists, Monterey, CA.

CARB. (2018). California Air Resource Board - Auction Information - Summary of Auction Settlement Prices and Results August 2018

CDP. (2016). Embedding a carbon price into business strategy. Retrieved from https://b8f65cb373b1b7b15febc70d8ead6ced550b4d987d7c03fcdd1d.ssl.cf3.rackcdn.com/cms/reports/documents/00 0/001/132/original/CDP Carbon Price 2016 Report.pdf?1474269757:

CertainTeed. (2013). Environmental Product Declaration for Sustainable Insulation Unfaced and Kraft Faced Batts. Retrieved from

CIA. (2018). The World Factbook - Geography: US - Area: Land.

CRI. (2014). Carpet Maintenance Guidelines for Commercial Applications. Retrieved from http://carpet-rug.com/commercial-customers/cleaning-and-maintenance/index.cfm:

Drywall Finishing Council. (2017). Environmental Product Declaration for Joint Compound. Retrieved from

Ducker. (2008). 2008 Industry Sustainability Summary Report - Plant Averages. Retrieved from

Ecoinvent. (2017). Ecoinvent life cycle assessment data v3. Retrieved from http://www.ecoinvent.org/database/

EIA. (2018). Table 1.1 Primary Energy Overview. Monthly Energy Review - September 2018.

Environmental Protection Agency. (2018). Tool for the Reduction and Assessment of Chemical and other Environmental Impacts (TRACI) 2.1.

EPA. (1993). Life Cycle Assessment: Inventory Guidelines and Principles. Retrieved from

EPA. (1997). Brick and Structural Clay Product Manufacturing Volume I: Section 11.3, AP-42: Compilation of Air Pollutant Emission Factors. Retrieved from Found at: http://www.epa.gov/ttn/chief/ap42/ch11/final/c11s03.pdf:

European Commission. (2003). Integrated Pollution Prevention and Control (IPPC): Best Available Techniques for the Textile Industry. Retrieved from

Fantke, P. E., Bijster, M., Guignard, C., Hauschild, M., Huijbregts, M., Jolliet, O., Kounina, A., Magaud, V., Margni, M., McKone, T.E., Posthuma, L., Rosenbaum, R.K., van de Meent, D., van Zelm, R. (2017). USEtox ${ }^{\circledR} 2.0$ Documentation (Version 1). Retrieved from http://usetox.org:

Forbo. (2013a). Environmental Product Declaration - Marmoleum 2.0 and $2.5 \mathrm{~mm}$ Resilient Floor Covering. Retrieved from https://www.forbo.com/flooring/en-au/environment/greenstar/epd-s-environmental-product-declarations/p7m6me:

Forbo. (2013b). Environmental Product Declaration - Eternal Resilient Heterogenous Vinyl Floor Covering. Retrieved from https://www.forbo.com/flooring/en-au/environment/greenstar/epd-s-environmental-product-declarations/p7m6me:

FPInnovations. (2013). Product Category Rules for North American Gypsum Boards. Retrieved from

FPInnovations. (2015). Product Category Rules for North American Structural and Architectural Wood Products. Retrieved from

FPInnovations. (2017). Life Cycle Assessment of Western Red Cedar Decking, Siding, and Alternative Products. Retrieved from

Franklin Associates. (2010). Life Cycle Inventory of 100\% Post-Consumer HDPE and PET Recycled Resin from Post-Consumer Containers and Packaging Retrieved from

Frischknecht, R. J., N.; Althaus, H.J.; Doka, G.; Dones, R.; Hischier, R.; Hellweg, S.; Humbert, S.; Margni, M.; Nemecek, T.; Spielmann, M. (2007). Implementation of Life Cycle Impact 
Assessment Methods: Data v2.0. ecoinvent report No. 3. Retrieved from Dübendorf, Switzerland:

Fuller, S., \& Petersen, S. (1996). Life-Cycle Costing Manual for the Federal Energy Management Program, 1995 Edition. NIST handbook 135.

GA. (2014). Environmental Product Declaration for Typical (5/8" Type X) North American Gypsum Boards. Retrieved from

Gloria, T. P., Lippiatt, B. C., \& Cooper, J. (2007). Life-Cycle Impact Assessment Weights to Support Environmentally Preferable Purchasing in the United States. Environmental science \& technology, 41(21), 7551-7557.

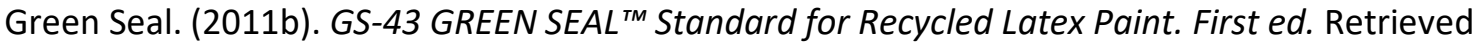
from Washington, DC.:

Hosking, J. (2012). Recommended Size for Flooring Staples / Nails". Retrieved from retrieved at http://www.hoskinghardwood.com:

Hubbard, S., \& Bowe, S. (2008). CORRIM: Phase II Final Report, Life-Cycle Inventory of Solid Strip Hardwood Flooring in the Eastern United States. Retrieved from

Huijbregts, M. A. J., Steinmann, Z. J. N., Elshout, P. M. F., Stam, G., Verones, F., Vieira, M., . . . Zelm, R. v. (2017). ReCiPe2016: a harmonised life cycle impact assessment method at midpoint and endpoint level. Int J Life Cycle Assess, 22(138).

International Organization for Standardization (ISO). (2006a). Environmental Management -Life-Cycle Assessment -- Principles and Framework, International Standard 14040.

International Organization for Standardization (ISO). (2006b). Environmental Management -Life-Cycle Assessment -- Principles and Framework, International Standard 14044.

IPCC. (2013). Climate Change 2013, The Physical Science Basis. Retrieved from http://www.climatechange2013.org:

Lavappa, P., \& Kneifel, J. (2018). Energy Price Indices and Discount Factors for Life-Cycle Cost Analysis - 2018, Annual Supplement to NIST Handbook 135. (NISTIR 85-3273-33).

Levin, L. (1996). Best Sustainable Indoor Air Quality Practices in Commercial Buildings. Paper presented at the Third International Green Building Conference and Expostion - 1996, Gaithersburg, MD.

Lippiatt, B. (2007). BEES 4.0: Building for Environmental and Economic Sustainability Technical Manual and User Guide. Retrieved from

Lu, D., Overcash, M., \& Realff, M. (2008). Care and Maintenance of Commercial Carpet Conventional and Next Generation Technology: Contents Of Use Phase Gate To Gate; Life Cycle Inventory Summary. Retrieved from

Mahalle, L. (2011). A Comparative Life Cycle Assessment of Canadian Hardwood Flooring with Alternative Flooring Types. Retrieved from

Moore, M., \& Viscusi, W. (1990). Models for estimating discount rates for long-term health risks using labor market data. Journal of Risk and Uncertainty, 3(4), 381-401.

NAIMA. (2013a). EPD for Light and Heavy Density Mineral Wool Board. Retrieved from

NAIMA. (2013b). EPD for Mineral Wool Loose Fill. Retrieved from

NAPA. (2017). Product Category Rules (PCR) For Asphalt Mixtures. Retrieved from http://www.asphaltpavement.org/EPD:

NAS. (2017). Valuing Climate Damages: Updating Estimation of the Social Cost of Carbon Dioxide. Retrieved from http://nap.edu/24651:

National Institute of Standards and Technology (NIST). (2010). Building for Environmental and Economic Sustainability (BEES) Online Software. Retrieved from http://ws680.nist.gov/Bees/(A(fStnHf6rOQEkAAAAYmY5MzY4YWYtZTQ2Yi00NDkOLTk2O DItNjcxOTk2NTIxNGQ2ZOcOW65aCyEnzYI8zFbw-aGALRo1))/Default.aspx 
National Renewable Energy Laboratory (NREL). (2012). U.S. Life-Cycle Inventory Database (LCI). Retrieved from http://www.nrel.gov/lci/

NSF International. (2014). Flooring: Carpet, Resilient, Laminate, Ceramic, Wood Version 2. Retrieved from

NSF International. (2017). Architectural Coatings. Retrieved from https://standards.nsf.org/apps/group public/download.php/28098/ACA\%20PCR\%20\%2 006-17-15\%20-\%20Final.pdf

OIRA. (2011). Regulatory Impact Analysis: A Primer. https://obamawhitehouse.archives.gov/sites/default/files/omb/inforeg/regpol/circulara-4 regulatory-impact-analysis-a-primer.pdf: Office of Information and Regulatory Affairs.

OMB. (1992). GUIDELINES AND DISCOUNT RATES FOR BENEFIT-COST ANALYSIS OF FEDERAL PROGRAMS.

OMB. (2003). Circular A-4. https://www.whitehouse.gov/sites/whitehouse.gov/files/omb/circulars/A4/a-4.pdf.

OMB. (2017). Report of the President's Economic Advisors , Analytical Perspectives. Retrieved from

ORNL. (2012). Measure Guideline: Transitioning to Three Coat Stucco to One Coat Stucco with EPS. Retrieved from Oak Ridge, TN:

Owens Corning. (2013a). Environmental Product Declaration for EcoTouch Kraft-Faced Insulation. Retrieved from

Owens Corning. (2013b). Environmental Product Declaration for Unbonded Loosefill. Retrieved from

PAC-CLAD. (2015). Environmental Product Declaration for Roll Formed Steel and Aluminum Panels. Retrieved from

Paint Product Stewardship Initiative. (2006). Life Cycle Assessment Results for Six "Pure" Methods for Managing Leftover Paint. Draft Report. Retrieved from For more information, go to http://www.productstewardship.us:

PCA. (2016a). Environmental Product Declaration for Portland Cements. Retrieved from ASTM International, West Conshohocken, PA:

PCA. (2016b). Environmental Product Declaration for Masonry Cements. Retrieved from ASTM International, West Conshohocken, PA:

PE International. (2013). CONCRETE. Retrieved from

PRe Sustainability. (2018). SimaPro. Retrieved from https://simapro.com/

PricewaterhouseCoopers/Ecobilan. (2001). Eco-profile of high-volume commodity phthalate esters (DEHP/DINP/DIDP). Retrieved from

RFCl. (2013a). Environmental Product Declaration - Vinyl Composite Tile. Retrieved from https://rfci.com/environmental-product-declaration/:

RFCl. (2013b). Environmental Product Declaration - Homogenous Vinyl Flooring. Retrieved from https://rfci.com/environmental-product-declaration/:

RGGI. (2018). The Regional Greenhouse Gas Initiative - Auction Results

Rosenbaum, R. K. e. a. (2008). USEtox-the UNEP-SETAC toxicity model: recommended characterisation factors for human toxicity and freshwater ecotoxicity in life cycle impact assessment. International Journal of Life Cycle Assessment, 13, 532-546.

Ryberg, M., et al.;. (2014). Updated US and Canadian normalization factors for TRACI 2.1. Clean Techn Environ Policy, 16(329). doi:https://doi.org/10.1007/s10098-013-0629-z

Sandbag. (2018). European Union Allowance (EUA) Price - April 2008 to September 2018. AVAQMD Rule \#1168 Adhesive and Sealant Applications, (2011). 
Scharff, R., \& Viscusi, W. (2011). Economic Inquiry, 49(4), 959-972. doi:https://doi.org/10.1111/j.1465-7295.2009.00191.x

Subramanian, V., Ingwersen, W., Hensler, C., \& Collie, H. (2012). Comparing product category rules from different programs: learned outcomes towards global alignment. The International Journal of Life Cycle Assessment, 17(7), 892-903.

Sustainable Solutions Corporation. (2016). Vinyl, Insulated Vinyl, and Polypropylene Siding Life Cycle Assessment Retrieved from (Royersford, PA, July 2016)

TCNA. (2014). Environmental Product Declaration - Ceramic Tile. Retrieved from https://www.tcnatile.com/images/pdfs/EPD-for-Ceramic-Tile-Made-in-NorthAmerica.pdf:

U.S. EPA Science Advisory Board. (1990). Reducing Risk: Setting Priorities and Strategies for Environmental Protection, SAB-EC-90-021. Washington, DC.

U.S. EPA Science Advisory Board. (2000). Toward Integrated Environmental Decision-Making, EPA-SAB-EC-00-011. Washington, DC.

U.S. Green Building Council. (2018). Building product disclosure and optimization environmental product declarations. Leadership in Energy and Environmental Design (LEED) Building Design + Construction $(B D+C)$ : New Construction / v4. Retrieved from https://www.usgbc.org

UL. (2016). PCR Guidance for Building-Related Products and Services: Part B: Joint Compound EPD Requirements. Retrieved from

UL. (2018). Environment - Environmental Product Declarations.

UL Environment. (2013a). Environmental Product Declaration - North American softwood plywood. Retrieved from

UL Environment. (2015). Cladding System Products. Retrieved from www.ul.com/businesses/environment:

UL Environment. (2018a). Part A: Life Cycle Assessment Calculation Rules and Report Requirements. Retrieved from www.ul.com/businesses/environment:

UL Environment. (2018b). Part B: Building Envelope Thermal Insulation EPD Requirements. Retrieved from www.ul.com/businesses/environment:

US Census. (2018). United States Census - QuickFacts - UNITED STATES - Population, Census, April 1, 2010.

USG Corporation. (2014). The Gypsum Construction Handbook, 7th Ed. . Retrieved from Wiley, March 2014

USGS. (2018). Estimated Use of Water in the United States in 2015. Retrieved from Water Availability and Use Science Program:

Warner, J., \& Pleeter, S. (2001). The Personal Discount Rate: Evidence from Military Downsizing Programs. The American Economic Review, 91(1), 33-53.

Working Group on Social Cost of Carbon, I. (2016). Technical Support Document: Technical

Update of the Social Cost of Carbon for Regulatory Impact Analysis Under

Executive Order 12866. Retrieved from

World Bank. (2018). Carbon Pricing Dashboard.

World Bank Group. (2018). State and Trends of Carbon Pricing 2018. Retrieved from https://openknowledge.worldbank.org/bitstream/handle/10986/29687/978146481292 7.pdf? sequence $=5 \&$ isAllowed $=\mathrm{y}$ :

Wright, S., Smithers, A., Warburton, P., Pepper, G., Goldberg, J., Brodie, H., . . Napier, R. (2011). Practical History of Financial Markets. Retrieved from 
https://www.ebsglobal.net/EBS/media/EBS/PDFs/Practical-History-Financial-MarketsCourse-Taster.pdf: 